\title{
Evaluation of Reduced-Scale Confined Inflatable Structure for Tunnel Safety
}

Subhadeep Ghosh

West Virginia University

Follow this and additional works at: https://researchrepository.wvu.edu/etd

\section{Recommended Citation}

Ghosh, Subhadeep, "Evaluation of Reduced-Scale Confined Inflatable Structure for Tunnel Safety" (2012). Graduate Theses, Dissertations, and Problem Reports. 4858.

https://researchrepository.wvu.edu/etd/4858

This Thesis is protected by copyright and/or related rights. It has been brought to you by the The Research Repository @ WVU with permission from the rights-holder(s). You are free to use this Thesis in any way that is permitted by the copyright and related rights legislation that applies to your use. For other uses you must obtain permission from the rights-holder(s) directly, unless additional rights are indicated by a Creative Commons license in the record and/ or on the work itself. This Thesis has been accepted for inclusion in WVU Graduate Theses, Dissertations, and Problem Reports collection by an authorized administrator of The Research Repository @ WVU. For more information, please contact researchrepository@mail.wvu.edu. 


\title{
Evaluation of Reduced-Scale Confined Inflatable Structure for Tunnel Safety
}

\author{
Subhadeep Ghosh \\ Thesis submitted to the \\ Benjamin M. Statler College of Engineering \& Mineral Resources \\ West Virginia University \\ in partial fulfillment of the requirements for the degree of \\ Master of Science \\ in \\ Civil Engineering \\ Dr. Eduardo Sosa, Ph.D., Chair \\ Dr. Ever Barbero, Ph.D. \\ Dr. Gregory Thompson, Ph.D. \\ Dr. Indrajit Ray, Ph.D. \\ Department of Civil and Mechanical \& Aerospace Engineering \\ Morgantown, West Virginia \\ 2012
}

Keywords: elongation; friction; inflatable; leakage; plug; seepage; slippage; tunnel

Copyright 2012 Subhadeep Ghosh 


\section{Abstract \\ Evaluation of Reduced-Scale Confined I nflatable Structure for Tunnel Safety}

\section{Subhadeep Ghosh}

Tunnel safety deals with isolation of zone of disaster in case of flooding, fire, release of toxic gases and roof collapse. Disaster zone isolation, if successful, can result in lesser loss, in terms of human lives and revenue. An inflatable plugging system made of Vectran fiber was proposed to be installed at certain intervals of the tunnel length and deployed around the disaster zone for effective isolation. The study deals with a quarter-scale (of full scale) tunnel with plugging system for only flooding. It was tested at design pressure of plug and at limiting equilibrium conditions of both plug and tunnel pressures. The external loading was in terms of only water pressure to simulate the occurrence of flooding from superincumbent water way.

The inflatable plug was investigated under low pressure unconstrained inflation and high pressure confined inflation to study the elongation characteristics of its end caps in terms of longitudinal elongation. The front end cap of the plug was also scanned with a laser range finder at various levels of pressure up to the design pressure to obtain the 3-D surface and contour plot of the expansive nature of the surface under confined condition.

The primary function of the plug was to act as a floodgate by virtue of the friction between the plug surface and the tunnel wall developed by the normal force generated on the tunnel wall due to plug pressure. External pressure was applied on the plug in the form of confined water pressure. Real life possibilities of the plug slip was simulated in multiple experiments ranging from forced to unforced slip for which the friction coefficient of the system was evaluated. It was found that the plug slipped at a lower ratio of external to internal pressure than the pressure ratio of slip under normal condition with the reduction in effective contact length of the plug with the tunnel concrete. It was also found that the mass of the plug has variable impact on the occurrence of slippage from about $10 \%-50 \%$ of air by volume. The effect of abrasion of tunnel and plug surface was also evaluated which resulted in higher pressure ratios of slip than under smooth tunnel wall and plug surface.

Leakage characteristics of this plugging system were evaluated. The pressure ratio along with the plug positioning, plug surface characteristics and the level of oversizing of the plug were the main influencing factors. Since the dependency of leakage was on the above four factors, a range of leakage values were obtained for a single pressure ratio. A leakage mitigation device was employed but it showed inconclusive results due to its dependency on the above four factors simultaneously. Dependency of slippage on leakage was considered and hence the seepage water pressure study was considered.

Seepage water pressure study was conducted to measure the pressure of seeping water along various points of the cylindrical length of the plug at various circumferential depths. The variation of seepage pressure was linear from rear to front of the plug. It was also found that the coefficient of variation of the seepage water pressure at different depths of the circumference at the same longitudinal location increased from the rear of the plug to the front. This led to the understanding of the profile of the seepage water pressure. It was found to be axial at the rear of the plug, and both axial and circumferential (towards gravity) at other points along the cylindrical length. The water profile was evaluated in terms of loss of kinetic and gain in potential energy as well as the loss of head due to friction from plug webbing and tunnel wall.

The correlation between the occurrence of slippage and seepage water pressure was found to be inconclusive with the system friction coefficient reflecting similar values with the use of single layered Vectran plug. The presence of more abrasion on the plug surface on the front compared to the rear can be termed as an existence of correlation on the other hand. 


\section{Acknowledgements}

I would specially like to thank Byron Rapp for his esteemed assistance with the experimental logistic, setup and valuable inputs throughout the study process. I would like to thank Dr. Gregory Thompson for his invaluable expertise in data acquisition set up and his unparalleled problem solving skills which inspired me to a great extent. I would like thank Dr. Indrajit Ray, who inspired me to pursue my Master's degree in US at WVU, without which all this would never have happened for me. I would also like to thank Dr. Ever Barbero for being such a fine instructor and supporting me through this process of study. No amount of appreciation is enough for my advisor, Dr. Eduardo Sosa, who treated me more as his friend than as a student and fine-tuned my confidence to perform through all kinds of uncertainties that a student can possibly face in grad life.

I would also like thank Zac Lucader and Richard Atkinson for handling the software and the electronic side of the data acquisition system. I would like to thank Kevin L. Peil for helping me to run some of the tests and also for his help in running the friction and the abrasion tests for me. I would like thank my work mates at the hanger Perry (P.J.) Spaur and John Wattick whose constant company and the chance of in-depth discussion on any topic got me going.

Thanks to my office mates at B11 for the wonderful time spent together, making this grad-life a memorable one. My room-mates namely Manish Roy and Arkamitra Kar need to be thanked for their warmth and affection which made we feel at home away from home. Thanks to all my friends in Morgantown who has made it my hometown.

My special thanks go out to my parents and my elder brother for supporting me in whatever I do. They have never made me feel the dearth of role models from any walks of life. Thanks to all my friends back in India who endured everything with me through thick and thin. 


\section{Table of Contents}

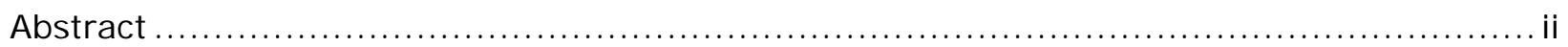

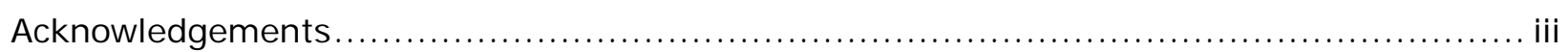

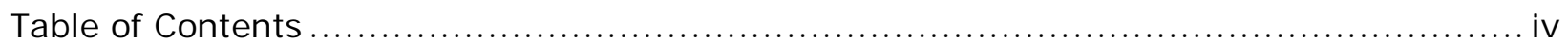

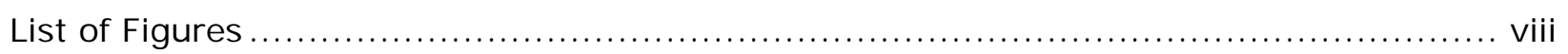

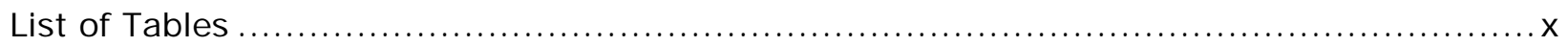

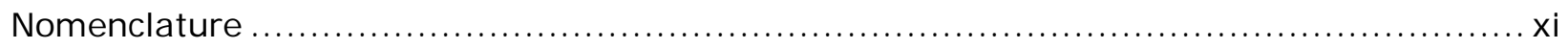

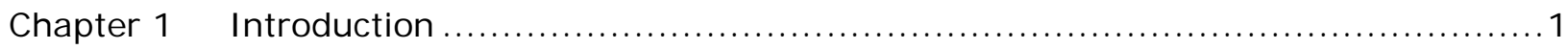

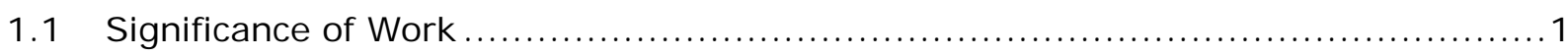

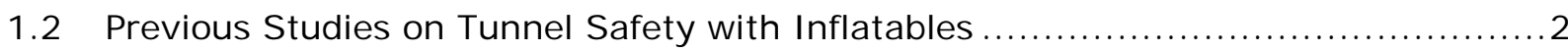

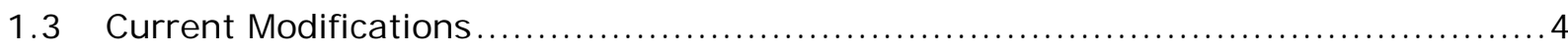

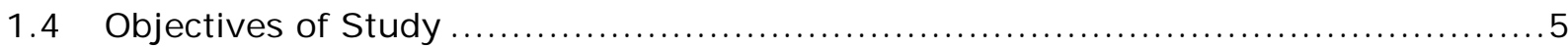

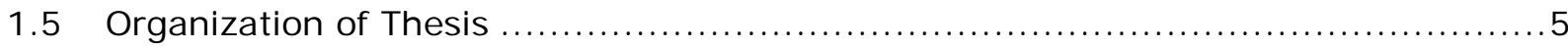

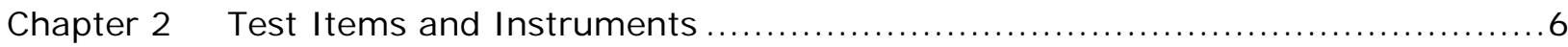

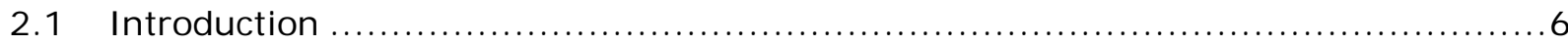

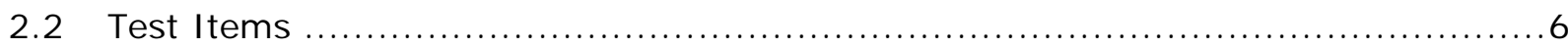

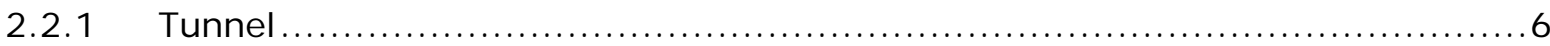

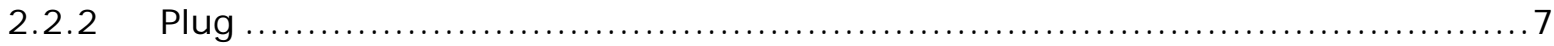

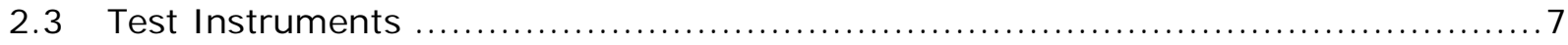

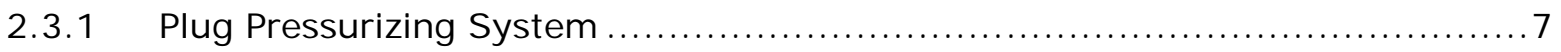

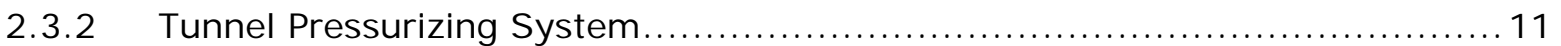

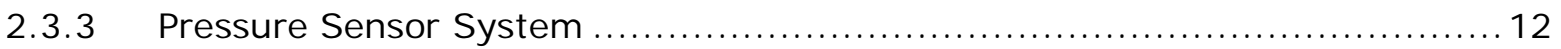

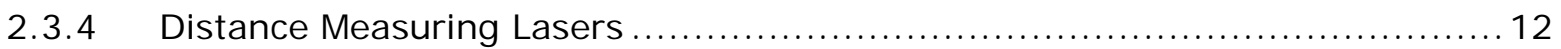

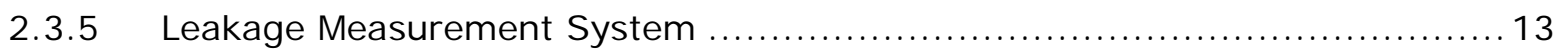

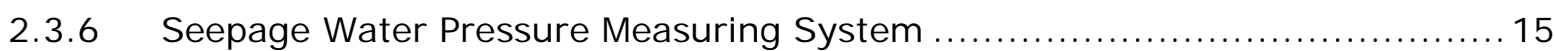

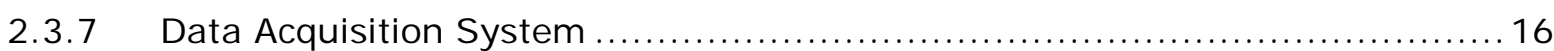

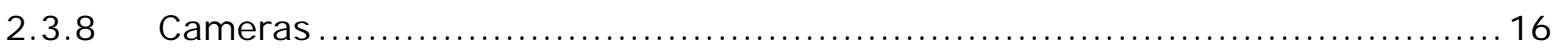

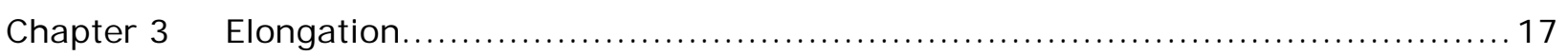

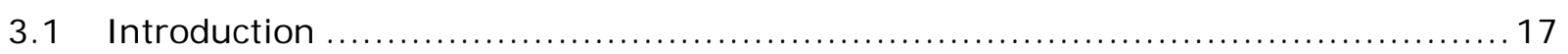

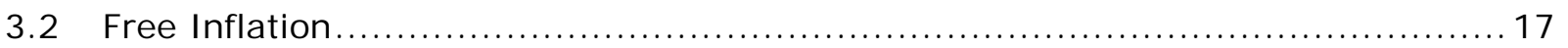

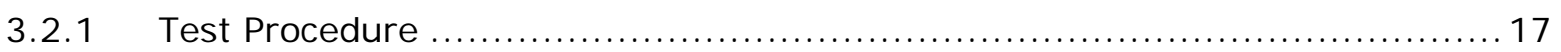

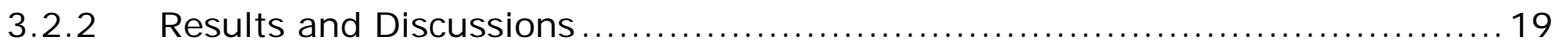

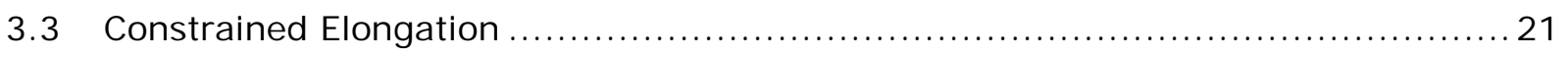




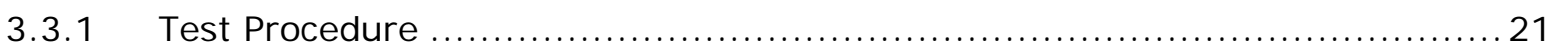

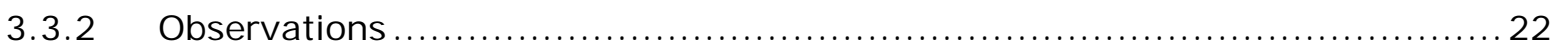

3.3.3 End Cap Tip Elongations \& Total Elongation .............................. 23

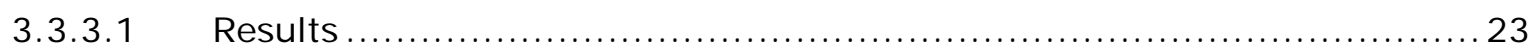

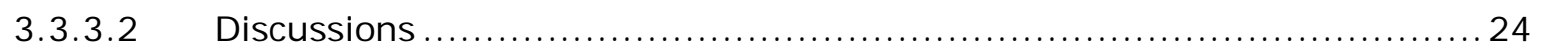

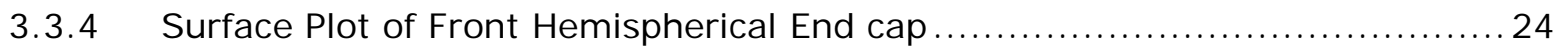

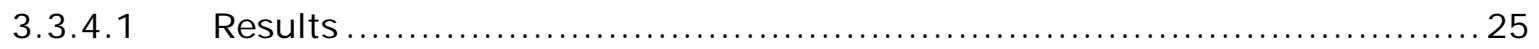

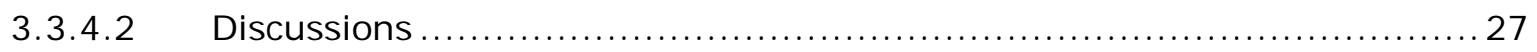

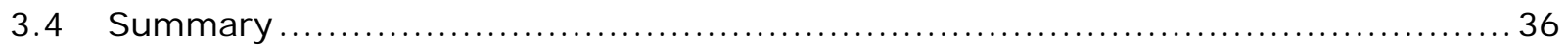

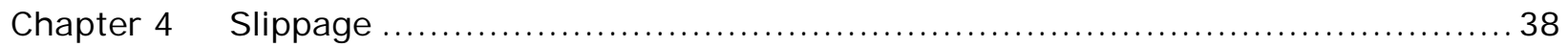

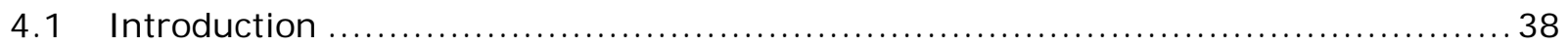

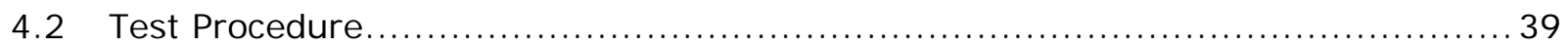

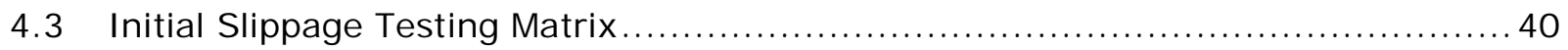

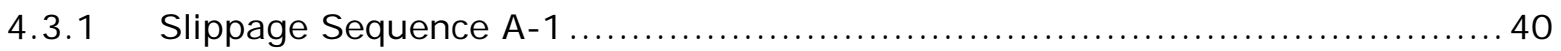

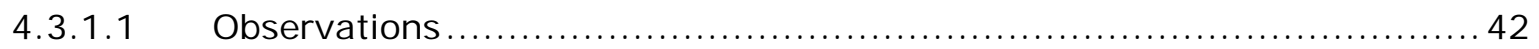

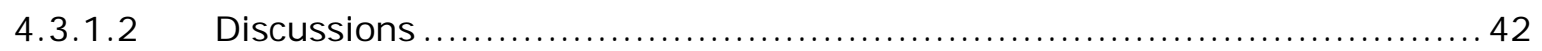

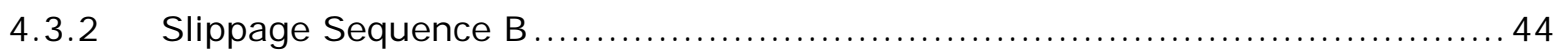

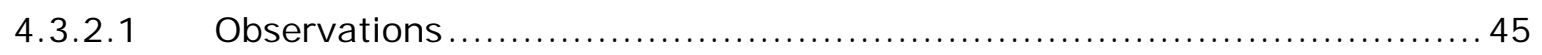

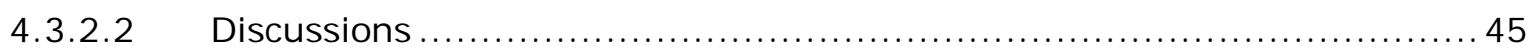

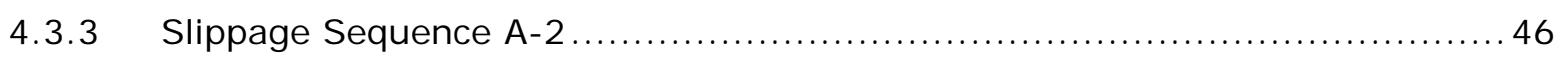

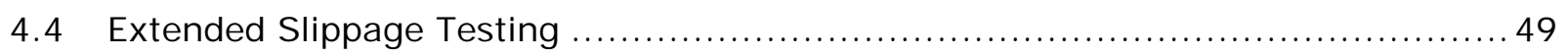

4.4.1 Investigating Effective Contact Length on Tunnel Concrete..................49

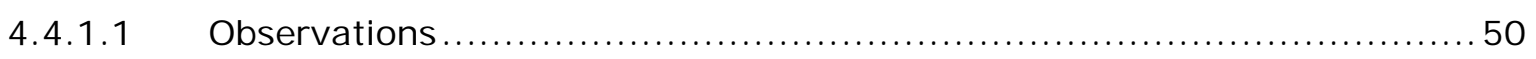

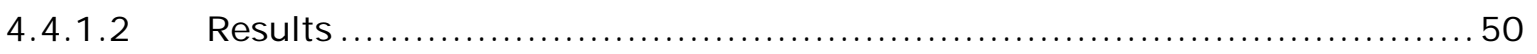

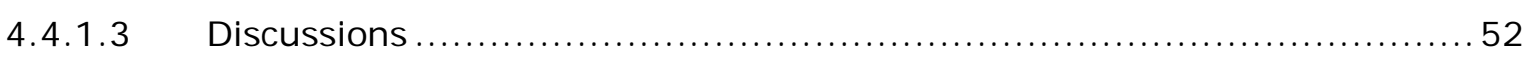

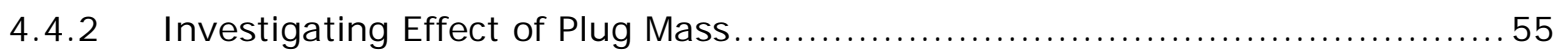

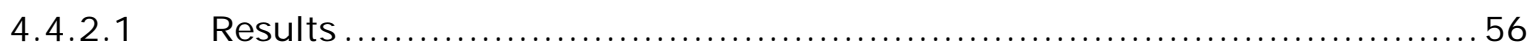

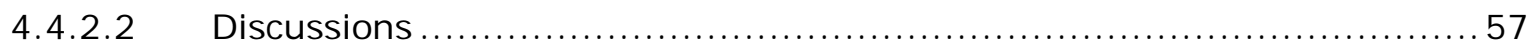

4.5 Holding resistance comparison for testing on tunnel concrete $\ldots \ldots \ldots \ldots \ldots \ldots \ldots \ldots \ldots \ldots$

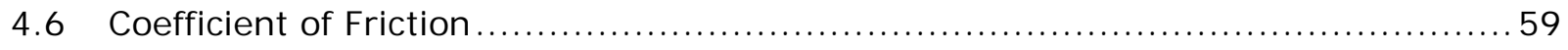

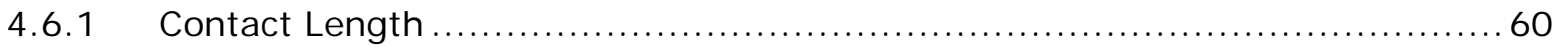

4.6.2 Friction Coefficient Excluding Hydrostatic Pressure ..........................60 60

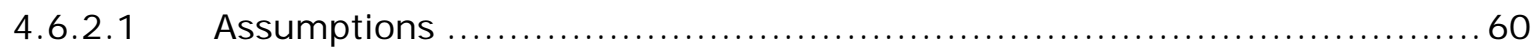

4.6.2.2 Computation of Forces Governing Equilibrium........................... 61 


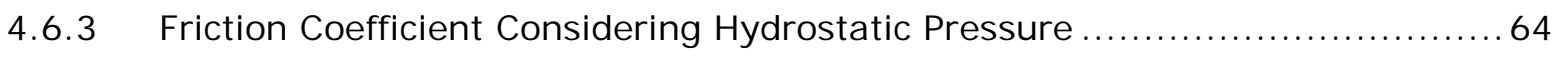

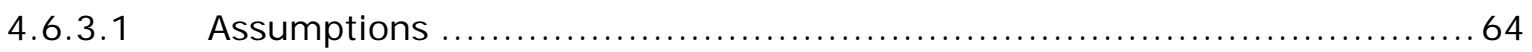

4.6.3.2 Computation of Forces Governing Equilibrium .......................... 65

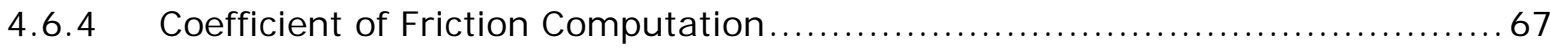

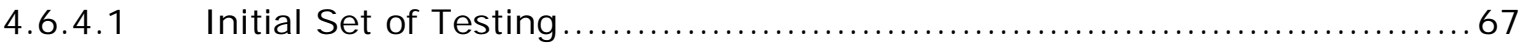

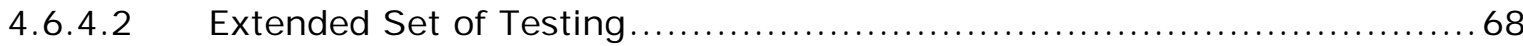

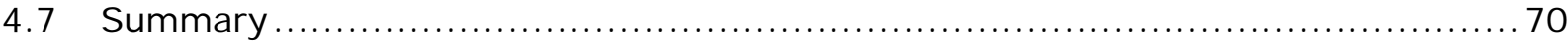

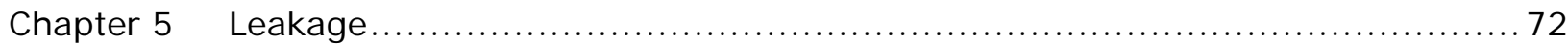

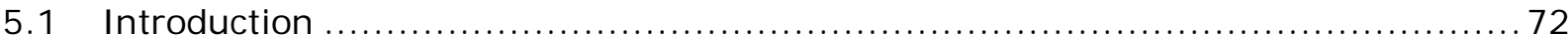

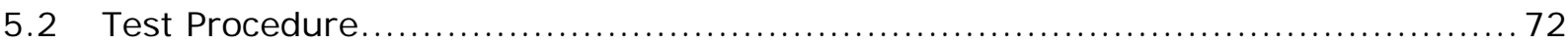

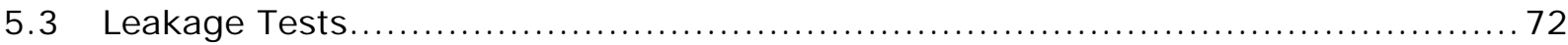

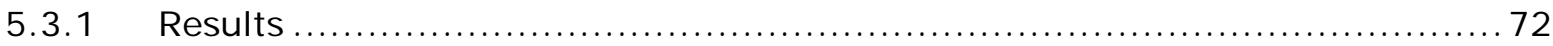

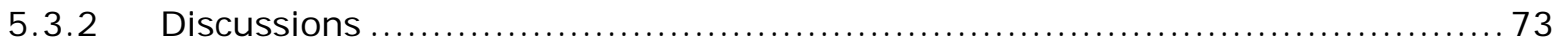

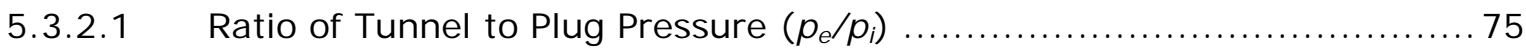

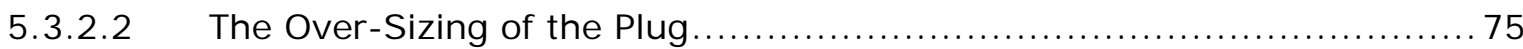

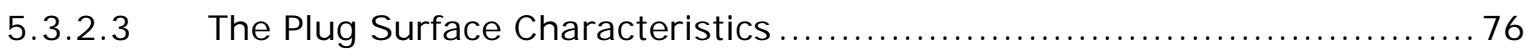

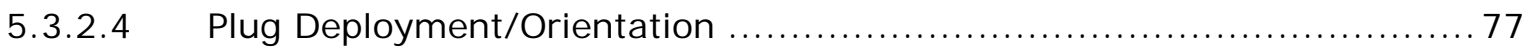

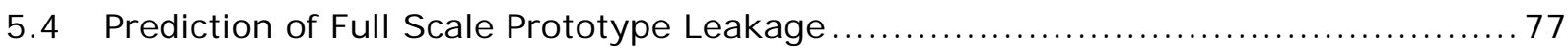

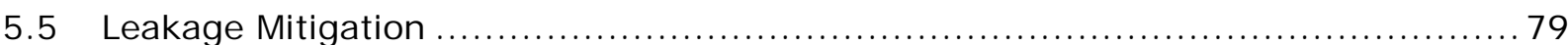

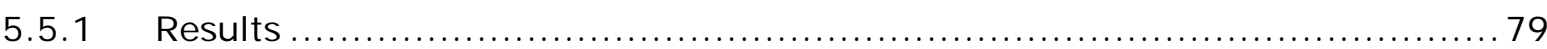

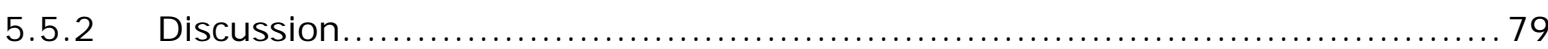

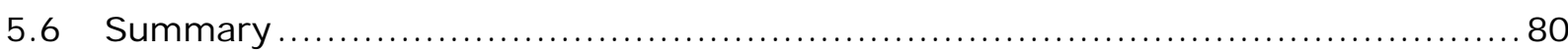

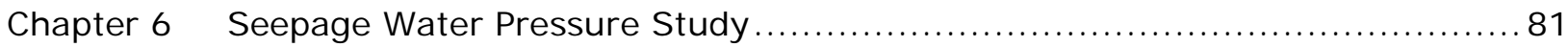

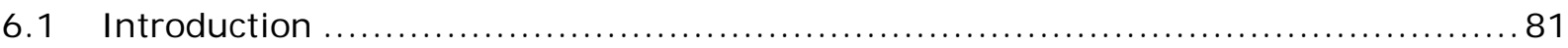

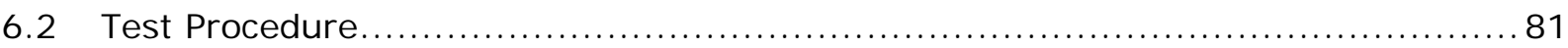

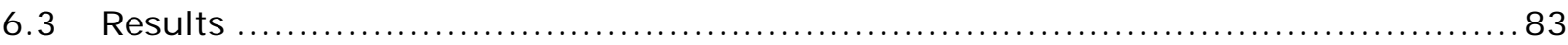

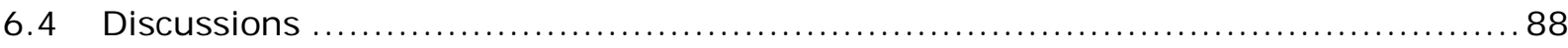

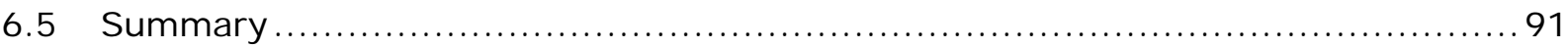

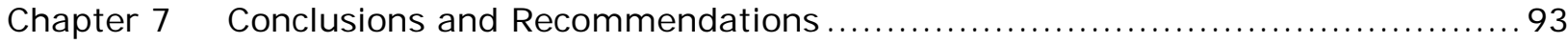

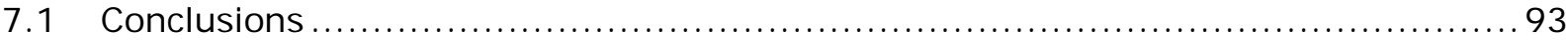

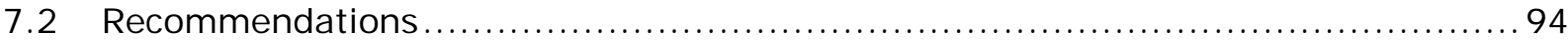

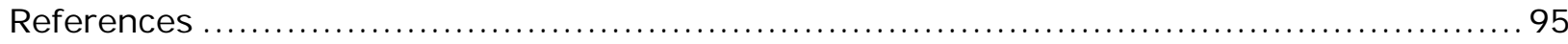

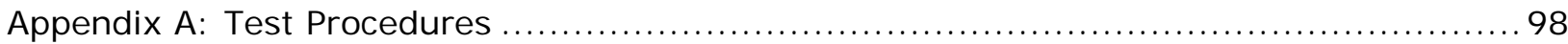

Appendix B: Front End Cap Surface Plot Data ....................................... 104 


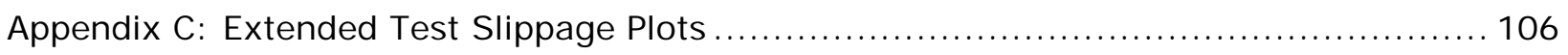

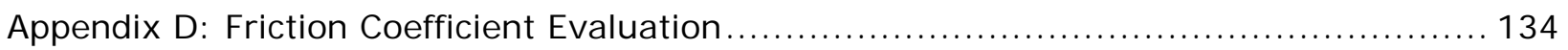

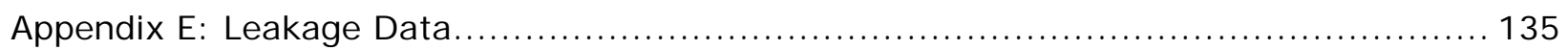

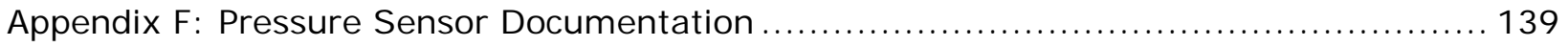




\section{List of Figures}

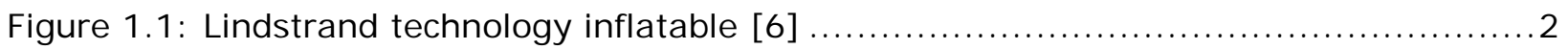

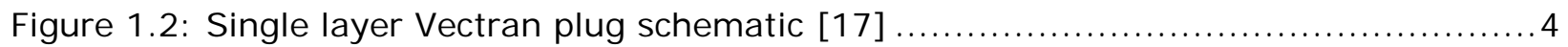

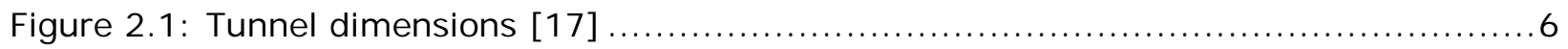

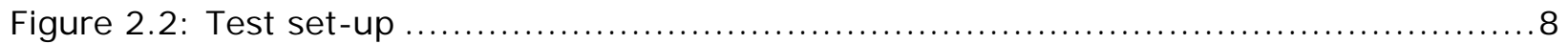

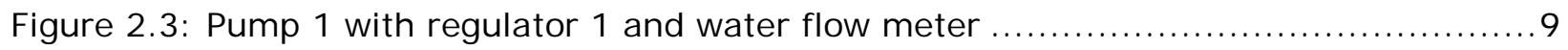

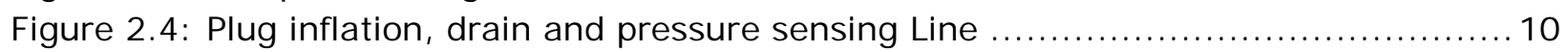

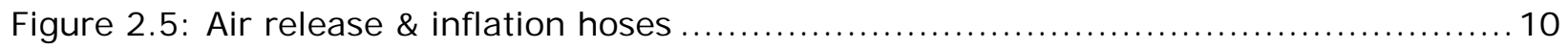

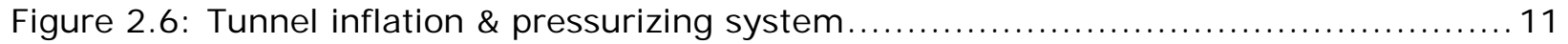

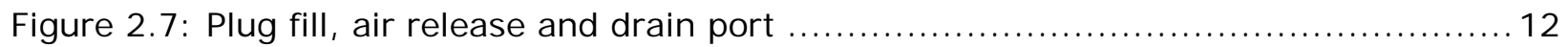

Figure 2.8: Metal pipe mouth taped to teflon pipe; teflon pipe through port cam lock ...... 13

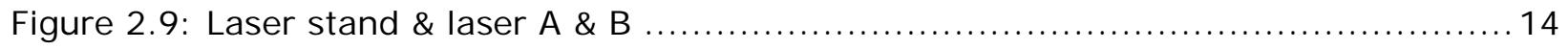

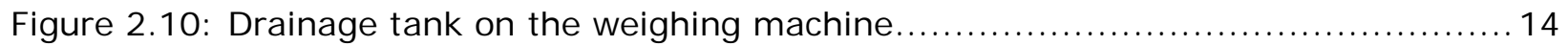

Figure 2.11: Seepage pressure measuring setup: 1) quarter point $0^{\circ}$ sensor; 2 ) connector between aluminium and teflon pipe; 3) keyed seepage pressure gauge setup; 4) $0^{\circ}, 90^{\circ}$, $180^{\circ}$ and $270^{\circ}$ pipes running through the length of the tunnel for reading seepage pressure

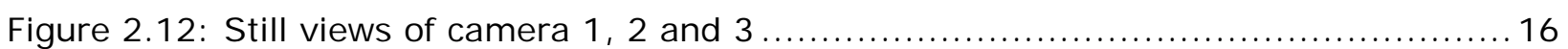

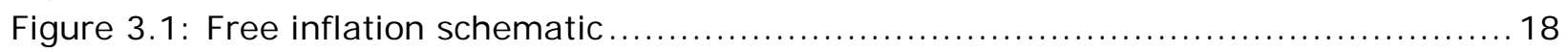

Figure 3.2: Free test set-up: 1) complete setup; 2) front laser pointed towards tip of end cap; 3) laser mark at the tip of front end cap; 4) rear laser pointed towards tip of end cap18 Figure 3.3: Plug circumference measurement locations ................................. 19

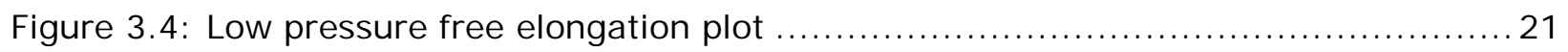

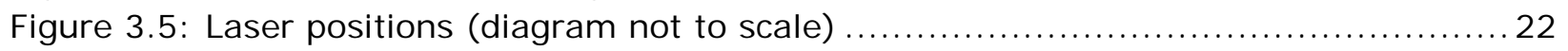

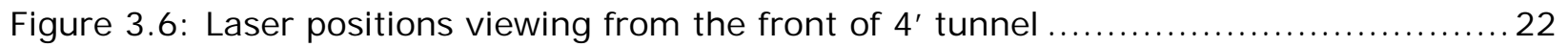

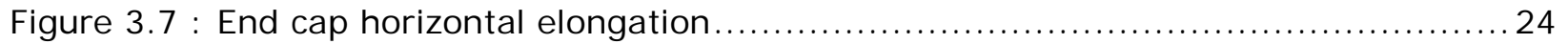

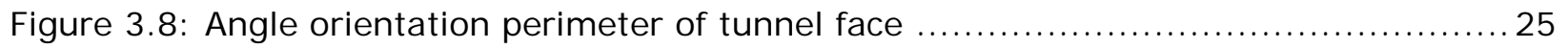

Figure 3.9: Elongation plot at a radius of 3.8" from the center of tunnel face for $360^{\circ}$

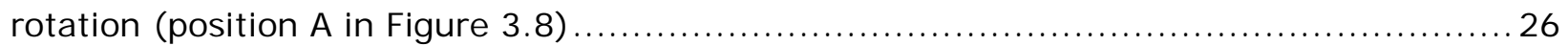

Figure 3.10: Elongation plot at a radius of $7.7^{\prime \prime}$ from the center of tunnel face for $360^{\circ}$

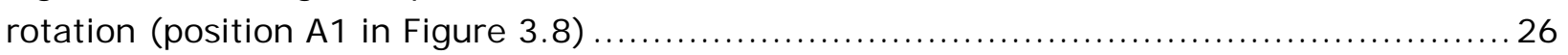

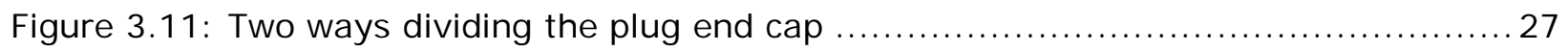

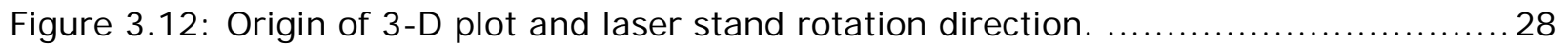

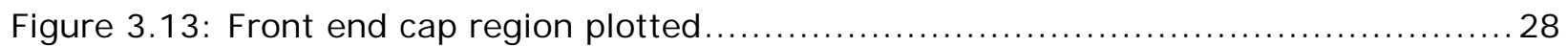

Figure 3.14: Best fit surface plot for 15 psi plug pressure.............................. 29

Figure 3.15: Contour plot for 15 psi plug pressure.................................... 29

Figure 3.16: Best fit surface plot for 30 psi plug pressure.............................. 30

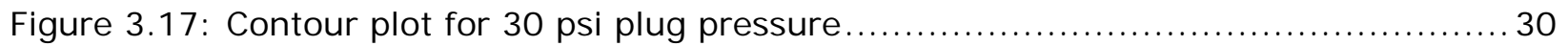

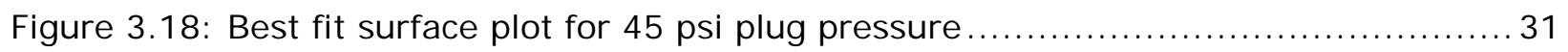

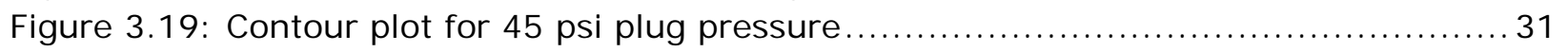

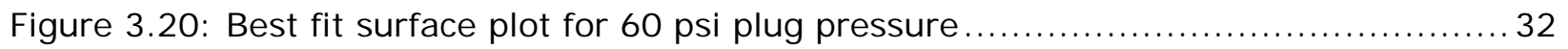

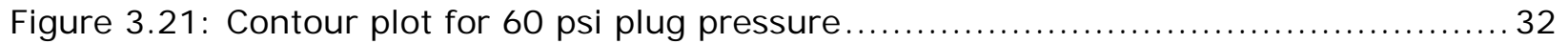

Figure 3.22: Best fit plots for 15, 30, $45 \& 60$ psi: A comparison ............................ 33

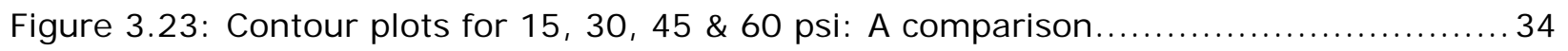

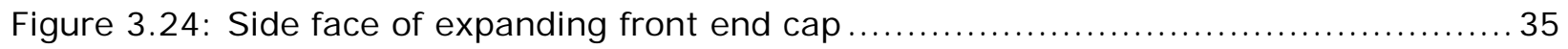




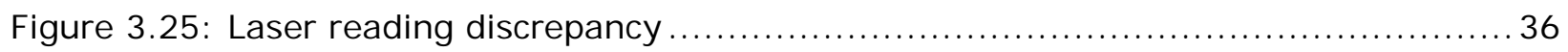

Figure 4.1: Schematic representation of the test piping system for slippage test ............ 39

Figure 4.2: Slippage: tunnel 20 - plug 30 psi............................................ 41

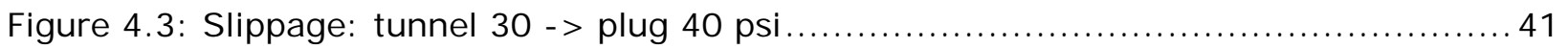

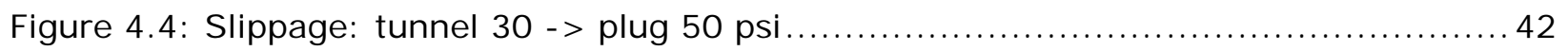

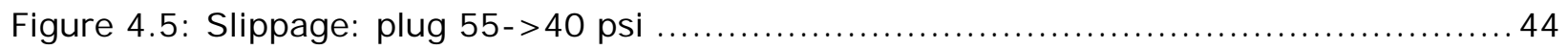

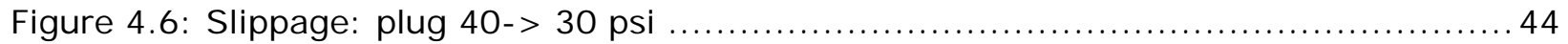

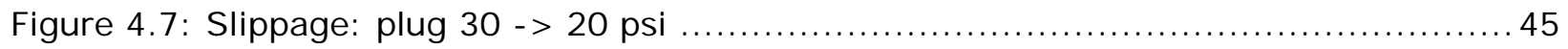

Figure 4.8: Uncontrolled slippage: tunnel 10 - > plug 20 psi............................ 46

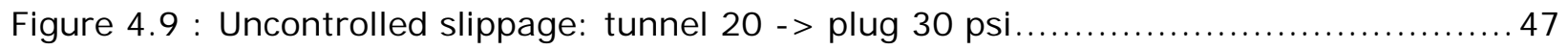

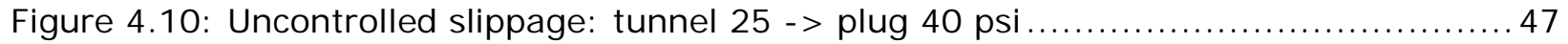

Figure 4.11: Representative holding resistance variation with trial number for Test \#1 for

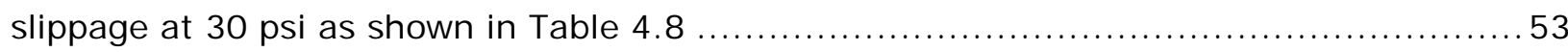

Figure 4.12: Representative holding resistance variation with trial number for Test \#10 for

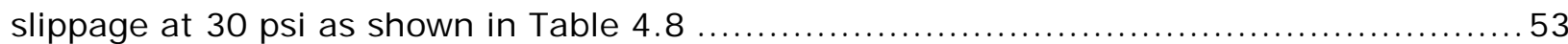

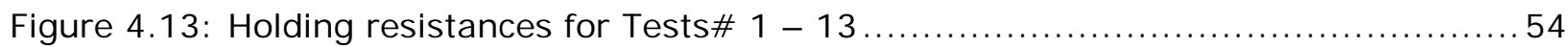

Figure 4.14: Different tunnel concrete lining 1) abraded zone 2) un-abraded surface....... 55

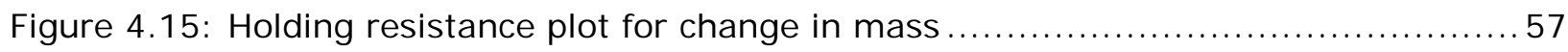

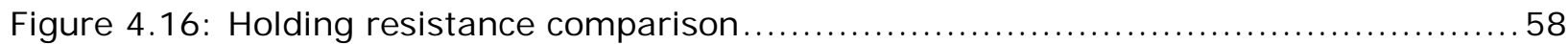

Figure 4.17: Webbing surface comparison: 1) initial plug surface prior to any testing, 2)

plug surface for extended testing, 3) close up view of abraded vectran webbing ............59

Figure 4.18: Representation of external pressure on the rear end cap....................62

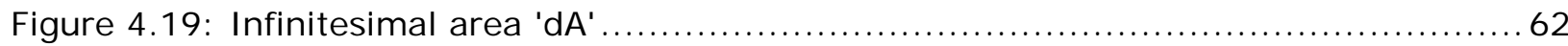

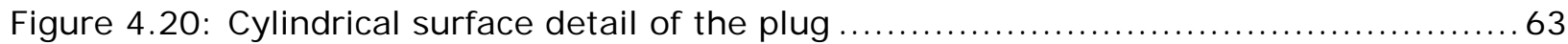

Figure 4.21: Hydrostatic tunnel pressure distribution ..................................... 65

Figure 4.22: Hydrostatic pressure distribution in cylindrical section of the plug .............66 66

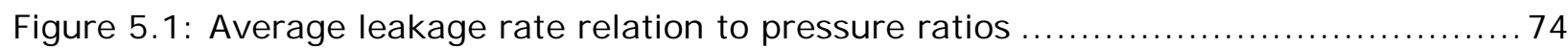

Figure 5.2: Single layered plug \& tri-layered plug leakage comparison $\ldots \ldots \ldots \ldots \ldots \ldots \ldots \ldots 75$

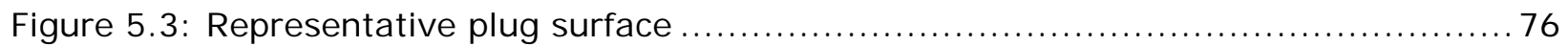

Figure 5.4: Different orientations of the plug: 1) end cap facing downward; 2) end face

upward; 3) laser b pointing at the center; 4) end cap face left (laser b pointer on right); 5)

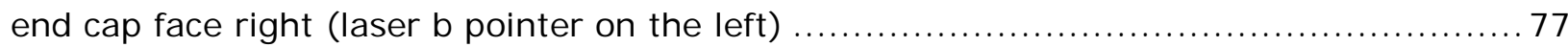

Figure 5.5: Leakage mitigation setup: 1) neoprene pad positioning with respect to the plug;

2 ) the test set up; 3 ) wet tunnel wall after the test showing leak $\ldots \ldots \ldots \ldots \ldots \ldots \ldots \ldots \ldots \ldots 79$

Figure 6.1: Schematic for setting up for seepage pressure measuring system .............. 82

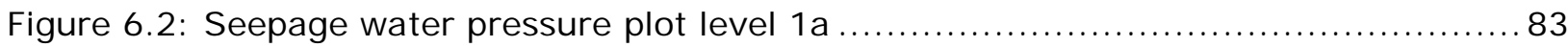

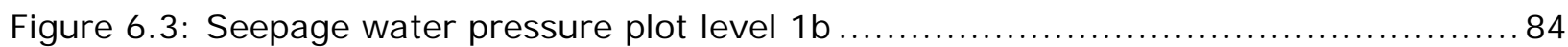

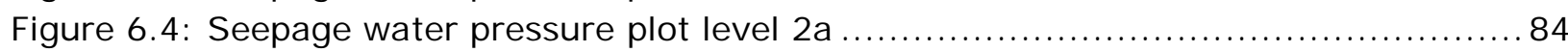

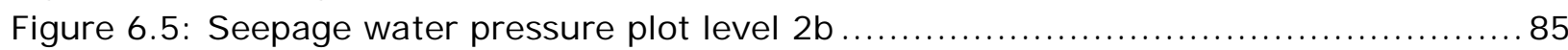

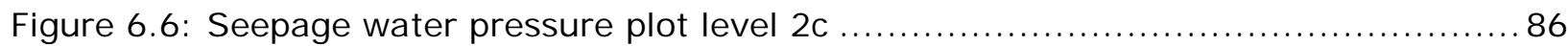

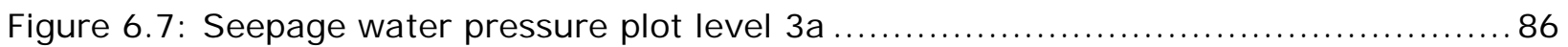

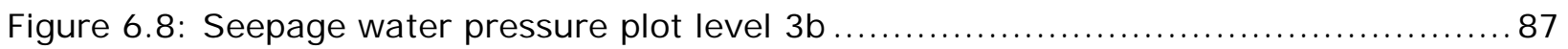

Figure 6.9: Seepage water pressure plot level $3 c \ldots \ldots \ldots \ldots \ldots \ldots \ldots \ldots \ldots \ldots \ldots \ldots \ldots \ldots . \ldots \ldots$

Figure 6.10: Variation of COV for seepage pressure study at various locations of

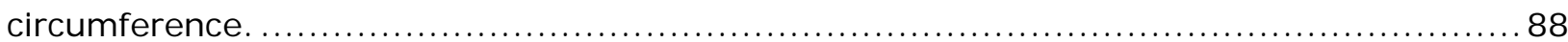

Figure 6.11: Seepage water-mark post testing on the tunnel wall ....................... 91 


\section{List of Tables}

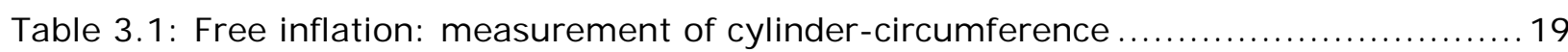

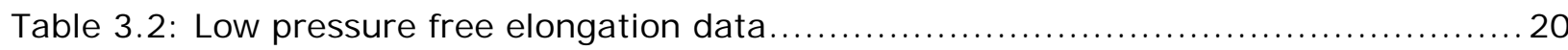

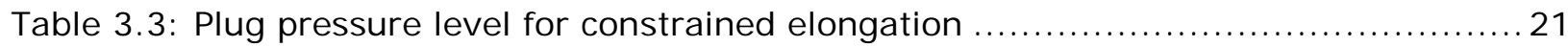

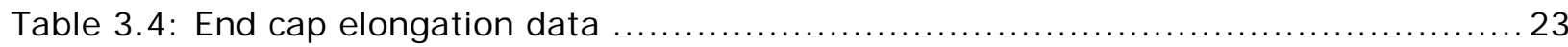

Table 4.1 : Pressure combinations for slippage: sequence $A-1 \ldots \ldots \ldots \ldots \ldots \ldots \ldots \ldots \ldots \ldots . \ldots \ldots$

Table 4.2 : Pressure for uncontrolled slippage: sequence $A-2 \ldots \ldots \ldots \ldots \ldots \ldots \ldots \ldots \ldots \ldots \ldots \ldots$

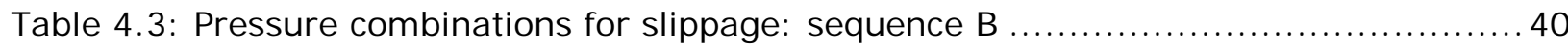

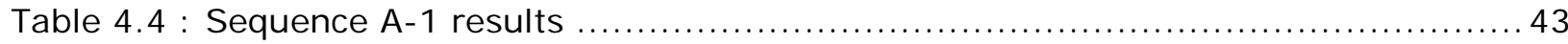

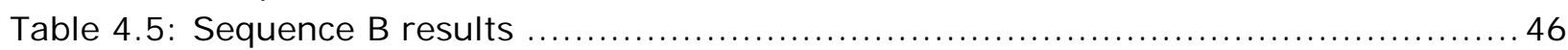

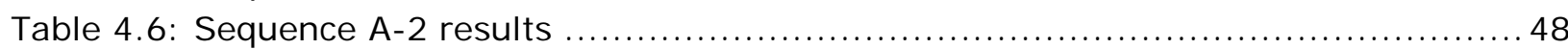

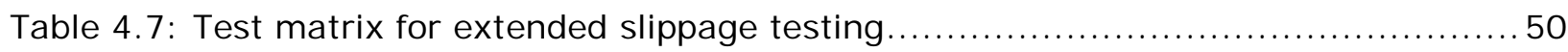

Table 4.8: Slippage test results with reduced effective length of plug on concrete (diagrams

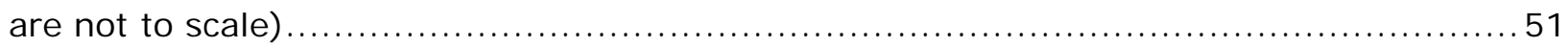

Table 4.9: Slippage test results with scraped and smooth tunnel wall ...................... 52

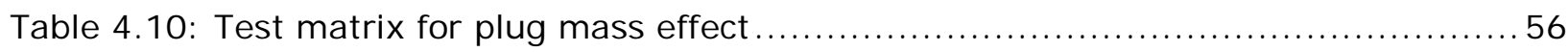

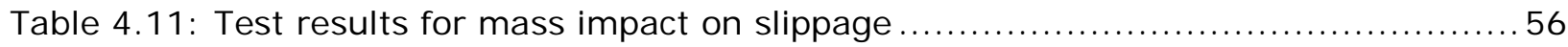

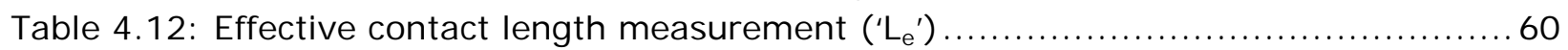

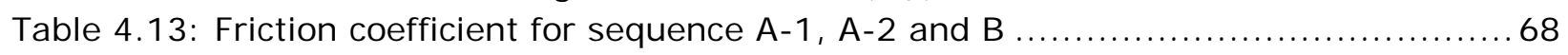

Table 4.14: Friction coefficient for extended testing ................................... 69

Table 4.15: Coefficient of friction comparison for different test scenario $\ldots \ldots \ldots \ldots \ldots \ldots \ldots \ldots . \ldots \ldots$

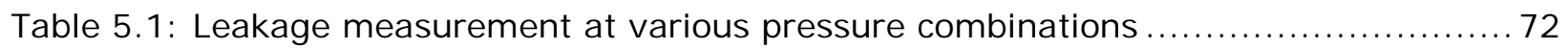

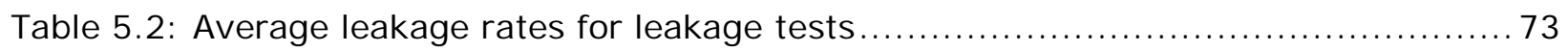

Table 5.3: Leakage data for single layered Vectran plug [17] for plug pressure of .......... 74

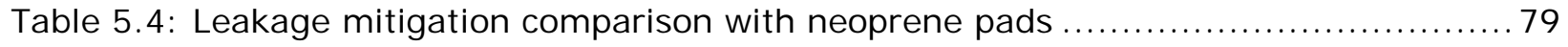

Table 6.1: Pressure levels for seepage water pressure test $\ldots \ldots \ldots \ldots \ldots \ldots \ldots \ldots \ldots \ldots \ldots \ldots 1$

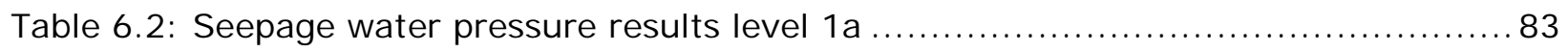

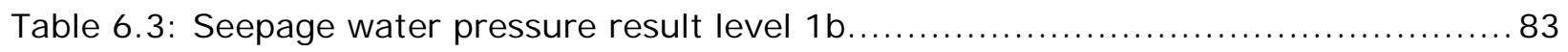

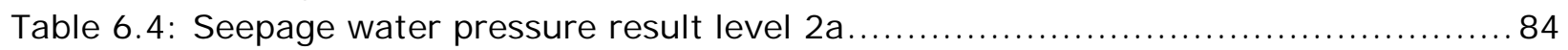

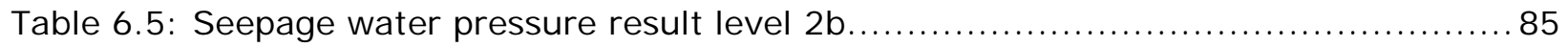

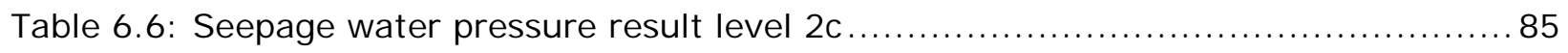

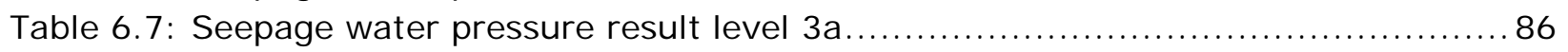

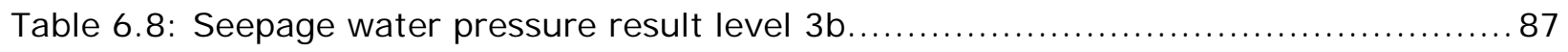

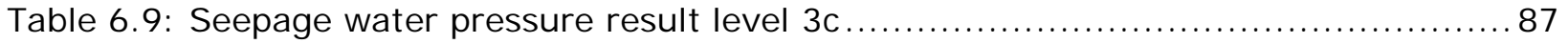




\section{Nomenclature}

psi: pounds per square inch

Horse Power: one horse power equals 746 watts (Energy)

DC: direct current

AC: alternating current

$1 \mathrm{~mm}$ : millimeter

$1 \mathrm{~cm}$ : centimeter

$\mathrm{R}^{2}$ : coefficient of determinations

$p_{\mathrm{e}}$ : external pressure i.e. pressure of water in tunnel space behind the plug

$\mathrm{p}_{\mathrm{i}}$ : internal pressure i.e. pressure of water in the plug

$\left(p_{e} / p_{i}\right)$ : pressure ratio for external to internal pressure

$\mathrm{L}_{\mathrm{e}}$ : plug effective contact length with tunnel concrete lining

$\mathrm{L}_{\mathrm{re}}$ : reduced plug effective contact length with tunnel concrete lining

$\mathrm{F}_{\text {ext }}$ : total net external force acting on the plug due to applied tunnel pressure

$\mathrm{R}$ : internal radius of the tunnel

D: internal diameter of the tunnel

L: cylindrical length of the plug

$\mu$ : coefficient of friction

$Y$ : specific weight of water

$1 \mathrm{lb}$ : 1 pound

1 in: 1 inch (1")

$1 \mathrm{ft}: 1$ foot (1')

gpm: gallons per minute

$1 * \mathrm{~L}$ : full cylindrical length of the plug from the front rope

$0.75^{*} \mathrm{~L}$ : three quarter of the cylindrical length from the front rope

$0.5^{*} \mathrm{~L}$ : half of the cylindrical length from the front rope

$0.25^{*} \mathrm{~L}$ : quarter of the cylindrical length from the front rope

g: acceleration due to gravity 


\section{Chapter 1 Introduction}

\subsection{Significance of Work}

Engineers have made significant progress in the field of inflatable structures. Inflatable structures for space exploration in terms of inflatable satellites, inflatable antennas, space suit, solar concentrators, inflatable air bag landing system [1, 2, 3] etc. have been prevalent since the 1960s. There was the realization of the advantage of using inflatable structure for light-weight transportable buildings, low-cost space stations and lunar bases with the advent of the Air-beam Technology [4, 5]. Inflatable structures has also been tailored for variety of safety concerns like underground tunnel fire protection [6], large mine flooding remediation using "grout bag" [7], plugging pipes for repair under extreme environment [8], blast-resistant inflatable shelter, blast mitigation barriers and environment control regions for protection against toxic environment [9]. But there has not been any precedent study for ensuring safety for underground tunnels under the circumstances of sudden flooding, tunnel roof collapse or release of toxic gases. Disaster like the King's Cross Fire in 1988 [10] and the Great Chicago Flood in 1992 [11, 12] led to a serious notion of designing such a protection system that would deploy within minutes of the disaster, isolating the section. This in turn can increase the time for human evacuation and minimize damage leading to normal resumption of services, reducing the ultimate loss of property and revenue.

Inflatable structures possess operational advantage over any other structure made of metal or concrete. The application for tunnel safety against flooding could have been mitigated by the installation of floodgates at different points along the length of the tunnel. However, the installation of flood gates require long term closure of such a tunnel and major change in the infrastructure thereby causing inconvenience and it is certainly expensive. An inflatable structure with its high mechanical packaging efficiency [1], deployment reliability [1] and relatively low weight [1] can fit the bill for an inexpensive safety measure. Inflatable structures are generally manufactured from fabrics made of polymeric materials with various combinations of design. The use of these fabrics has higher advantage of strengthto-weight ratio but have lower modulus of elasticity [13]. This implies that while it shows comparable strength to steel, an inflatable structure would potentially deflect or deform " $x$ " time more as the inverse ratio of their moduli. This factor enables them to be used in application where higher deflection is allowed and does not contribute to use discomfort.

An underground vehicular tunnel was mimicked at the hanger facility of West Virginia University with 16' diameter and approximately 43' long cylindrical tunnel. This full scale set up reflected a realistic condition with respect internal tunnel contours and the actual behavior of the plug in case of deployment during flooding. The inflatable plugging system was tested for conformance with the tunnel contour and the amount of water leakage. But the full scale plugging system could not be evaluated for slippage test and the evaluation of friction coefficient, an important aspect for effective plugging. This was due to the sheer scale of the set up and the risk involved with slipping the plug and damaging the infrastructure. Repeatability of tests in full scale for more than one trial was also an issue due to time and resources utilized in conducting just one test. A quarter scale model (4' 
diameter tunnel) of the full scale set up was hence manufactured with smooth circular contour unlike a real tunnel. This set up facilitated the study of the behavior of the plug under ideal scenario of plugging (ideal scenario meaning, the absence of irregular contour of the tunnel cross section) with much less resources and greater ease of repeatability [14]. This quarter scale model also involved minimal risk for the slippage test.

This study primarily deals with the reduced scale 4' diameter tunnel inflatable plugging system designed and manufactured by the team and tested at hangar facility of the West Virginia University (WVU). The tests were conducted to study mechanical behavior of the plugging system under various internal and external loading scenarios. The plug was tested for the nature elongation with increasing internal pressure, slippage under various combination of internal to external pressures, leakage characteristics and seepage water pressure characteristics.

\subsection{Previous Studies on Tunnel Safety with I nflatables}

An inflatable tunnel plug was designed by Lindstrand Technologies Limited. to combat tunnel fire $[10,6]$. The plug that was installed at every 100 meters interval restricts the flow of air blocking off the availability of the oxygen. This application can also be used for blocking off the source of toxic gases if released under the influence of any terrorist attack or otherwise. The flat inflatable have zipper on the center allowing people inside the tunnel to escape from the disaster zone. The material consists of glass fiber fabric coated with free silicone rubber with aluminium flakes. The material is temperature resistant up to $842^{\circ} \mathrm{F}$. It does not risk the deployment of fireman under active burning condition since the inflatable can be deployed remotely. Currently this system has been installed in in London Underground Victoria Line. This has also been successfully tested at the New Hubertus tunnel in Hague, Netherlands and Brenner Pass in Italy [6]. This system, being effective for containing fire and toxic gases, does not possess the ability to contain water under high pressure in case of flooding.

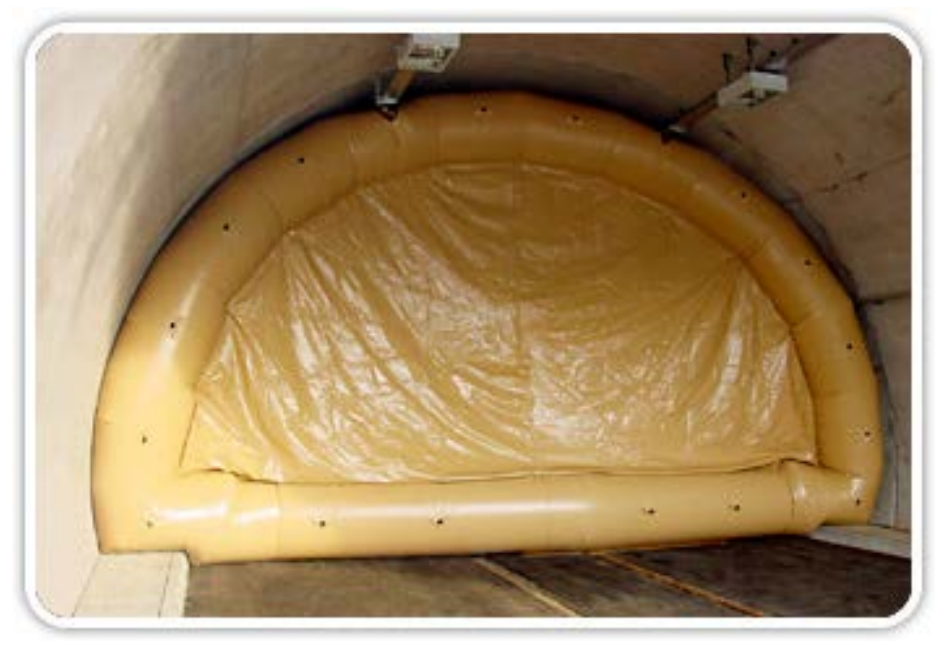

Figure 1.1: Lindstrand technology inflatable [6] 
Peterson Product Company has been providing inflatable pipe plugs for repairing and temporarily blocking pipelines in factories and water supply network [8]. In 2009, they developed an innovative solution of deploying an inflatable grout bag for uranium mine tunnel sealing at Cigar Lake Mine [7]. The mine was cleared of all debris, followed by water inflation of the grout bag, positioning with a remotely operated vehicle and then filling up with grout and pushing the water out for a permanent seal. This facilitated the sealing of the tunnels susceptible to frequent flooding under the ground level [7].

In 2007, WVU, sponsored by the Department of Homeland Security (DHS), Science and Technology division in partnership with Pacific Northwest National Laboratory (PNNL), and industry collaborators initiated the Resilient Tunnel Project (RTP) $[15,16]$. The aim of this project was to develop an inflatable plugging structure that can be deployed remotely, withstand high internal fluid pressure to generate motion impeding friction between the tunnel wall and the inflatable, and restrict the flow of high pressure water in the tunnel originated by flooding. The application was specially meant for tunnels running under waterways which are susceptible to suffering from flooding. The high pressure of water in the tunnel would have been caused by a breach in the tunnel wall leading to influx of water at a pressure close to the superincumbent hydrostatic pressure of the waterway at the depth of the tunnel [16].

A prototype tunnel was manufactured for full scale study that was a $16^{\prime}$ diameter cylindrical tunnel, approximately 43' long which was installed at the WVU hangar Facility. But due to the scale of this model construction, and the difficulties inherent to doing extensive testing at this scale, a reduced scale model was proposed. It was decided to study the plugging system at a quarter scale with a 4' diameter pre-tensioned concrete [17] tunnel and 4' diameter inflatable plug to fit into it. The quarter scale tunnel does not possess any of the features of the full-scale tunnel, possessing a completely circular circumference with smooth concrete surface. Hence, this quarter-scale tunnel can be coined as an ideal tunnel with ideal cross section to exhibit the inflatable plug structural and mechanical behavior under "ideal" conditions.

A single layer inflatable manufactured from Vectran fabric with a cylindrical shape with spherical end caps on either side was designed by the team for the first phase of quarter scale testing [17].

Vectran is a fiber manufactured by Hoechst-Celanese $[1,13]$. It is a high performance multi-fiber yarn spun from liquid crystal polymer called Vectra. It possesses high strength and rigidity [18]. It also possesses commendable resistance to degradation from handling and packing due to its flex-crack/abrasion resistance [1]. Vectran has also been used for applications like Mars Pathfinder Airbag Landing system for impact attenuation [1], ropes and cables, fiber optic strength members, printed circuit boards, sailcloth, reinforced hulls, golf clubs, tennis racquets, textile and composites and for chemical resistant packing and gasket [18]. 


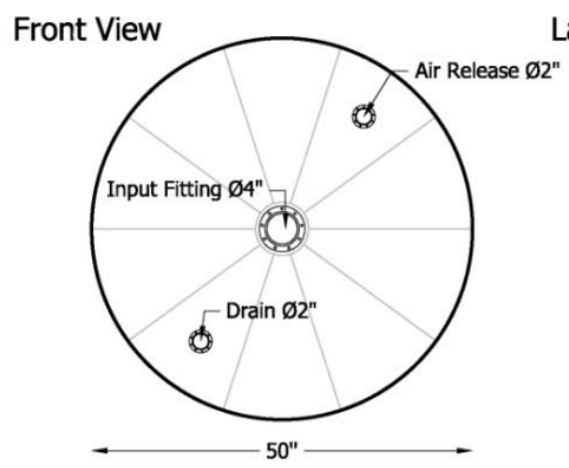

Lateral View

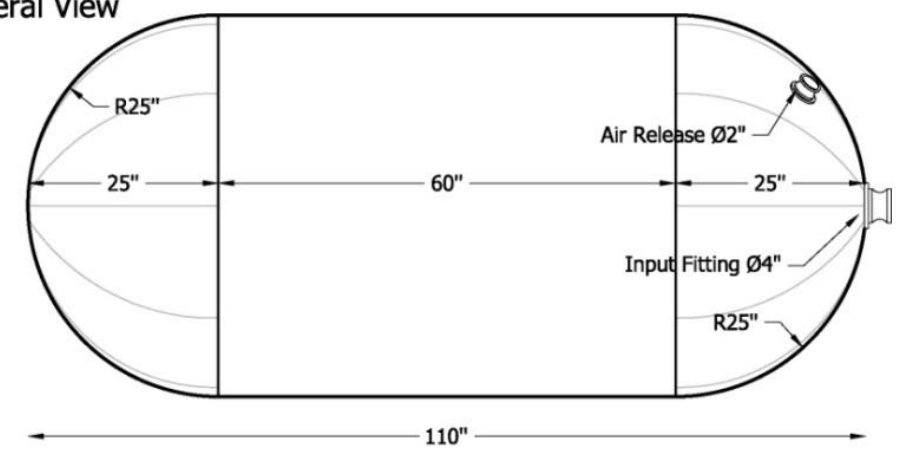

Figure 1.2: Single layer Vectran plug schematic [17]

Figure 1.2 above shows the schematic diagram of the single layer plug design with a spherical diameter of 50" and cylindrical length of 60". The design pressure of the plug was 40 psi. It had an approximate volume of 800 gallons. The Vectran fabric was coated with urethane on either side for waterproofing and additional abrasion resistance for outside. The plug front spherical face had three ports namely air-release, drain and fill port [17].

The quarter scale plug withstood all the tests as reported in [17]. The 16' inflatable was subsequently made of the single layer Vectran fabric as the quarter scale and tested on the full scale tunnel setup. The full scale inflatable did not pass the water pressurization test [19]. This led to modifications in terms of the structural aspect of inflatable plug design for withstanding high water pressure under confined state.

\subsection{Current Modifications}

The new quarter-scale plug is a tri-layered inflatable structure [19]. The innermost layer consists of polyurethane fabric which is able to withstand internal water pressure, followed by Vectran fabric layer in the middle and the Vectran woven webbings on the outside [19]. The webbings on the cylindrical surface section run in both circumferential and axial directions. The spherical end caps have webbings running in both directions towards the edges while towards the center of the end cap it runs radially inward. This tri-layered plug withstood the full scale tests [20, 21, 22 and 23].

Webbing inflatable has been used for various space structures and other applications as structural reinforcements. Torpedo Recovery Float [24], Collapsible Hyperbaric Chamber [24], Orbital Space Station [24], Lunar Deployable Habitat [24] and Mars Exploration Rover Airbag for impact attenuated landing $[1,24]$ are the examples of such usage.

The polyurethane and Vectran fabric bladder was made larger than the Vectran webbing containment in terms of volume. This allows the stress predominantly taken by the webbing to be distributed to inner layers only at windows of no webbings beyond certain value of pressure. These windows were only present around the tip of the end caps. The layers are indexed (by stitching) together at an angle $45^{\circ}$ to the webbing length in order to counter for shearing effect between the layers. The other details of the reduced-scale plug are discussed extensively in Chapter 2 under "Test Items and Instruments." 


\subsection{Objectives of Study}

The objectives of the study were as follows:

1. Analyze the nature of expansion of the inflatable described in the previous section and resulting elongation under the following conditions.

a. Study under low pressure (0-3.2 psi) unconstrained inflation with air.

b. Study under high pressure (15-68 psi) constrained inflation with water.

2. Analyze the slip behavior of the plugging system and evaluate the system coefficient of friction for various combinations as mentioned below.

a. Derive equations for evaluating the coefficient of friction for the system.

b. Initial set of testing for controlled and uncontrolled slip with available concrete surface and the new tri-layered plug.

c. Extended set of testing to evaluate:

i. The effect of varying effective contact length of the plug with tunnel concrete surface.

ii. The effect of varying the mass of the plugging system.

iii. The effect of abrading the tunnel concrete lining.

iv. The effect of abrading the plug surface on smooth concrete.

d. Comparison of the results with the reports of single layered Vectran Plug studied previously [17].

3. Evaluate leakage characteristics of the plugging system.

a. Leakage measurement and comparison with the Single Layered Plug studied previously [17].

b. Leakage estimation for full-scale system.

c. Leakage mitigation.

4. Evaluate seepage water pressure between the plug surface and the tunnel wall.

a. Study at various orientations along the tunnel wall circumference and along the different points of the plug cylindrical length.

\subsection{Organization of Thesis}

This thesis consists of seven chapters including the current one. The first chapter deals with "Significance of Work," a background study and the current modifications for the quarter scale testing. The second chapter deals with the Test Items and the Test Instruments. Thereafter, the next four chapters deal with each one of the primary objectives stated in under the above section, "Objectives of Study."

Each chapter begins with a brief introduction. Then the chapters are segregated as mentioned above under the subtopics of "Objectives of Study" with subsequent experimental observations, results obtained and discussions. A summary is then drawn to summarize the findings.

The last chapter deals with "Conclusions and Recommendations" for further study which deals with an overall summary and possible avenues of further investigations. 


\section{Chapter 2 Test I tems and I nstruments}

\subsection{I ntroduction}

Testing items involved the quarter scale 48" interior diameter concrete pipe as tunnel and 49" diameter tri-layered Vectran plug. Test instruments involved air compressor and hydraulic system for tunnel and plug pressurizing, pressure sensor system, distance measuring lasers, leakage measuring scale system, seepage pressure measuring system and the data acquisition system.

\subsection{Test I tems}

\subsubsection{Tunnel}

The tunnel is a nominal 48" internal diameter pipe. The rear end of the tunnel was sealed while the front the front end was left open. It was constructed with spiral steel reinforcement with concrete inner and outer layer. The cylindrical part of the tunnel was designed for a maximum of 90 psi and the end cap was rated at 60 psi. The tunnel was supported on I-beams to minimize the chances of cracking in the longitudinal direction due to deflection [17]. A diagram of the concrete tunnel with approximate dimensions is provided in Figure 2.1.

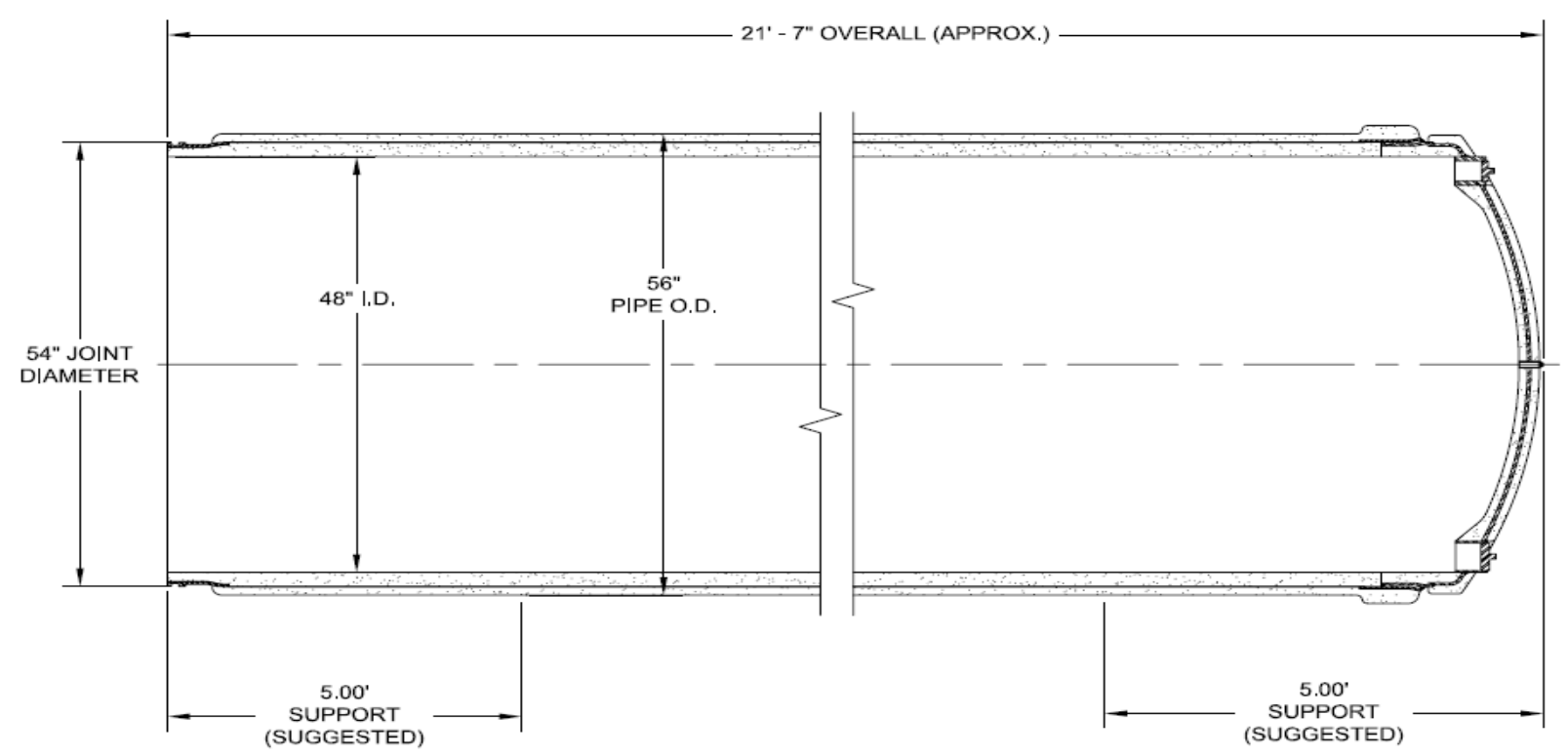

Figure 2.1: Tunnel dimensions [17]

The concrete liner on the inside surface of the tunnel was classified as ICRI-CSP \#1 [25] smooth concrete [17]. Smooth concrete was also ensured in the inner lining of the tunnel to ensure the minimum of abrasion to the plug surface due to repeated tests [17]. Most of the tests in the purview of this thesis have been conducted on this smooth concrete 
lining. Some tests were made by varying the contact length of the plug with concrete by partly covering it by low friction materials like Teflon and Polyethylene films. These films were attached to the plug surface by using dual side tape adhesive. A diagram of the concrete tunnel is provided in Figure 2.1.

\subsubsection{Plug}

The plug used for tests reported in this thesis was manufactured by ILC Dover. It consists of three layers: 1) Webbing Layer; 2) Protective Layer and 3) Bladder Layer [26]. The plug consists of two cylindrical segments with end caps on either end. The plug had a cylindrical length of 50" and the cylindrical and spherical diameter of 49".

The external layer made of Vectran webbings formed "closed webbing net" which acted as the primary load carrying member for the structure [26]. Such webbings as primary structural membrane was based on the proven cases of redundancy, where breaking of one webbing does not adversely affect the structure. The cylindrical section was completely covered with woven webbings, whereas the hemispherical end caps were partly covered by the hoop webbings. Ropes were used to terminate one set of webbings [26].

The protective layer under the webbing matrix is made of Vectran fabric which supported the pressure between webbing spaces provided in the end caps. This layer was uncoated, sewn fabric to avoid air entrapment [26].

The bladder layer was lightweight polyester coated with urethane which acted as a pressure retention layer. This layer was heat sealed to minimize leakage and bulk [26].

All the above layers were indexed together to ensure proper alignment. The axial webbings on the end cap were stitched to the protective layer for end cap alignment [26].

This plug has only two ports. The plug inflation/drain and the air release ports were male parts having 2" cam-lock grooves fitted to an aluminum flange at the top and the bottom of the front hemispherical end cap. The aluminium flanges were fitted with screws to the protective layer and the interior bladder.

\subsection{Test Instruments}

Figure 2.2 represents a general schematic diagram of the test set up with the test instruments.

\subsubsection{Plug Pressurizing System}

Air Compressor: The hangar air compressor (as shown as "Air Supply Unit" in Figure 2.2) was used which could attain a maximum supply pressure of 120 psi. Due to such high supply pressure, the air inflow to the plug was controlled by a valve. The air compressor was used in various inflation processes including free inflation tests and to study the effect of mass of plug in slippage tests. It was commonly used in all constrained inflation cases for positioning of the plug to ensure proper alignment with the lasers and for positioning the lasers prior to water testing. Not that the plug was generally inflated to only 1 psi due to potential explosive power of a large volume. 


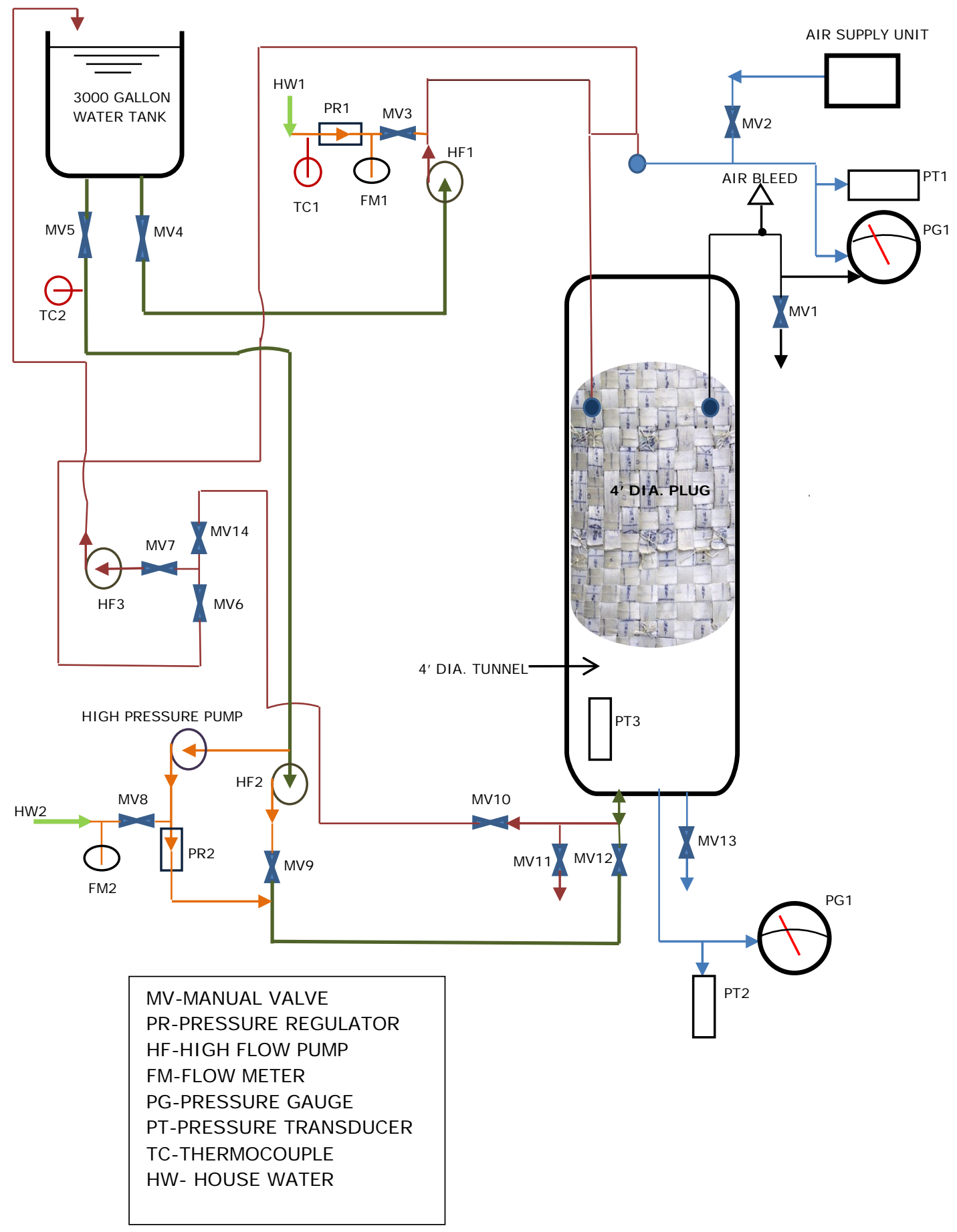

Figure 2.2: Test set-up 
High Flow Pump 1: A 3.0 HP pump [17] (shown as "HF" in Figure 2.2) was used to draw water from the 3000 gallons water tank and fill the plug; and push the air out of it till the air release port has steady jet of water coming out of it. The pump was shut henceforth.

Regulator 1: The manual regulator (shown as "PR1" in Figure 2.2) used to regulate the pressure of water in the plug. The ranges of the regulator used were $5-35$ psi and 25 psi to 75 psi. It was operated by turning the screws clockwise for increasing the pressure and counter clockwise to reduce the pressure. This regulator was fixed at the mouth of a house water supply in order control the amount of water flowing in the plug for plug pressurizing.

House Water: A house water supply (shown as "HW" in Figure 2.2) of 75 psi supply pressure was used to pressurize the plug with water beyond the usual filling of the plug. The pressurization was controlled with Regulator 1.

Neptune Flow Meter: A flow meter (shown as "FM" in Figure 2.2) was installed at the junction where the garden hose from house water was attached to Regulator 1 to control the plug pressure. The flow meter has an analog display with a least count of 0.1 gallon. It sends out signal as pulses that can be read by the computer and calibrated in Scimitar software to display in gallons.

Figure 2.3 shows the above components.

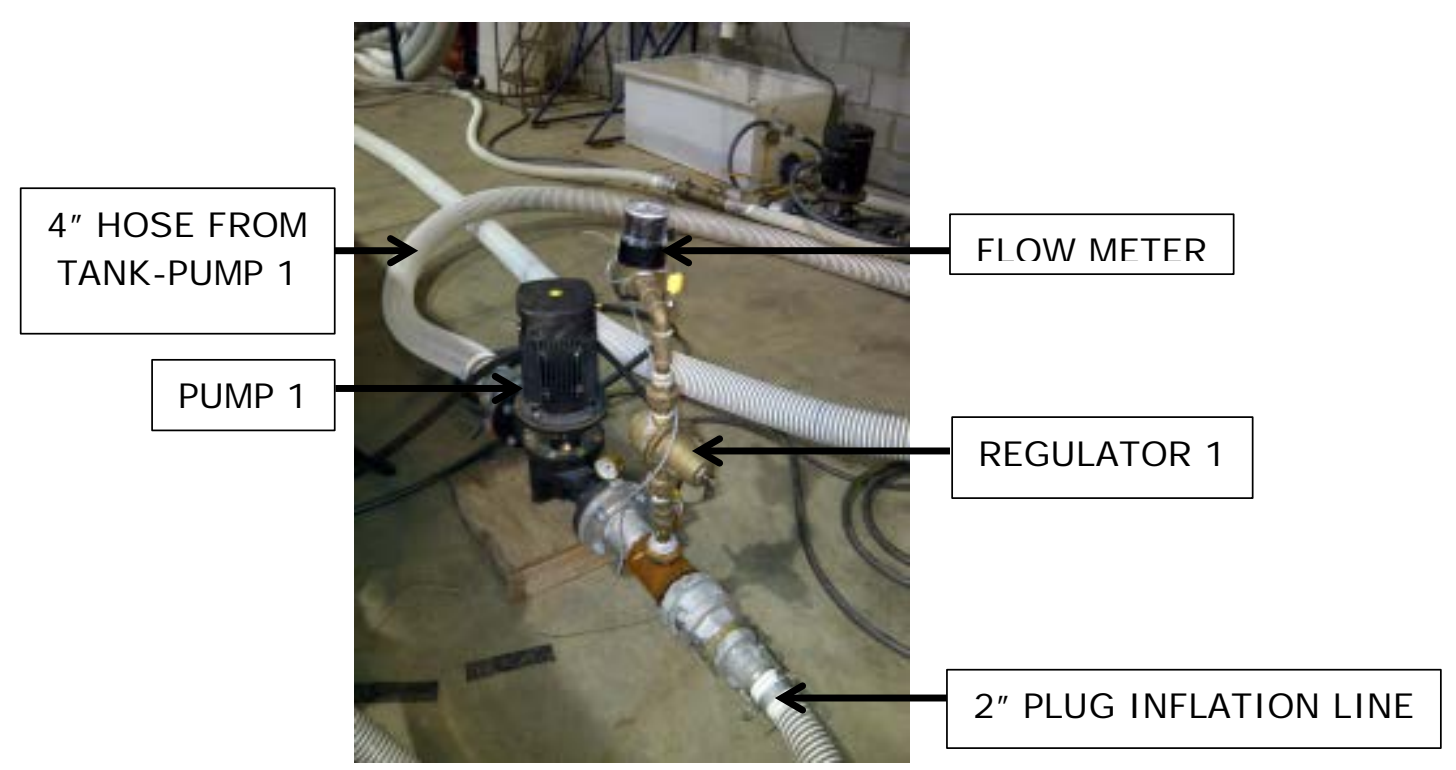

Figure 2.3: Pump 1 with regulator 1 and water flow meter

Inflation/ Drain Hoses for the Plug: The plug inflation and air release ports were both of $2 "$ internal diameters. The inflation/drain hoses were classified as EPDM rubber and PVC Suction and Discharge Water Hose with Wear Strips. It has an operating temperature range $-13^{\circ} \mathrm{F}$ to $140^{\circ} \mathrm{F}$ [27]. These wear-strips made of polyethylene and PVC provides reinforcement and protects the hose from damage caused by dragging [27]. The hose from the tank to the high flow Pump 1 was 4" internal diameter. The hose from Pump 1 to the 
plug had a 2" internal diameter. The lines in Figure 2.2 represent the hoses where the olive green line represents the 4" hoses and the red accent represents the 2" hoses.

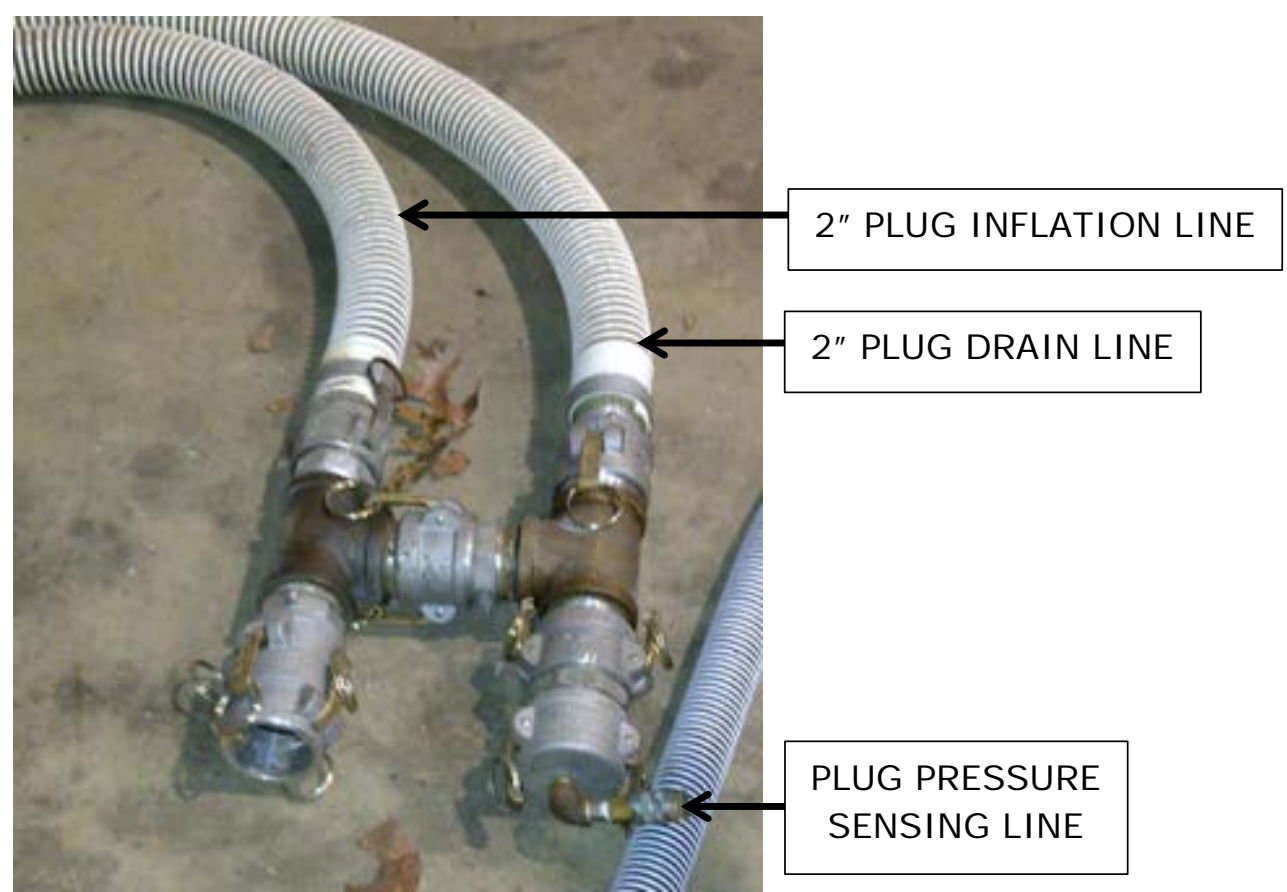

Figure 2.4: Plug inflation, drain and pressure sensing Line

Air Release Hose: Three-quarter inch rubber air release garden hose was used with a valve at the mouth to let out compressed air from the plug during inflation. Figure 2.5 shows the position of the air release hose and the inflation hose for the plug.

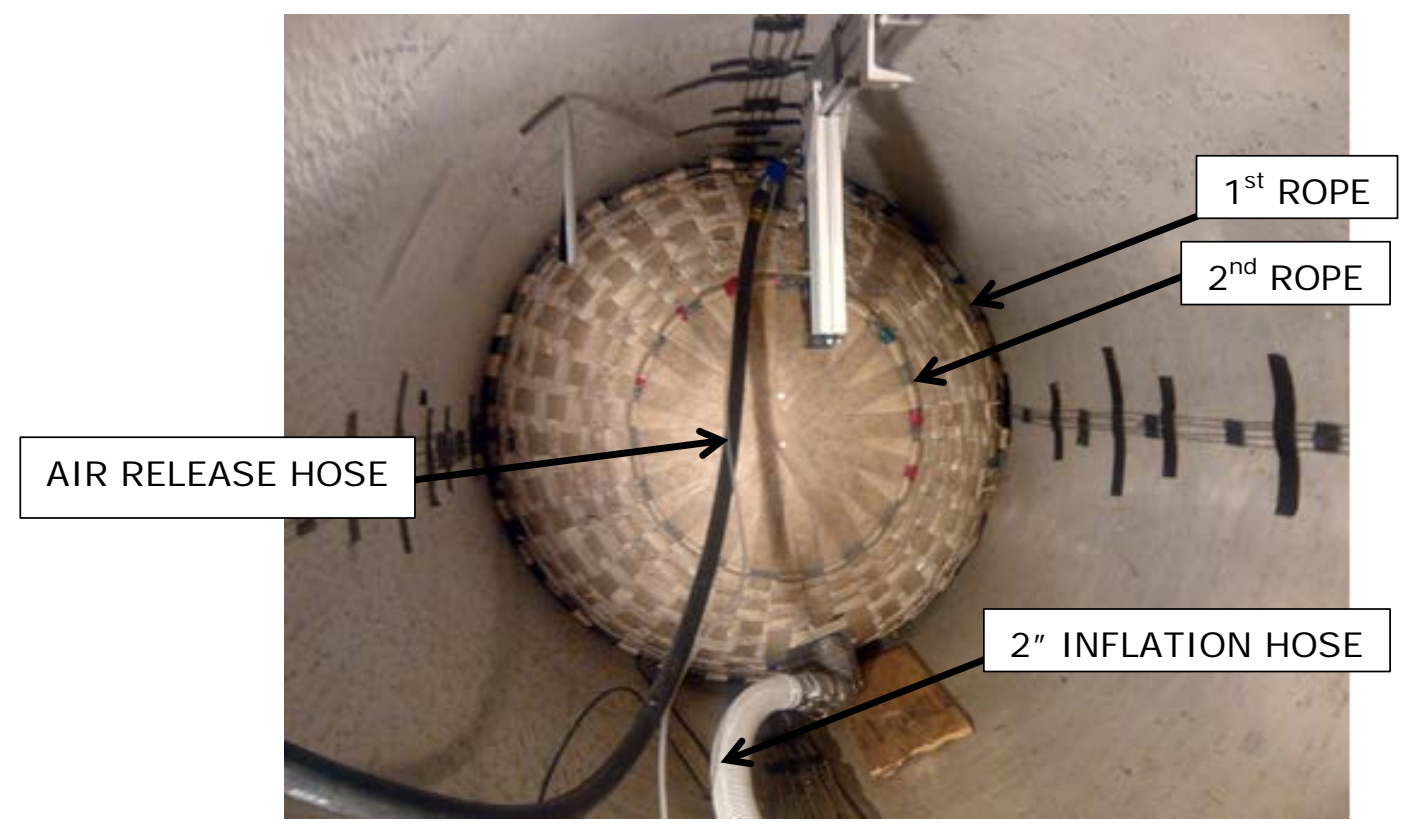

Figure 2.5: Air release \& inflation hoses 


\subsubsection{Tunnel Pressurizing System}

High Flow Pump 2: A second 3.0 HP pump [17] was used to draw water from the 3000 gallons water tank and fill the tunnel behind the inflated plug, push the air out of it till the tunnel air release port has steady jet of water coming out of it. The pump was shut henceforth.

Regulator 2: A second manual regulator was used to regulate the pressure of water in the tunnel space. The ranges of the regulators used were 5 - 35 psi and 25 psi to 75 psi. It was operated by turning the screws clockwise for increasing the pressure and vice versa. This regulator was fixed in the channel used by the high pressure pump to maintain and increase the pressure of water in the tunnel

High Pressure Pump: This 2.0 HP pump [17] was used to pressurize the tunnel water by using water from the 3000 gallons water tank. Since there was a possibility of significant leakage of tunnel water, between the plug surface and the tunnel wall, there was possibility of facing difficulty with the maintenance of tunnel pressure over considerable amount of time. This was the reason why high pressure pump instead of the house water supply was available for tunnel pressurization.

Filling and Drain Hoses for the Tunnel: The filling and the draining hoses used were of the same specifications as the ones for plug inflation. The filling hoses had an internal diameter of 4 " whereas the drain hoses had an internal diameter of 2".

Figure 2.6 and 2.7 shows the set-up of the components described above.

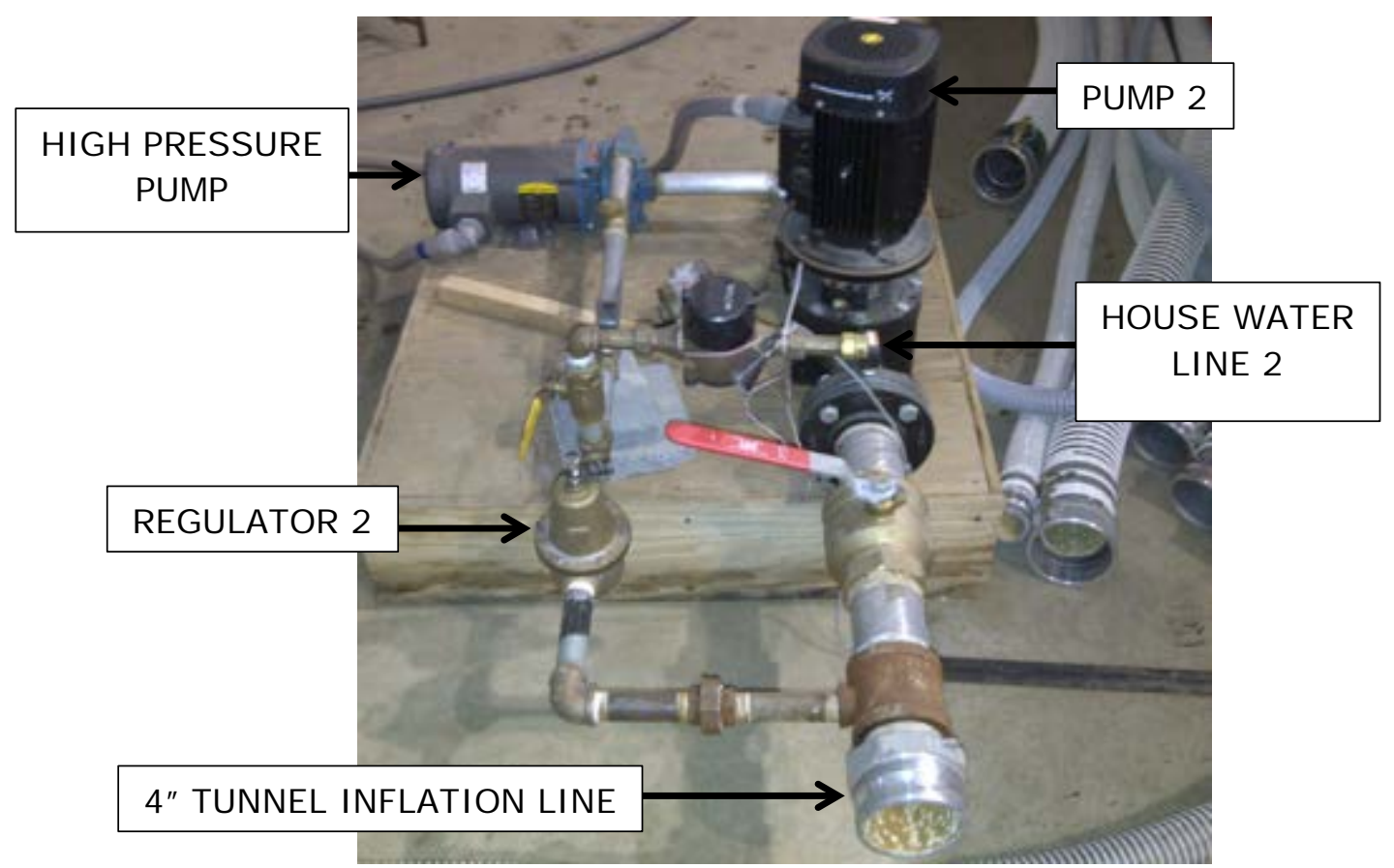

Figure 2.6: Tunnel inflation \& pressurizing system 


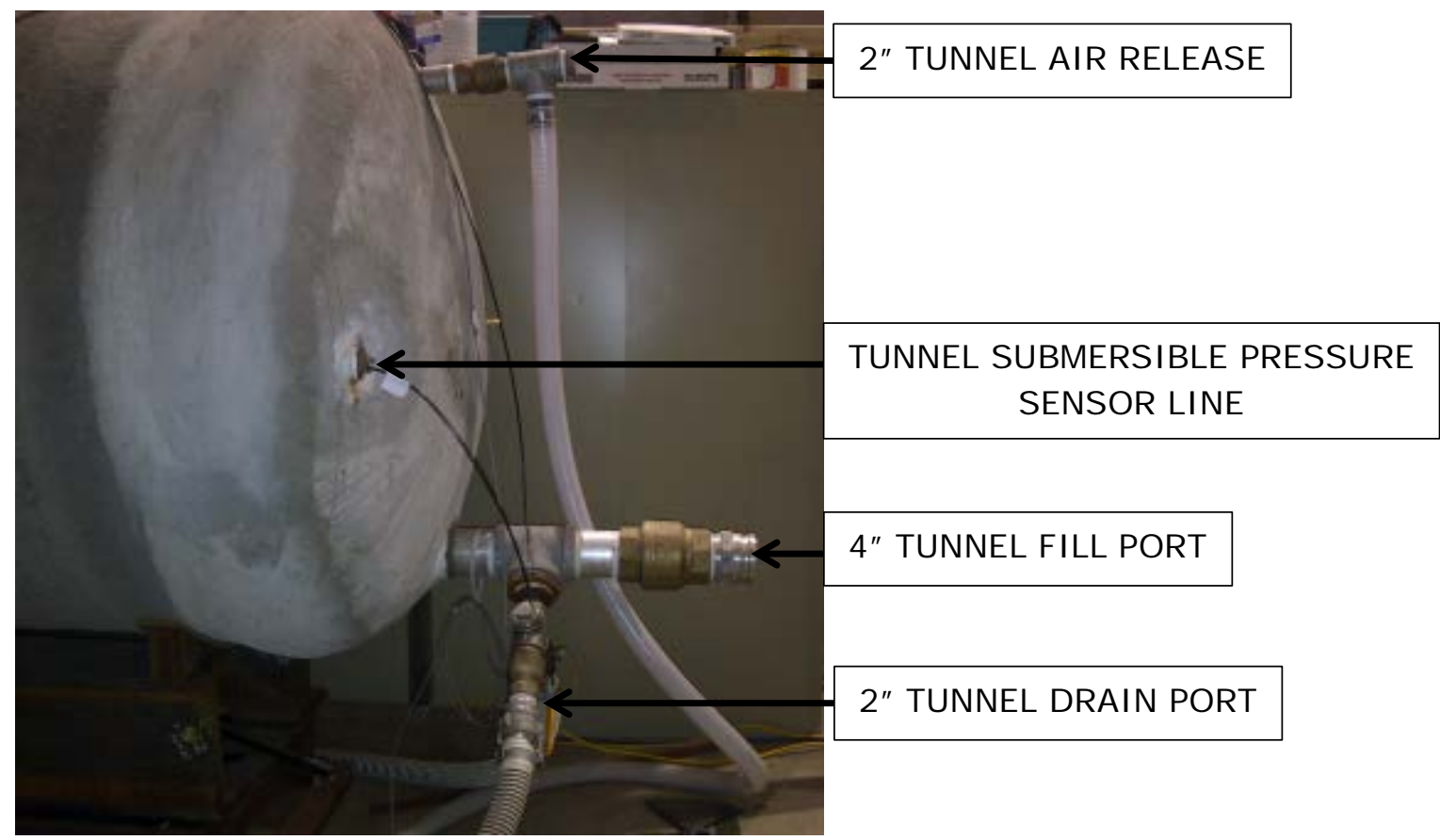

Figure 2.7: Plug fill, air release and drain port

\subsubsection{Pressure Sensor System}

Plug Pressure Sensor System: The transducers were calibrated with Fluke Pressure Calibrator and the calibration data incorporated in to Scimitar software (as slope and offset) to display the pressure in "psi." For the initial set of testing, two pressure transducers of range 0-100 psi were positioned at the mid-level of the plug. For the extended set of testing a new sensing point was added. A heavy mouth pipe was inserted in the plug through the air-release port cam lock assembly to lie at the bottom of the plug. This pipe led to an outside pressure transducer (0-100 psi) and a manual gauge positioned at the bottom level of the tunnel to measure the bottom pressure. Details are provided in Appendix F.

Tunnel Pressure Sensor System: The pressure transducers were calibrated the same way as previously mentioned. Two of these having range of 0-50 psi were inserted at the rear of the tunnel at the mid-level. A submersible pressure sensor was used of the range 0-30 psi. During the extended set of testing, a pipe was installed where the transducers were initially plugged and made to run to the transducer (0-50 psi) installed at the bottom level of the tunnel. Two submersible sensors were used of the range 0-30 psi. Details are provided in Appendix F.

\subsubsection{Distance Measuring Lasers}

Laser A, B and C: Leica lasers A, B and C called Leica Disto D8 were used as shown Figure 2.8. They were connected to the Data Acquisition System via Bluetooth. They have a measuring accuracy of $\pm 1.0 \mathrm{~mm}$ and a range of $200 \mathrm{~m} / 650 \mathrm{ft}$. $/ 780 "$. They also have an inclination measurement capability of $360^{\circ}$. The laser batteries were removed and an adapter was used to convert direct AC supply power to DC power for continuous usage and reduce battery waste. 


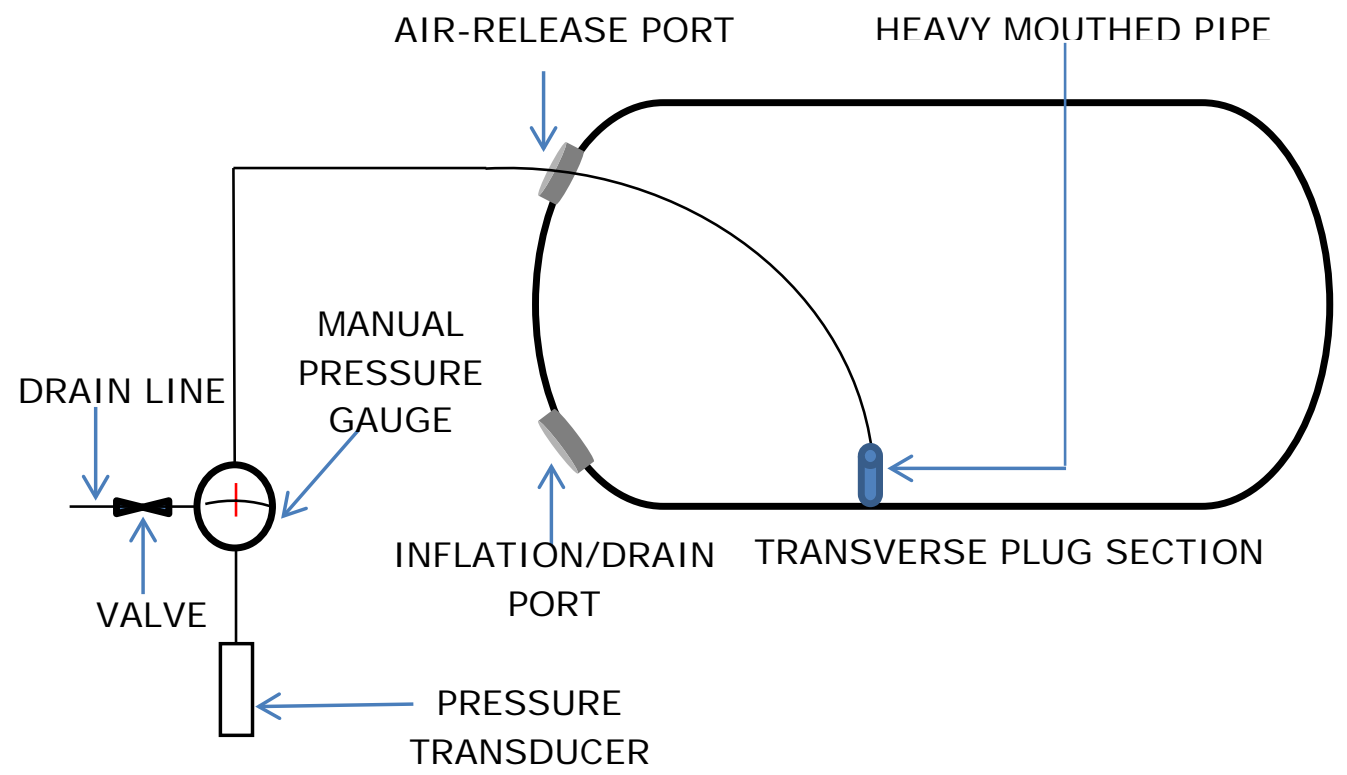

Figure 2.8: Metal pipe mouth taped to Teflon pipe; Teflon pipe through port cam lock

Laser $1 \& 2$ : Keyence lasers $1 \& 2$ were stationary lasers positioned inside the tunnel. They were to Keyence model LK-G 400 series lasers. The minimum measuring range was from $299 \mathrm{~mm}$ to a maximum measuring range of $497 \mathrm{~mm}$ along the laser ray i.e. having a measuring range of $194 \mathrm{~mm}, 7.6 "$. They had a least count of 0.001 millimeters.

Laser Stand: A rotating laser stand which was facilitated by a gear box was installed in front of the tunnel. The laser stand had laser A and B installed one on top of this other in a box. The box could translate radially to defined positions. This rotating laser stand facilitated in plotting the surface for different levels of plug pressure values.

\subsubsection{Leakage Measurement System}

Drainage Tank: A drainage tank was positioned right under the mouth of the tunnel outlet to collect the leaking water between the tunnel wall and the plug surface from the tunnel space.

Ohaus Weighing Scale: A Ohaus digital scale was positioned under the drainage tank. This was to measure the mass of the leakage water collected. The change mass of the drainage tank was noted during the measurement of the leakage and the time taken for that change of mass to happen was also noted. The Ohaus scale was connected to the data acquisition software via an RS232 interface and recorded by the Scimitar software. 


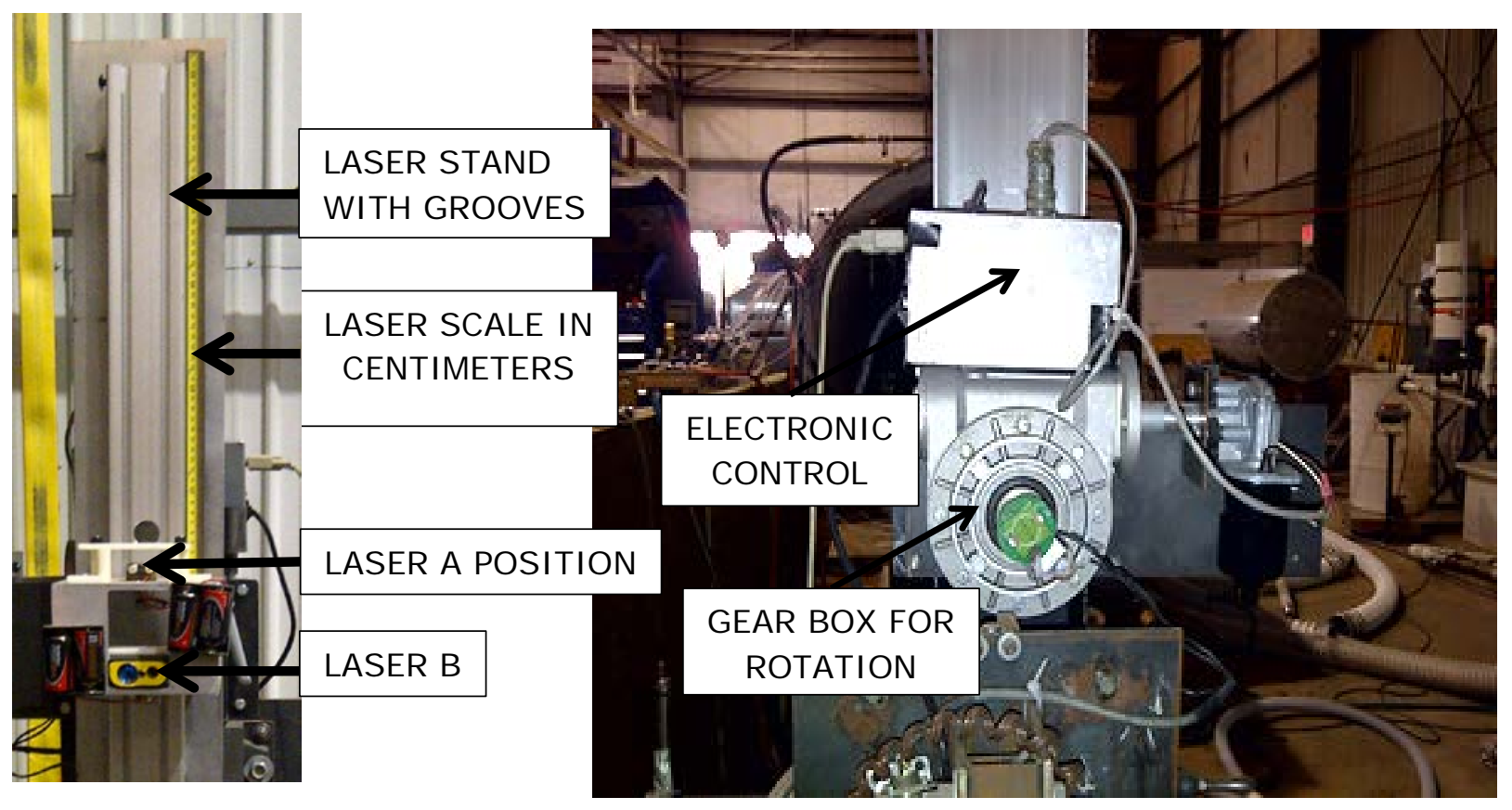

Figure 2.9: Laser stand \& laser A \& B

Flowline Ultrasonic Level Transmitter: It measured depth of the water by sending high frequency waves and with known velocity and records the time taken by the wave to reflect back to the receptor from the water surface. Knowing the depth of the tank and subtracting the output from it gives the depth of water which facilitated the leakage measurement during the tests. The transmitter has a range of 33" and shows output terms of 4-20 mA.

Figure 2.10 shows the above three components.

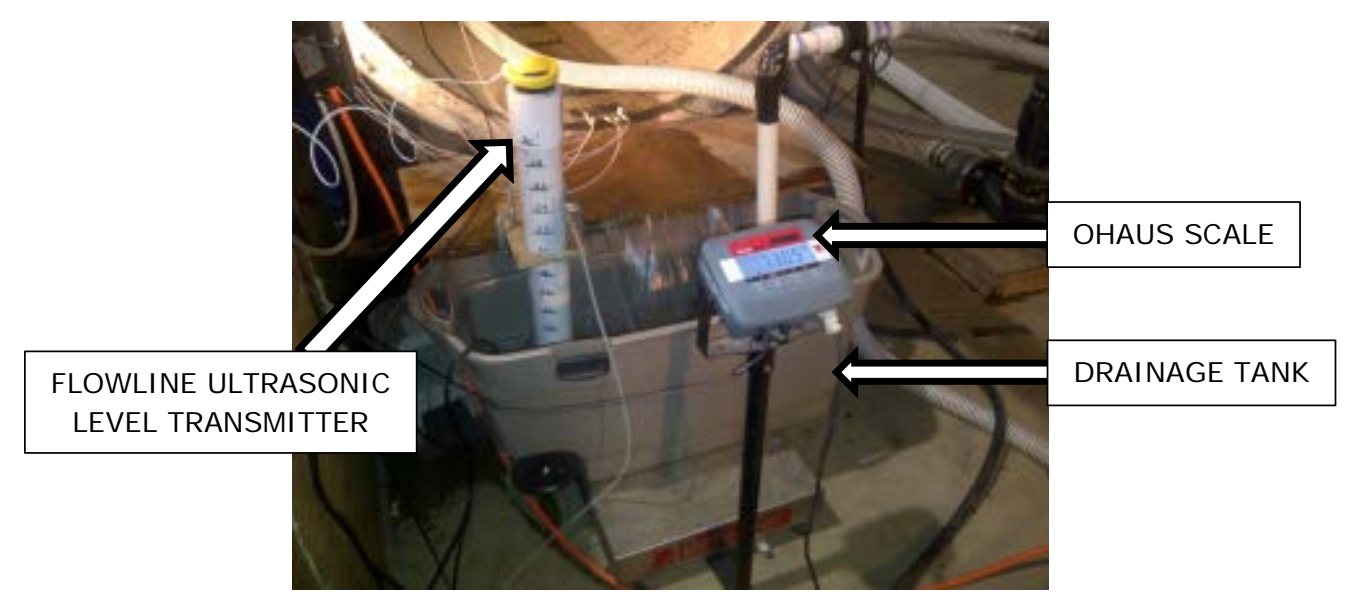

Figure 2.10: Drainage tank on the weighing machine 


\subsubsection{Seepage Water Pressure Measuring System}

Seepage Pressure: Aluminium tubes of 1/8" diameter were installed inside the tunnel for quarter, half, three quarter and full cylindrical length of the plug. The orientation of install was initially $0^{\circ}, 90^{\circ}, 180^{\circ}$ and $270^{\circ}$ followed by another set at $45^{\circ}, 180^{\circ}, 225^{\circ}$ and $315^{\circ}$ with respect to the circumference of the tunnel (see Figure 2.11). The aluminium tubes that continued till the edge of the tunnel were continued outside into Teflon tubes of same diameter. The Teflon tubes were connected with corresponding single key pressure recording system. Each seepage pressure measuring location had a corresponding key i.e. for four angles of orientation along the circumference and four points along the plug cylindrical length, there were 16 keys, eight keys per instrument and one drain key per instrument. To measure the seepage water pressure of a location on the plug surface/tunnel wall, the corresponding key had to be opened and all the other keys including the drainage key should be closed. The drainage key was primarily used to reset the system and get rid of air bubbles. Figure 2.11 shows the different parts of seepage water pressure measuring system.
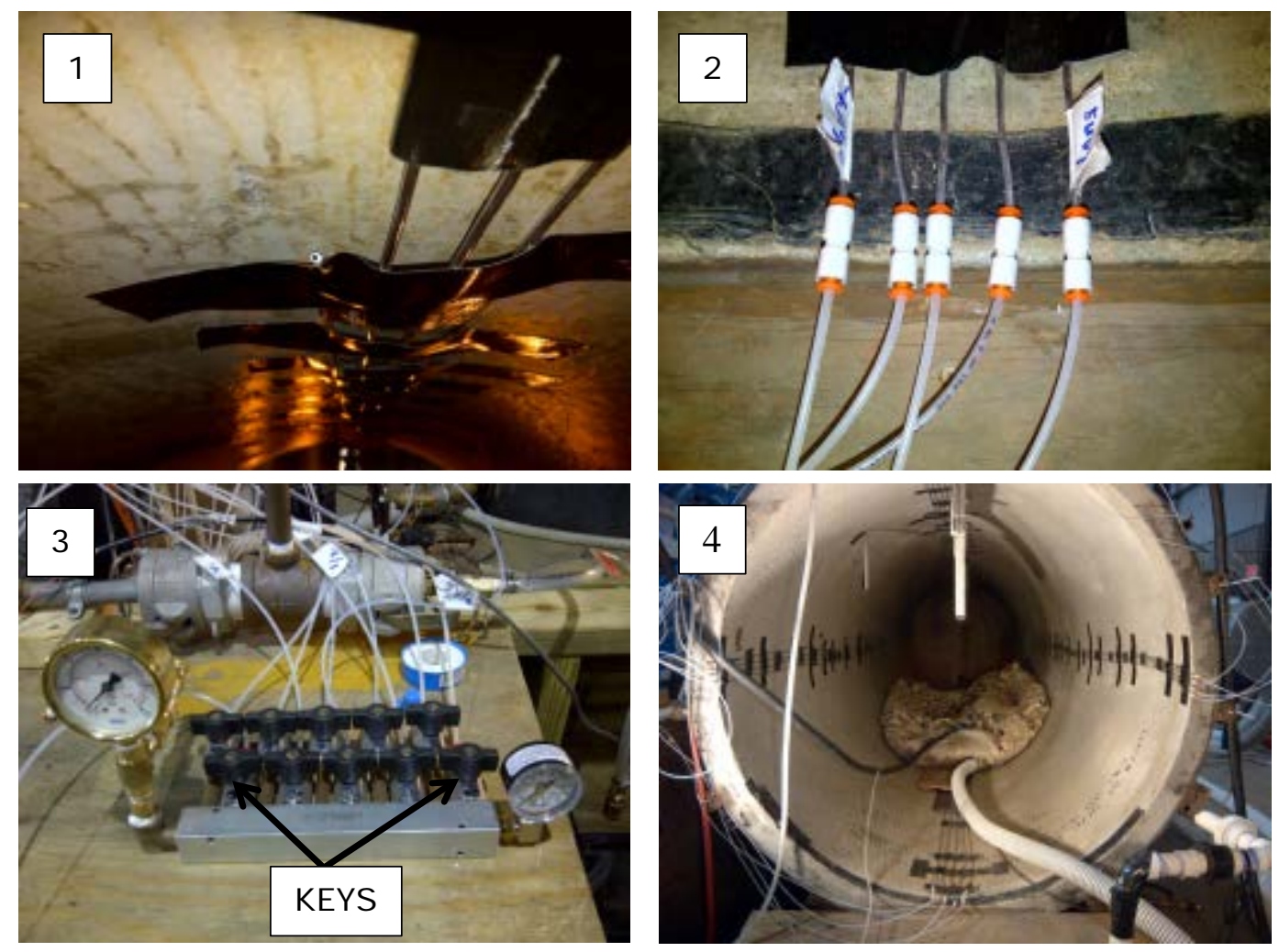

Figure 2.11: Seepage pressure measuring setup: 1) quarter point $0^{\circ}$ sensor; 2) connector between aluminum and Teflon pipe; 3) keyed seepage pressure gauge setup; 4) $0^{\circ}, 9^{\circ}$, $180^{\circ}$ and $270^{\circ}$ pipes running through the length of the tunnel for reading seepage pressure 


\subsubsection{Data Acquisition System}

Laptop: A laptop computer was used for capturing the reading of the Keyence lasers $1 \& 2$ and then transmitting the same to the main data acquisition terminal.

Main Terminal: It consisted of a tower, monitor and battery backup. The Scimitar software was developed by the CAFÉE, MAE, West Virginia University. It was used for reading all the data acquired from the testing system. All the transducer data were recorded in terms of volts which were converted through a linear calibration intercepts and slope prerecorded in the Scimitar software. The flow meter data were recorded in terms of pulses which were then converted to gallons of water based on calibration. The pressures were read by using pressure transducers and displacements were read by using the lasers.

\subsubsection{Cameras}

Camera 1 and Camera 2: These were close circuit video cameras transmitting to the computer display with simultaneous recording. These cameras were installed on the aluminium stand holding laser 1 and 2 inside the tunnel on the front of the plug.

Camera 3: This was a submersible camera installed at the back near the tunnel end cap facing the plug on the rear end cap. It was mainly used to gauge the level of water in the tunnel space behind the plug and to record any abnormal occurrence that may occur while testing.

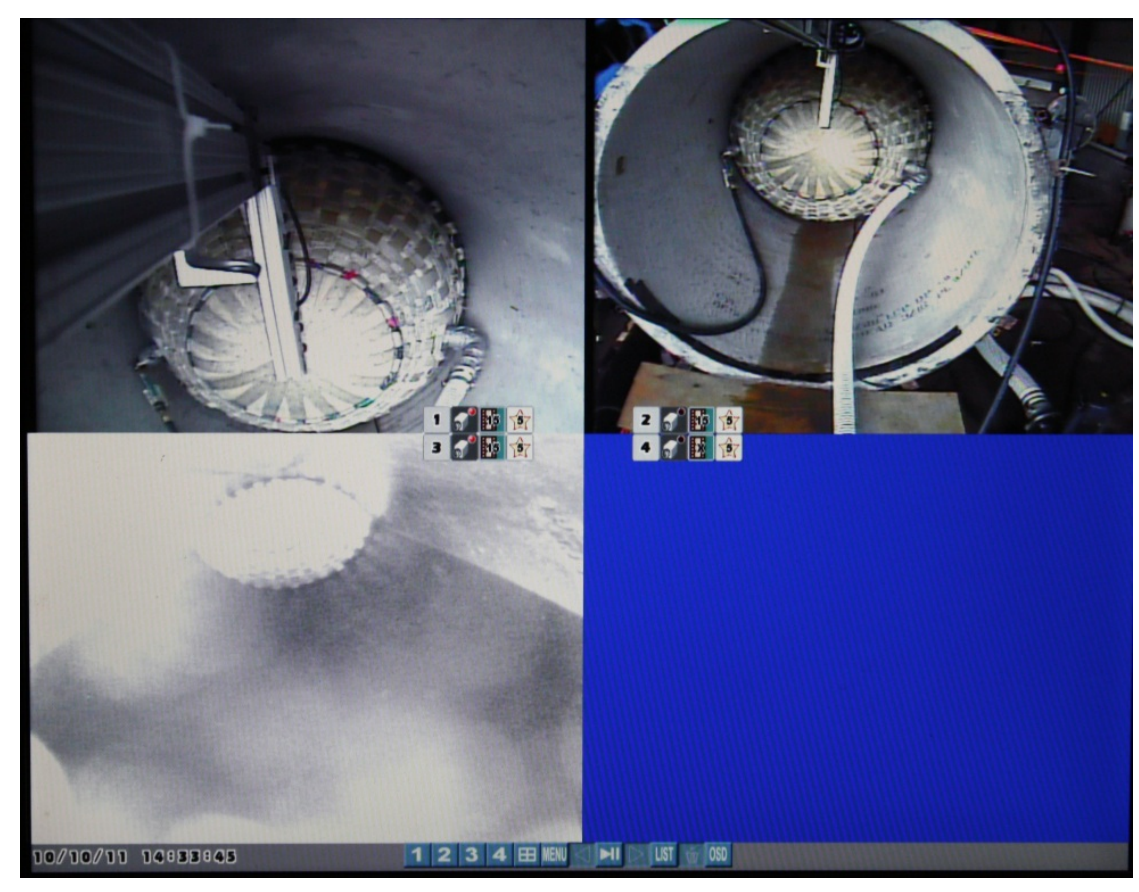

Figure 2.12: Still views of camera 1, 2 and 3 


\section{Chapter 3 Elongation}

\subsection{I ntroduction}

These series of tests were primarily conducted to study the behavior of the plug as structural member that can withstand design pressure (68 psi). An unconstrained "free" air inflation test was first conducted to study the nature of plug elongation without the interference of constraining effect of the 48" concrete pipe. The test facilitated a better understanding of the inflation behavior of the plug as an independent member. On free inflation the inflated dimensions of the plug was also measured in terms cylindrical length and perimeter to determine the general impact of sizing during constrained inflation.

Constrained inflation and pressurization of the plug was further conducted with water at ambient temperature inside the 48" quarter scale tunnel for pressure levels of 15, 30, 45, 60 and 68 psi (design requirement). After each pressure level was reached, the surface of the plug exposed to the open tunnel end was scanned with lasers which moved both radially and axially. This provided the nature of the inflated plug surface at various pressure levels. The end cap horizontal tip elongations at both the front and the rear were also evaluated to understand the deflection behavior of the plug.

\subsection{Free Inflation}

Low pressure free air inflation of the quarter scale plug was necessitated for the evaluation of the physical integrity and to detect possible leakages, distortions and drawbacks in the overall construction. The test was conducted to make sure that the plug was prepared for the subsequent tests under high water pressure, constrained condition. Free elongation was carried at with only pressurized air from an air compressor with a regulator at the inlet to control the pressure. The pressure sensor was placed on the other port of the plug to sense the applied air pressure. Since the test was performed outdoors, it was also ensured that the plug was not affected physically by any external conditions like strong wind or rain for accuracy in laser data recording. The displacement measuring lasers were placed on either side of the plug to record the total longitudinal elongation (end cap elongation) of the plug.

\subsubsection{Test Procedure}

Figure 3.1 shows the test set up. The test procedure for the free elongation test is provided in Appendix A. Figure 3.2 shows the photographs of the test set up. 


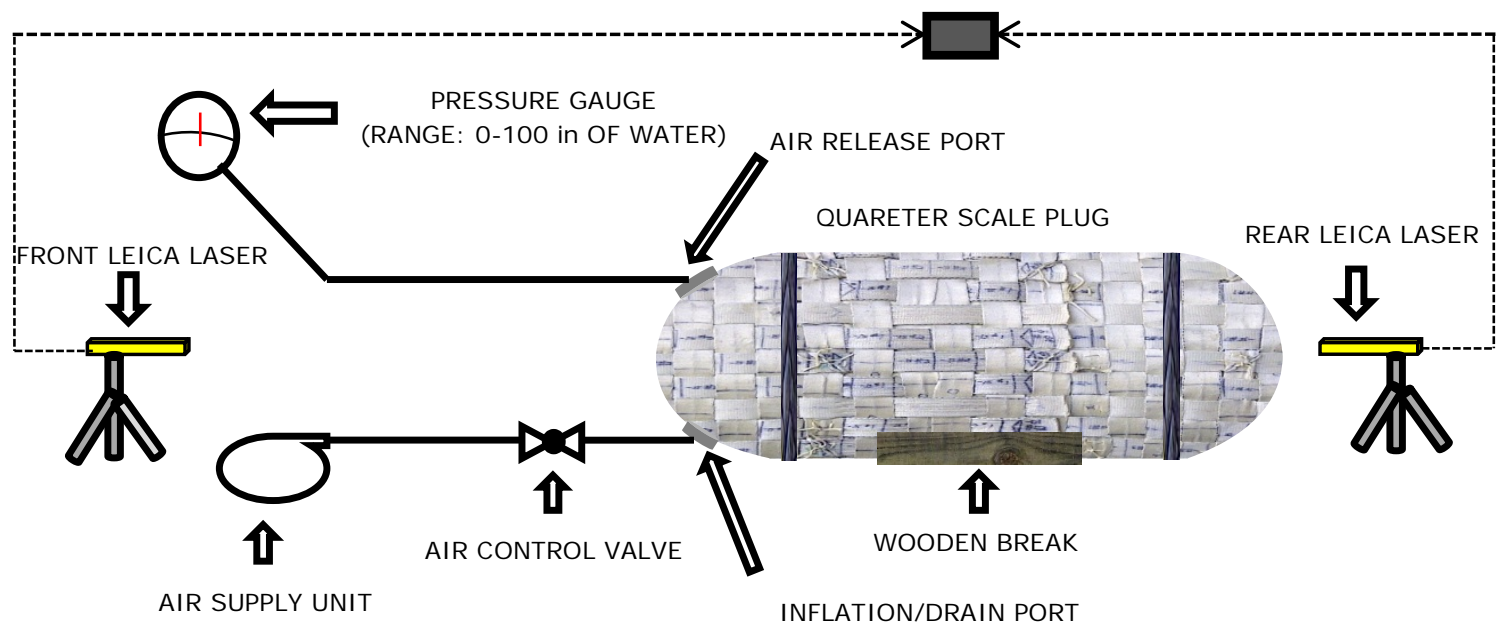

Figure 3.1: Free inflation schematic

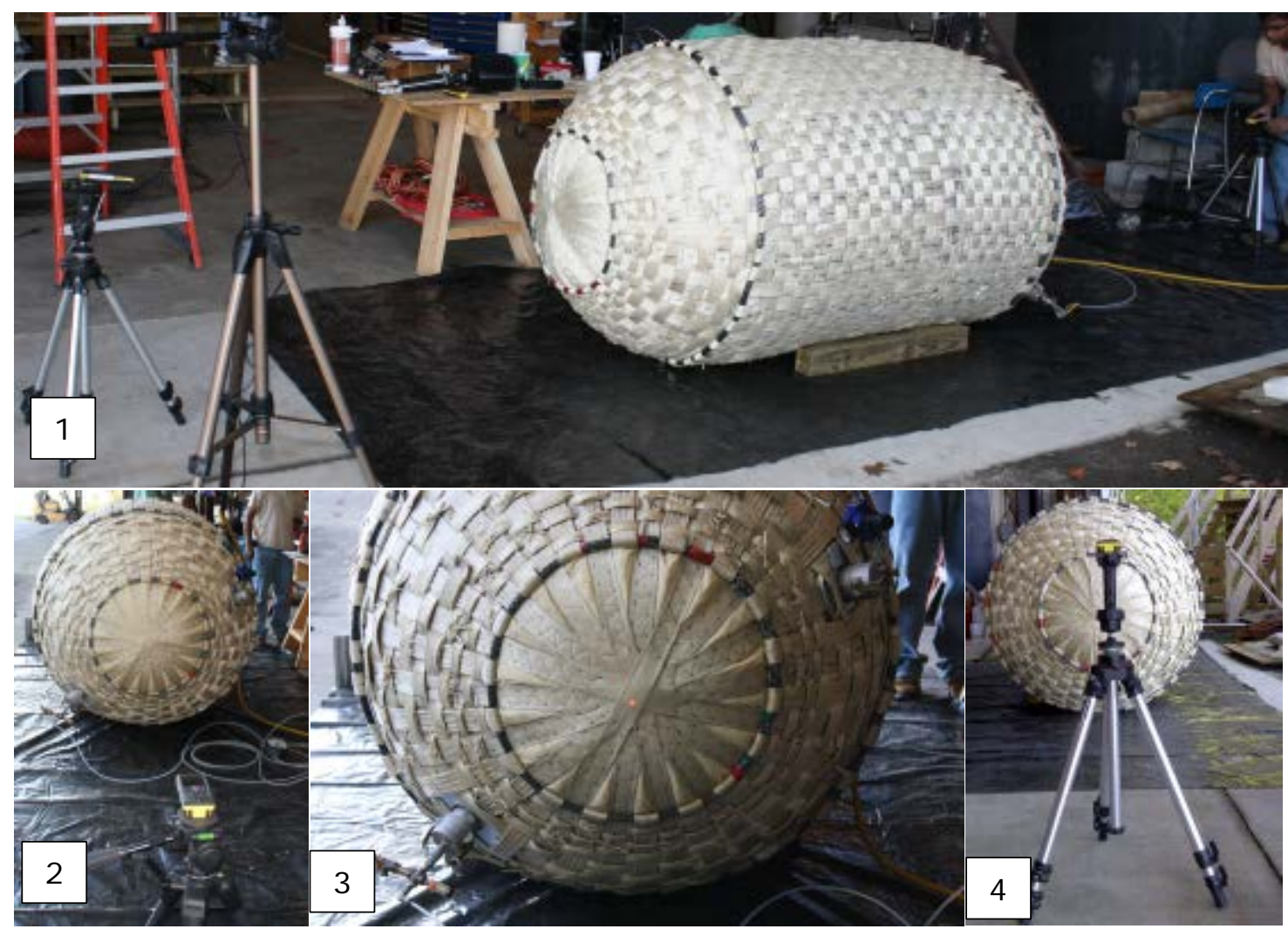

Figure 3.2: Free test set-up: 1) complete setup; 2 ) front laser pointed towards tip of end cap; 3) laser mark at the tip of front end cap; 4) rear laser pointed towards tip of end cap 


\subsubsection{Results and Discussions}

The plug did not exhibit any apparent structural defect like fabric tear or leakage. The tapering nature of the cylindrical section was detected when the measurement of the circumference was taken as shown in Figure 3.3. Some of the webbings did not stretch to the maximum limit since the applied pressure was only limited to 90 inches of water (3.2 psi).

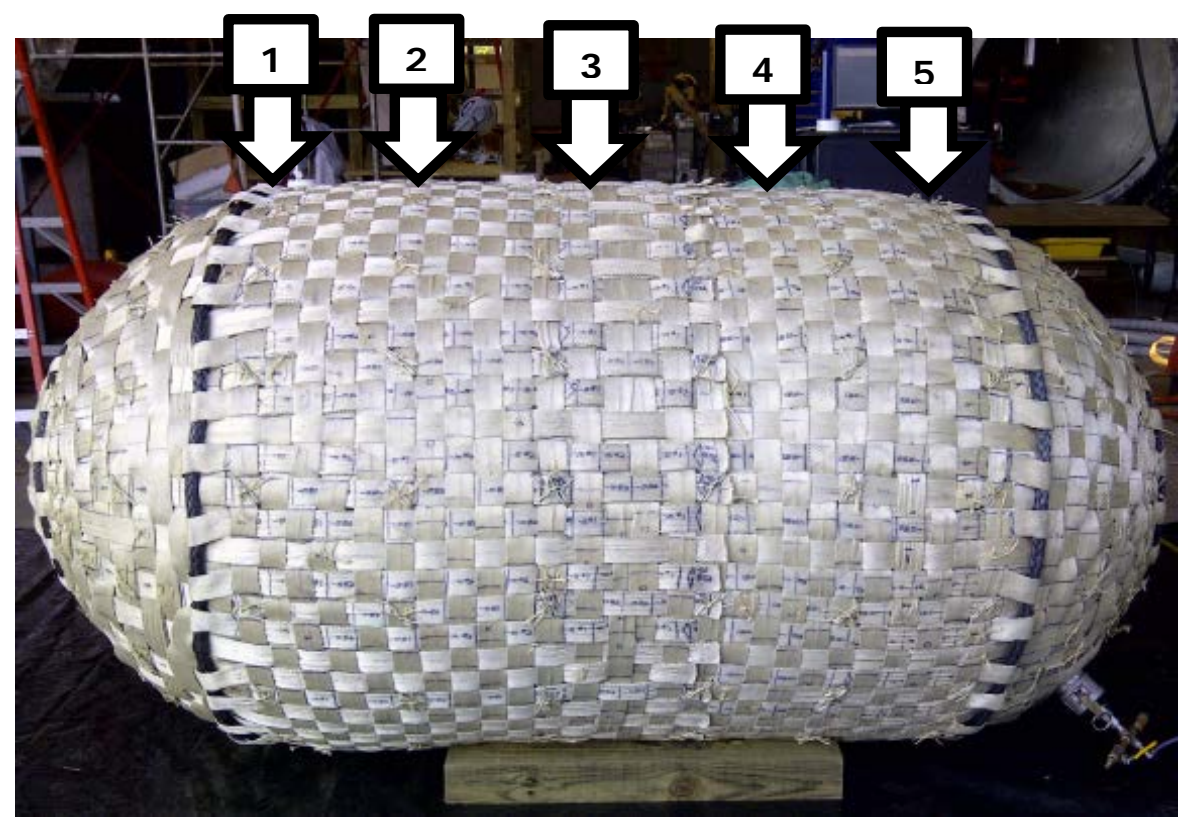

Figure 3.3: Plug circumference measurement locations

Table 3.1 summarizes the measured length of the circumferences at the above locations showed in Figure 3.3 at 2 psi pressure and the subsequent diameters for those locations were calculated from it.

Table 3.1: Free inflation: measurement of cylinder-circumference

\begin{tabular}{|c|c|c|}
\hline $\begin{array}{c}\text { Location } \\
\text { Figure 3.3 }\end{array}$ & $\begin{array}{c}\text { Measured } \\
\text { circumferential } \\
\text { Length (in) }\end{array}$ & $\begin{array}{c}\text { Calculated } \\
\text { diameter of the } \\
\text { location (in) }\end{array}$ \\
\hline 1 & 149.4 & 47.5 \\
\hline 2 & 152.4 & 48.5 \\
\hline 3 & 153.7 & 49.0 \\
\hline 4 & 153.0 & 48.7 \\
\hline 5 & 150.0 & 47.8 \\
\hline
\end{tabular}

The plug has a design cylindrical length of 45" but the measured rear rope to front rope distance was found out to be 57". This shows that the junction of the cylindrical section of the plug and hemispherical section is not exactly located at the position of the rope (as visually perceived). The cylindrical diameter varies from a maximum of 49" at the center to 
48.5" on the edges. This gives the plug a slightly tapering shape. This dimensions provided an oversizing of $2 \%$ with respect to the dimension of the 48" pipe. The single layered Vectran plug used in [17] had a uniform cylindrical diameter of 50" which provided an oversizing of $4.2 \%$.

Table 3.2 provides the summary of measurements carried out following the procedure described in the previous section.

Table 3.2: Low pressure free elongation data

\begin{tabular}{|c|c|c|c|c|}
\hline Air Pressure & $\begin{array}{c}\text { Air } \\
\text { Pressure } \\
\text { (inches of water) }\end{array}$ & $\begin{array}{c}\text { Rear } \\
\text { Elongation } \\
\text { (in) }\end{array}$ & $\begin{array}{c}\text { Front } \\
\text { Elongation } \\
\text { (in) }\end{array}$ & $\begin{array}{c}\text { Total } \\
\text { Elongation } \\
\text { (in) }\end{array}$ \\
\hline 14 & 0.5 & 0 & 0 & 0 \\
\hline 28 & 1.0 & 0.11 & -0.05 & 0.06 \\
\hline 42 & 1.5 & 0.24 & -0.14 & 0.11 \\
\hline 50 & 1.7 & 0.29 & -0.14 & 0.15 \\
\hline 56 & 2.0 & 0.32 & -0.16 & 0.16 \\
\hline 60 & 2.1 & 0.35 & -0.17 & 0.18 \\
\hline 70 & 2.5 & 0.35 & -0.17 & 0.18 \\
\hline 80 & 2.8 & 0.38 & -0.18 & 0.20 \\
\hline 90 & 3.2 & 0.41 & -0.16 & 0.25 \\
\hline
\end{tabular}

The laser data for the initial value of pressure $(0.5 \mathrm{psi})$ was assumed to be the zero reference and all the other elongations measured at different pressures were computed based on that. As seen from Figure 3.4 the front elongation displayed a tendency to shrink beyond $0.5 \mathrm{psi}$. There looks to be a steady increase in the rear elongation with the increase in pressure. The total elongation of the plug is the summation of the rear and front elongation. From the plot (Figure 3.4), the behavior of the plug under low pressure seems to follow a linear tendency with the fitting line for total elongation with a coefficient of determination [28] i.e. $\mathrm{R}^{2}=0.95$.

Low pressure free elongation data points at an anomaly between the behavior of the front and the rear end cap of the plug. The inflation and the air release port are installed on the front end cap of the plug. During the low pressure inflation the weight of the aluminum ports bears down on the front end cap leading to a possible shrinkage. There may also be the possibility of greater webbing density in the front end cap of the plug than at the rear which controls the expansion of the inner fabric on either side. The higher density of webbing on the front may be a cause of increasing restraint with increasing pressure causing shrinkage. The other aspect of unequal expansion may be the possibility of having more inner fabric at the rear than at the front which results in this natural tendency of pulling the plug to the rear. It is interesting to see whether this phenomenon persists at higher applied pressures too. 
The plots below shows the behavior of the rear and the front end cap tip with the increase in pressure. The plot also shows the total elongation of the plug.

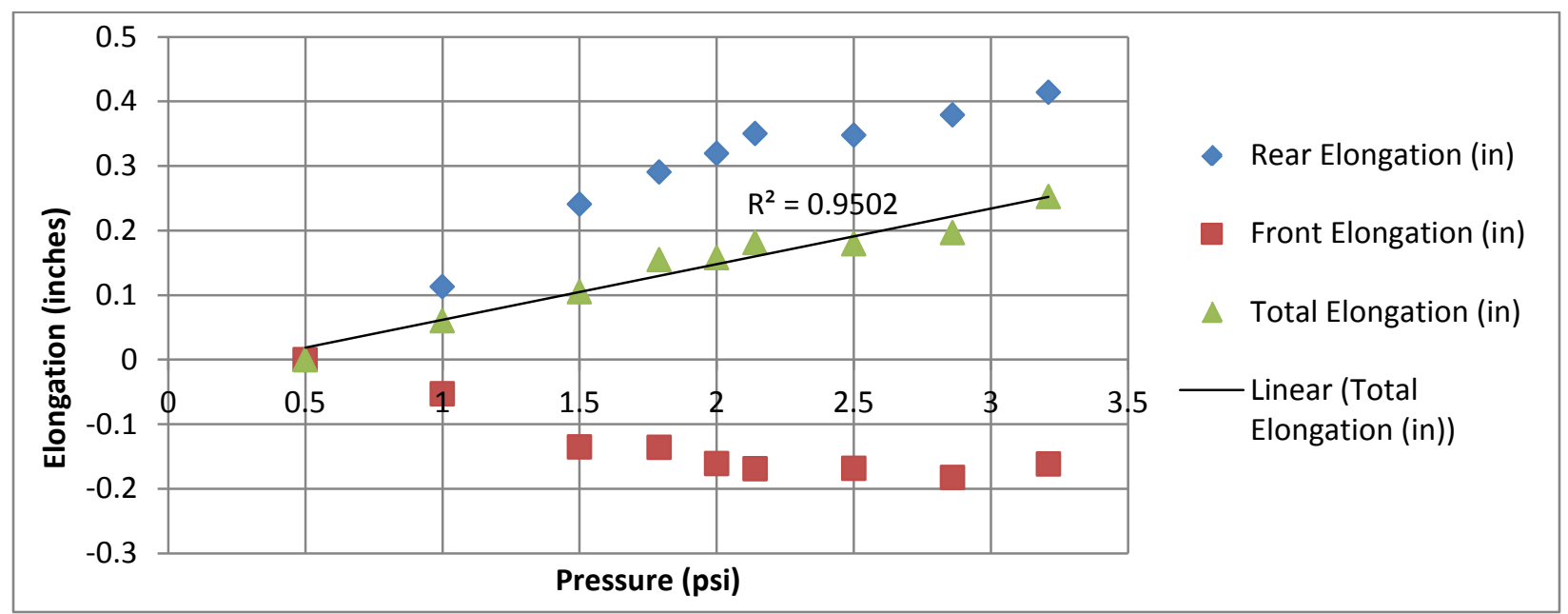

Figure 3.4: Low pressure free elongation plot

\subsection{Constrained Elongation}

The objectives of the test include verifying the structural integrity of the plug when inflated in constrained condition, detection of water leakages, measuring elongation due to the application of pressure and to measure the maximum contact length of the plug with the tunnel surface. For the whole process, 15 psi was considered as zero reference and the plug elongations were measured at 30, 45, 60 and 68 psi as per the application requirement.

Table 3.3: Plug pressure level for constrained elongation

\begin{tabular}{|c|c|}
\hline Level & $\begin{array}{c}\text { Internal Pressure }\left(\mathrm{P}_{\mathrm{i}}\right) \\
(\mathrm{psi})\end{array}$ \\
\hline 1 & 15 \\
\hline 2 & 30 \\
\hline 3 & 45 \\
\hline 4 & 60 \\
\hline 5 & 68 \\
\hline
\end{tabular}

\subsubsection{Test Procedure}

The test procedure is provided in Appendix A. Also the schematic representation is shown in Figure 2.2. Figure 3.5 and Figure 3.6 shows the position of different lasers which were used for measuring the plug displacement and elongation. 


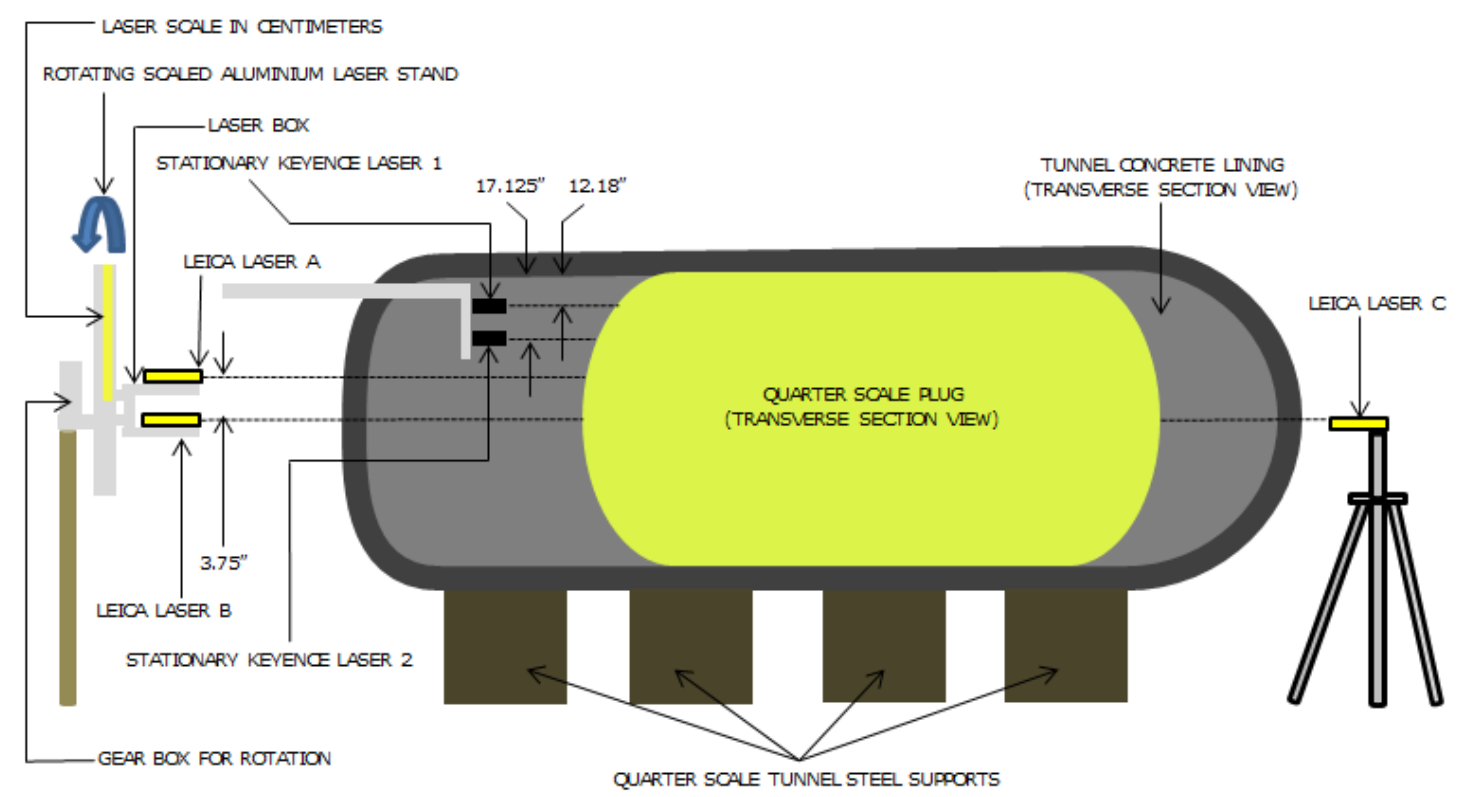

Figure 3.5: Laser positions (diagram not to scale)

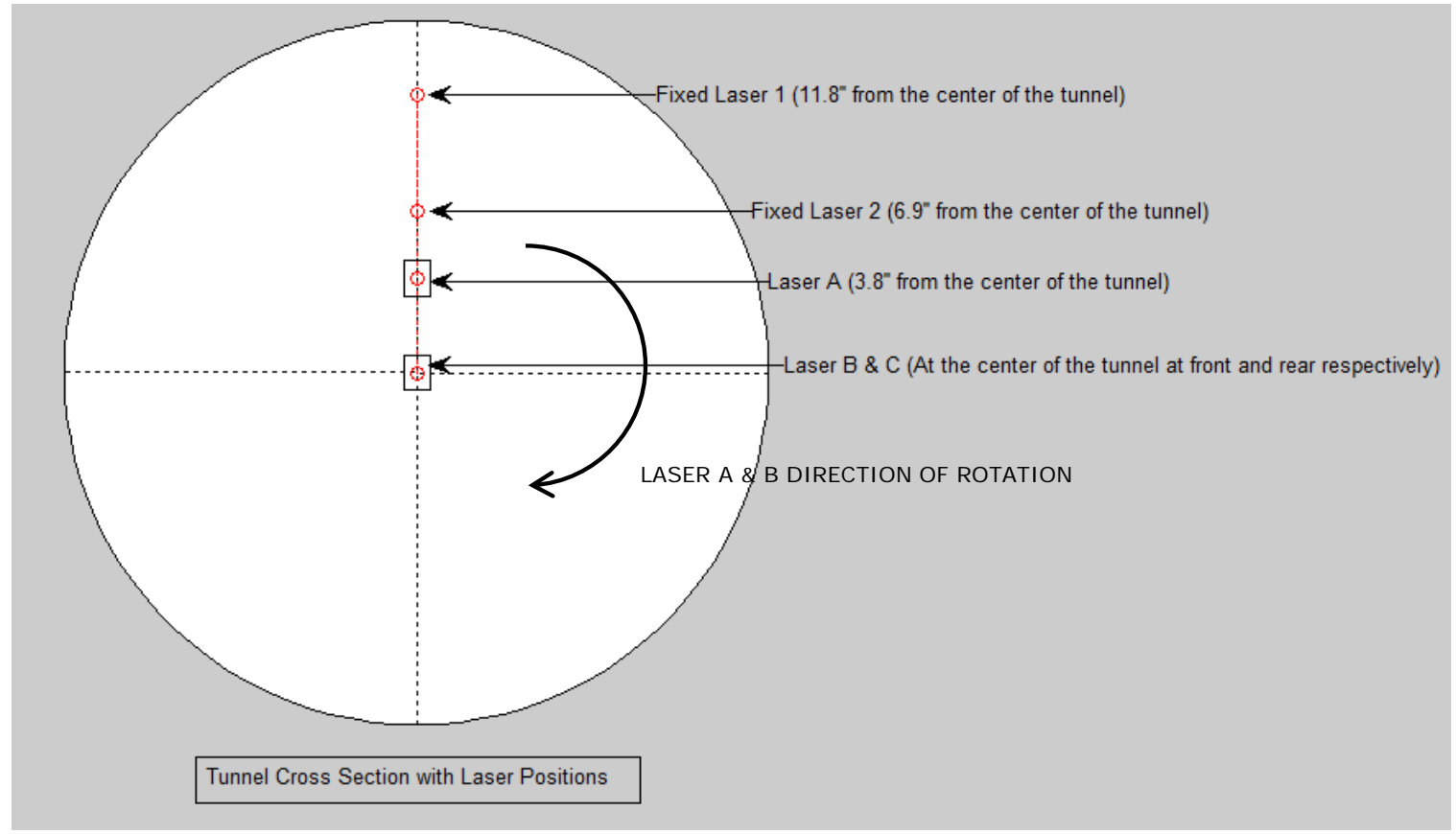

Figure 3.6: Laser positions viewing from the front of 4' tunnel

\subsubsection{Observations}

The protective layer of Vectran fabric and the bladder membrane are oversized with respect to the exterior Vectran webbings. This was done in order to make the Vectran webbings, both in hoop and axial direction to carry the impact of increasing membrane stress. The Vectran webbing on the increase of pressure stretched only till a certain point. 
This point was reached around a pressure of 30 psi, when the Vectran fabric and the polyurethane bladder pushed out from between the windows in the webbings. This resulted in the formation of localized bulges of the internal bladder in between two strands of hoop webbings. This was noted at the tip of the hemispherical cap where there were substantial spaces between two webbings. The internal bladder forcing out against the webbings also made audible stretching noise indicating the presence of stress concentrations on the bladder between the webbings in the zone of the bulge.

The results for constrained elongation can be categorized into following categories: 1) front and rear end cap tip displacement and subsequent total elongation under constrained pressurization from laser $B$ and $C$; and 2) surface plot of hemispherical end cap by planer rotation of laser A and B (see Figure 3.5 and Figure 3.6) through $360^{\circ}$.

\subsubsection{End Cap Tip Elongations \& Total Elongation}

The end cap displacements (hemispherical caps at the ends) were measured with lasers $\mathrm{B}$ and $\mathrm{C}$ at the front and the rear of the quarter scale tunnel, respectively (see Figure 3.5). Care was taken so that the laser pointer of lasers $B$ and $C$ coincided with the center of the tunnel. As mentioned previously, 15 psi was considered as a zero reference for the computation and the readings were subsequently recorded at 30, 45, 60 and 68 psi.

\subsubsection{Results}

The results of measurement are summarized in Table 3.4 and plotted in Figure 3.7.

Table 3.4: End cap elongation data

\begin{tabular}{|c|c|c|c|c|}
\hline $\begin{array}{c}\text { Plug } \\
\text { Pressure } \\
\text { (psi) }\end{array}$ & $\begin{array}{c}\text { Front Surface } \\
\text { Elongation } \\
\text { (in) }\end{array}$ & $\begin{array}{c}\text { Rear Surface } \\
\text { Elongation } \\
\text { (in) }\end{array}$ & $\begin{array}{c}\text { \% Difference } \\
\text { in } \\
\text { Elongation } \\
\text { w.r.t. Front }\end{array}$ & $\begin{array}{c}\text { Total } \\
\text { Elongation } \\
= \\
\text { Rear + Front } \\
\text { (in) }\end{array}$ \\
\hline 15 & 0 & 0 & 0 & 0 \\
\hline 30 & 0.07 & 0.30 & 322 & 0.37 \\
\hline 45 & 0.12 & 0.33 & 171 & 0.45 \\
\hline 60 & 0.13 & 0.37 & 197 & 0.50 \\
\hline 68 & 0.17 & 0.41 & 150 & 0.58 \\
\hline
\end{tabular}




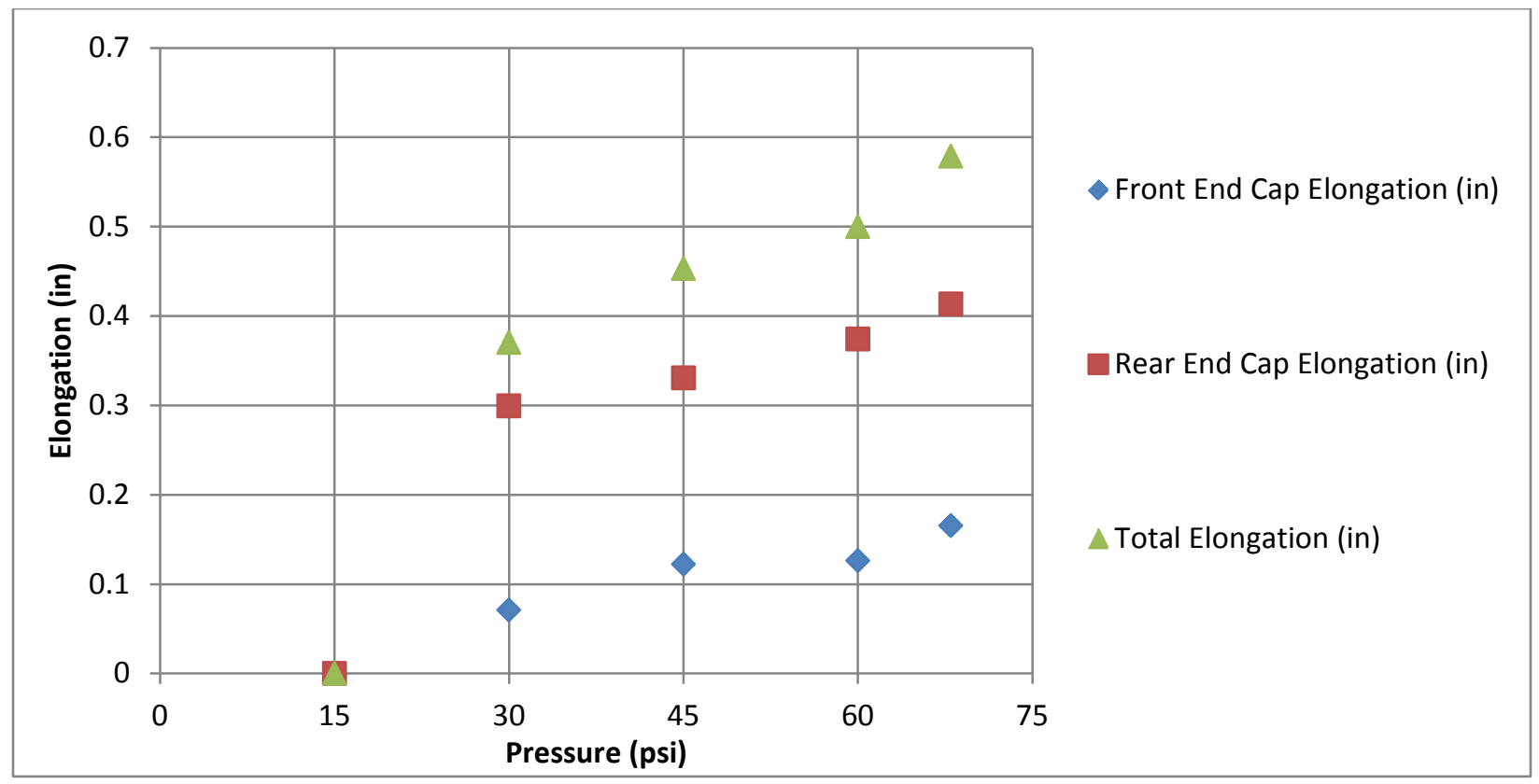

Figure 3.7 : End cap horizontal elongation

\subsubsection{Discussions}

As Table 3.4 shows, the rear end cap expanded at average of $210 \%$ more than the front end cap. The possible reason for the above being the pressurized inflation hose pushing against the front end cap with the increasing pressure. Also the presence of cam lock fittings for the drain and the inflation ports has in turn increased the net weight of the front end cap resulting in the above result.

\subsubsection{Surface Plot of Front Hemispherical End cap}

Lasers A and laser B (see Figure 3.5) were mounted on a rotatable stand, where both the lasers could be moved on a groove in the radial direction. It was also ensured that the radial movement of both the laser followed the plumb line running diametrically through the center of the tunnel (see Figure 3.6). A laser position scale which was marked in centimeters with 1 millimeter being the least count was mounted on the vertical stand to ascertain the position of the lasers with respect to the tunnel. The lasers were held in rectangular box attached to the laser stand. It was ensured that the scale pointer of the laser box was at zero on the laser scale and the bottom laser B was coinciding with the center of the tunnel face simultaneously. Lasers $A$ and $B$ were at an elevation difference of 3.8" (see Figure 3.6). Laser B was $8.9 \mathrm{~cm}$ below the laser box pointer and laser A was 1.5 $\mathrm{cm}$ above it (see Figure 3.6 and Figure 2.9). Laser B coinciding with the center of the tunnel was the starting point of laser reading during the steady increase in plug pressure. The laser stand had a gear box attached to it which facilitated its rotation by $360^{\circ}$ in clockwise direction towards the face of the tunnel. Once the desired pressure was reached, the pressure was allowed to stabilize for a couple of minutes. Then a data set was recorded for $360^{\circ}$ laser stand rotation. The laser box pointer was then raised by $3.9^{\prime \prime}(10 \mathrm{~cm})$ measured on the laser scale and the data recorded for another complete $360^{\circ}$ laser stand rotation. 
The objective of this laser set up was to scan the surface of the hemisphere at different distances from the tip of the hemisphere determine the elongation at different value of pressures.

\subsubsection{Results}

For Laser Scale (L.S.) $0 \mathrm{~cm}$ the laser box pointer was at zero centimeter mark. The rotation data for Laser A (at a height of $3.8^{\prime \prime}=9.5 \mathrm{~cm}$ above the center of the tunnel face) was collected as shown below. The readings where extracted for every point for $45^{\circ}$ rotation of the laser stand. Appendix B, Table B- 1 shows the readings from laser A for $360^{\circ}$ rotation at radius of 3.8" from the center of the tunnel face. Appendix B, Table B-2 also shows the readings of laser $A$ at a radius of 7.7" and laser $B$ at a radius of 3.9" from the center of the tunnel face for $360^{\circ}$ rotation.

The angular orientation along the circumference of the tunnel has been represented below (Figure 3.8) along with the 2-dimensional plots (Figure 3.9 and Figure 3.10) for the expansive nature of various surface points of the front end cap hemisphere.

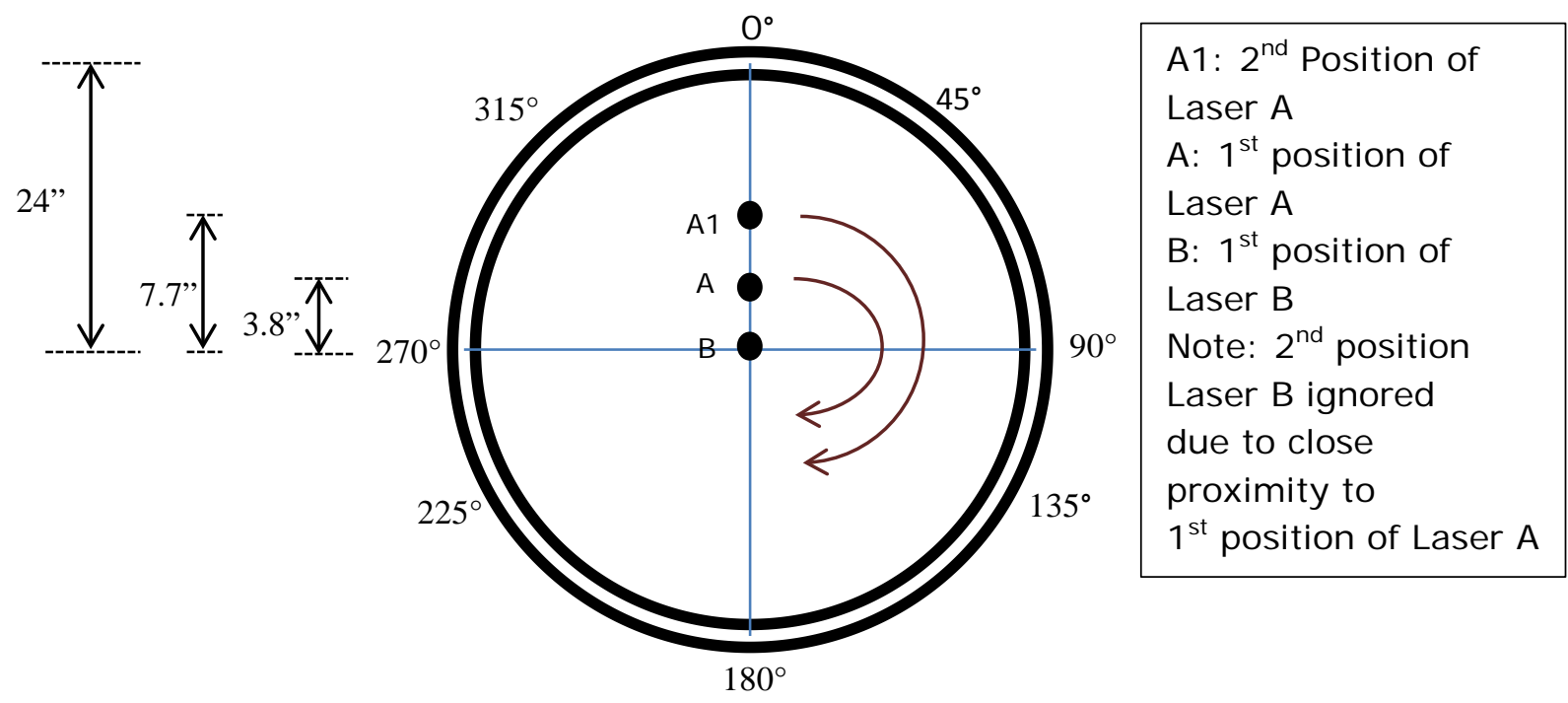

Figure 3.8: Angle orientation perimeter of tunnel face 


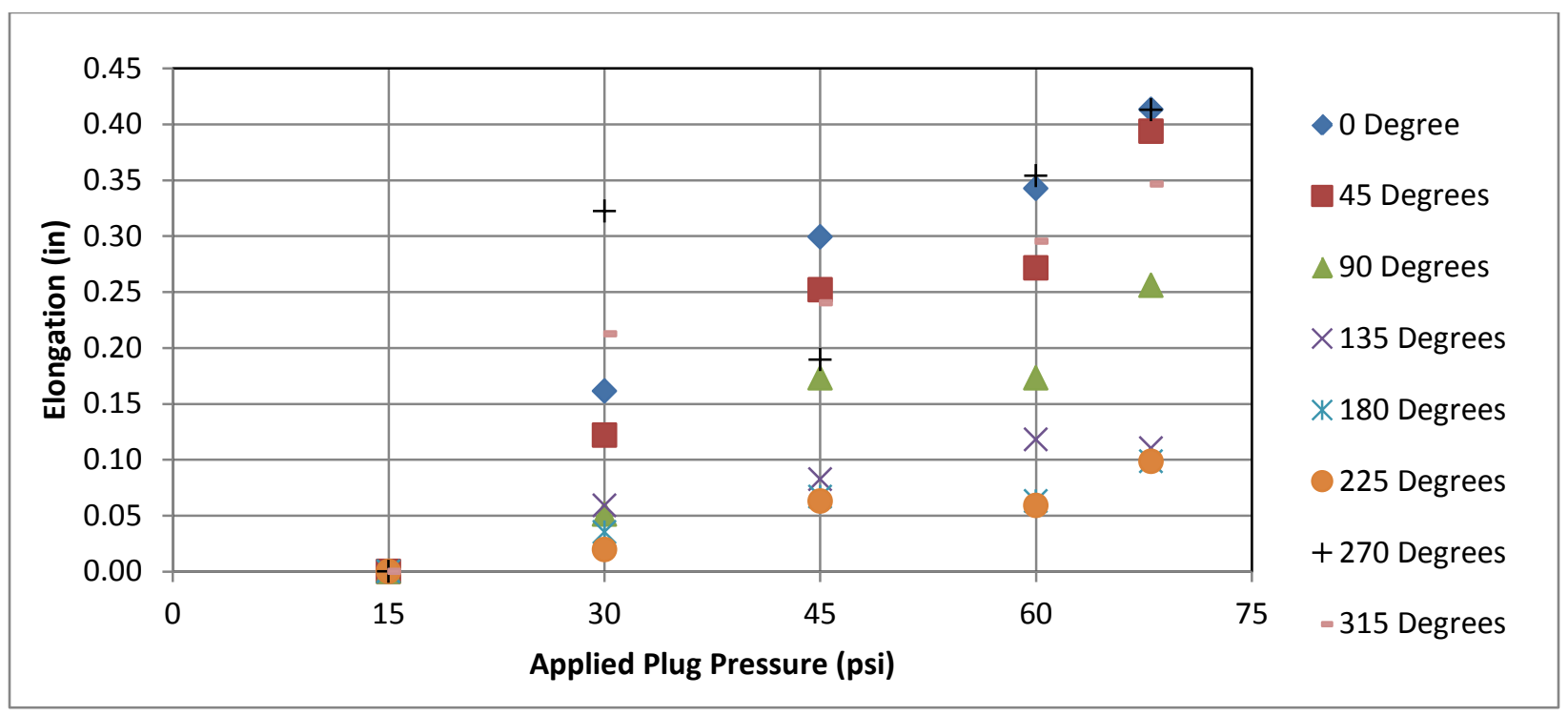

Figure 3.9: Elongation plot at a radius of 3.8" from the center of tunnel face for $360^{\circ}$ rotation (position A in Figure $\mathbf{3 . 8}$ )

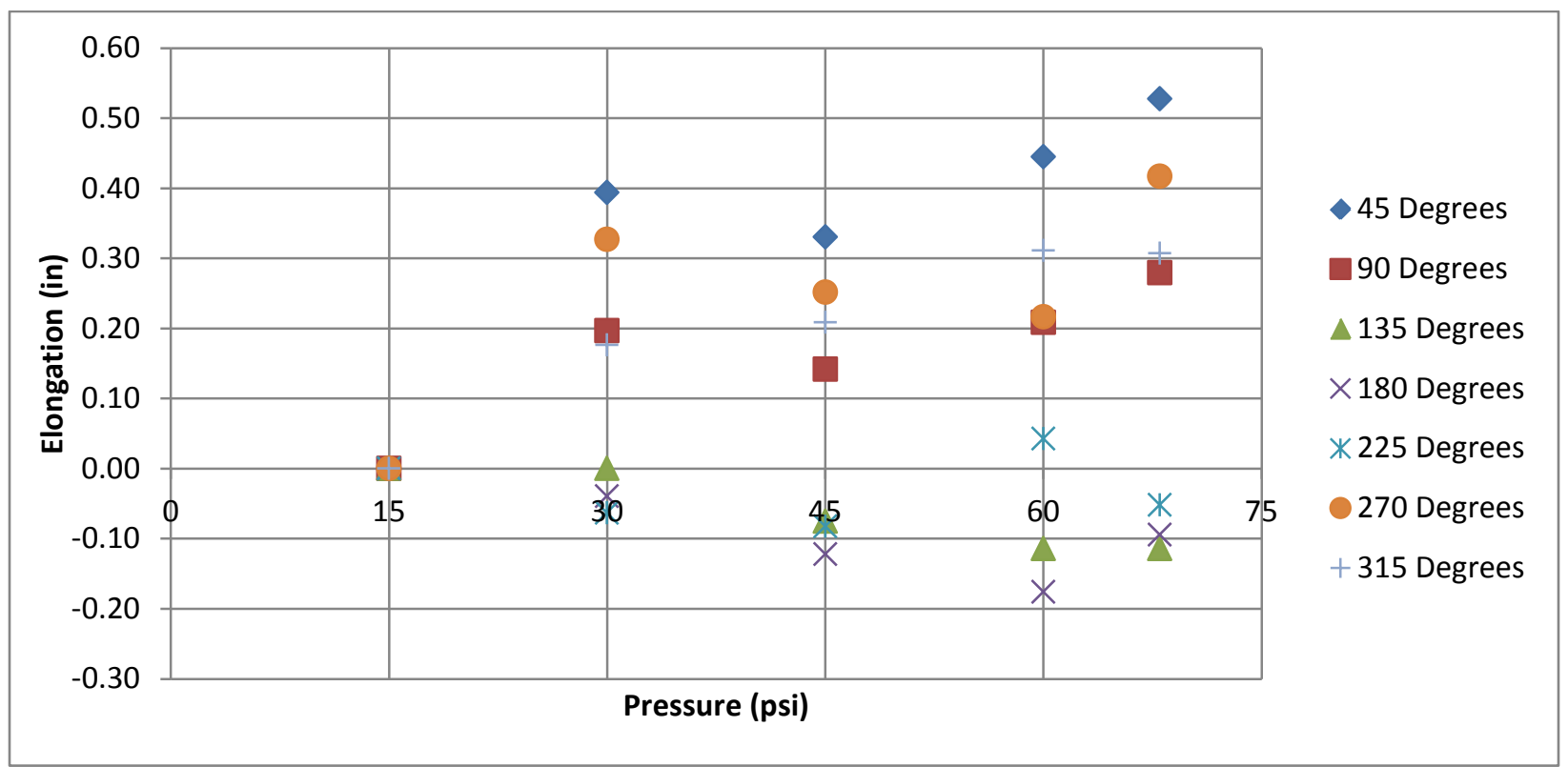

Figure 3.10: Elongation plot at a radius of 7.7" from the center of tunnel face for $360^{\circ}$ rotation (position A1 in Figure 3.8)

The plot for laser rotations at different heights from the center point of the tunnel face reflects different behaviors at different locations of the spherical end cap. In general, the plug end cap expands and then contracts considerably with the increase in pressure and with the increase in distance from the center of the tunnel face. It is best to divide the plug face into four zones on the basis of X-Y coordinate axes as Quadrant 1, 2, 3 and 4 (see Figure 3.11). The other method is dividing the hemispherical surface as Zone 1 and Zone 2 as illustrated in Figure 3.11. 


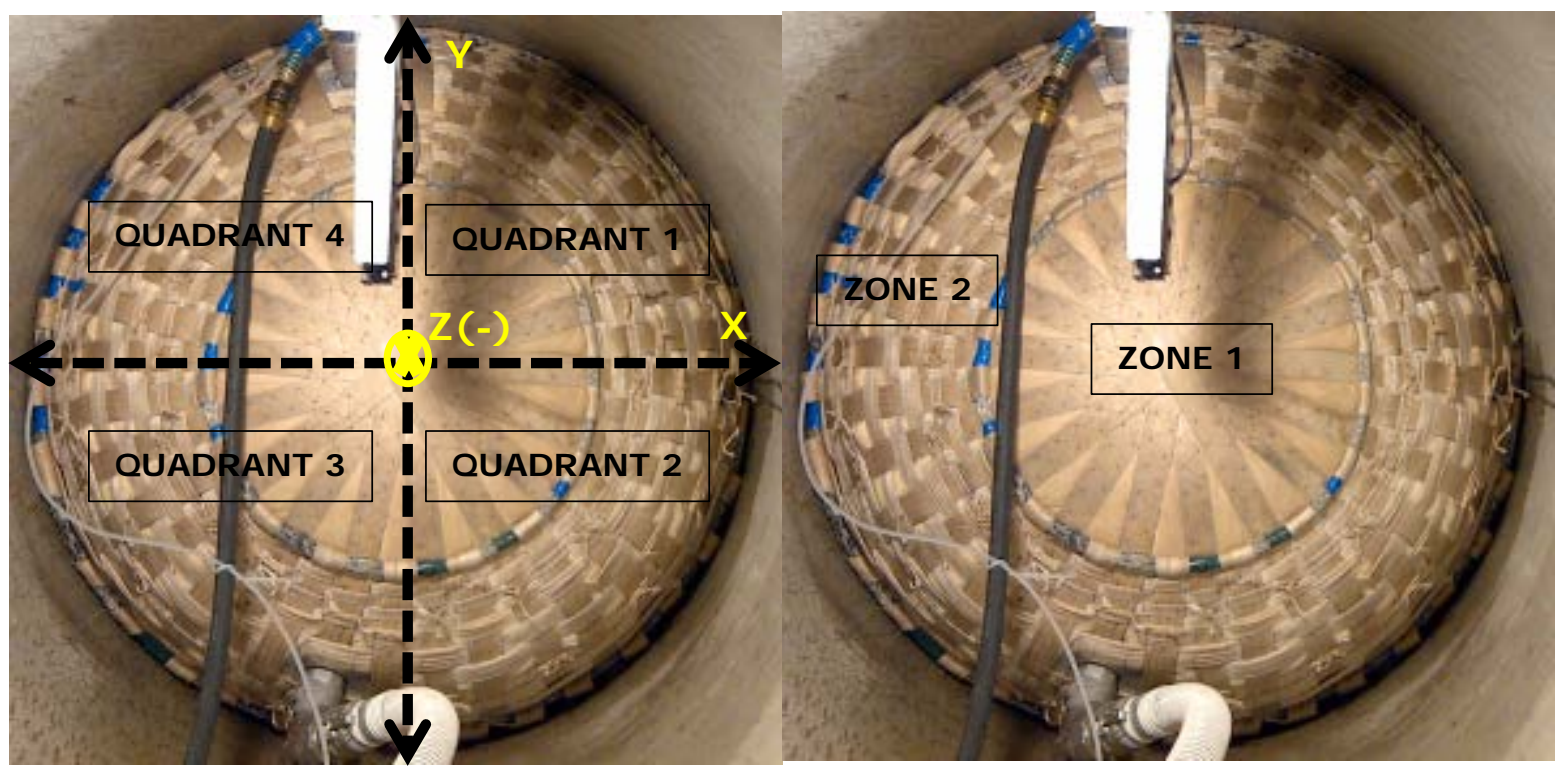

Figure 3.11: Two ways dividing the plug end cap

\subsubsection{Discussions}

The smaller rope on the hemispherical surface that defines the change in webbing matrix has a length of 74". This defines the Zone 1 (see Figure 3.11) as a circular region of radius 5.8". Rest of the hemispherical plug is Zone 2. According to this division of zones, results plotted in Figure 3.9 are in Zone 1 while results shown in Figure 3.10 are in Zone 2. This behavior of contraction at higher pressures instead of expansion seemed to be prevalent in both zones but the predominant effect was seen in Quadrant 2 and 3. Zone 2 from Figure 3.10 show greater number points encountering irregular contraction than for Zone 1. This may be due to higher constraining effect of webbings in hoop and axial direction and the presence of the inflation port and air release port in Zone 2.

A best fit surface plot was generated in Matlab with the data recorded through the vertical and rotational movement of lasers $A$ and $B$. The position of Laser $B$ on the laser stand is considered as the origin of the 3-D plot whose laser ray coincides with the center of the tunnel's circular face. The Lasers $A$ and $B$ are free to move from origin to $Y(+)$ direction and rotate in the $X-Y$ plane. Below are the 3-D best fit surface plots at 15, 30, 45 and 60 psi of the plug pressure. The $X, Y$ and $Z$ points for every level of pressure were obtained for every $45^{\circ}$ of $360^{\circ}$ rotation with radius of $3.8^{\prime \prime}$, and $7.7^{\prime \prime}$. The $X, Y$ and $Z$ points were then used to obtain a best fit cubic interpolated surface by using the command "fit" with in Matlab. Since the end cap of the plug constitutes a hemisphere, a smooth curved surface was deemed to be its ideal representation. True continuity of the points were offered by cubic interpolation and hence used here. The best fit surface was then plotted with the "plot" command. The $\mathrm{X}, \mathrm{Y}$ and $\mathrm{Z}$ coordinates follows the origin and coordinate system as shown in Figure 3.12. Figure 3.13 shows the region of front cap plotted. 


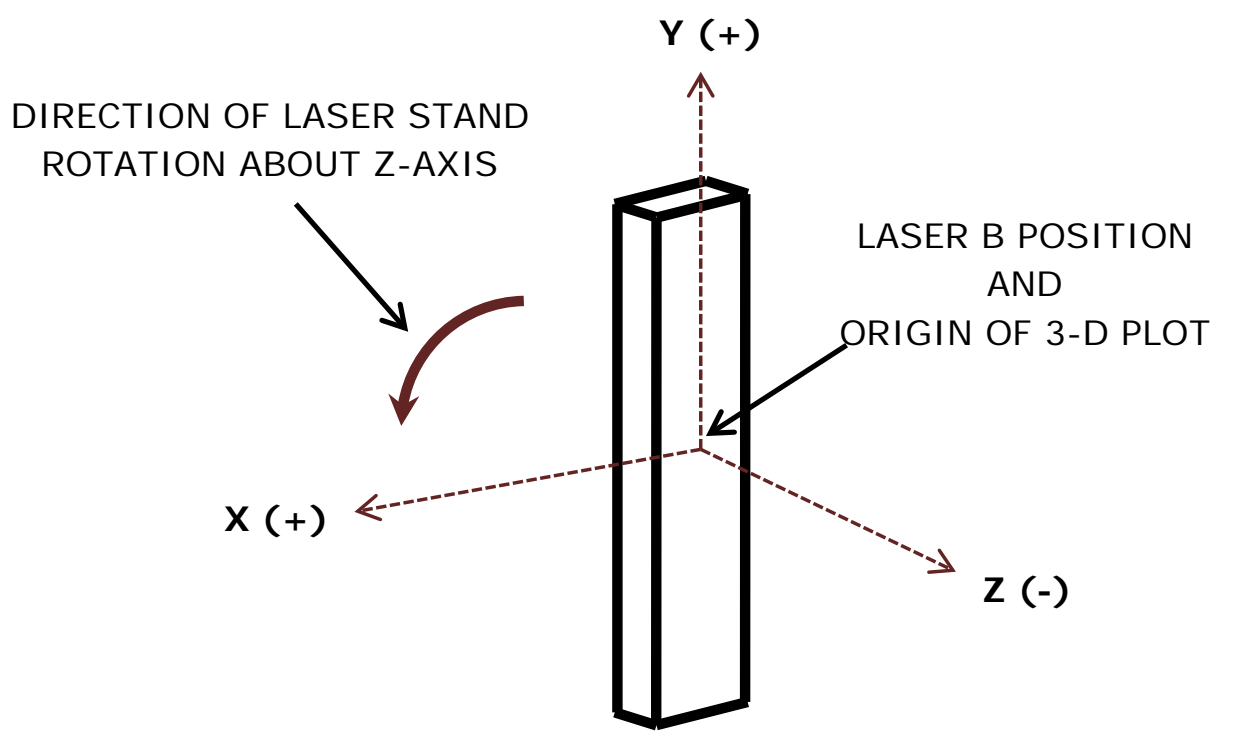

ALUMINUM LASER STAND FACING THE TUNNEL MOUTH

Figure 3.12: Origin of 3-D plot and laser stand rotation direction.

The best fit surface plots $\left(R^{2}=1\right)$ shows the inconsistency of the front spherical end cap expansion. This was also noted during free inflation and in the above plots (see Figure 3.9 and Figure 3.10) for elongation of points on the hemisphere. From Figure 3.22, Figure 3.23 and Figure 3.24 the surface for 45 psi contracted beyond what it was at 30 psi for quadrant $2 \& 3$. Same was also valid for 60 psi surface contracting beyond what it was at 45 psi in quadrant $1 \& 4$. Figure 3.14 to Figure 3.21 show the surface and contour plot at pressure level of $15,30,45$, and 60 psi.

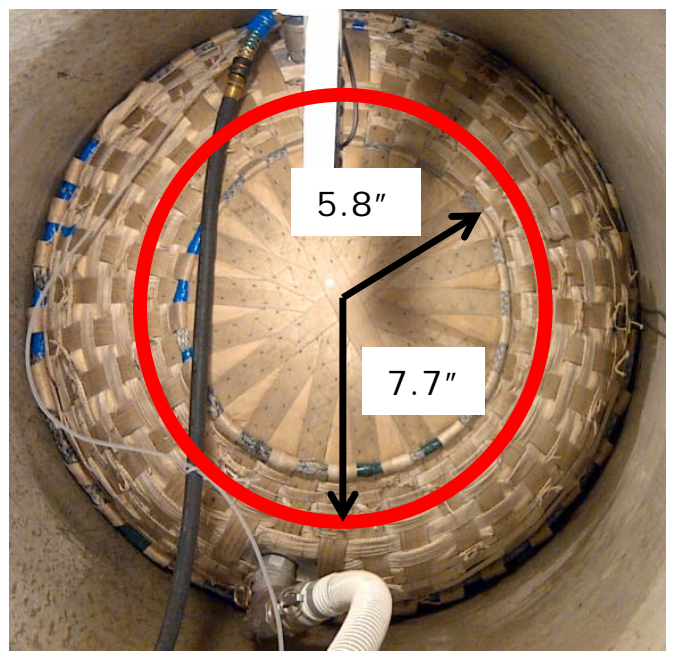

Figure 3.13: Front end cap region plotted 


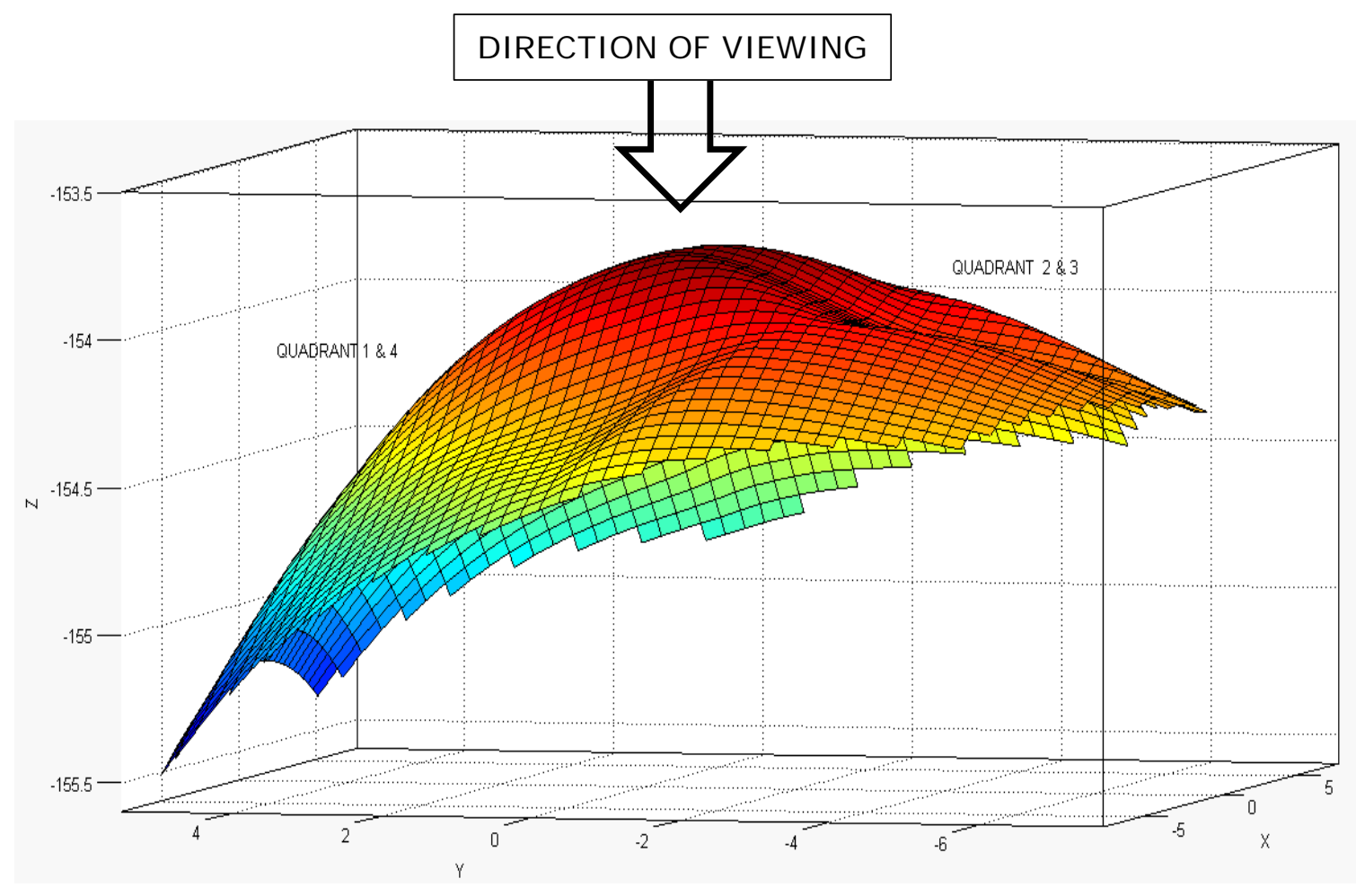

Figure 3.14: Best fit surface plot for 15 psi plug pressure

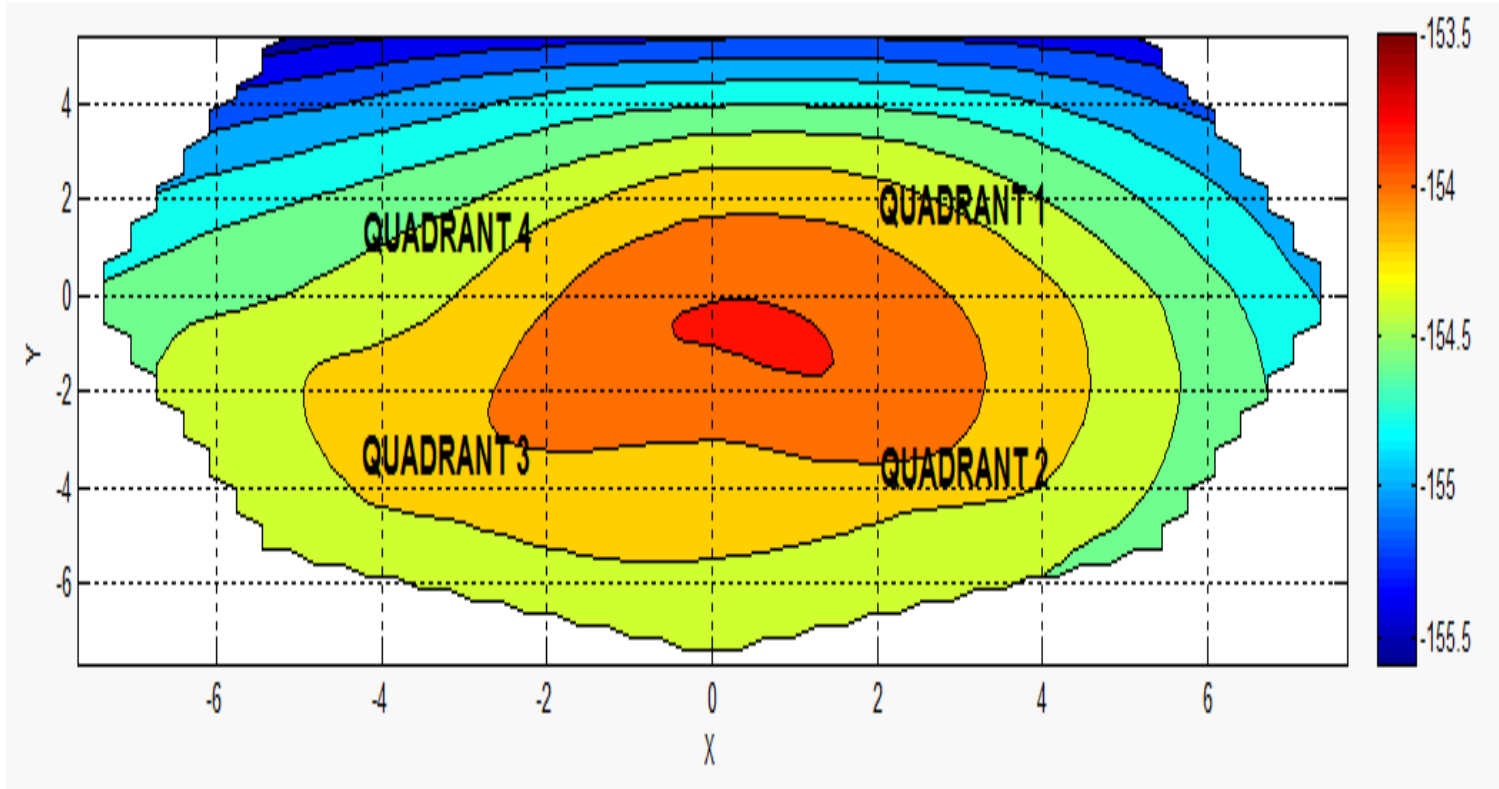

Figure 3.15: Contour plot for 15 psi plug pressure 


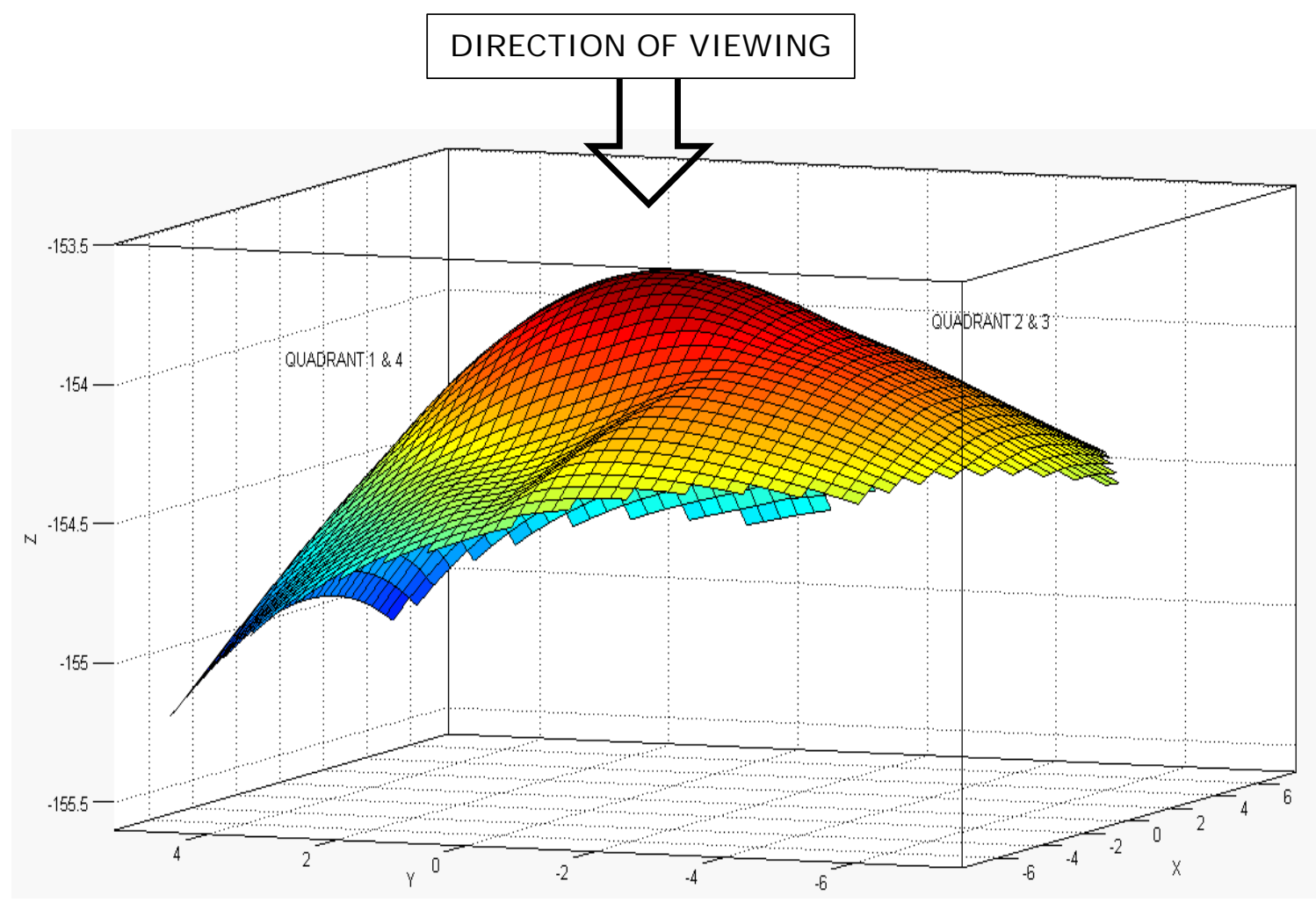

Figure 3.16: Best fit surface plot for 30 psi plug pressure

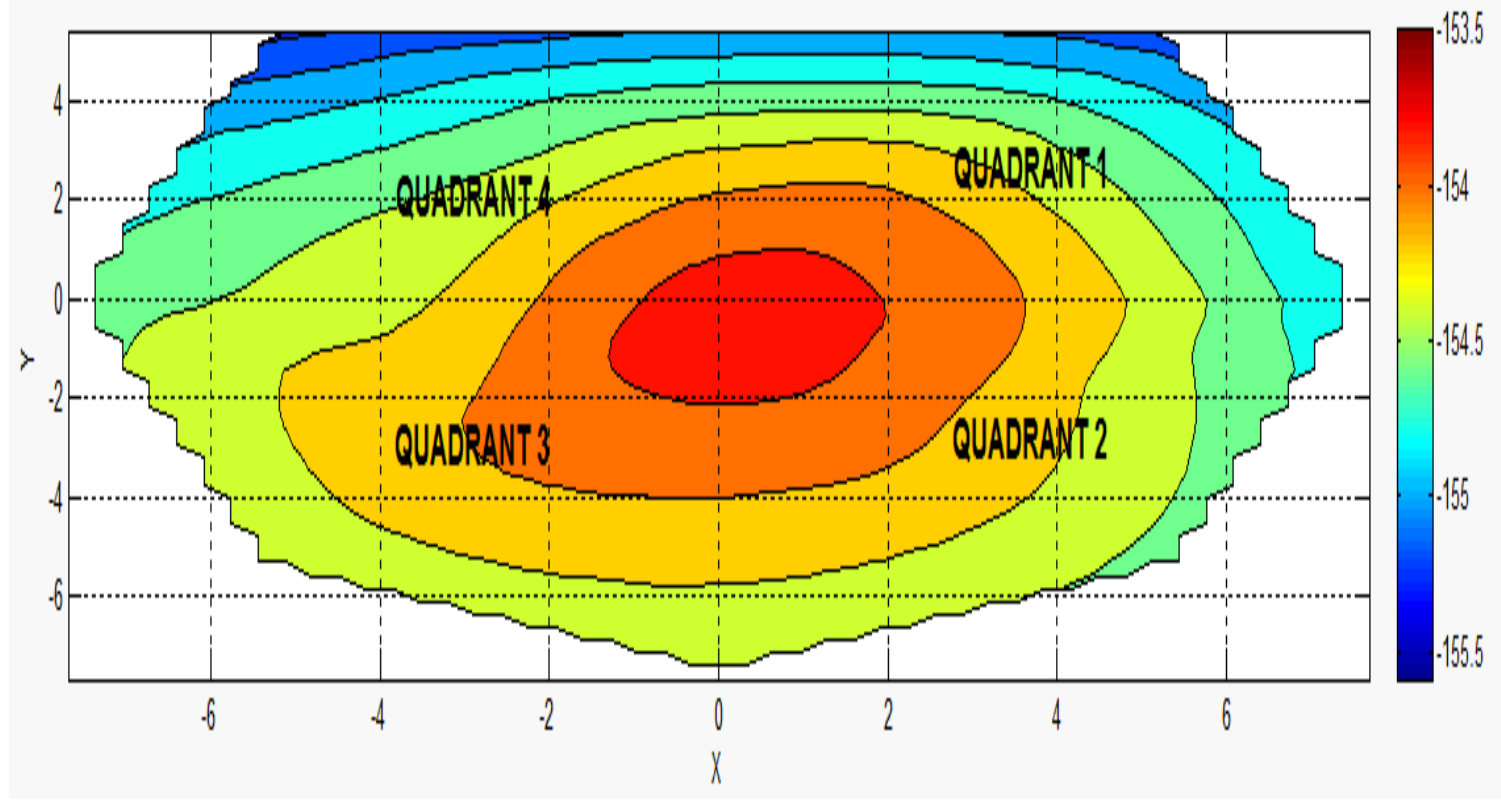

Figure 3.17: Contour plot for 30 psi plug pressure 


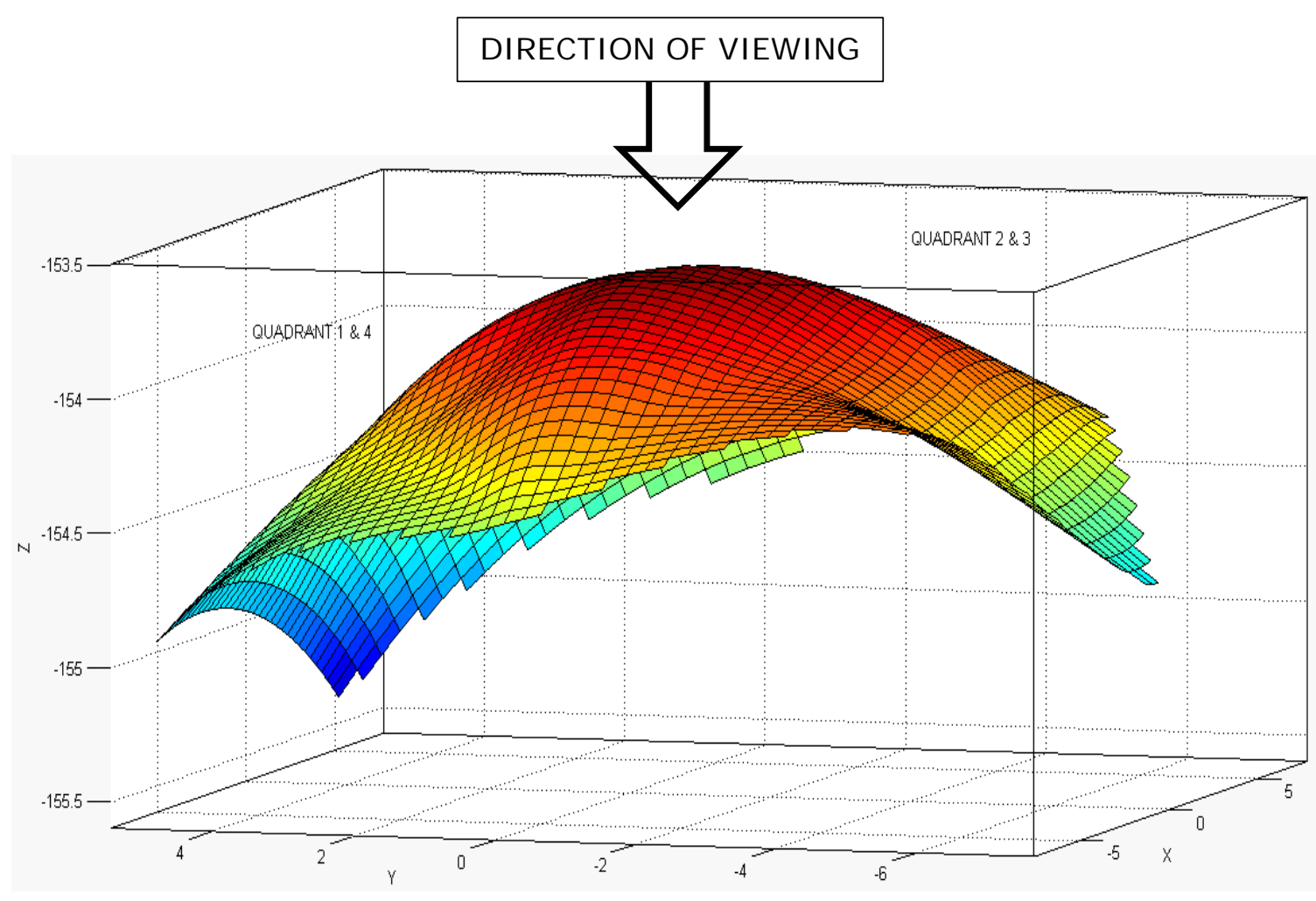

Figure 3.18: Best fit surface plot for 45 psi plug pressure

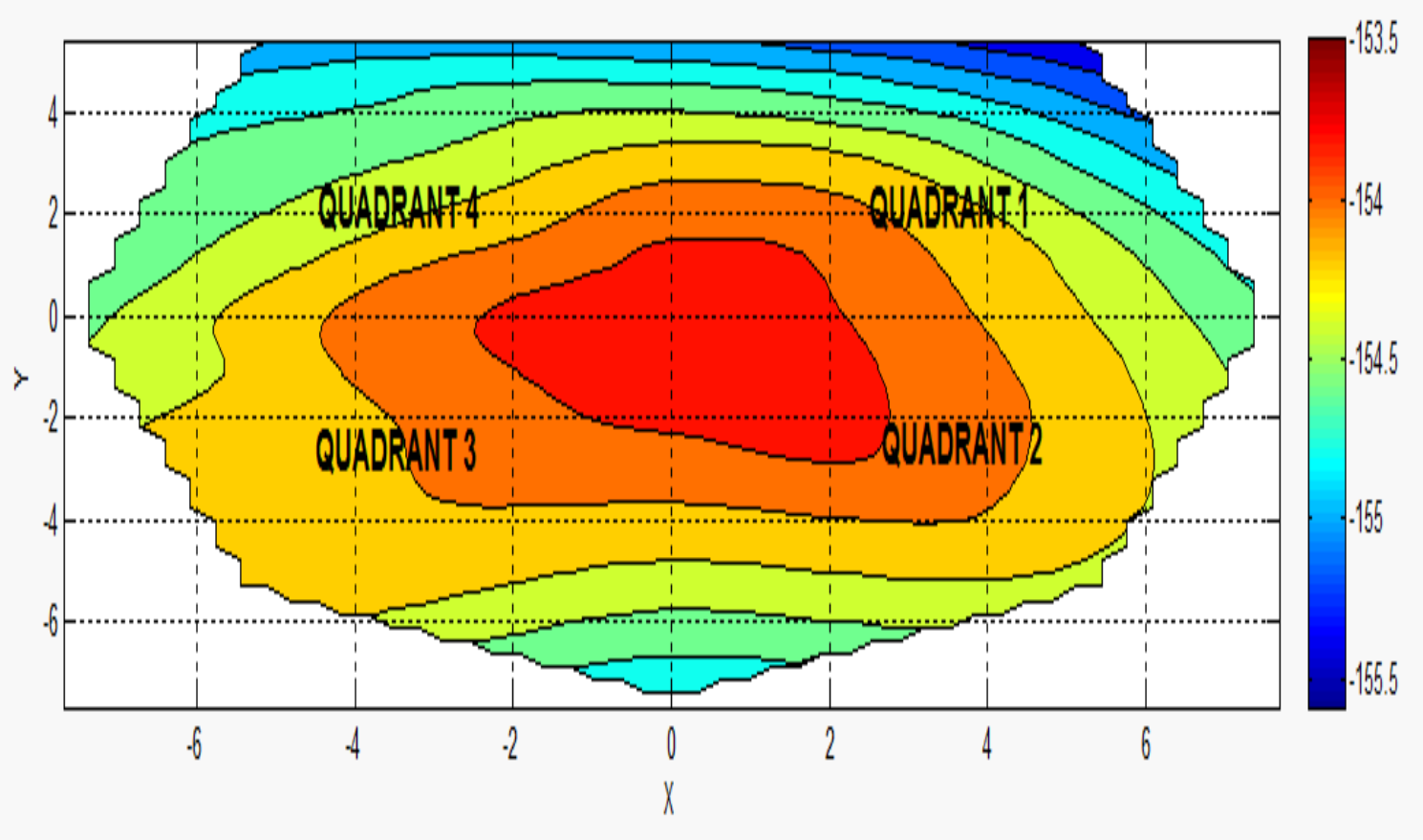

Figure 3.19: Contour plot for 45 psi plug pressure 


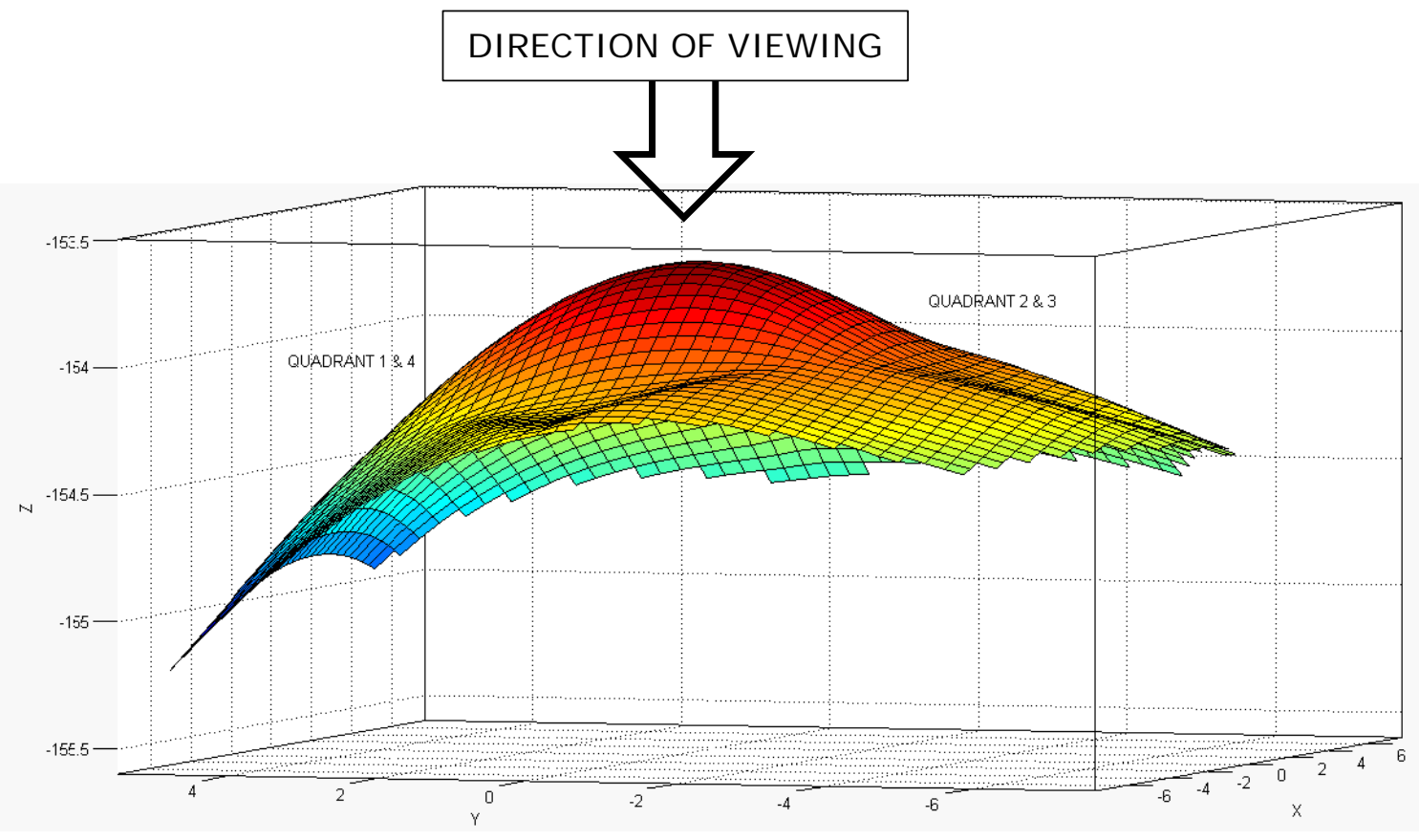

Figure 3.20: Best fit surface plot for 60 psi plug pressure

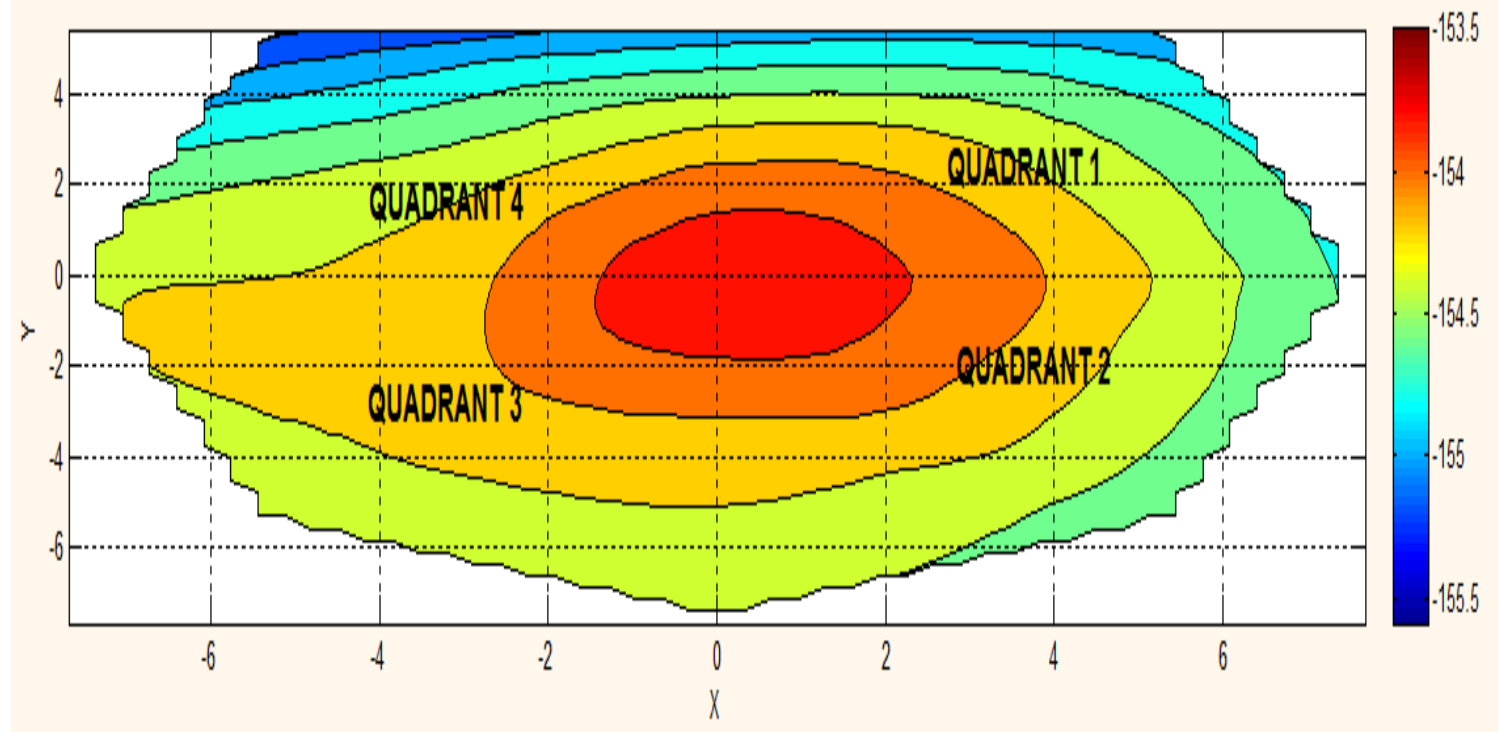

Figure 3.21: Contour plot for 60 psi plug pressure 


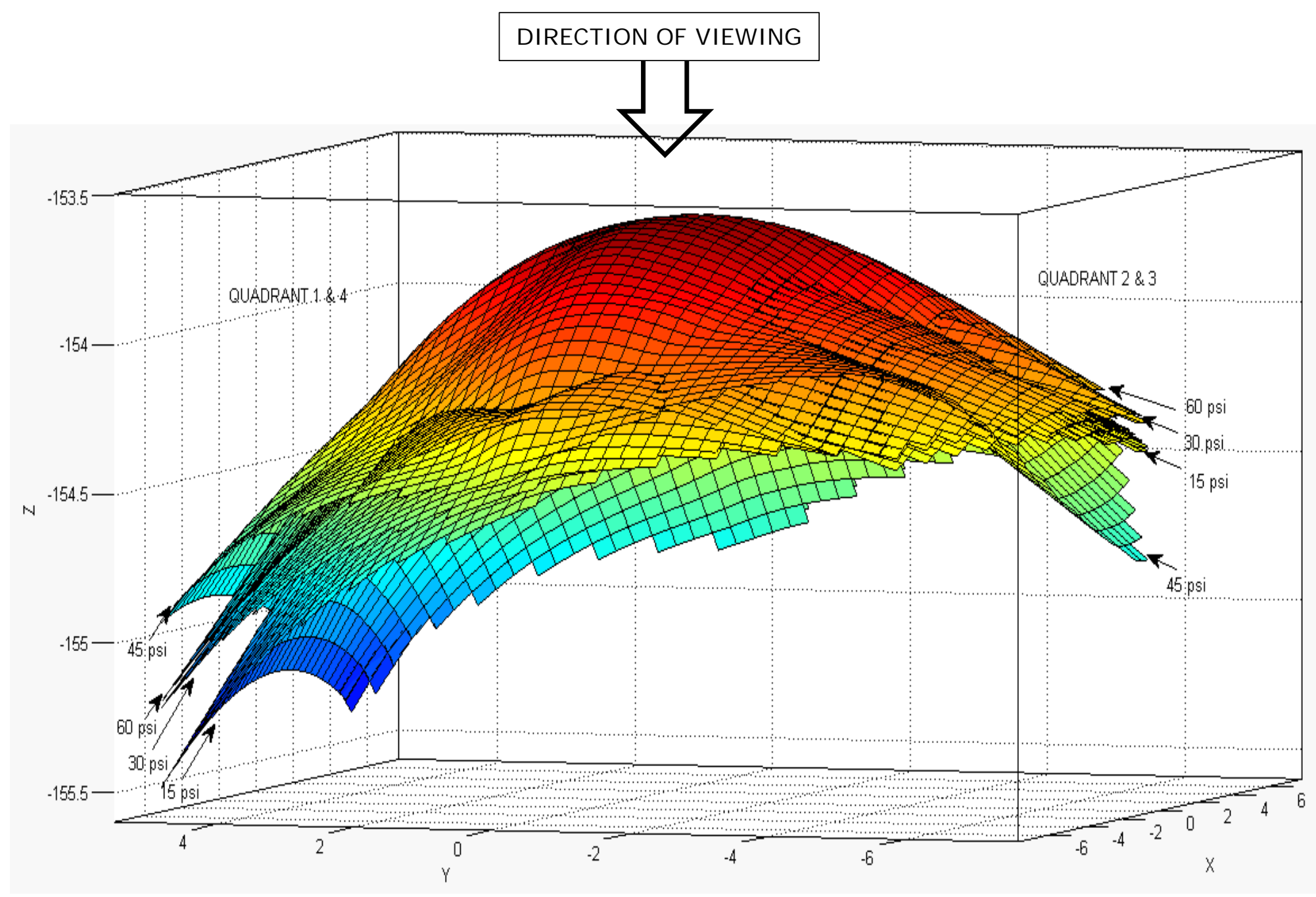

Figure 3.22: Best fit plots for 15, 30, $45 \& 60$ psi: A comparison 


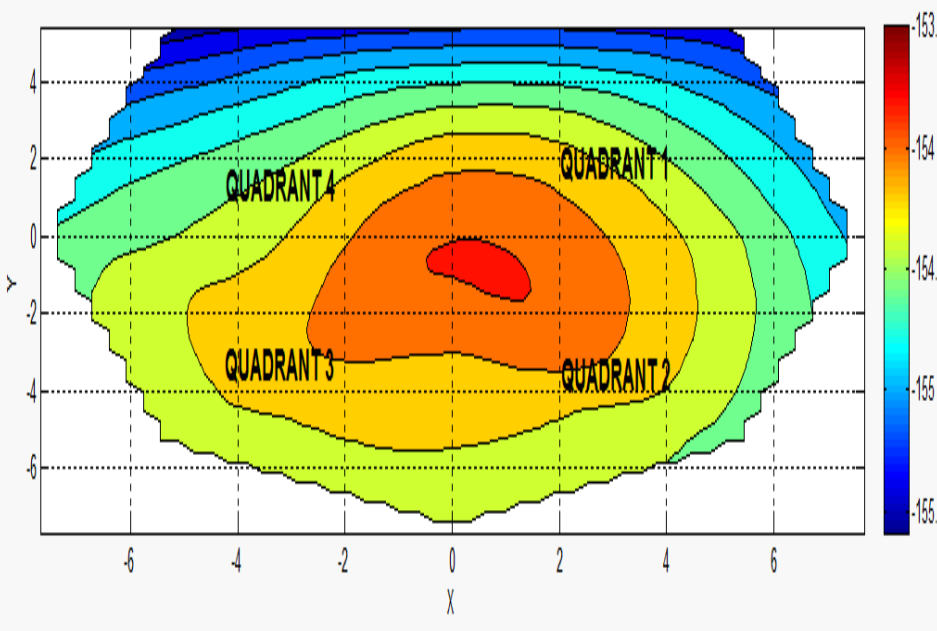

15 psi

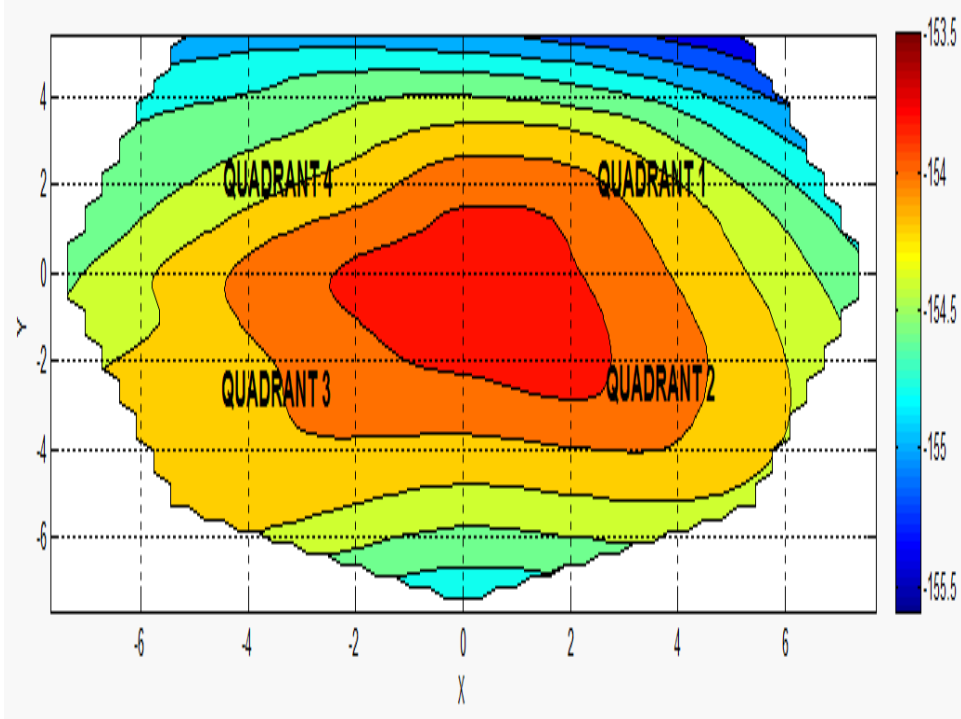

45 psi

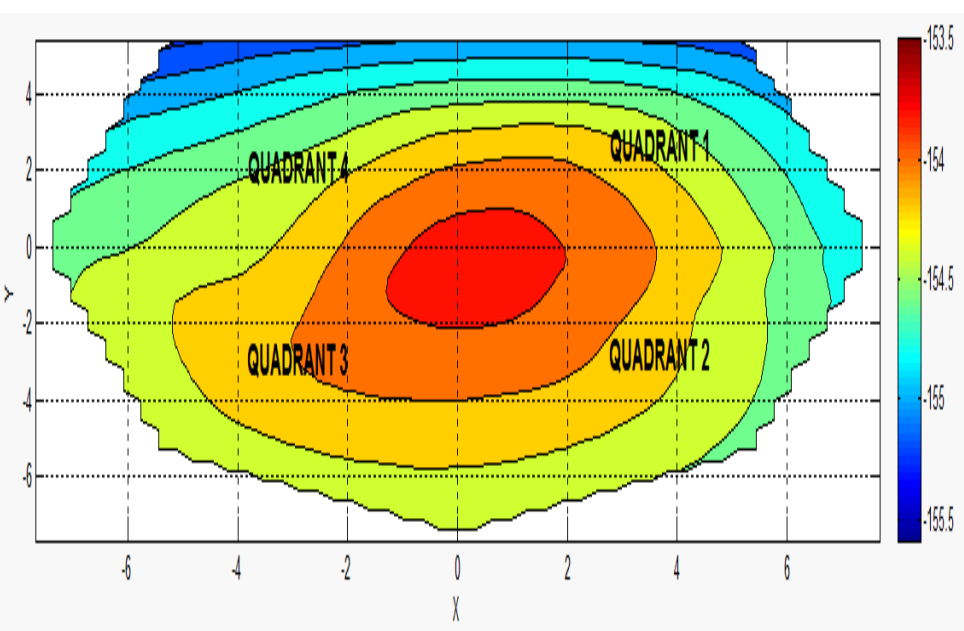

30 psi

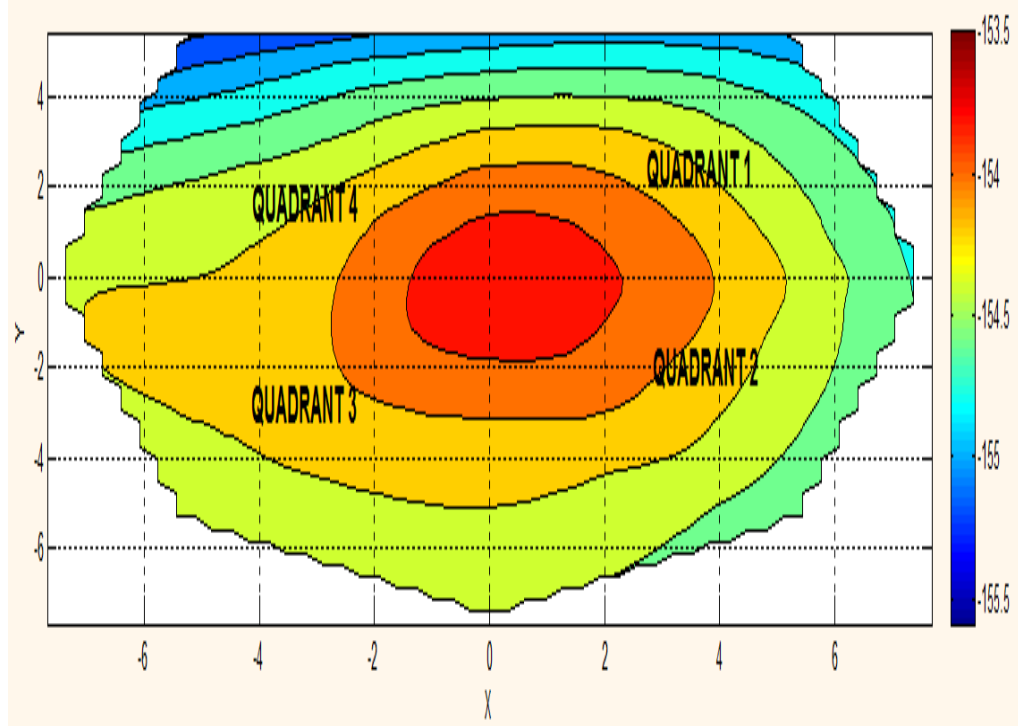

60 psi

Figure 3.23: Contour plots for 15, 30, $45 \& 60$ psi: A comparison 


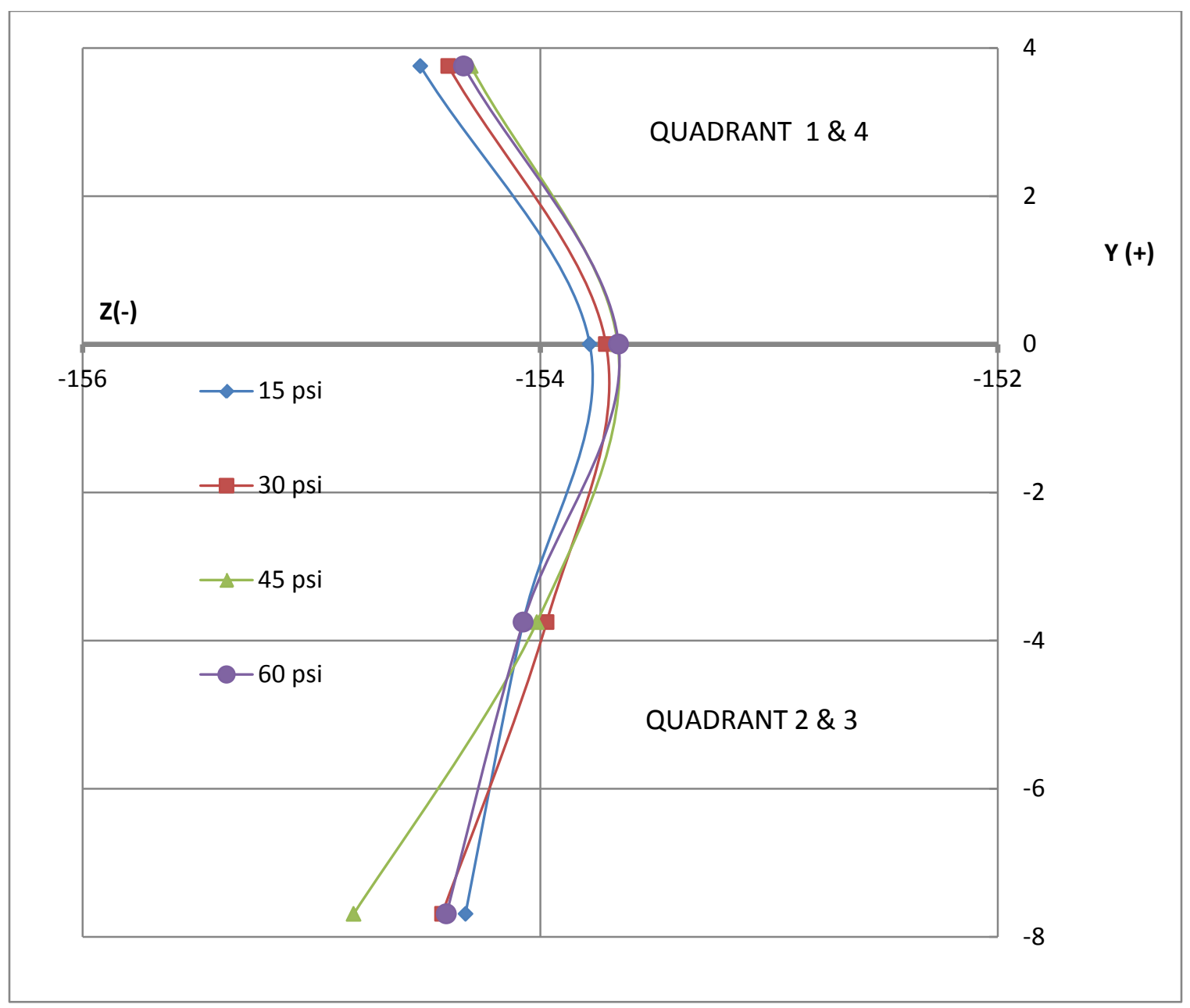

Figure 3.24: Side face of expanding front end cap

A graphical plot of any of the laser data (as shown in Figure 3.9 and Figure 3.10) above is discrepant due to the radial nature of expansion of the hemispherical end cap. This has been described in Figure 3.25.

The average difference of laser readings for a set of pressure increase $(15,30,45$, $60 \& 68$ psi) for a particular orientation of laser (shown in Figure 3.8) varies between 0.02" to $0.1{ }^{\prime \prime}$ (which is reflected in Figure 3.25 as $0^{\prime \prime} O^{\prime \prime \prime}$ ). This small shift in the reading does not impact the elongation study but it should be noted that the distance of a single representative point on the end cap for a particular position of laser is measured only once (since it moves out of range) during the process of pressurizing. 


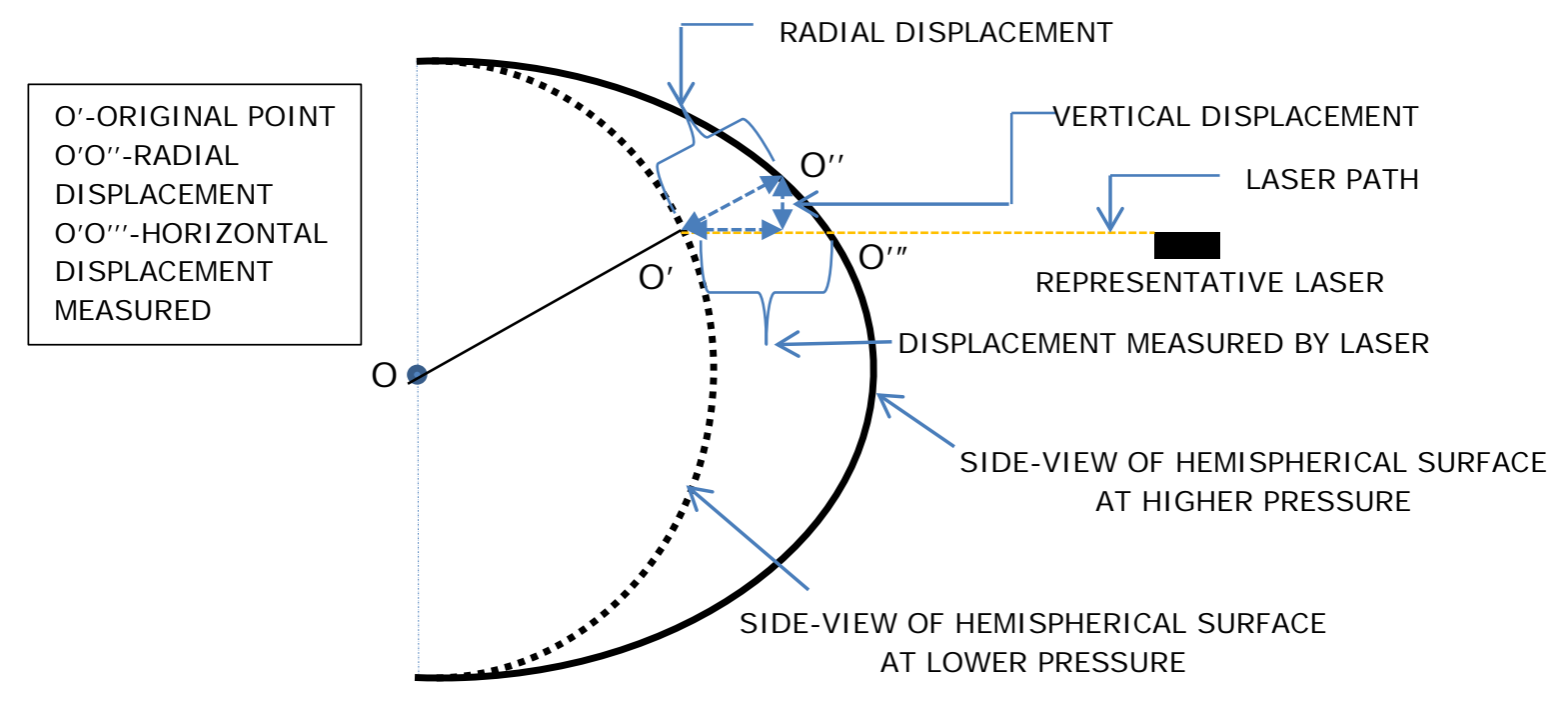

Figure 3.25: Laser reading discrepancy

\subsection{Summary}

The elongation test objectives were: 1 ) Measure the free inflation dimensions of the plug; 2) Record the rear and the front end cap elongation for free inflation and compute total elongation; 3) Check for structural defect and leakages; 4) Record rear and front end cap elongation under constrained inflation and compute total elongation; 5) Generate surface plot for the effect of increasing plug pressure for front end cap.

The measurement of free inflated dimensions reflected a different level of over-sizing when compared to the single layered Vectran plug used in [17] in terms of cylindrical perimeter with respect to the tunnel ( $\sim 2 \%$ for the tri-layered plug $\& \sim 4 \%$ for the single layered plug). The reduced level of over-sizing may have minimized the possibility of the formation of wrinkles during confined inflation.

Under free inflation the front end cap shrunk considerably with the positive elongation of the rear end cap. This reflected a possibility of unequal material distribution between the front and the rear end cap, having more materials at the rear than at the front. Also the pressure ports might have resulted in irregular webbing matrix in Zone 2 (outer zone of the end cap) on the front end cap prompting irregular behavior. The total free elongation appears to follow a linear tendency as the inflation pressure increases. However, all these observations were made at relatively low pressures and the results may change at higher unconfined inflation pressure.

The best fit surface plots and the contour plots indicated expansion and irregular contraction at certain points on the front end cap with the increase in pressure. It is the best possible representation of a 3-D surface which was deemed to have expanded radially.

The constrained front and rear end cap elongation showed marked difference but unlike free elongation at low pressures, the front end cap elongation was recorded as a positive value. The aforesaid explanation of the inflation and the drain port pushing against 
the front end cap and the unequal distribution of material between the front and the rear end cap might be the primary causes of such a difference in elongation. After the inflation pressure of 30 psi the total elongation appears to follow a linear tendency as the pressure increases. 


\section{Chapter 4 Slippage}

\subsection{I ntroduction}

The application of this system of plugging a tunnel section in public transit system has been designed to work safely under certain specific circumstances. Say the plug shape is maintained at an internal pressure $p_{i}$. The pressure of the water behind the plug, the external pressure $p_{e}$ will be dependent on the source of water entering the tunnel. If the tunnel lies under a river bed, then the external pressure will be directly proportional to the height of the water in the river. During an incident like the flooding of the tunnel from river bed breach, the plug will be deployed and pressurized with certain internal pressure, but the applied internal pressure should keep into account the possible maximum external pressure possible in the affected tunnel section. Ideally the internal pressure should always be greater than the external pressure $\left(p_{i}>p_{e}\right)$ to maintain the consistency and shape of the plugging system. There can be two possibilities of the external pressure approaching the plug pressure or vice versa:

(A) The first case scenario is that the there is a sudden unexpected rise in external pressure $\left(p_{e}\right)$ (initially $p_{e}<p_{i}$ ) and the external pressure approaches the internal pressure. Here, there are two possibilities:

A-1) sensing a rise in external (tunnel) pressure the plug pressure does not change.

A-2) the plug pressure does not have any control to it and it increases initially due to a rise in external pressure to a certain extent but slips due to unequal increase with the tunnel pressure.

(B) The second scenario is when a puncture develops in the plug and the pumps (assuming pressurization of the plug with water) fail to maintain the designated pressure, the pressure in the plug will fall (initially $p_{e}<p_{i}$ ) and approach the external pressure. Assuming all the other parameters as in friction, contact area between the tunnel wall and plug surface remains unaffected as in the ideal case scenario, the plug will slip as soon as $p_{i} \rightarrow p_{e}$.

These special phenomena make it imperative to study the slippage characteristics of the 4' diameter webbed Vectran plug in the quarter scale tunnel in order to evaluate the coefficient of friction between the tunnel wall and the plug surface. An initial study was previously conducted on a single layered Vectran plug in the same quarter scale tunnel [17]. But since then, major design changes have taken place, constituting the new plugging system. As for the changes in design, the change in length, diameter and surface material are to be considered for further evaluation of slippage behavior and friction coefficient.

This chapter deals with experiment procedures, results, observations and discussions of controlled and uncontrolled slippage under conditions of modified tunnel surface conditions, reduced contact length with tunnel concrete and reduced mass of the plug. Coefficient of friction is also be evaluated for the above cases. 


\subsection{Test Procedure}

Figure 4.1 shows the test setup for slippage test. The procedures are listed in Appendix A. The setup has a drainage tank added to it along with two submersible pumps.

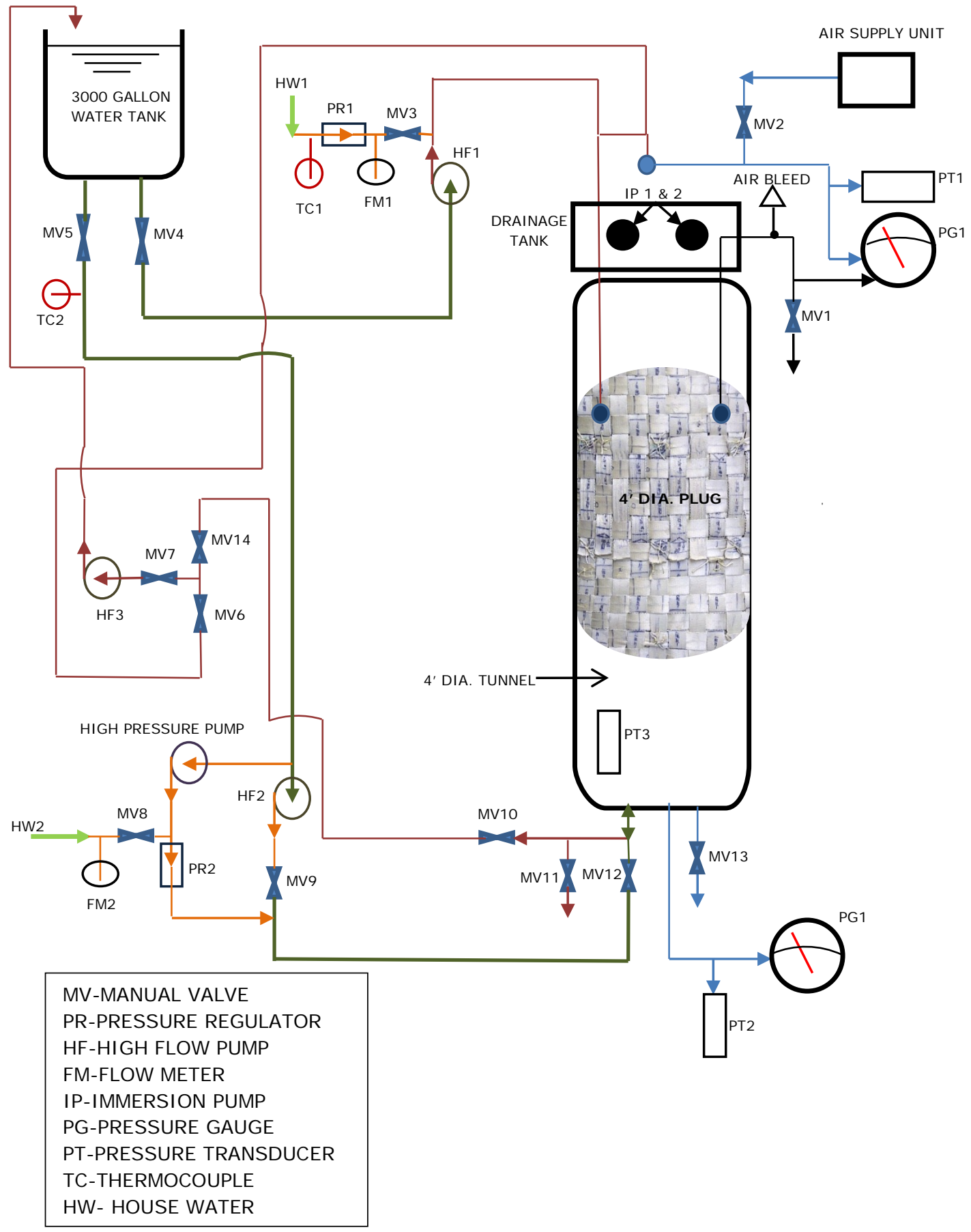

Figure 4.1: Schematic representation of the test piping system for slippage test 


\subsection{I nitial Slippage Testing Matrix}

Table 4.1, Table 4.2 and Table 4.3 shows the testing matrix with various pressure combinations for initial slippage tests. Each level in the below tables were repeated for three trials. The test procedure for the slippage test is mentioned in the Appendix A.

Table 4.1 : Pressure combinations for slippage: sequence A-1

\begin{tabular}{|c|c|c|c|}
\hline Sequence A & Level & $\begin{array}{c}\text { Inflation } \\
\text { pressure } \\
p_{i} \\
{[p s i]}\end{array}$ & $\begin{array}{c}\text { External } \\
\text { (Tunnel) } \\
\text { pressure } \\
p_{e} \\
{[p s i]}\end{array}$ \\
\hline$p_{i}$ constant & 1 & 30 & $20 \rightarrow 30$ \\
\cline { 2 - 4 }$p_{\mathrm{e}}$ increasing & 2 & 40 & $30 \rightarrow 40$ \\
\cline { 2 - 4 } & 3 & 50 & $30 \rightarrow 50$ \\
\hline
\end{tabular}

Table 4.2 : Pressure for uncontrolled slippage: sequence A-2

\begin{tabular}{|c|c|c|c|}
\hline Sequence A-1 & Level & $\begin{array}{c}\text { Inflation } \\
\text { pressure } \\
\mathrm{p}_{\mathrm{i}} \\
{[\mathrm{psi}]}\end{array}$ & $\begin{array}{c}\text { External } \\
\text { (Tunnel) } \\
\text { pressure } \\
\mathrm{pe}_{\mathrm{e}} \\
{[\mathrm{psi}]}\end{array}$ \\
\hline \multirow{3}{*}{$\mathrm{p}_{\mathrm{e}}$ increasing } & 1 & $20 *$ & $10 \rightarrow 20$ \\
\cline { 2 - 4 } & 2 & $30 *$ & $20 \rightarrow 30$ \\
\cline { 2 - 4 } & 3 & $40 *$ & $25 \rightarrow 40$ \\
\hline \multicolumn{2}{|c}{ *Pressure not controlled }
\end{tabular}

Table 4.3: Pressure combinations for slippage: sequence B

\begin{tabular}{|c|c|c|c|}
\hline Sequence B & Level & $\begin{array}{c}\text { Inflation } \\
\text { pressure } \\
\mathrm{p}_{\mathrm{i}} \\
{[\mathrm{psi}]}\end{array}$ & $\begin{array}{c}\text { External } \\
\text { (Tunnel) } \\
\text { pressure } \\
\mathrm{p}_{\mathrm{e}} \\
{[\mathrm{psi}]}\end{array}$ \\
\hline \multirow{3}{*}{$\begin{array}{c}\mathrm{p}_{\mathrm{i}} \text { decreasing } \\
\mathrm{p}_{\mathrm{e}} \text { constant }\end{array}$} & 1 & $55 \rightarrow 40$ & 40 \\
\hline & 2 & $40 \rightarrow 30$ & 30 \\
\hline & 3 & $30 \rightarrow 20$ & 20 \\
\hline
\end{tabular}

\subsubsection{Slippage Sequence A-1}

The different pressure combinations for slippage test Sequence A are compiled in Table 4.1. The plot of pressure variations for the tunnel and the plug and their displacement are shown below in Figure 4.2, Figure 4.3 and Figure 4.4. 


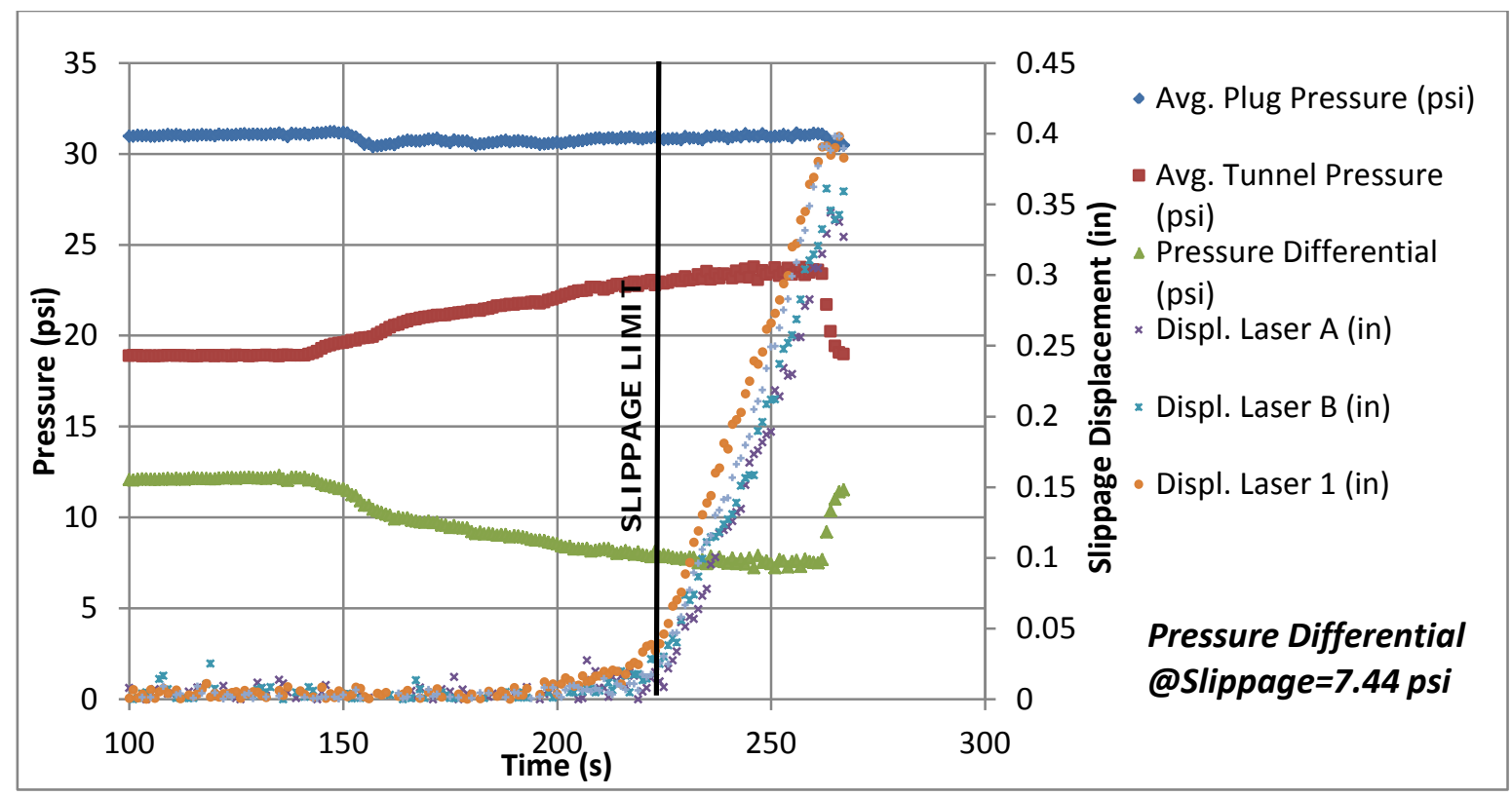

Figure 4.2: Slippage: tunnel 20 -> plug 30 psi

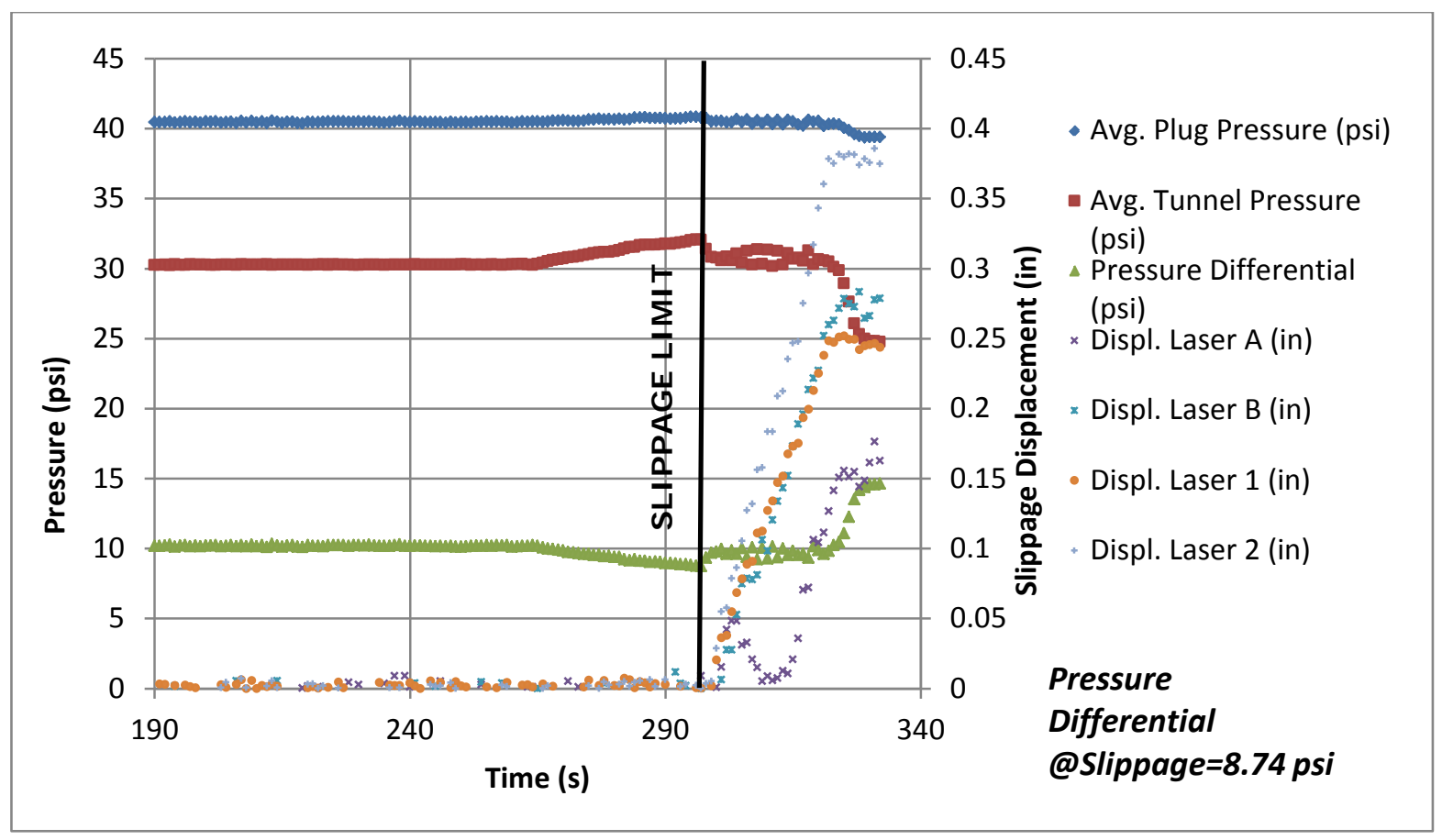

Figure 4.3: Slippage: tunnel 30 -> plug 40 psi 


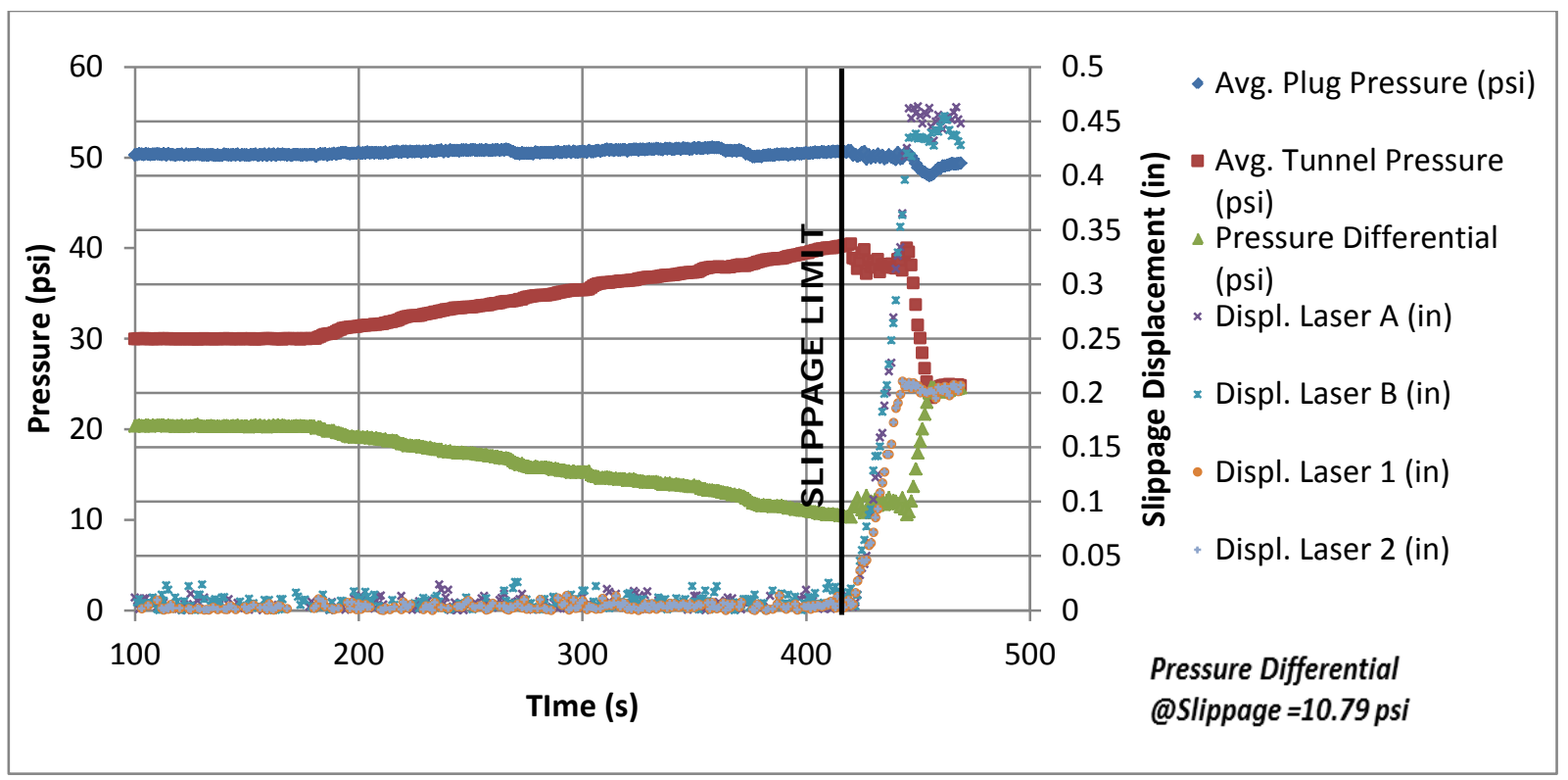

Figure 4.4: Slippage: tunnel 30 -> plug 50 psi

\subsubsection{Observations}

The higher the target external pressure, the more difficult it was to attain it through tunnel pressure. This was due continuous water leakage between the plug surface and the tunnel wall. With an average rate of pressure increase of 2.9 psi per minute, it was ensured that there was no sudden jump in tunnel pressure. The slippage of the plug in the tunnel was accompanied with loud "thudding" noise. The first thudding noise indicated the onset of slip; the overcoming of limiting static friction. There was a tendency of the tunnel pressure to drop sharply right after the first slip and considerable effort had to be made on pressure regulator (as PR2 in Figure 4.1) to maintain the tunnel pressure. In order to get a clear plot of slippage displacement, the attempt to increase/maintain the tunnel pressure (after the first slip) was continued till a steady set of thudding noises were heard one after the other. It was also observed that the pressure differential, the difference between the plug and the tunnel pressure, increased with an increase in the target slippage pressure.

\subsubsection{Discussions}

Figure 4.2, Figure 4.3 and Figure 4.4 showed the plot of tunnel pressure, plug pressure, pressure differential and the displacements recorded with different lasers with time. Ideally, the point in the plot of maximum tunnel pressure, minimum pressure differential and sudden and appreciable positive displacement (axial movement of plug) at the same instance of time defines the slippage limit in the plots. Table 4.4 displays the results for the test of Sequence A- 1 . 
Table 4.4: Sequence A-1 results

\begin{tabular}{|c|c|c|c|c|c|c|}
\hline \multirow{3}{*}{$\begin{array}{c}\text { SEQUENCE } \\
\text { A-1 }\end{array}$} & $\begin{array}{l}\text { Plug pressure } \\
\text { CONSTANT }\end{array}$ & \multicolumn{2}{|c|}{$\begin{array}{c}\text { Tunnel } \\
\text { pressure } \\
\text { I NCREASI NG } \\
\end{array}$} & $\begin{array}{l}\text { Tunnel } \\
\text { pressure } \\
\text { reached }\end{array}$ & $\begin{array}{l}\text { Differential at } \\
\text { Slippage }\end{array}$ & $\begin{array}{l}\text { Holding } \\
\text { Resistance }\end{array}$ \\
\hline & $p_{i}$ & \multicolumn{2}{|c|}{$\mathrm{p}_{\mathrm{e}}$} & $\mathrm{p}_{\mathrm{re}}$ & $\left(p_{i}-p_{r e}\right)$ & $\mathrm{p}_{\mathrm{re}} / \mathrm{p}_{\mathrm{i}}$ \\
\hline & [psi] & \multicolumn{2}{|c|}{ [psi] } & [psi] & [psi] & [\%] \\
\hline \multirow{3}{*}{ Trial \# 1} & 30 & 20 & $\rightarrow 30$ & 23.8 & 6.23 & 0.79 \\
\hline & 40 & 30 & $\rightarrow 40$ & 31.8 & 8.20 & 0.80 \\
\hline & 50 & 30 & $\rightarrow 50$ & 37.7 & 12.30 & 0.75 \\
\hline \multirow{3}{*}{ Trial \# 2} & 30 & 20 & $\rightarrow 30$ & 23.3 & 6.75 & 0.78 \\
\hline & 40 & 30 & $\rightarrow 40$ & 31.8 & 8.21 & 0.79 \\
\hline & 50 & 30 & $\rightarrow 50$ & 39.8 & 10.23 & 0.80 \\
\hline \multirow{3}{*}{ Trial \# 3} & 30 & 20 & $\rightarrow 30$ & 22.6 & 7.44 & 0.75 \\
\hline & 40 & 30 & $\rightarrow 40$ & 31.3 & 8.74 & 0.78 \\
\hline & 50 & 30 & $\rightarrow 50$ & 39.2 & 10.79 & 0.78 \\
\hline & & & & & Average & $0.78 \pm 0.02$ \\
\hline
\end{tabular}

Figure 4.3 and Figure 4.4 show a clear representation of slippage at higher pressures, with the plug displacement and tunnel pressure fall happening at the same instance of time as indicated by the slippage limit. When the plug slips there is an evident increase of tunnel volume in which the pressure is being applied leading to fall in the external pressure. With lower pressure it is easier to compensate for the loss of pressure/increase in volume than at the higher pressures. All the above mentioned plots also make it evident that the plug slips as one unit mass during the onset of slippage since all the lasers start recording appreciable displacement at the same instance of time. The laser data recorded beyond the slippage limit for level 2 and level 3 of slippage (Table 4.1) shows as erratic movement of the plug. This occurrence might be a result of the inflation port or the air release port metal elbows hitting the tunnel wall constraining the plug movement on one side resulting in unequal displacement. It may also be due to movement of the front end cap downward and then further left and right movement after the first slip.

As observed from Table 4.4, the pressure differential between the plug and the tunnel increased with an increase in the level of target tunnel pressure as in Sequence A-1 (Table 4.1). But what will be interesting to note is the ratio of external to internal pressure at the point of slippage called as "Holding Resistance" in Table 4.4.

The average value for holding resistance was 0.78 with a standard deviation of \pm 0.018 (Table 4.4). This value indicates that the plug slips in the quarter scale tunnel when the external pressure is approximately $78 \%$ of the internal pressure over a range of $30-50$ psi. 


\subsubsection{Slippage Sequence B}

The pressure combinations for different levels of forced slippage sequence $B$ has already been compiled in Table 4.3. The plots for different testing levels are shown in Figure 4.5, Figure 4.6 and Figure 4.7.

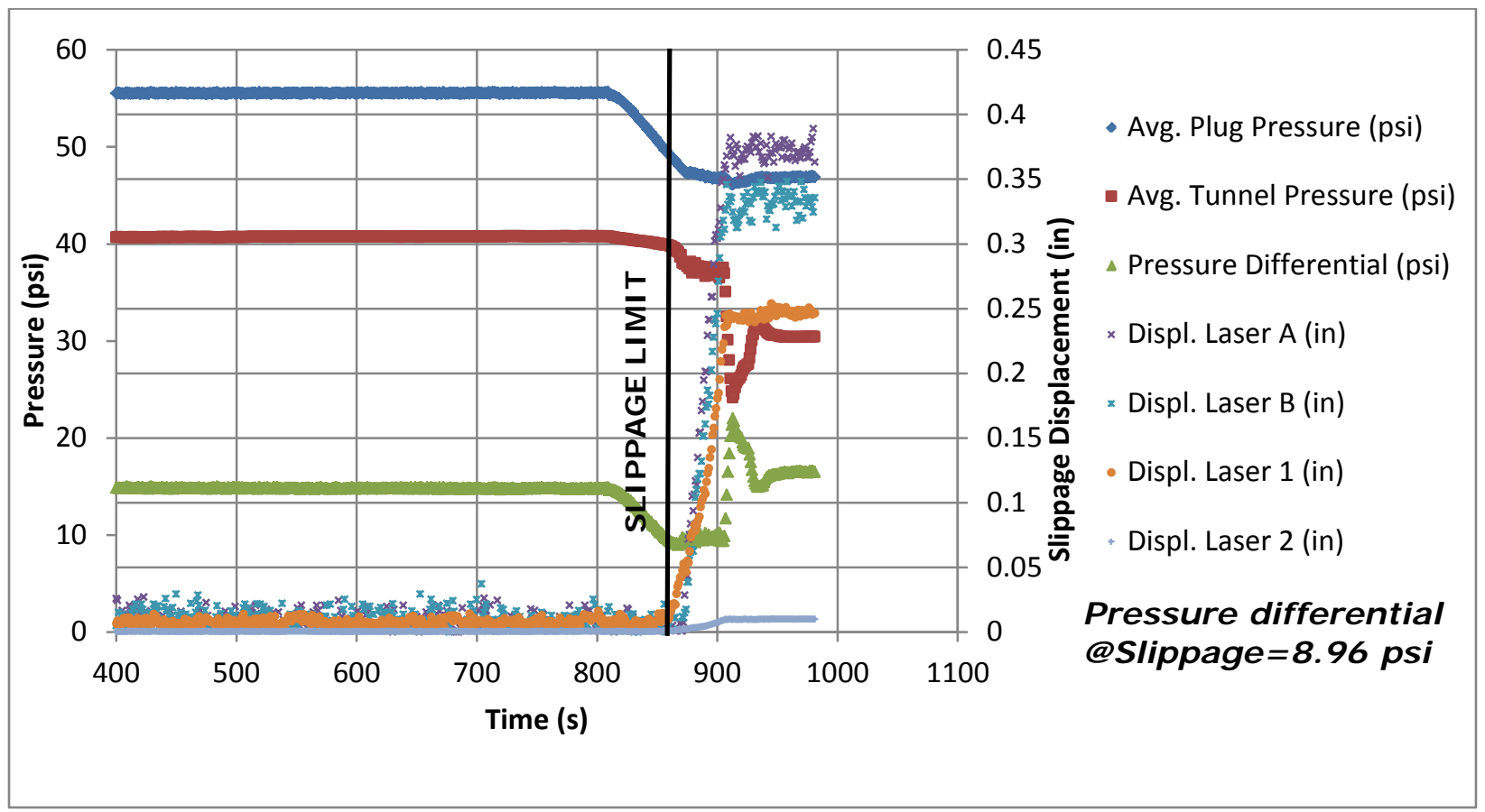

Figure 4.5: Slippage: plug 55->40 psi

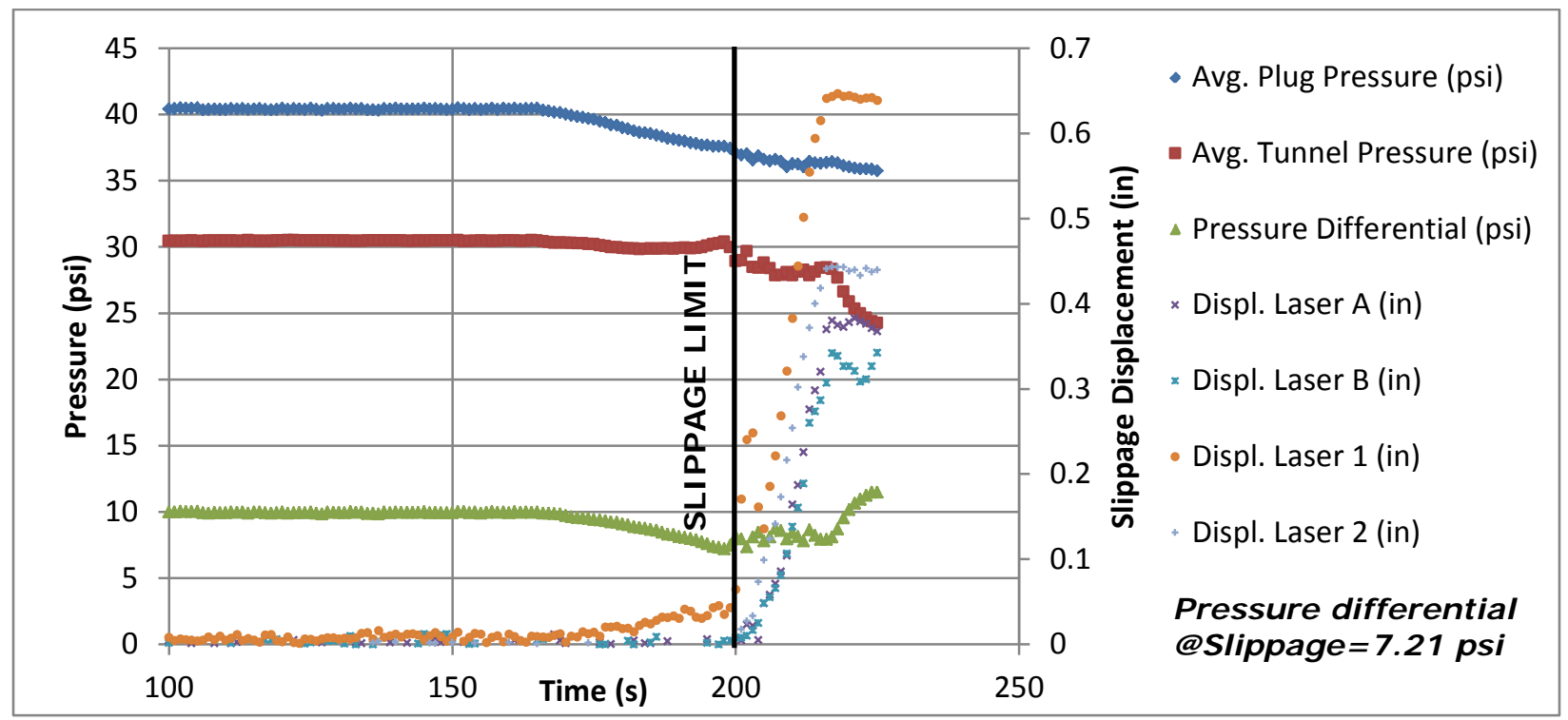

Figure 4.6: Slippage: plug 40-> 30 psi 


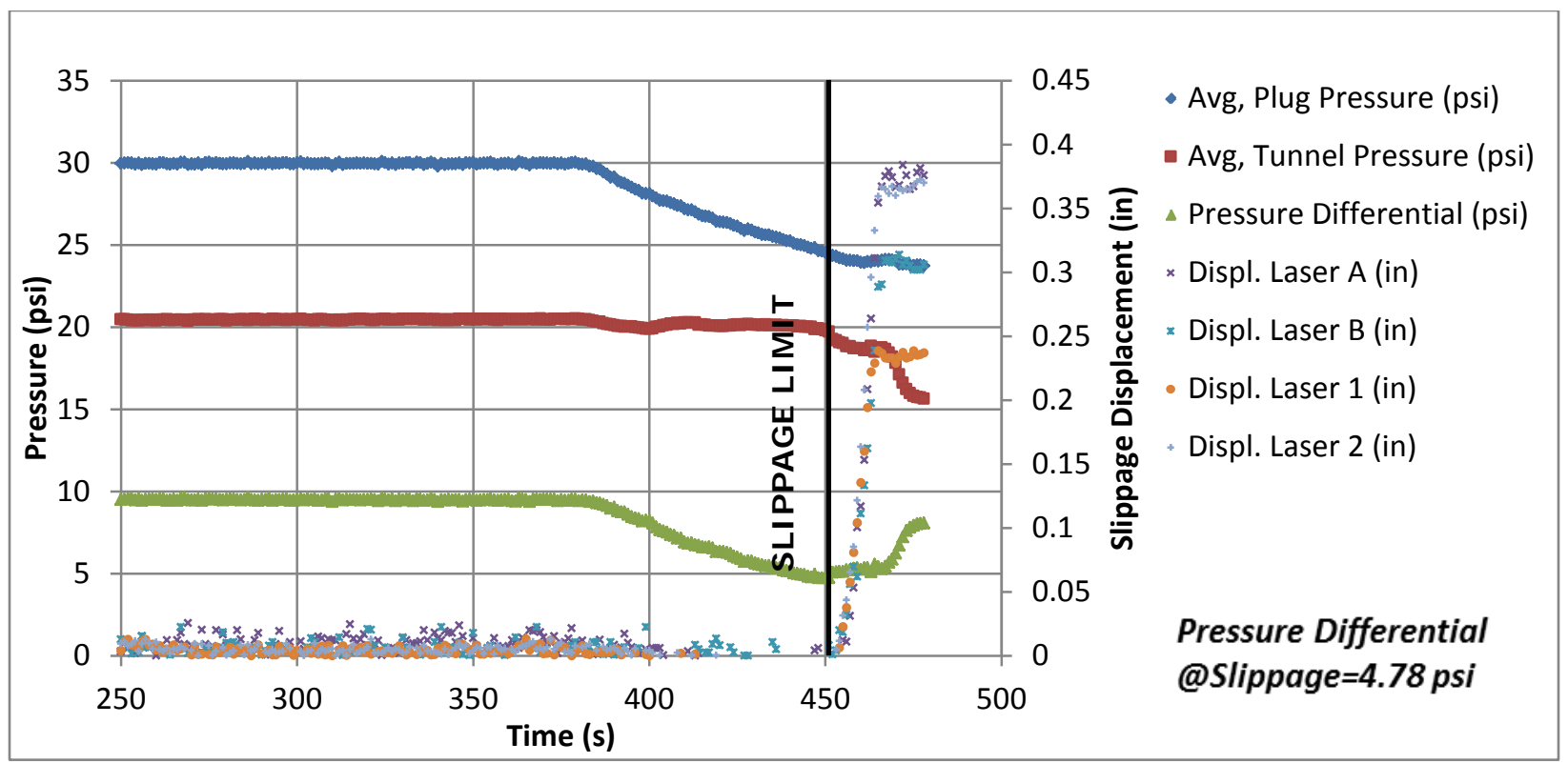

Figure 4.7: Slippage: plug 30 -> 20 psi

\subsubsection{Observations}

The slippage limit for Sequence $B$ is defined on the basis of appreciable positive displacement recorded on the lasers and a minimum pressure differential as seen in Figure 4.5, Figure 4.6 and Figure 4.7. This experiment was conducted to simulate a condition similar to a leaking plug losing pressure, leading to slippage in the tunnel. As mentioned in the observation of Sequence A-1, the onset of slippage was accompanied by thudding noise.

\subsubsection{Discussions}

The effect of slippage showed all the signs as discussed in Section 4.3.1.2. What was interesting to note in this sequence of experiments is the holding resistances. There has been an increase in the holding resistance (see Table 4.5) to an average of 0.80 than last observed at slippage in Sequence A-1 (0.78). This is only an approximate $2.5 \%$ increase with $1.8 \%$ of coefficient of variation, but in the context of analysis it can be concluded that the plug showed higher holding resistance. 
Table 4.5: Sequence $B$ results

\begin{tabular}{|c|c|c|c|c|c|c|}
\hline \multirow{3}{*}{$\begin{array}{c}\text { SEQUENCE } \\
\text { B }\end{array}$} & \multicolumn{2}{|c|}{$\begin{array}{l}\text { Plug pressure } \\
\text { DECREASI NG }\end{array}$} & $\begin{array}{c}\text { Tunnel } \\
\text { pressure } \\
\text { CONSTANT }\end{array}$ & $\begin{array}{l}\text { Plug pressure } \\
\text { reached }\end{array}$ & $\begin{array}{c}\text { Differential at } \\
\text { Slippage }\end{array}$ & $\begin{array}{c}\text { Holding } \\
\text { Resistance }\end{array}$ \\
\hline & \multicolumn{2}{|c|}{$\mathrm{p}_{\mathrm{i}}$} & $\mathrm{p}_{\mathrm{e}}$ & $\mathrm{p}_{\mathrm{ri}}$ & ( $\mathrm{p}_{\mathrm{ri}}$-pe) & $\mathrm{p}_{\mathrm{i}} / \mathrm{p}_{\mathrm{re}}$ \\
\hline & \multicolumn{2}{|c|}{ [psi] } & [psi] & [psi] & [psi] & [\%] \\
\hline \multirow{3}{*}{ Trial \# 1} & 55 & $\rightarrow 40$ & 40.0 & 49.8 & 9.81 & 0.80 \\
\hline & 40 & $\rightarrow 30$ & 30.0 & 37.8 & 7.82 & 0.79 \\
\hline & 30 & $\rightarrow 20$ & 20.0 & 25.5 & 5.50 & 0.78 \\
\hline \multirow{3}{*}{ Trial \# 2} & 55 & $\rightarrow 40$ & 40.0 & 49.0 & 8.96 & 0.82 \\
\hline & 40 & $\rightarrow 30$ & 30.0 & 37.7 & 7.72 & 0.80 \\
\hline & 30 & $\rightarrow 20$ & 20.0 & 24.6 & 4.58 & 0.81 \\
\hline \multirow{3}{*}{ Trial \# 3} & 55 & $\rightarrow 40$ & 40.0 & 49.6 & 9.58 & 0.81 \\
\hline & 40 & $\rightarrow 30$ & 30.0 & 37.2 & 7.21 & 0.81 \\
\hline & 30 & $\rightarrow 20$ & 20.0 & 24.8 & 4.78 & 0.81 \\
\hline & & & & & Average & $0.80 \pm 0.01$ \\
\hline
\end{tabular}

\subsubsection{Slippage Sequence A-2}

The uncontrolled slippage was conducted as per Table 4.2. The air release port as mentioned in the test procedure was kept shut. The results are plotted in Figure 4.8, Figure 4.9 and Figure 4.10 for three levels of pressure.

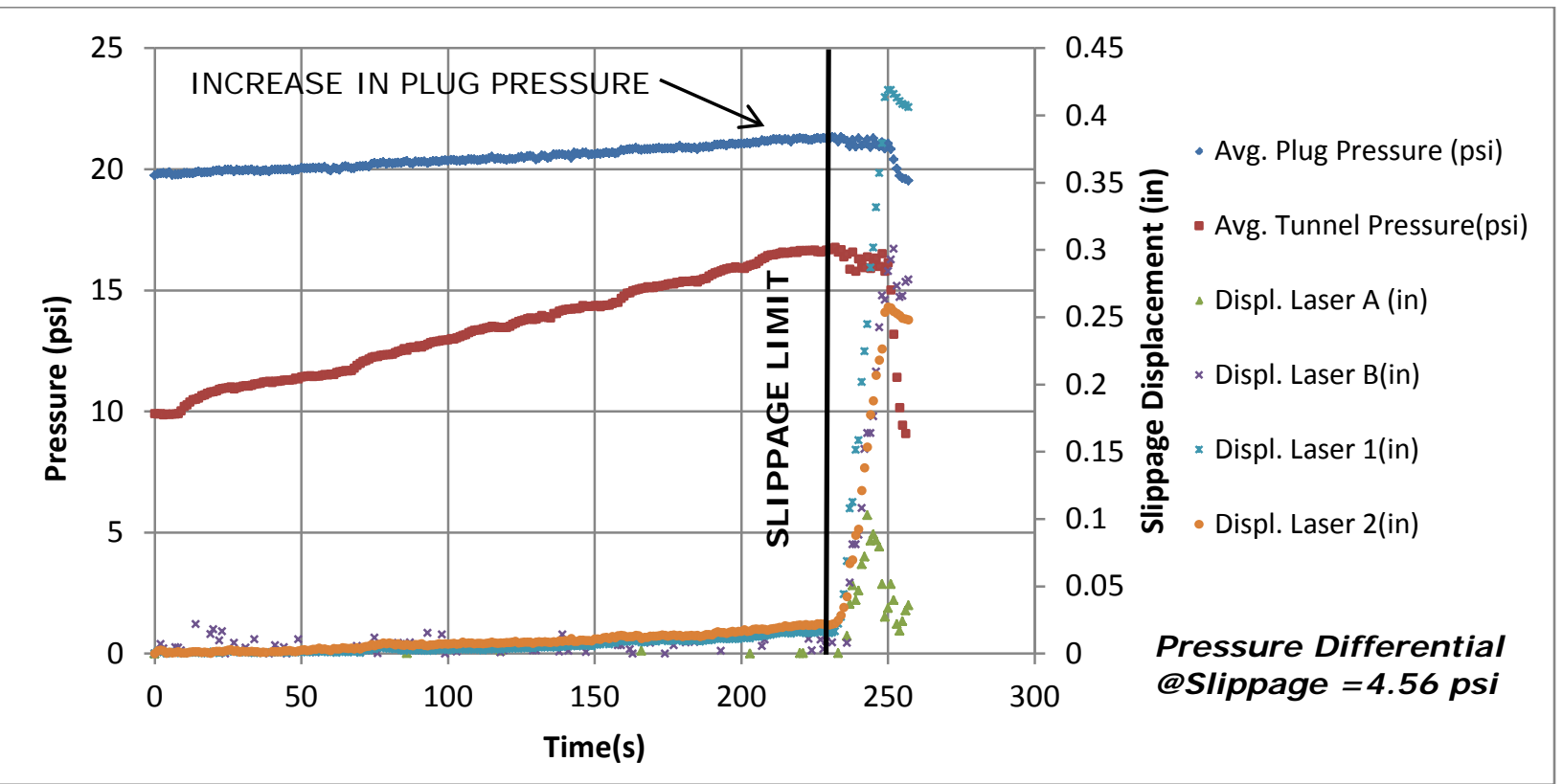

Figure 4.8: Uncontrolled slippage: tunnel 10 -> plug 20 psi 


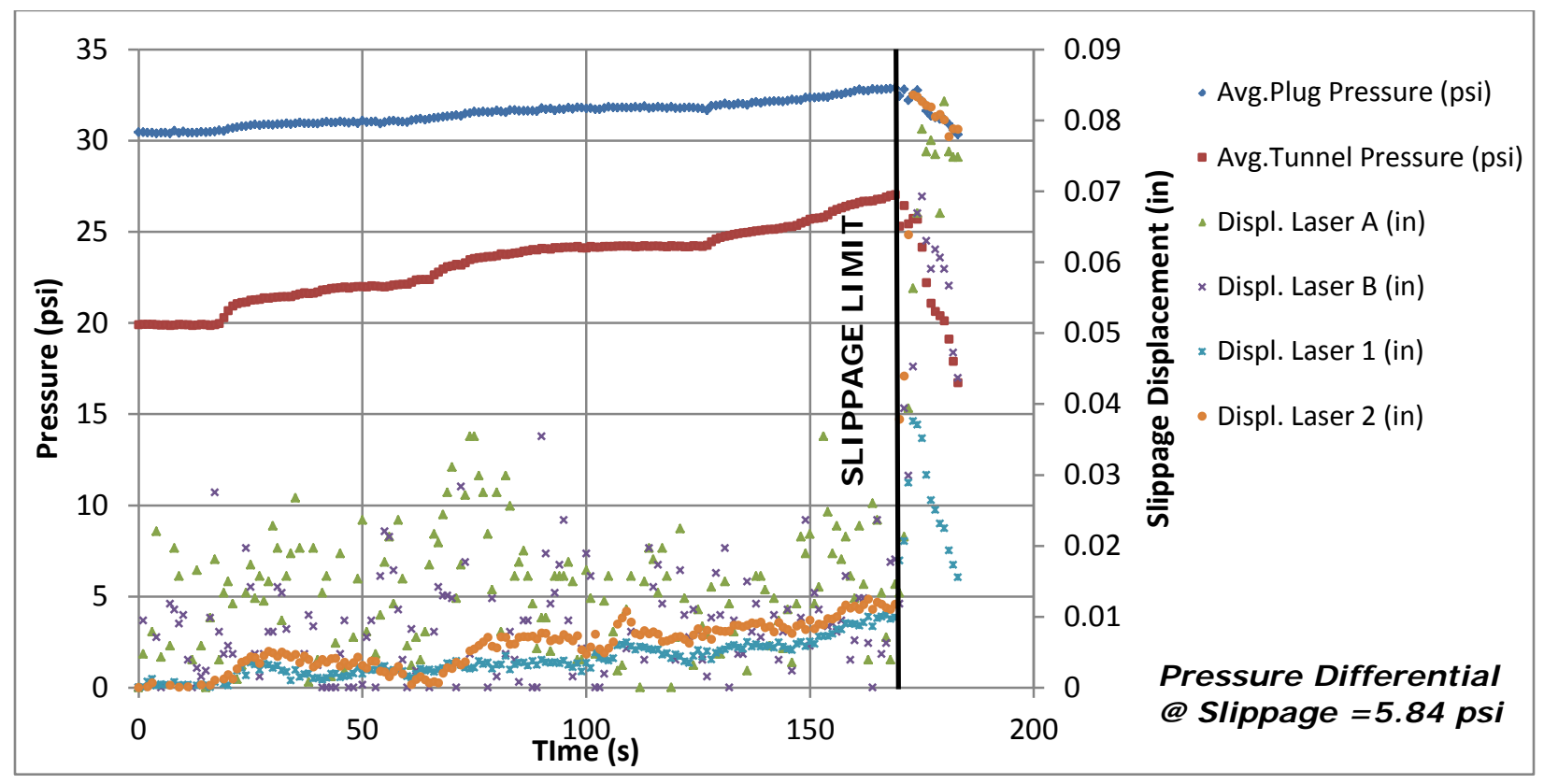

Figure 4.9 : Uncontrolled slippage: tunnel 20 -> plug 30 psi

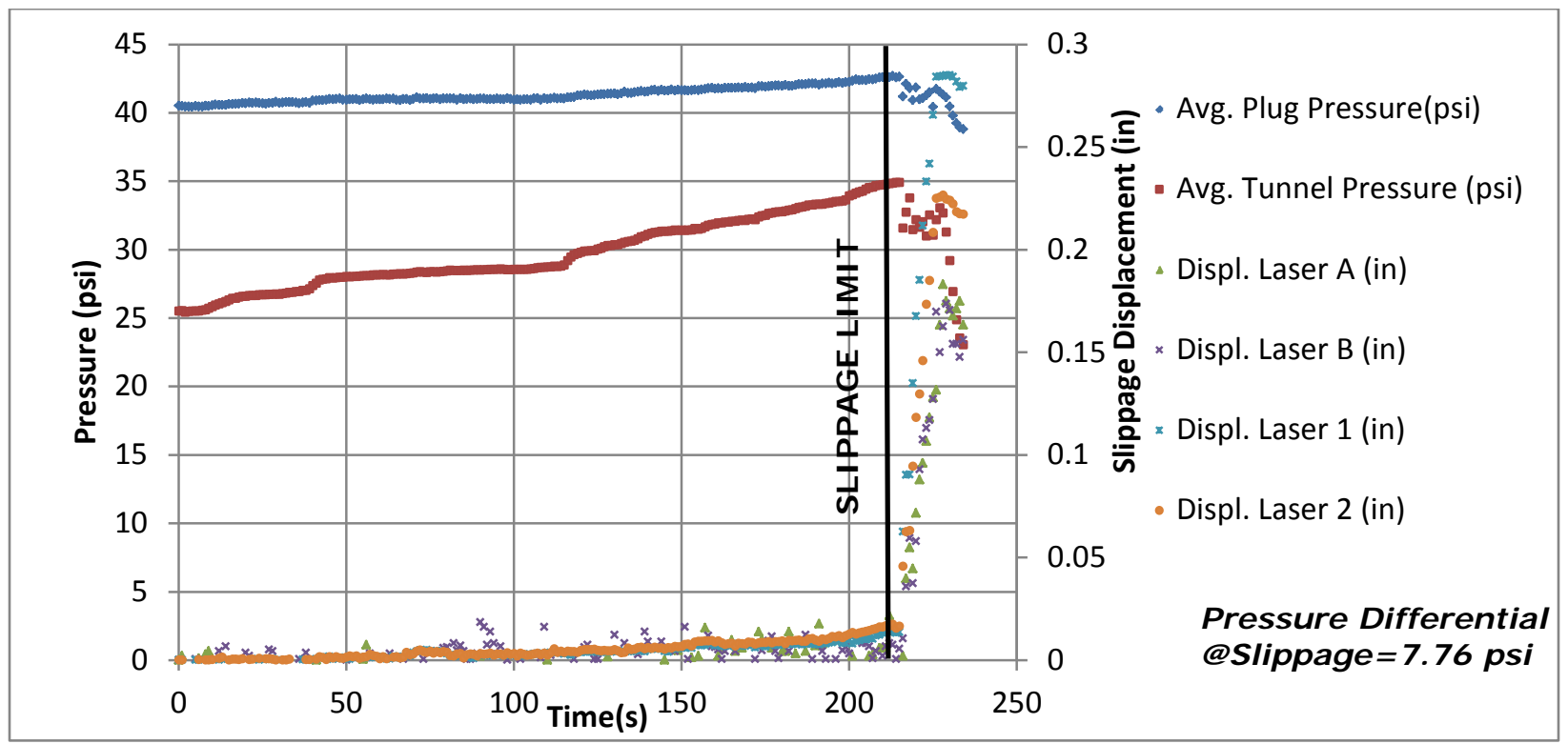

Figure 4.10: Uncontrolled slippage: tunnel 25 -> plug 40 psi

The plots (Figure 4.8, Figure $4.9 \&$ Figure 4.10) as seen above for uncontrolled slippage show the effect of increasing the tunnel pressure and not controlling the plug 
pressure. The plug pressure shows as steady increase with the increase in tunnel pressure until the differential becomes small enough (or more accurately the ratio of external to internal pressure was large enough) for plug to slip. This experiment was also a yardstick of how much the plug pressure may increase with the increase in tunnel pressure and at what point does the plug slip. This was also a realistic failure criterion for the plug (pressure exceeding the design pressure) due to an uncontrolled increase in tunnel pressure. The percentage increase in plug pressure with the percentage increase in tunnel pressure can be studied under the three level of slippage. An average increase in tunnel pressure by $48 \%$ increases the plug pressure by $9 \%$ as shown in Table 4.6.

Table 4.6: Sequence A-2 results

\begin{tabular}{|c|c|c|c|c|c|c|c|c|c|}
\hline \multirow{3}{*}{$\begin{array}{c}\text { SEQUENCE } \\
\text { A-2 }\end{array}$} & $\begin{array}{c}\text { Plug } \\
\text { pressure } \\
\text { I nitially } \\
\text { CONSTANT }\end{array}$ & $\begin{array}{c}\text { Tunnel } \\
\text { pressure } \\
\text { I NCREASING }\end{array}$ & $\begin{array}{c}\text { I nitial } \\
\text { tunnel } \\
\text { pressure }\end{array}$ & $\begin{array}{l}\text { Plug } \\
\text { pressure } \\
\text { reached }\end{array}$ & $\begin{array}{l}\text { Tunnel } \\
\text { pressure } \\
\text { reached }\end{array}$ & $\begin{array}{l}\text { Differential } \\
\text { at slippage }\end{array}$ & $\begin{array}{l}\text { Holding } \\
\text { resistance }\end{array}$ & $\begin{array}{c}\% \\
\text { Increase } \\
\text { in plug } \\
\text { pressure }\end{array}$ & $\begin{array}{c}\% \\
\text { Increase in } \\
\text { Tunnel } \\
\text { pressure }\end{array}$ \\
\hline & $\mathrm{p}_{\mathrm{i}}$ & & $p_{e}$ & $p_{\text {ri }}$ & $\mathrm{p}_{\mathrm{re}}$ & $\left(p_{r i}-p_{r e}\right)$ & $\mathrm{p}_{\mathrm{re}} / \mathrm{p}_{\mathrm{ri}}$ & $\begin{array}{c}\left(p_{r i}-p_{i}\right) / p_{i} \\
\quad \times 100 \\
\end{array}$ & $\begin{array}{c}\left(p_{\mathrm{re}}-p_{\mathrm{e}}\right) / p_{\mathrm{e}} \\
\times 100 \\
\end{array}$ \\
\hline & [psi] & [psi] & [psi] & [psi] & [psi] & [psi] & [\% ] & [\% ] & [\% ] \\
\hline \multirow{3}{*}{ Trial \# 1} & $20 *$ & $10 \rightarrow 20$ & 10 & 21.33 & 16.77 & 4.56 & 0.79 & $7 \%$ & $68 \%$ \\
\hline & $30 *$ & $20 \rightarrow 30$ & 19.8 & 32.25 & 25.78 & 6.47 & 0.80 & $8 \%$ & $30 \%$ \\
\hline & $40 *$ & $25 \rightarrow 40$ & 25 & 42.67 & 34.91 & 7.76 & 0.82 & $7 \%$ & $40 \%$ \\
\hline \multirow{3}{*}{ Trial \# 2} & $20 *$ & $10 \rightarrow 20$ & 10 & 22.19 & 17.98 & 4.21 & 0.81 & $11 \%$ & $80 \%$ \\
\hline & $30 *$ & $20 \rightarrow 30$ & 21.8 & 31.45 & 25.58 & 5.87 & 0.81 & $5 \%$ & $17 \%$ \\
\hline & $40 *$ & $25 \rightarrow 40$ & 26.2 & 42.65 & 34.48 & 8.17 & 0.81 & $7 \%$ & $32 \%$ \\
\hline \multirow{3}{*}{ Trial \# 3} & $20 *$ & $10 \rightarrow 20$ & 10.7 & 22.57 & 18.28 & 4.29 & 0.81 & $13 \%$ & $71 \%$ \\
\hline & $30 *$ & $20 \rightarrow 30$ & 20 & 32.88 & 27.04 & 5.84 & 0.82 & $10 \%$ & $35 \%$ \\
\hline & $40 *$ & $25 \rightarrow 40$ & 25 & 44.02 & 36.67 & 7.35 & 0.83 & $10 \%$ & $47 \%$ \\
\hline & & & & & & Average & $0.81 \pm 0.01$ & $\mathbf{9 \%}$ & $47 \%$ \\
\hline
\end{tabular}

* Pressure not controlled

The first test of each of the three trials showed the highest percentage tunnel pressure increase compared to the other tests of the trial. This was due to lower initial tunnel pressure and lower pressure differential at the beginning of the test. The plug pressure increase as seen in the plots above (Figure 4.8, Figure $4.9 \&$ Figure 4.10) should be happening due to a certain decrease in the plug volume. Since, the plug pressure regulator maintained the applied pressure from the supply of house water ( $1^{\text {st }}$ variable of plug pressure=constant) and the valve MV1 (Figure 4.1) was kept shut ( $2^{\text {nd }}$ variable of plug pressure $=$ constant) the only parameter that varied in the whole set up was the tunnel pressure. The assumption of the plug end cap maintaining shape at the rear of the plug, inside the tunnel, incident to the tunnel pressure, as a rigid membrane subjected to the tunnel pressure on the outside and internal (inflation) pressure on the inside, was debatable. This was evident from the occurrence of increase in plug pressure due to the increase in tunnel pressure. This could have occurred only under the circumstance of the plug reducing in volume. The volume reduction, considering the cylindrical wall was constrained by the tunnel wall and the front end cap was exposed to only atmospheric pressure on the outside, was due to the shrinking of rear hemispherical end cap and pushing of whole volume of plug water towards the front end cap under pressure. The front 
end cap being constrained by the webbings results in reduction in volume increasing pressure. Since, this is a closed system of water mass, the occurrence can be defined by the equation:

$$
\begin{gathered}
P V=K \\
\{\mathrm{P}=\text { Pressure, } \mathrm{V}=\text { Volume }\}
\end{gathered}
$$

Another important factor as noted from Table 4.6 that the external pressure reaches to about $81 \%$ of the internal pressure before the plug slips. This was the highest ratio of external to internal pressure noted for the initial set of testing.

\subsection{Extended Slippage Testing}

The extended set of test was conducted within the plug pressure range of $10-40$ psi. It was hence used to evaluate the mechanical behavior of plugging system in the tunnel by varying other parameters like the plug cylindrical length or the plug mass. This lower pressure range for testing was to ensure a longer life of the plug.

The tests were conducted by varying the following parameters of the quarter scale tunnel system:

1. The plug effective contact length with the tunnel concrete was reduced by covering a part of tunnel wall with low friction materials like Teflon and Polyethylene (plastic) of

$1 / 32$ " thickness. This was to determine the effect of different values of reduced effective contact length of the plug with the Tunnel concrete.

2. Determine the effect of mass of the plug on the phenomenon of slippage.

\subsubsection{I nvestigating Effective Contact Length on Tunnel Concrete}

All the tests summarized in Table 4.7 were conducted with the plug pressure falling to approach tunnel pressure. The following tests were conducted for the evaluation of the above parameter.

Tests 1-13 were conducted to ascertain the effect of reducing the effective contact length of the plug for objective as stated above in 1. Test\#13 acted as a control for this set of test.

For Table 4.8, ' $\mathrm{L}_{\mathrm{re}}$ ' stands for approximate reduced effective plug contact length of the plug on tunnel concrete wall; " $p_{e}$ " is external (tunnel) applied pressure; " $p_{i}$ " is internal (plug) pressure for slip.

For Table 4.9, "Le" is the effective plug contact length. All the other notations have the same meaning. 
Table 4.7: Test matrix for extended slippage testing

\begin{tabular}{|c|l|}
\hline Test\# & \multicolumn{1}{|c|}{ Test Description } \\
\hline 1 & $30^{\prime \prime}$ width plastic covering 26" of cylindrical length of plug from the back rope \\
\hline 2 & $30^{\prime \prime}$ width plastic covering 16" of cylindrical length of plug from the back rope \\
\hline 3 & $30^{\prime \prime}$ width plastic covering 12" of cylindrical length of plug from the back rope \\
\hline 4 & $30^{\prime \prime}$ width Teflon covering $26^{\prime \prime}$ of cylindrical length of plug from the back rope \\
\hline 5 & $30^{\prime \prime}$ width Teflon covering 16" of cylindrical length of plug from the back rope \\
\hline 6 & $30^{\prime \prime}$ width Teflon covering 12" of cylindrical length of plug from the back rope \\
\hline 7 & $30^{\prime \prime}$ width Teflon covering of cylindrical length of plug in the middle. \\
\hline 8 & $30^{\prime \prime}$ width Teflon covering 26" of cylindrical length of plug from the front rope \\
\hline 9 & $30^{\prime \prime}$ width Teflon covering 16" of cylindrical length of plug from the front rope \\
\hline 10 & $30^{\prime \prime}$ width Teflon covering 12" of cylindrical length of plug from the front rope \\
\hline 11 & Clean concrete but front part of plug on previous test's scraped adhesive \\
\hline 12 & Clean concrete but rear part of plug on previous test's scraped adhesive \\
\hline 13 & Control: Clean concrete plug moved forward beyond the scraped surface \\
\hline
\end{tabular}

\subsubsection{Observations}

Each set of slippage tests at particular slippage pressure were repeated for five iterations. The general observations were as follows:

1. The holding resistance was the least for the first trial under most cases when compared to the other four trials for Tests\# 1-6.

2. For Tests\# 8-10, the holding resistance showed a distinct fall with the increase in iteration number.

3. The movement of the plug during the slippage with an average movement of 0.38 " inches for each individual test. Hence, ' $\mathrm{L}_{\mathrm{re}}$ ' as reduced effective contact length with the tunnel concrete of plug varied for each test.

4. During the occurrence of slippage the plug's front nose was observed to move downward along with moving forward towards right or left.

5. Slippage tests were generally accompanied by the usual "thudding" noise except for Tests\# 8-10. Tests\# 8-10 exhibited noiseless slippage which was detected only through laser readings.

6. Since the maximum permissible plug pressure for the tests were fixed at 40 psi (in order to increase the life of the plug), the first slippage pressure for the tunnel was deemed to be $30 \mathrm{psi}$. But the for Test\# 6 and Test\# 7, the first slippage pressure was reduced to around 20 psi, since the plug (40 psi) slipped with the tunnel pressure around 29 psi.

\subsubsection{Results}

Table 4.8 represents the test results for Tests\# 1-10 with the tunnel concrete covered with Teflon and plastic for different percentage of the length of the cylindrical section. Table 4.9 represents the retest on smooth tunnel concrete and adhesive scraped concrete of the tunnel lining. All the below tests listed in Table 4.8 had five trials. 
Table 4.8: Slippage test results with reduced effective length of plug on concrete (diagrams are not to scale)

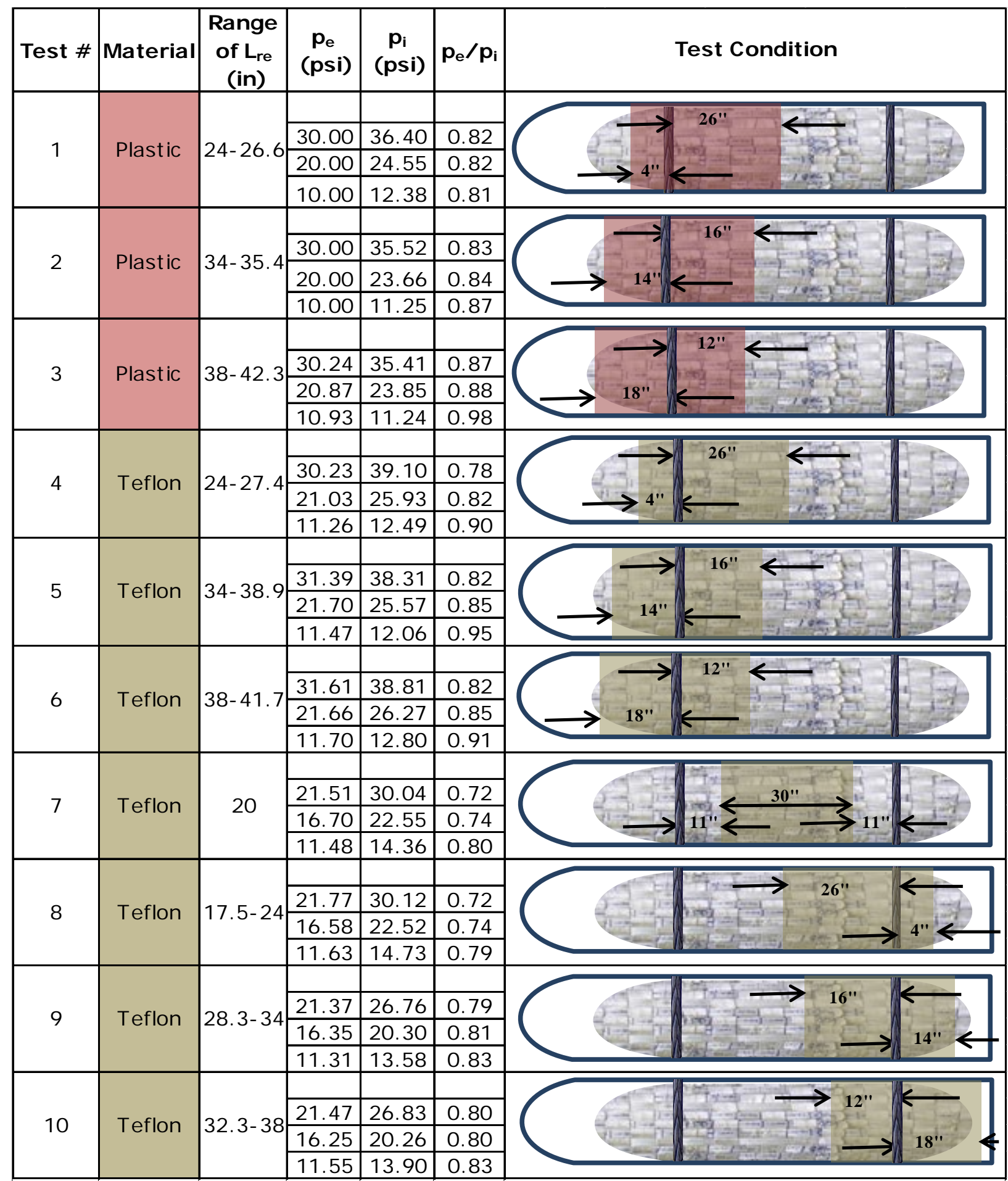


Table 4.9: Slippage test results with scraped and smooth tunnel wall

\begin{tabular}{|c|c|c|c|c|c|c|}
\hline Test \# & Material & $\mathrm{L}_{e}$ (in) & $\begin{array}{l}\mathrm{p}_{\mathrm{e}} \\
(\mathrm{psi})\end{array}$ & $\begin{array}{l}p_{i} \\
(p s i)\end{array}$ & $\mathrm{p}_{\mathrm{e}} / \mathrm{p}_{\mathrm{i}}$ & Test Condition \\
\hline \multirow{3}{*}{11} & \multirow{3}{*}{$\begin{array}{l}\text { Adhesive } \\
\text { Scraped } \\
\text { Concrete }\end{array}$} & \multirow{3}{*}{50} & 30.01 & 30.81 & 0.97 & \multirow{3}{*}{$\begin{array}{l}\text { Front } 10 " \text { cylindrical length on } \\
\text { adhesive scraped concrete }\end{array}$} \\
\hline & & & 20.31 & 20.47 & 0.99 & \\
\hline & & & 10.06 & 8.82 & 1.14 & \\
\hline \multirow{3}{*}{12} & \multirow{3}{*}{$\begin{array}{l}\text { Adhesive } \\
\text { Scraped } \\
\text { Concrete }\end{array}$} & \multirow{3}{*}{50} & 29.49 & 33.47 & 0.88 & \multirow{3}{*}{$\begin{array}{c}\text { Rear 10" cylindrical length on } \\
\text { adhesive } \\
\text { scraped concrete }\end{array}$} \\
\hline & & & 20.20 & 22.86 & 0.89 & \\
\hline & & & 9.82 & 9.58 & 1.00 & \\
\hline \multirow{3}{*}{13} & \multirow{3}{*}{$\begin{array}{l}\text { Normal } \\
\text { Smooth } \\
\text { Concrete }\end{array}$} & \multirow{3}{*}{50} & 29.99 & 32.78 & 0.92 & \multirow{3}{*}{ Smooth tunnel wall } \\
\hline & & & 20.14 & 20.91 & 0.95 & \\
\hline & & & 10.13 & 9.29 & 1.09 & \\
\hline
\end{tabular}

\subsubsection{Discussions}

As stated in the observation 1 above, the plot in Figure 4.11 shows the increase in pressure ratio with the increase in iteration number. This has a direct co-relation with the minor increase of reduced contact length of the plug with concrete. Observing the "Test Condition" of Test\# 1 in Table 4.8, it shows the effective contact length of the plug being covered by the plastic. With every test, the plug moves more towards the front of the tunnel, reducing the coverage area by the plastic on the plug, thereby minutely increasing the effective contact length of the cylindrical part of the plug with the wall of the tunnel (by about 1.7" for each iteration). It thereby increases the resistance of the plug to hold more tunnel pressure. Hence, it reflects the effect of small increase of cylindrical contact length of plug with slippage.

As again stated in observation 2, the pressure ratio showed a distinct fall with the iteration number. As can be seen from Table 4.8, Tests\# 8-10 under Test Condition, the schematic showed that as the tunnel slips towards the front of the tunnel, the cylindrical surface of the plug gains more contact with the Teflon surface, thereby reducing the limiting friction of the system by reducing the effective contact length with concrete. This leads to reduction in resistance with increase in iteration, reducing pressure ratios as shown in Figure 4.12. Both observations 1 and 2 effectively reflect the impact on the pressure ratio due to minor change of plug effective contact length with the concrete wall of the tunnel. 


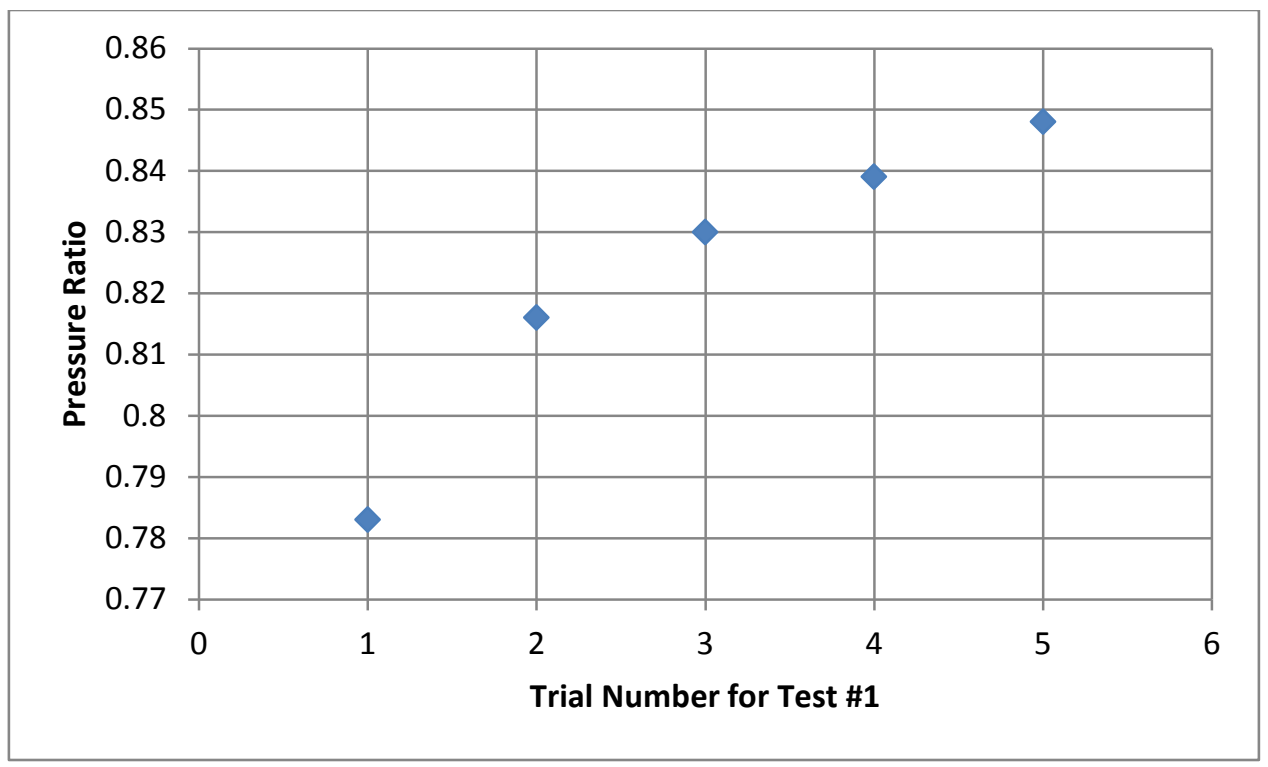

Figure 4.11: Representative holding resistance variation with trial number for Test \#1 for slippage at 30 psi as shown in Table 4.8

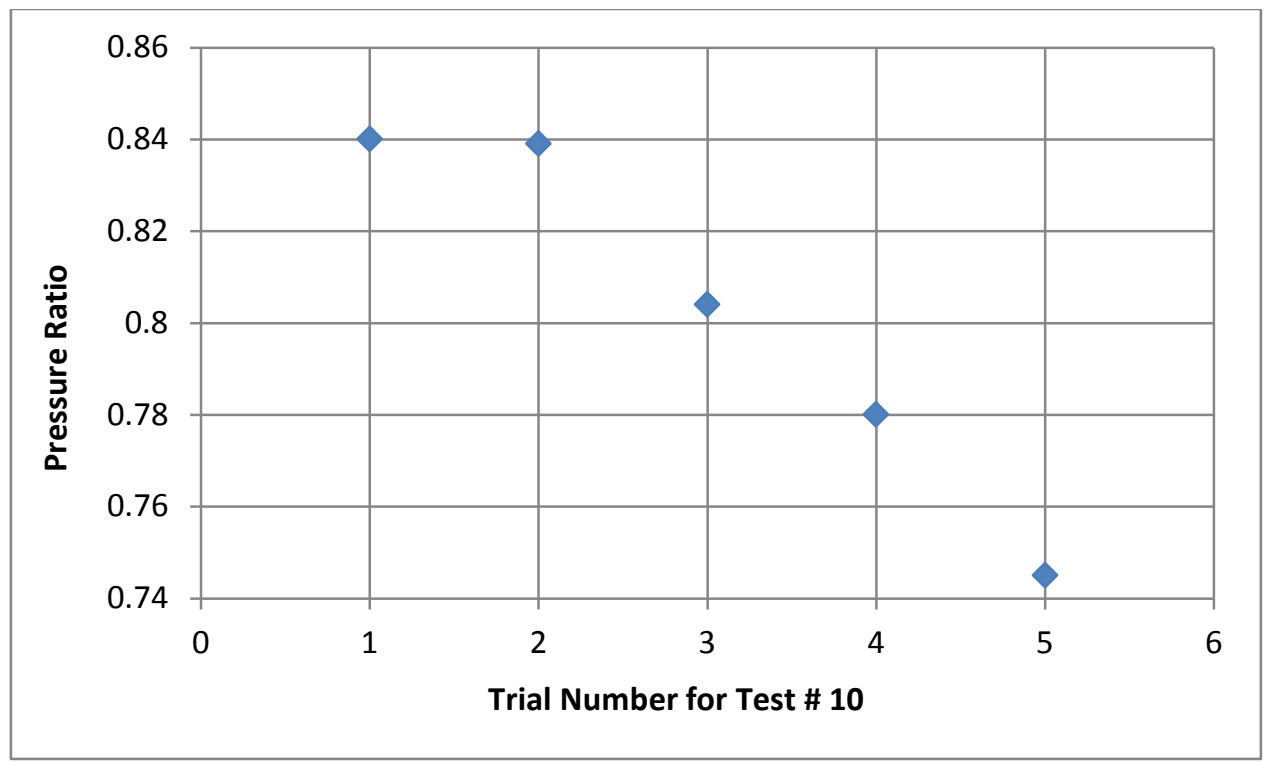

Figure 4.12: Representative holding resistance variation with trial number for Test \#10 for slippage at $\mathbf{3 0}$ psi as shown in Table 4.8

Observation 3 can be explained from the above discussion. Observation 5 reflects that the plug in the tunnel behaves more like a cork rather than a uniform seal with the cylindrical section being more in contact with the tunnel wall at the front than at the rear. This assumption can be further confirmed by visual inspection of the plug cylindrical surface webbings which showed more abrasion at the front of the cylinder than at the rear. Observation 4 also throws some light on this behavior. This phenomenon of the nose moving downward indicates the presence of a non-uniform distribution of frictional forces related to the effective contact area, making the top of the front part move against the 
tunnel roof resulting in the thudding noise. This lack of thudding noise for Tests\# 8-10 gets mitigated by the Teflon covering on the tunnel wall giving the impression of a cork.

Observation 6 for Tests\# 7 and Test\# 8 primarily results due to the use of Teflon which drastically reduces the effective contact length. Anomaly of this behavior can be noted since, for a similar condition of Test\# 4 where the tunnel wall was covered at the rear of the plug with Teflon (with 26" from the rear rope) there was no early slip as in the case of Test\# 8. This again reaffirms the plug behaving as a cork up front.

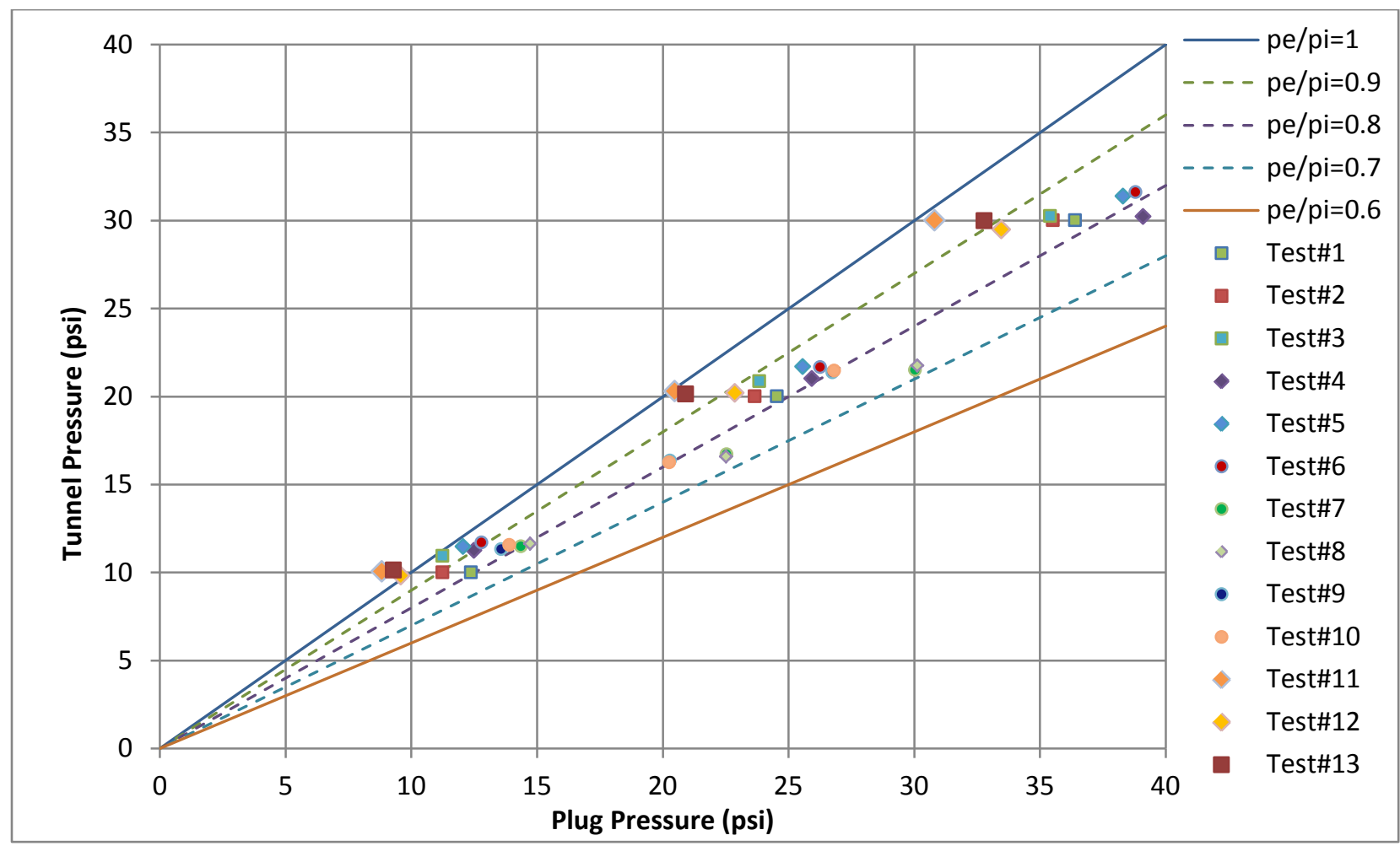

Figure 4.13: Holding resistances for Tests\# 1 - 13

In Figure 4.13, "pe/pi" implies the ratio of external (Tunnel Pressure) to internal pressure (Plug Pressure). The higher the holding resistance, the higher was the resistance of the plug to hold tunnel pressure. Discussions for Figure 4.13 are as follows:

1. Tests\# 1-3 and Tests\# 4-6, the holding resistance increases with the reduction in plastic/Teflon length covering the rear cylindrical surface (see "Test Condition" Table 4.8).

2. Test\# 1 and Test\# 4 had the same configuration with different material Plastic for Test\# 1 and Teflon for Test\# 4. When the holding resistances were considered for the two tests, it was observed that they were similar at lower pressure, but the gap widened at higher pressure slip, with the value for Teflon being lower than that for plastic. This reflected the effectiveness of Teflon as a low friction material when compared to plastic.

3. Comparing Test\# 2 with Test\# 5 showed the same comparison as the comparison between Test\# 1 and Test\# 4. 
4. Comparing Test\# 3 and Test\# 6 revealed lower holding resistances at all level of pressures for slip for Test\# 6.

5. Test\# 7 and Test\# 8 showed the minimum of the holding resistances varying from 0.7 to 0.75 . Test\# 7 has the maximum cover of Teflon surface among all the surface modifications (see Table 4.8) implying the minimum effective contact length with the tunnel wall. Test\# 8 was an anomaly considering that Test\# 4 reflected similar set up, except that the Teflon was covering the rear cylindrical length in Test\# 4. This reflects the impact of cylindrical surface on the front compared to the rear.

6. Test\# 9 and Test\# 10 reflects similar results with holding resistances higher than Test\# 8 as expected with reduced Teflon cover.

7. Tests\# 11, Test\# 12 and Test\# 13 showed similar results at lower pressures (10psi) but showed more variability at higher pressures. Test\# 11 showed higher holding resistance (by almost 0.1 ) at a higher pressure (around 30 psi) compared to Tests\# 12 and Test\# 13. This implies the greater impact of abraded concrete surface at the front cylindrical surface than at the rear. A picture of abraded tunnel concrete lining due to scraping of the adhesive is shown in Figure 4.14.

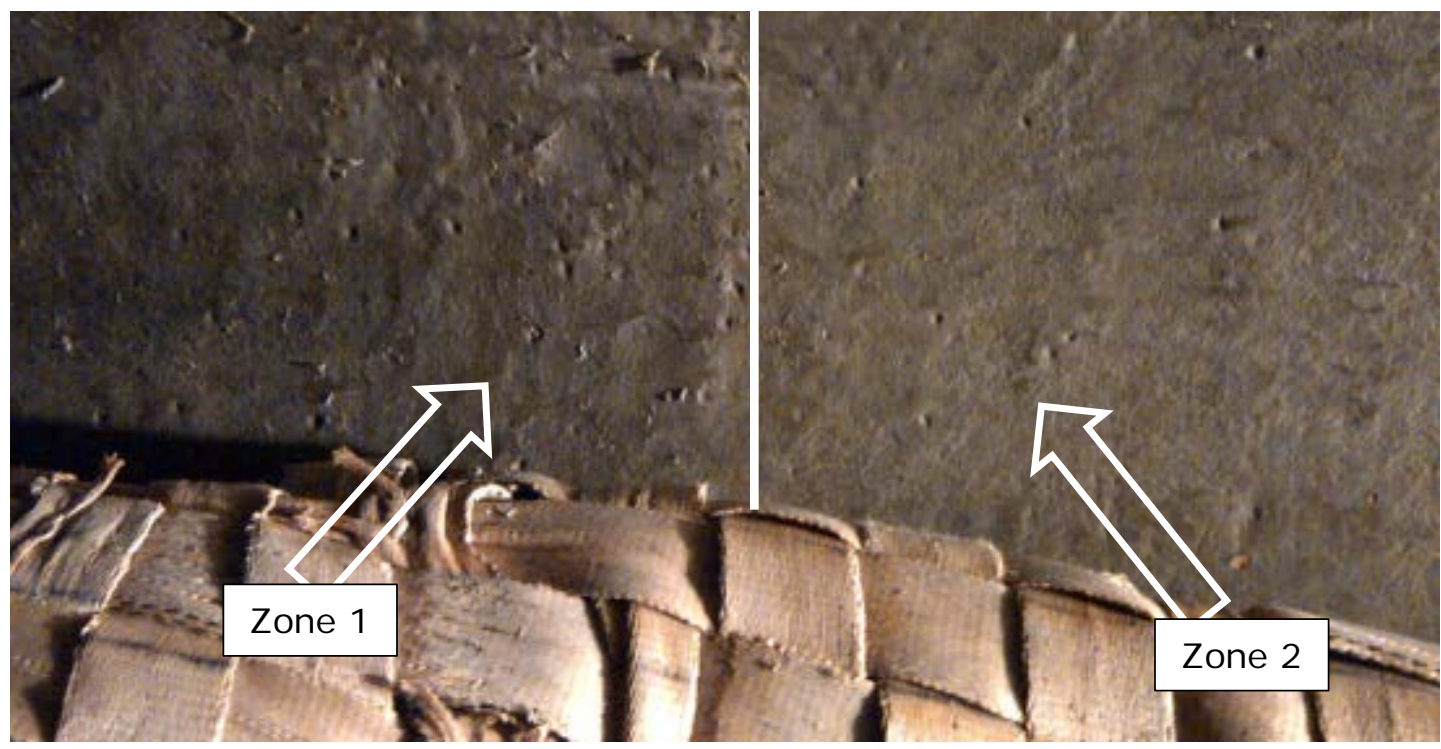

Figure 4.14: Different tunnel concrete lining 1) abraded zone 2) un-abraded surface

\subsubsection{I nvestigating Effect of Plug Mass}

The plug was filled up with water to a hydrostatic pressure of 2 psi in order to determine volume of water flowing in to the plug to make it completely full i.e. till the point all the air in the plug gets pushed out.

The plug volume was geometrically computed considering cylindrical length of 45", spherical/cylindrical diameter as 48" (considering confined inflation) and material thickness as $0.25 "$ to be $135857.5 \mathrm{in}^{3}$ or 588 gallons. The flow rate for garden hose was 8.87 gallons/minute and the volume of water to push all the air out and reach a hydrostatic pressure of about 2 psi was 550 gallons. The total average time taken to fill the plug was 57 
minutes. The following tests were conducted to evaluate the effect on plug slip with variable plug mass as shown in Table 4.10:

Table 4.10: Test matrix for plug mass effect

\begin{tabular}{|c|l|}
\hline Test\# & \multicolumn{1}{|c|}{ Test Description } \\
\hline M-1 & Control: Plug with $100 \%$ water by volume \\
\hline M-2 & Plug with $90 \%$ water by volume and air pressurizing \\
\hline M-3 & Plug with $75 \%$ water by volume and air pressurizing \\
\hline M-4 & Plug with $50 \%$ water by volume and air pressurizing \\
\hline
\end{tabular}

Test M-1 to M-4 was conducted to ascertain the effect of the mass of the plug to the phenomenon of slippage. The pressure ranges for the plug was between 0-40 psi for these tests. Test\# M- 1 was the control for this set of test. All the above tests were conducted with the tunnel pressure approaching the plug pressure for slip.

The volume of water to fill the plug up completely to 2 psi hydrostatic pressure was noted. Now since, volume of water in the plug is directly proportional to the mass of water in the plug; the plug was drained by $10 \%$ of the water by mass to reach $90 \%$ of plug water by volume. While draining the water the plug was pressurized by connecting the air supply (from the air compressor) to the air release port. The above slippage tests were then conducted by increasing the tunnel pressure towards the plug pressure.

\subsubsection{Results}

Table 4.11 shows the result for slippage with varying plug mass from $100 \%$ to $50 \%$.

Table 4.11: Test results for mass impact on slippage

\begin{tabular}{|c|c|c|c|c|c|}
\hline Test \# & $\begin{array}{l}\mathrm{L}_{\mathrm{e}} \\
\text { (in) }\end{array}$ & $\begin{array}{l}\mathrm{p}_{\mathrm{e}} \\
(\mathrm{psi})\end{array}$ & $\begin{array}{c}p_{i} \\
(p s i)\end{array}$ & $\mathrm{p}_{\mathrm{e}} / \mathrm{p}_{\mathrm{i}}$ & $\begin{array}{c}\text { Test } \\
\text { Condition }\end{array}$ \\
\hline \multirow{4}{*}{ M-1 } & \multirow{4}{*}{50} & 35.08 & 40.20 & 0.85 & \multirow{4}{*}{$\begin{array}{c}100 \% \\
\text { Water }+ \\
0 \% \text { Air by } \\
\text { Volume }\end{array}$} \\
\hline & & 27.14 & 30.40 & 0.89 & \\
\hline & & 18.76 & 20.19 & 0.93 & \\
\hline & & 10.66 & 10.28 & 1.03 & \\
\hline \multirow{4}{*}{$M-2$} & \multirow{4}{*}{50} & 34.54 & 40.16 & 0.83 & \multirow{4}{*}{$\begin{array}{c}90 \% \\
\text { Water + } \\
10 \% \text { Air } \\
\text { by Volume }\end{array}$} \\
\hline & & 26.06 & 30.03 & 0.87 & \\
\hline & & 17.92 & 20.25 & 0.88 & \\
\hline & & 9.64 & 10.24 & 0.94 & \\
\hline \multirow{4}{*}{ M-3 } & \multirow{4}{*}{50} & 33.70 & 40.14 & 0.81 & \multirow{4}{*}{$\begin{array}{c}75 \% \\
\text { Water + } \\
25 \% \text { Air } \\
\text { by Volume }\end{array}$} \\
\hline & & 25.82 & 29.90 & 0.86 & \\
\hline & & 17.87 & 20.09 & 0.89 & \\
\hline & & 10.19 & 10.26 & 0.99 & \\
\hline \multirow{4}{*}{$M-4$} & \multirow{4}{*}{50} & 35.52 & 40.02 & 0.86 & \multirow{4}{*}{$\begin{array}{c}50 \% \\
\text { Water + } \\
50 \% \text { Air } \\
\text { by Volume }\end{array}$} \\
\hline & & 27.53 & 30.19 & 0.91 & \\
\hline & & 19.37 & 20.38 & 0.95 & \\
\hline & & 11.26 & 10.59 & 1.06 & \\
\hline
\end{tabular}




\subsubsection{Discussions}

The volume of water required to fill the plug was only 550 gallons showing an offset of 38 gallons. The only possible reason for this discrepancy being that the plug was compressing considerable amount of air. This reason though could be ruled out due to the issuance of steady jet of water from the air release port.

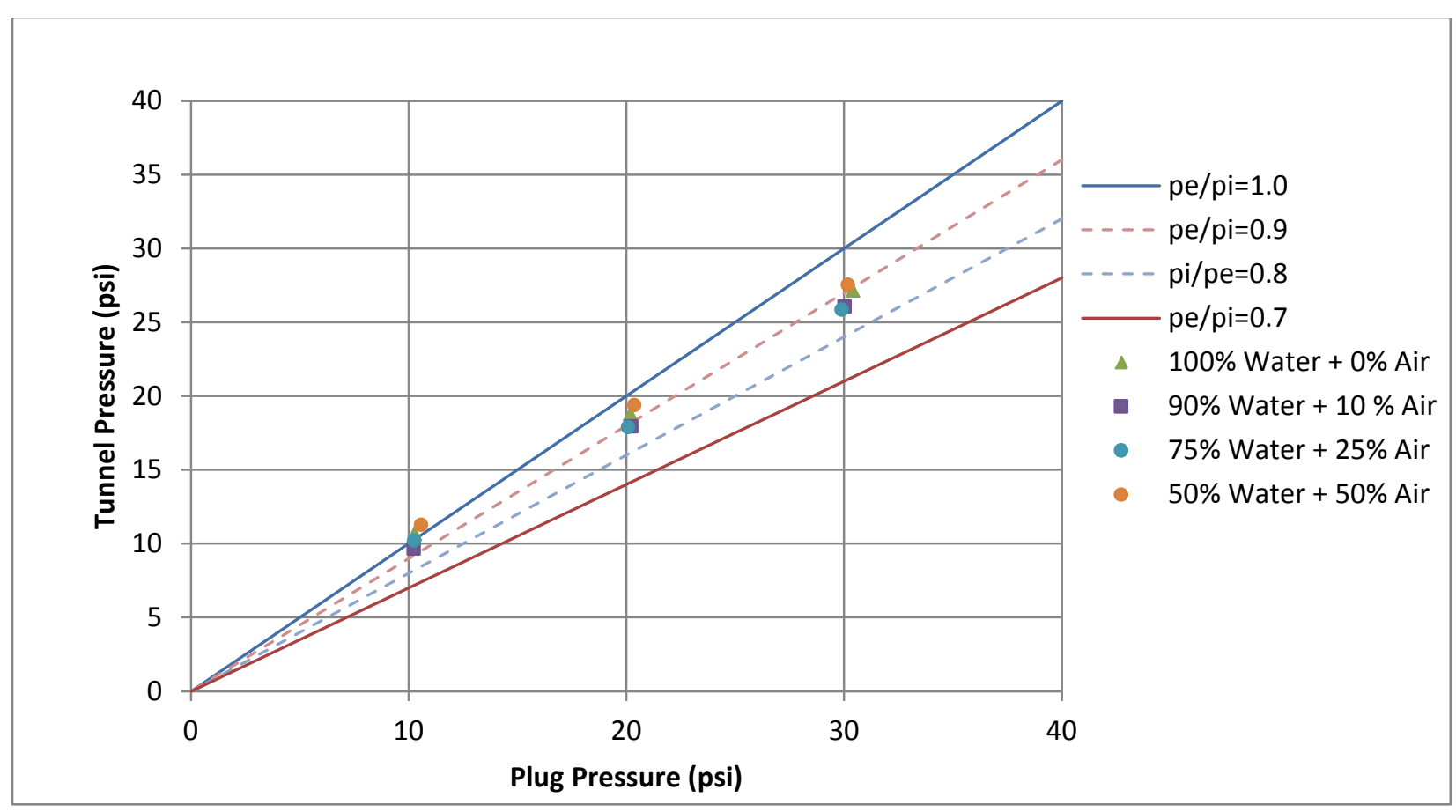

Figure 4.15: Holding resistance plot for change in mass

Careful observation of Figure 4.15 reveals that the change in behavior at slip of the plug with the change in mass was negligible from $100 \%$ to $75 \%$ range of variation of plug mass.

Test\# M-4 shows the maximum holding resistance. During the slippage of the plug with $100 \%$ water (100\% plug mass), the presence of hydrostatic pressure may lead to lesser acting plug pressure at the top than at the bottom of the tunnel wall. This in turn can reduce the normal forces contributing to friction at the top of the plug cylindrical wall than the bottom. Now with the variation of the plug mass and the air pressurization to $50 \%$ by volume, pressure exerted by the air at the top of the water was same read by the sensor at the bottom, resulting in more uniform normal reaction contributing to friction. This may have resulted in higher holding resistance for the case of slippage with $50 \%$ air by volume in the plug. Further studies need to be carried out with higher percentages of air by volume to ascertain the exact impact of plug mass on slip. 


\subsection{Holding resistance comparison for testing on tunnel concrete}

A comparison of the initial, extended and single layered Vectran plug [17] slippage testing was carried out. The comparison between initial and extended testing spells the effect of repeated use of the plug over a period of time. The comparison with available data in [17] was merely to differentiate the two plugs: single layer Vectran and the tri-layered closed webbed plug functionally. Figure 4.16 shows the pressure ratios for three representative cases for slippage on smooth tunnel concrete. Single layered plug data was obtained from [17], tri-layered-1: average slippage holding resistance obtained from initial set of testing (Table 4.4, Table 4.5 and Table 4.6) and tri-layered-2: average slippage holding resistance obtained from extended test shown in Table 4.9 under "Test condition" "Smooth tunnel wall."

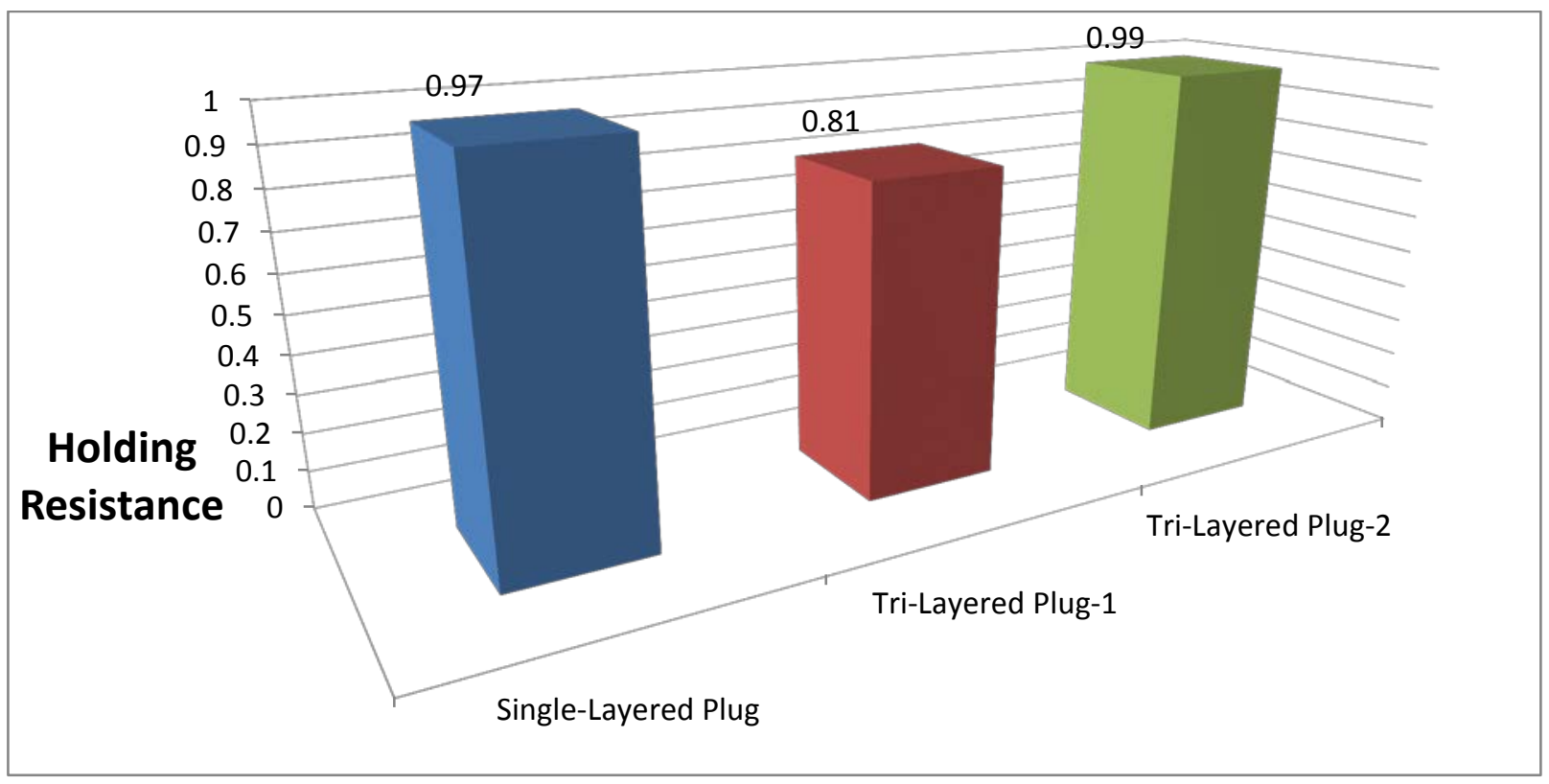

Figure 4.16: Holding resistance comparison

The most remarkable revelation from the above Figure 4.16 was the marked difference in holding resistances for various levels of pressure between the tri-layered plug initial and tri-layered plug extended tests. The initial test holding resistances hovered around the 0.81 while for the extended testing it varied from a lowest of 0.9 at higher pressures to above 1.0 at lower pressures. This calls for further investigation for parameters that has prompted this variation. A close examination of the plug surface revealed abraded webbings due to continuous slippage test under constrained condition inside the tunnel which changed the surface condition of the plug. Possibly, this change of surface condition has facilitated an improvement in the coefficient of friction of the system leading to a higher level of resistance than the initial set of testing. A comparison of the condition of the external surface of the webbed Vectran plug is shown in Figure 4.17. It is be noted that the plug used in underground vehicular tunnel transit will not have abraded plug surface, but be fresh from factory. 
The single layered Vectran plug as indicated from [17] was only tested for slippage up to only 24 psi which hence provides pressure ratios at a much lower range as unlike the test conditions of the tri-layered plug undergoing the slippage at around 49 psi as the maximum pressure. But the comparison of the holding resistance at similar level of pressure for the single layer Vectran (around $25 \mathrm{psi}$ ) indicates proximity of results with tri-layered extended testing. But in reality the data should be compared to the initial testing of the trilayered plug, since the effect of abrasion of single layer Vectran fibers has not been considered in [17].
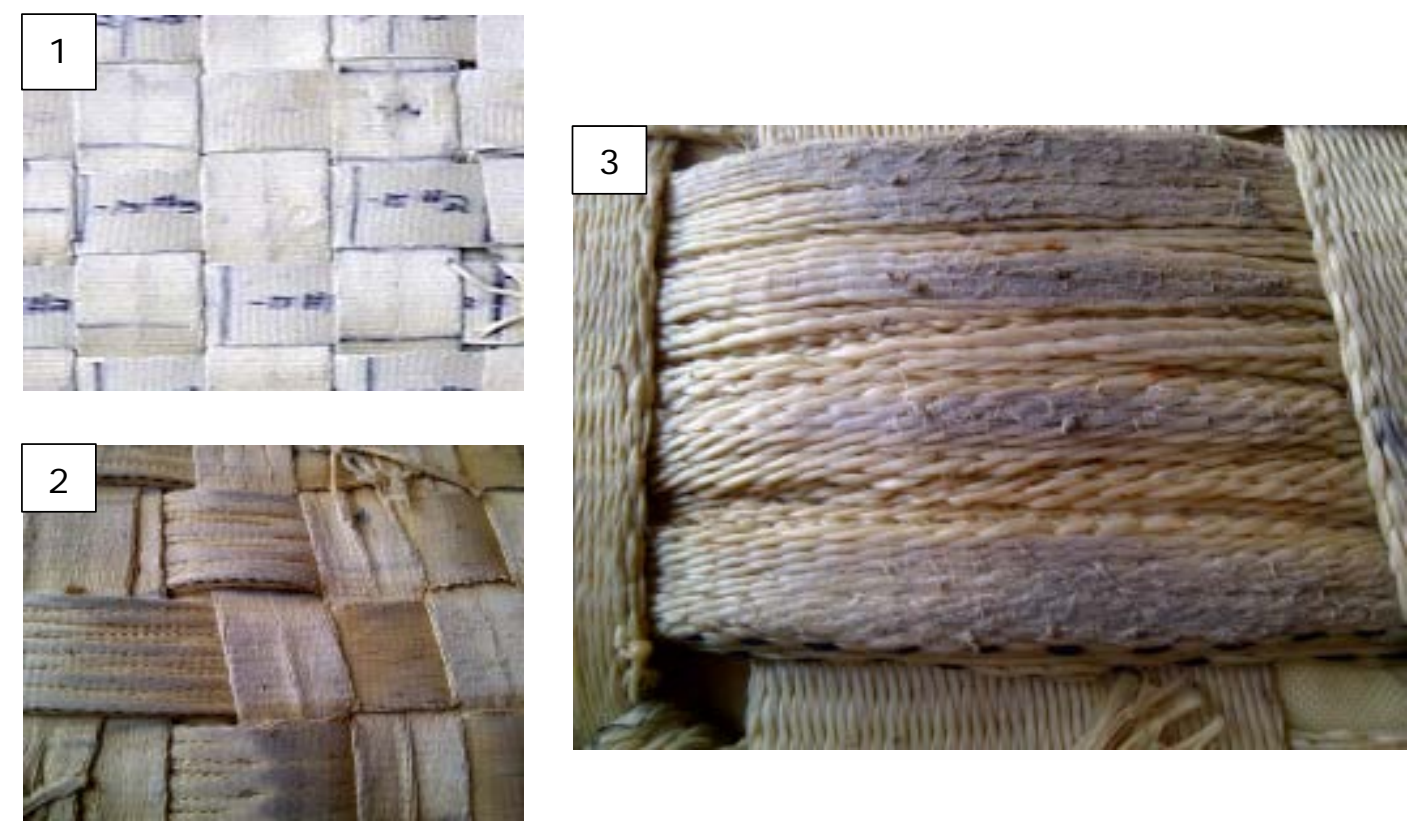

Figure 4.17: Webbing surface comparison: 1) initial plug surface prior to any testing, 2) plug surface for extended testing, 3) close up view of abraded Vectran webbing

The holding resistance for single layered Vectran plug was on average 0.97 whereas for tri-layered plug (initial tests), it was consistent around 0.80 . This was possibly due to the change in external texture and due to a reduction in the cylindrical length of the plug from 60" to 45". The other possible factor responsible for the reduction in holding resistance was the over-sizing of the plug with a maximum cylindrical diameter of 49" by only about $2 \%$ whereas the single layered Vectran was oversized by roughly $4.2 \%$. The evaluation of the effect of over-sizing was out of the scope of this work, but it is speculated that the results of that evaluation will provide further data that will contribute to the understanding of the variation of pressure ratios.

\subsection{Coefficient of Friction}

At the instance of slippage in the above experiments, the total force $\left(\mathrm{F}_{\text {ext }}\right)$ acting on the plug at a certain pressure due to the pressure of the water in the tunnel was assumed to be equal to the frictional force acting on the plug due to the normal force $(\mathrm{N})$ on the tunnel wall. The normal force $(\mathrm{N})$ was generated by the internal pressure applied in the plug 
through the cylindrical section of the plug. The contact area was the cylindrical section of the plug effectively in contact with the concrete lining of the tunnel.

The coefficient of friction would be calculated first by considering no hydrostatic pressure and only uniform pressure in the tunnel and plug. The coefficient of friction would then be computed by taking the hydrostatic pressure in the tunnel and the plug into consideration to understand the difference in results.

\subsubsection{Contact Length}

The contact length was evaluated while performing the test for constrained elongation inside the quarter scale tunnel (see Chapter 3 ). Chalk lines were set up at an orientation of $0^{\circ}, 90^{\circ}$ and $270^{\circ}$ (going clockwise see Figure 3.8) of the tunnel cross section. The plug was pressurized to its design pressure of $68 \mathrm{psi}$ and the maximum contact length of the plug with the tunnel wall was evaluated from the chalk line marks (after the plug was deflated). Results of the measurements are summarized in Table 4.12.

Table 4.12: Effective contact length measurement ( ' $\mathrm{L}_{\mathrm{e}}$ ')

\begin{tabular}{|c|c|c|}
\hline $\begin{array}{c}\text { Maximum Plug } \\
\text { Pressure (psi) }\end{array}$ & $\begin{array}{c}\text { Angular Position on } \\
\text { the Tunnel Wall }\left(^{\circ}\right)\end{array}$ & $\begin{array}{c}\text { Effective Contact } \\
\text { length (in) }\end{array}$ \\
\hline 68 & 0 & 44 \\
\hline 68 & 90 & 51.5 \\
\hline 68 & 270 & 54.25 \\
\hline
\end{tabular}

The 'Effective Contact length' $\left(L_{e}\right)$ at $0^{\circ}$ orientation was the least as it was observed that the plug has a tendency of drooping with the weight of water in it at the spherical end caps. The design geometrical cylindrical length of the plug was 45" indicating that part of the spherical end caps were becoming part of the cylindrical portion of the plug due to the $2 \%$ oversizing. Hence, the Effective Contact length for further computation was taken as $50 "$.

\subsubsection{Friction Coefficient Excluding Hydrostatic Pressure}

\subsubsection{Assumptions}

The assumptions on which the friction coefficient was computed were as follows:

1. The hemispherical end cap radius of the plug was equal to the internal radius of the tunnel.

2. The applied pressure in the plug $\mathbf{p}_{\mathbf{i}}$ was assumed to be uniform everywhere inside the plug.

3. The applied pressure in the tunnel $\mathbf{p}_{\mathbf{e}}$ was assumed to be uniform everywhere inside the tunnel.

4. The front and the rear end caps of the plug were assumed to be perfect hemispheres.

5. The hemispherical end cap on the rear end of the plug was assumed to have no vertical displacement with respect to the tunnel i.e. the sum of all the vertical forces on the end cap due to external pressure $\mathbf{p}_{\mathbf{e}}$ was zero. 
6. The hemispherical cap on the rear end of the plug was assumed to have no lateral displacement with respect to the length of the tunnel i.e. the sum of all the lateral forces on the end cap due to external pressure $\mathbf{p}_{\mathbf{e}}$ was zero.

7. The cylindrical wall of the plug was assumed to be in perfect contact with the wall of the tunnel. The net cylindrical contact length was obtained from the Section 4.6.1, i.e. 50".

8. The hemispherical end cap on the rear end of the plug was assumed to have remained in shape during the application of external pressure.

\subsubsection{Computation of Forces Governing Equilibrium}

Computation of External Force $\left(F_{\text {ext }}\right)$ on the Hemispherical Surface:

External Pressure $=\mathbf{p}_{\mathbf{e}}$

The equation for Force is given by [29]:

$$
F_{\text {ext }}=\iint P * d A
$$

Figure 4.18 represents an isometric view of a normal component of the external (tunnel) pressure acting on the rear end cap of the plug along with the projection of the horizontal semicircle at the height of the hemisphere at which this representative component of the pressure is acting. Figure 4.19 shows the dimensions infinitesimal rectangular area on the rear end cap on which the representative pressure vector is acting.

The infinitesimal small area ' $d A^{\prime}$ ' on the surface of the hemisphere is defined by Figure 4.19:

$$
d A=R * d \theta * R * \sin \theta * d \varphi
$$

As per the assumptions $(5,6)$ the component of forces $\mathrm{P}_{\mathrm{ae}} \cos \theta * d A$ (vertical) and $\mathrm{P}_{\mathrm{ae}} \sin \theta * \cos \varphi * d A$ (lateral) (from Figure 4.18) are cancelled out due to the symmetry of the hemispherical surface. The net force on the hemisphere acts only in the horizontal direction towards the open mouth of the tunnel. Hence, considering the horizontal component of force from the above Figure 4.18, ' $P$ ' from equation (4.2) where $P_{a e}=p_{e}$ (since the water pressure was assumed uniform everywhere):

$$
P=p_{e} * \sin \theta * \sin \varphi
$$




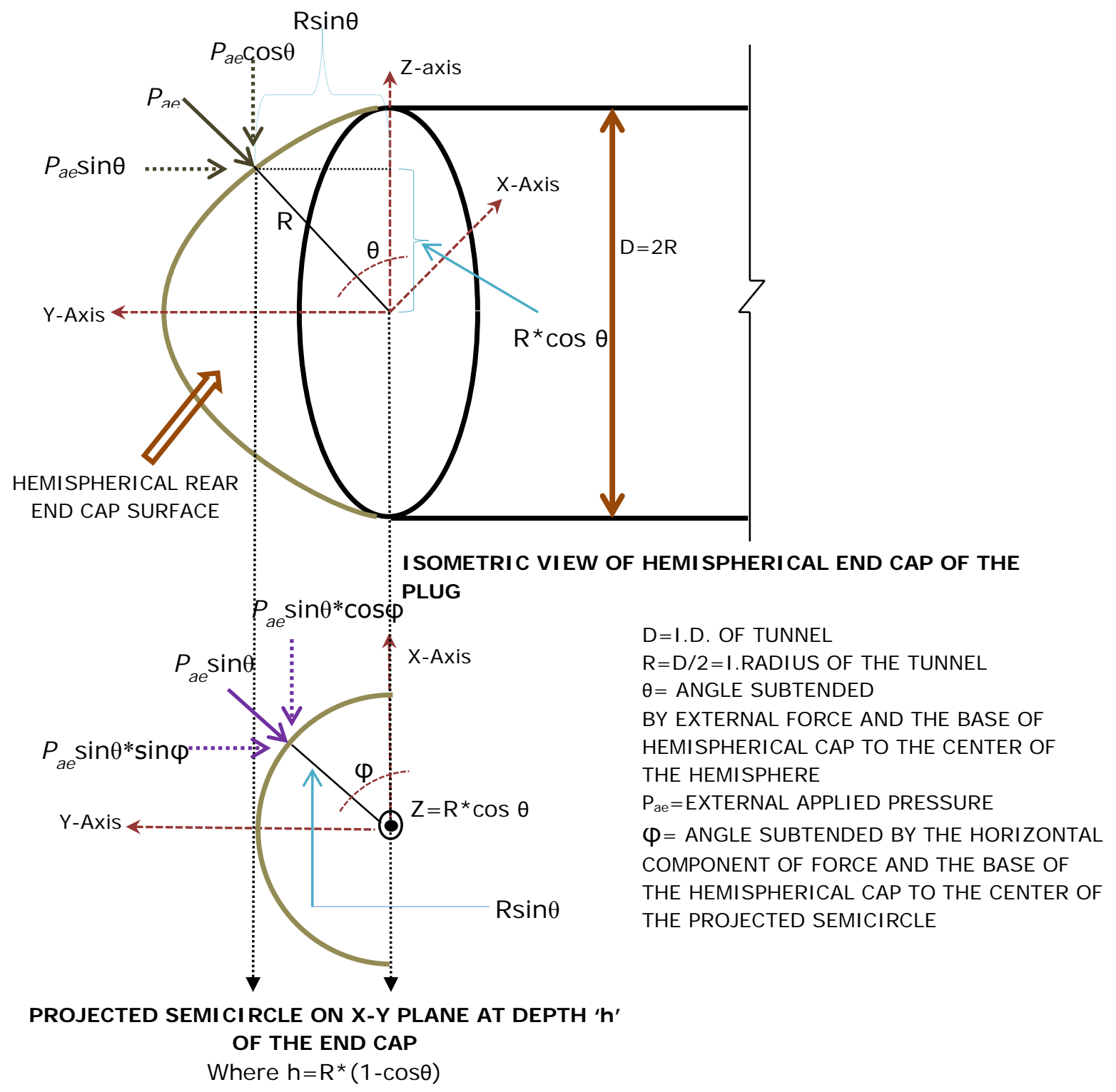

Figure 4.18: Representation of external pressure on the rear end cap

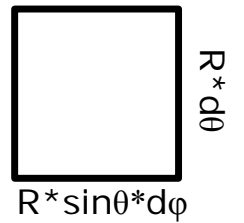

Figure 4.19: I nfinitesimal area 'dA' 
Substituting for ' $P$ ' and ' $d A$ ' from equation (4.3) and (4.4) respectively in (4.2) and taking integration limit for $0 \leq \theta \leq \Pi$ (for covering the height of the hemispherical surface from 0 to $D$; (see Figure 4.18) and for $0 \leq \phi \leq \Pi$ (for covering $180^{\circ}$ horizontal sweep of the semicircle at a certain depth of the hemisphere $\left.=R^{*}(1-\cos \theta)\right)$ the integral form of net external force $\left(F_{\text {ext }}\right)$ on the rear end cap will be:

$$
F_{\text {ext }}=\int_{0}^{\pi} \int_{e} p_{e} \sin \theta * \sin \varphi * R * R * \sin \theta * d \theta * d \varphi
$$

' $p_{e}$ ' and ' $R$ ' in equation (4.5) are constants and can be taken out of the integral. Evaluating the double integral in equation (4.5) we get:

$$
F_{\text {ext }}=p_{e} * 3.1415 * R^{2}
$$

The above equation is same as the equation of force from uniform external pressure applied on the circular projected area of the sphere of radius ' $R$ ' on $X-Z$ plane (Figure 4.18).

Hence, it can be concluded that when the hydrostatic pressure in the tunnel is ignored, the area of influence for calculating the $F_{\text {ext }}$ can be taken as the area of the projected circle on the $\mathrm{X}-\mathrm{Z}$ plane (i.e. $A=\pi^{*} \mathrm{R}^{2}$ ).

Computation of Internal Normal Force $(\mathrm{N})$ on the cylindrical surface of the plug:

The friction caused by the normal force on the wall of the tunnel is dependent on:

- Magnitude of applied internal pressure

- Area of contact between the plug and the tunnel

- Surface conditions of the plug and the tunnel wall.

Figure 4.20 shows the representation of uniform internal pressure acting on cylindrical section.

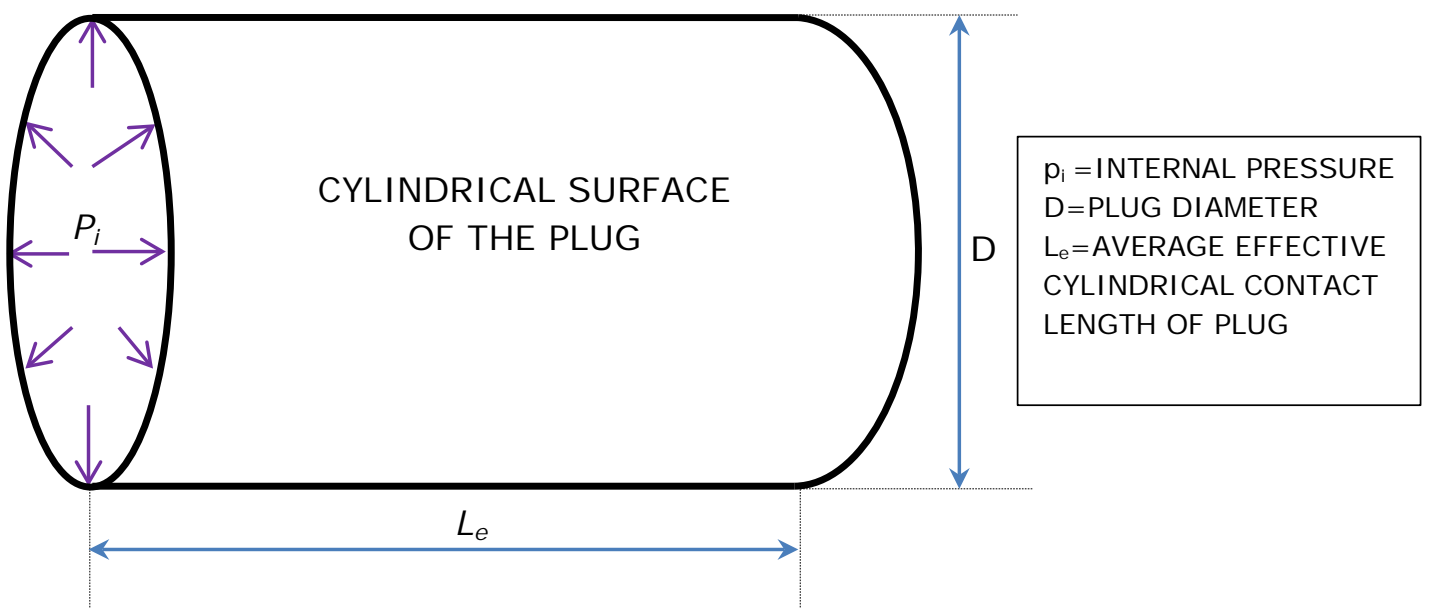

Figure 4.20: Cylindrical surface detail of the plug 
From Figure 4.20, the contact area of the plug based on assumption 7 was equal to the cylindrical surface area of the plug ' $S$ ' where:

$$
\begin{gathered}
S=\pi * D * L_{e} \\
N=p_{i} * S
\end{gathered}
$$

Substituting Equation (4.7) in Equation (4.8) we get:

$$
N=p_{i} * \pi * D * L_{e}
$$

For the coefficient of friction $(\mu)$ the external force on the plug is equal to the limiting friction of the system. The limiting friction of the system can be defined by both the internal and the external pressures at which slippage happens.

From classical laws of friction [30], the coefficient of friction $(\mu)$ is computed using (4.9) and (4.6):

$$
\begin{gathered}
\mu=\frac{F_{\text {ext }}}{N} \\
\mu=\frac{p_{e} * R}{p_{i} * 2 * L_{e}}
\end{gathered}
$$

\subsubsection{Friction Coefficient Considering Hydrostatic Pressure}

\subsubsection{Assumptions}

The following were the assumptions for computing coefficient of friction taking hydrostatic pressure into consideration:

1. The hemispherical end cap radius of the plug was equal to the internal radius of the tunnel.

2. The applied pressure in the plug $\mathbf{p}_{\mathbf{i}}$ was assumed to vary hydrostatically from the top to the bottom inside the plug with the pressure measured generally at the bottom.

3. The applied pressure in the tunnel $\mathbf{p}_{\mathbf{e}}$ was assumed to be varying hydrostatically inside the tunnel with the pressure generally measured at the halfway of the depth of the tunnel.

4. The front and the rear end caps of the plug were assumed to be a perfect hemispherical.

5. The hemispherical end cap on the rear end of the plug was assumed to have no vertical displacement with respect to the tunnel i.e. the sum of all the vertical forces on the end cap due to external pressure $\mathbf{p}_{\mathbf{e}}$ was zero.

6. The hemispherical cap on the rear end of the plug was assumed to have no lateral displacement with respect to the length of the tunnel i.e. the sum of all the lateral forces on the end cap due to external pressure $\mathbf{p}_{\mathbf{e}}$ was zero. 
7. The cylindrical wall of the plug was assumed to be in perfect contact with the wall of the tunnel. The net cylindrical contact length was obtained from the Section 4.6.1, i.e. 50".

8. The hemispherical end cap on the rear end of the plug was assumed to have remained in shape during the application of external pressure.

\subsubsection{Computation of Forces Governing Equilibrium}

Computation of external force $\left(F_{\text {ext }}\right)$ due to external pressure reading ' $\mathrm{P}_{\mathrm{e}}$ ':

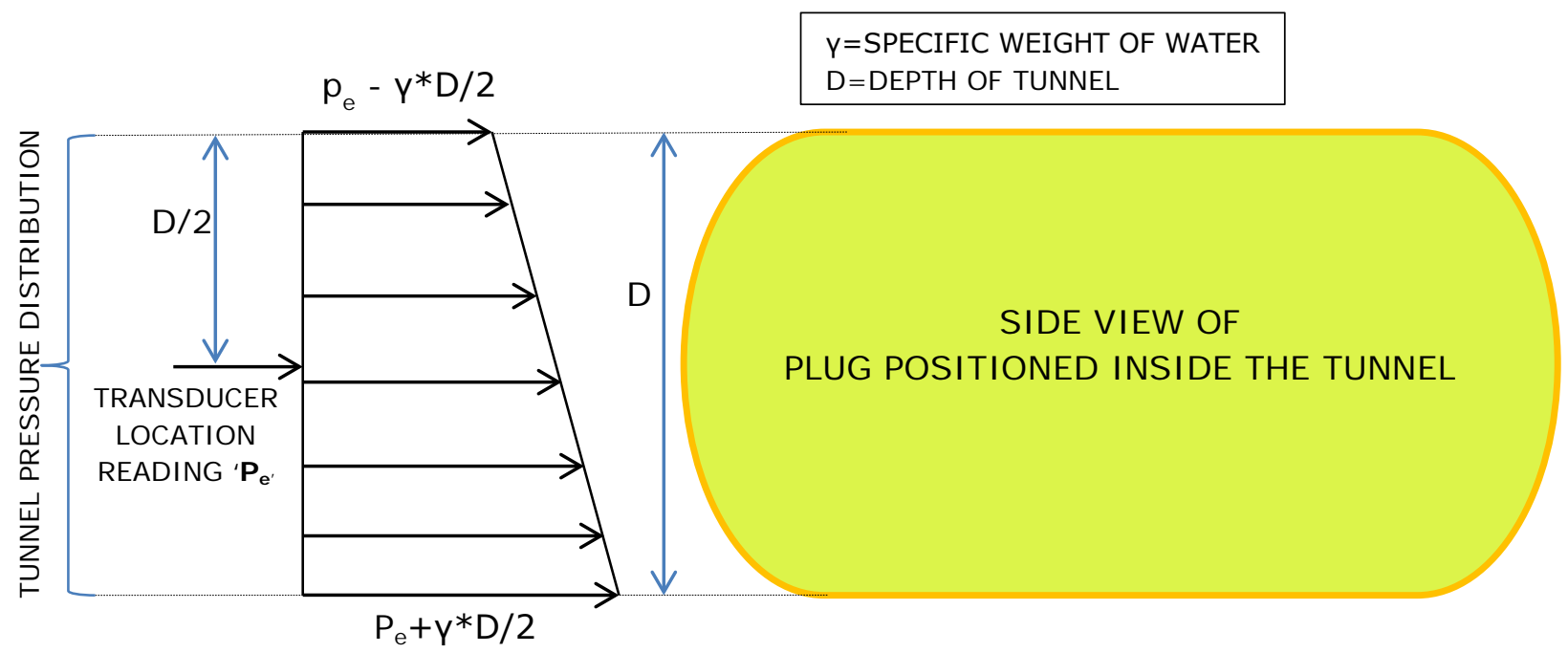

Figure 4.21: Hydrostatic tunnel pressure distribution

From the above Figure 4.21 the constant component of pressure across the depth of the tunnel ' $\mathrm{P}_{\text {ce }}$ ' is given by:

$$
P_{c e}=p_{e}-\gamma * \frac{D}{2}
$$

Equation (4.2) gives the formula for the total applied force. Referring to Figure 4.18 the pressure value ' $\mathrm{P}_{\mathrm{ae}}$ ' which defines the applied pressure at a certain depth, defined the value of ' $\theta$ ' (as referred to in Figure 4.18). ' $P_{a e}$ ' at a depth of $R^{*}(1-\cos \theta)$ as shown in Figure 4.18 and using equation (4.11):

$$
P_{a e}=P_{c e}+\gamma * R *(1-\cos \theta)
$$

Combining equation (4.3) \& (4.12) and substituting in equation (4.2) we get:

$$
F_{\text {ext }}=\iint_{0}^{\pi}\left(P_{c e}+\gamma * R *(1-\cos \theta)\right) * \sin \theta * \sin \varphi * \sin \theta * R^{2} * d \theta d \varphi
$$


Substituting equation (4.6) in equation (4.13a) we get:

$F_{\text {ext }}=P_{c e} * \pi * R^{2}+\iint_{0}^{\pi} \gamma * R^{3} *(1-\cos \theta) *(\sin \theta)^{2} * \sin \varphi * d \theta d \varphi$

Evaluating the integral in equation (4.13b) we have:

$$
F_{\text {ext }}=P_{c e} * \pi * R^{2}+\pi * \gamma * R^{3}
$$

The above equation is same as the equation of force from hydrostatic external pressure applied on the circular projected area of the sphere of radius ' $R$ '.

Hence, it can be concluded that even when the hydrostatic pressure in the tunnel is considered, the area of influence for calculating the $F_{\text {ext }}$ can be taken as the area of the projected circle (i.e. $A=\pi^{*} R^{2}$ ).

$$
F_{\text {ext }}=\left(p_{e}-\gamma * \frac{D}{2}\right) * \pi * R^{2}+\pi * \gamma * R^{3}
$$

Computation of Normal Force $(\mathrm{N})$ on the plug wall due to internal pressure ' $\mathrm{p}_{\mathrm{i}}$ ':

Figure 4.22 shows the variation internal pressure with depth with respect to the cylindrical cross section of the plug.

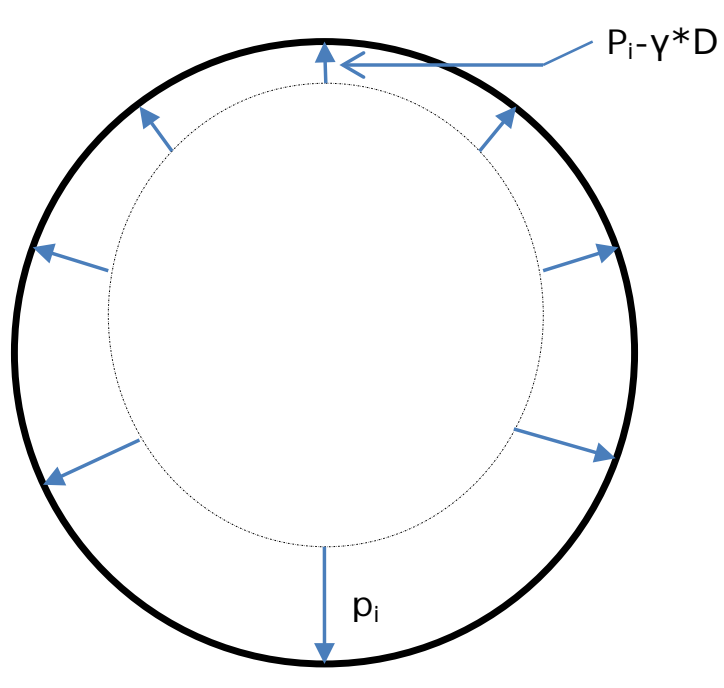

PRESSSURE DISTRIBUTION

THROUGH PLUG CYLINDRICAL CROSS SECTION

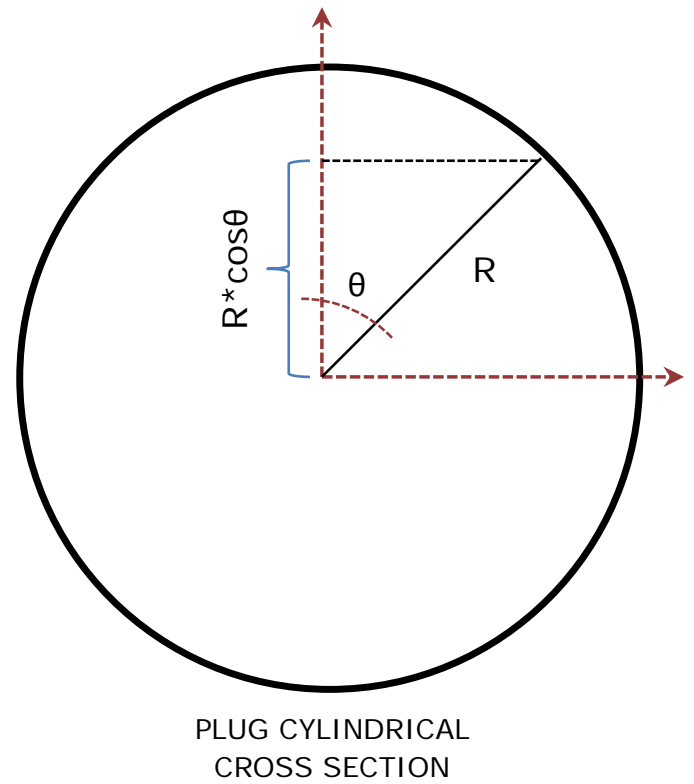

CROSS SECTION

Figure 4.22: Hydrostatic pressure distribution in cylindrical section of the plug 
Normal force $(\mathrm{N})$ on the tunnel wall due to internal plug hydrostatic and applied pressure 'Pi' is:

$$
N=\left(P_{i}-\gamma * D\right) * \pi * D * L_{e}+2 * \int P d A
$$

From Figure 4.22 and Figure 4.20 considering polar co-ordinate system we get:

$$
\begin{gathered}
d A=R d \theta * L_{e} \\
P=\gamma * R *(1-\cos \theta)
\end{gathered}
$$

Substituting equation (4.17) \& (4.18) into equation (4.16) and considering a $180^{\circ}$ vertical sweep of half of the cylindrical surface on the right (Figure 4.22) we have:

$$
N=\left(P_{i}-\gamma * D\right) * \pi * D * L_{e}+2 * \int_{0}^{\pi} \gamma * R *(1-\cos \theta) * R * L_{e} * d \theta
$$

Evaluating the above integral in equation (4.19) becomes:

$$
N=\left(P_{i}-\gamma * D\right) * \pi * D * L_{e}+2 * \gamma * \pi * R^{2} * L_{e}
$$

Using Equation (4.10a) for limiting friction condition of slippage the coefficient of friction $(\mu)$ can be mathematically defined as:

$$
\mu_{h}=\frac{\left(P_{e}-\gamma * \frac{D}{2}\right) * \pi * R^{2}+\pi * \gamma * R^{3}}{\left(P_{i}-\gamma * D\right) * \pi * D * L_{e}+2 * \gamma * \pi * R^{2} * L_{e}}
$$

\subsubsection{Coefficient of Friction Computation}

\subsubsection{I nitial Set of Testing}

The coefficient of friction under various test conditions of slippage as Sequence A- 1 , A-2 and B was computed and presented below in Table 4.13. The parameters ' $\mu$ ' and ' $\mu_{\mathrm{h}}$ ' in Table 4.13 were notations for coefficient of friction not considering and considering hydrostatic pressure, respectively. Equation (4.10b) was used to compute ' $\mu$ ' without taking hydrostatic pressure into consideration (considering only uniform applied pressure at all points) and equation (4.21) was used for more realistic consideration of the hydrostatic pressure in the tunnel along with the applied pressure. The values of different constant variables used in the equations (4.10b) and (4.21) are:

$$
\gamma=62.4 \frac{l b}{f t^{3}}=0.03611 \frac{l b}{i n^{3}}
$$




$$
\begin{gathered}
D=48^{\prime \prime} \\
R=24^{\prime \prime} \\
L_{e}=\text { Effective Contact Length }=50 "
\end{gathered}
$$

\begin{tabular}{|c|c|c|c|c|c|c|c|c|c|}
\hline \multirow[b]{2}{*}{ Trials } & \multicolumn{3}{|c|}{ Sequence A-1 } & \multicolumn{3}{|c|}{ Sequence A-2 } & \multicolumn{3}{|c|}{ Sequence B } \\
\hline & $\begin{array}{l}\mathrm{p}_{\mathrm{e}} / \mathrm{p}_{\mathrm{i}} \\
\text { @Slip }\end{array}$ & $\mu$ & $\mu_{\mathrm{h}}$ & $\begin{array}{l}\mathrm{pe}_{\mathrm{e}} / \mathrm{p}_{\mathrm{i}} \\
\text { @Slip }\end{array}$ & $\mu$ & $\mu_{\mathrm{h}}$ & $\begin{array}{l}\mathrm{pe}_{\mathrm{e}} / \mathrm{p}_{\mathrm{i}} \\
\text { @Slip }\end{array}$ & $\mu$ & $\mu_{\mathrm{h}}$ \\
\hline \multirow{3}{*}{ Trial \# 1} & 0.79 & 0.190 & 0.196 & 0.79 & 0.189 & 0.197 & 0.80 & 0.193 & 0.196 \\
\hline & 0.80 & 0.191 & 0.195 & 0.80 & 0.192 & 0.197 & 0.79 & 0.190 & 0.195 \\
\hline & 0.75 & 0.181 & 0.184 & 0.82 & 0.196 & 0.200 & 0.78 & 0.188 & 0.195 \\
\hline \multirow{3}{*}{ Trial \# 2} & 0.78 & 0.186 & 0.192 & 0.81 & 0.194 & 0.202 & 0.82 & 0.196 & 0.200 \\
\hline & 0.79 & 0.191 & 0.195 & 0.81 & 0.195 & 0.201 & 0.80 & 0.191 & 0.195 \\
\hline & 0.80 & 0.191 & 0.194 & 0.81 & 0.194 & 0.198 & 0.81 & 0.195 & 0.202 \\
\hline \multirow{3}{*}{ Trial \# 3} & 0.75 & 0.180 & 0.186 & 0.81 & 0.194 & 0.202 & 0.81 & 0.194 & 0.197 \\
\hline & 0.78 & 0.188 & 0.192 & 0.82 & 0.197 & 0.203 & 0.81 & 0.193 & 0.198 \\
\hline & 0.78 & 0.188 & 0.192 & 0.83 & 0.200 & 0.204 & 0.81 & 0.194 & 0.201 \\
\hline Average & 0.78 & 0.187 & 0.192 & 0.81 & 0.195 & 0.200 & 0.80 & 0.193 & 0.198 \\
\hline
\end{tabular}

Table 4.13: Friction coefficient for sequence A-1, A-2 and B

The friction coefficient computed in the case of ignoring hydrostatic pressure seems to be most conservative. Based on the connected surface properties, area of contact and the pressure at slippage, there can be only one value of friction coefficient. The variation is arising from the assumptions based on which it was computed. The friction computation from hydrostatic consideration was more accurate under physical circumstances. Also the exact contact length was used in the computation reducing the number of uncertainties. It can be noted from Table 4.13 that the friction coefficient of the system has a rise of about $2.6 \%$ when taking hydrostatic pressure variation into consideration.

\subsubsection{Extended Set of Testing}

The pressure transducers were moved for the extended set of testing when it comes to the reading of the tunnel pressure. The tunnel pressure was read at the bottom of the tunnel using two immersion sensors and one pressure transducer fixed outside at the level of bottom most point of the tunnel. Equation (4.10b) was used to computing ' $\mu$ ' without taking hydrostatic pressure into consideration (considering only uniform applied pressure at all points). Equation (4.21) was modified to take into account, the reading of the tunnel pressure at the bottom as seen below in Equation (4.21a):

$$
\mu_{h}=\frac{\left(P_{e}-\gamma * D\right) * \pi * R^{2}+\pi * \gamma * R^{3}}{\left(P_{i}-\gamma * D\right) * \pi * D * L_{e}+2 * \gamma * \pi * R^{2} * L_{e}}
$$


For Tests\# 1-10 as shown in Table 4.8, a part of the tunnel was covered in either Teflon or plastic (polyethylene) in order to gauge the impact of the tunnel concrete contact length of the plug. Vectran webbing was tested for friction coefficient [31] under wet condition with Teflon, Plastic and Concrete which came out to be an average value of 0.176 , 0.196 and 0.27 (test methods and results shown in Appendix D), respectively. All three friction coefficients were comparable to each other. Hence, Teflon and plastic (polyethylene) used in the Tests\# 1-10 cannot be considered as a frictionless material. This prompts the friction coefficient calculation to be conducted with the ' $\mathrm{L}_{e}$ ' as 50 " and evaluate the system friction coefficient as per equation (4.10b) and (4.21a). Tests\# 11-13 were also included since it brings the effect of adhesive scraped concrete surface and age effect of the plug webbing into consideration. Table 4.14 shows the friction coefficient computed for Tests\# 113 considering and not considering hydrostatic pressure.

Unlike in the case of initial testing, none of ' $\mu$ ' values in Table 4.14 could be singularly termed as conservative. Test\# 13 was the control test for this set of testing. Comparison with Test\# $13(\mu=0.237)$ of all the tests from Tests\# 1-10 reflected the reduction in system coefficient of friction with a minimum of $\mu=0.177$ to a maximum of $\mu=0.216$. Test\# 11 showed the highest of value with $\mu=0.25$, which reflects the effect of adhesive scraped tunnel concrete surface increasing friction coefficient of the system.

Table 4.14: Friction coefficient for extended testing

\begin{tabular}{|c|c|c|c|}
\hline Test\# & $\begin{array}{c}\text { Average } \\
\text { Holding } \\
\text { Resistance }\end{array}$ & $\mu$ & $\mu_{\mathrm{h}}$ \\
\hline 1 & 0.82 & 0.196 & 0.194 \\
\hline 2 & 0.85 & 0.206 & 0.205 \\
\hline 3 & 0.91 & 0.216 & 0.215 \\
\hline 4 & 0.83 & 0.199 & 0.197 \\
\hline 5 & 0.87 & 0.210 & 0.208 \\
\hline 6 & 0.86 & 0.204 & 0.203 \\
\hline 7 & 0.75 & 0.180 & 0.178 \\
\hline 8 & 0.75 & 0.180 & 0.177 \\
\hline 9 & 0.81 & 0.195 & 0.193 \\
\hline 10 & 0.81 & 0.195 & 0.193 \\
\hline 11 & 1.03 & 0.249 & 0.250 \\
\hline 12 & 0.92 & 0.223 & 0.223 \\
\hline 13 & 0.99 & 0.237 & 0.238 \\
\hline
\end{tabular}

A comparison of the three sets of testing on tunnel concrete for coefficient of friction can be made based on corresponding average holding resistance and corresponding geometric dimensions. Table 4.15 shows a summary of the three set of testing which include single layered Vectran from [17], tri-layered plug-initial testing and tri-layered plug extended testing. Consideration of hydrostatic pressure in the tunnel and the plug does not reflect much difference in the value of ' $\mu$,' with respect to when it was not considered 
showing a coefficient of variation of only $1.8 \%$ on an average. Hence, the hydrostatic pressure was not considered for the below calculation. In terms of design it was also noted that the single layered Vectran plug [17] has a cylindrical length of 60" as compared to trilayered plug of 45". The comparison is represented in Table 4.15.

Table 4.15: Coefficient of friction comparison for different test scenario

\begin{tabular}{|c|c|c|}
\hline Cases & $\begin{array}{c}\text { Average } \\
\text { pressure ratio }\end{array}$ & $\boldsymbol{\mu}$ \\
\hline Single-layered Vectran plug [17] & 0.97 & 0.194 \\
\hline Tri-layered plug- initial test & 0.80 & 0.192 \\
\hline Tri-layered plug- extended test & 0.99 & 0.237 \\
\hline
\end{tabular}

As with any system, the coefficient of friction is independent of geometric parameters and can only change with any change in physical conditions of the surface in contact. Similarity of results for single layered Vectran plug and tri-layered plug-initial test proves this hypothesis. But a jump in the value of ' $\mu$ ' for tri-layered plug-extended test indicated a change in surface condition either of the plug webbing or of the tunnel concrete. As shown in Figure 4.17, repeated slippage test have led to abrasion of the plug webbings leading to a higher friction coefficient.

The friction coefficient may have been influenced by the water leaking between the plug and the tunnel wall. The current plug has webbed structure which allows water to easily seep through it. This occurrence makes the study of leakage and seepage water pressure effect more relevant.

\subsection{Summary}

The plug slippage testing has been primarily divided into two sets of testing, the initial set of testing and the extended set of testing. The initial set of testing dealt with slippage of the tri-layered plug (soon after receiving it in the facility) on tunnel concrete surface under conditions of pressure both controlled and uncontrolled. The holding resistances for initial slippage tests were found to have a range of 0.78 to 0.82 .

The extended set of testing dwelled on the study of influence of different parameters on the occurrence of slip. The parameters varied were the effective contact length of the plug with tunnel concrete and plug mass. It was found that the plug's resistance to slip reduces with the reduction of the effective contact length with concrete. The plug mass did not affect the occurrence of slippage from range of $100 \%$ to $75 \%$ plug mass variation. But the plug mass at $50 \%$ did show higher holding resistance at all three levels of slip. However, further tests conducted closer to the design pressure of the plug and with lesser mass of plug (less than $50 \%$ ) are needed to confirm these results.

It was also found during the course of the extended testing the abrasion of the plug surface i.e. the abrasion of the webbing on the surface with repeated slippage test had led to higher holding resistances for slippage similar to conditions used for initial testing (range 
of 0.92 -1.09). Also the slippage test occurring on abraded concrete due to the scrubbing of adhesive showed the highest ratios of all the extended tests (range of $0.97-1.14$ ).

Comparison of the holding resistances for single layered Vectran [17] and tri-layered plug-initial testing revealed a disparity in data (pressure ratios [17] $0.95-0.99$ and pressure ratios initial test 0.78-0.82). This was attributed to the new design of the plug with lesser cylindrical length and different external texture. The effect of abrasion of the plug surface for single layered Vectran plug was not discussed in [17].

Friction coefficients of the whole system for all the above cases were discussed. The coefficient of friction remained constant under different scenarios of loading with a range 0.19 to 0.20 . But the friction coefficient varied drastically with the scraping of the tunnel concrete and the abrasion of plug webbings reaching a maximum of $0.23-0.25$ for the system.

Considerable amount of leak was observed for the system, which hence has been studied in the next chapter. It was also observed that water seeped along the whole $360^{\circ}$ circumference of the plug from the rear to the front. Hence a study of this seepage water pressure at various locations of the cylindrical section of the plug can be an important addition to the evaluation of this tri-layered Vectran webbed plug. 


\section{Chapter 5 Leakage}

\subsection{Introduction}

Leakage through the 4' tunnel between the plug surface and the tunnel wall has already been studied [17]. But a complete change in the design of the plug has necessitated a new study on the leakage characteristics of the plug. The probable factors that may impact the leakage characteristics of this new plug are 1) the uneven webbing surface finish and 2) the over-sizing of the plug. Since, the primary objective of the plug is to block the tunnel completely; it is of great importance that the leakage characteristics of the system be studied. An estimation of the leakage of the 16' diameter plug with this new design is also suggested. In case of real time disaster, the study of leakage can throw some light on the leaked rate of flow of water giving an idea of the evacuation time.

\subsection{Test Procedure}

Figure 4.1 shows test set up and the test procedure can be found in Appendix A.

\subsection{Leakage Tests}

Leakage tests were conducted at various pressure combinations of the plug and the tunnel as presented below in Table 5.1.

Table 5.1: Leakage measurement at various pressure combinations

\begin{tabular}{|c|c|c|}
\hline Level & $\begin{array}{c}\text { Plug Pressure } \\
\text { (psi) }\end{array}$ & $\begin{array}{c}\text { Tunnel Pressure } \\
\text { (psi) }\end{array}$ \\
\hline 1 & 25 & 10 \\
\hline 2 & 25 & 15 \\
\hline 3 & 30 & 10 \\
\hline 4 & 30 & 15 \\
\hline 5 & 30 & 20 \\
\hline 6 & 35 & 15 \\
\hline 7 & 35 & 20 \\
\hline 8 & 35 & 25 \\
\hline
\end{tabular}

\subsubsection{Results}

The change in mass of the drainage tank due to the leaked water and time taken for the change of mass as recorded was incorporated in the following equations to obtain the leakage rate in gallons per minute. From [29]:

$$
\operatorname{Volume}\left[\mathrm{in}^{3}\right]=\frac{\text { Mass }[\mathrm{lbs}]}{\text { Specific Weight of Water }(\gamma)\left[\frac{\mathrm{lb}}{\mathrm{in}^{3}}\right]}
$$

$$
1 \text { inch }^{3}=0.004329 \text { gallons }
$$




$$
\begin{gathered}
\qquad \gamma=0.0361 \frac{l b}{i n^{3}} \\
\text { Leakage Rate[Gallons per minute] }=\frac{\text { Volume [Gallons] }}{\text { Time [minutes] }}
\end{gathered}
$$

Table 5.2 summarizes the average leakage rate under various levels of internal and external pressure as described in Table 5.1. The full table for all the trials has been provided in Appendix E.

Table 5.2: Average leakage rates for leakage tests

\begin{tabular}{|c|c|c|c|c|}
\hline Level & $\begin{array}{c}\text { Plug Pressure } \\
(\mathrm{psi})\end{array}$ & $\begin{array}{c}\text { Tunnel Pressure } \\
(\mathrm{psi})\end{array}$ & $\begin{array}{c}\text { Pressure Ratio } \\
\mathrm{p}_{\mathrm{e}} / \mathrm{p}_{\mathrm{i}}\end{array}$ & $\begin{array}{c}\text { Average Leakage Rate } \\
\text { (from 3 trials) } \\
\text { (gallons/minute) }\end{array}$ \\
\hline 1 & 25 & 10 & 0.40 & 12.37 \\
\hline 2 & 25 & 15 & 0.60 & 16.07 \\
\hline 3 & 30 & 10 & 0.33 & 11.01 \\
\hline 4 & 30 & 15 & 0.50 & 15.13 \\
\hline 5 & 30 & 20 & 0.66 & 16.63 \\
\hline 6 & 35 & 15 & 0.43 & 12.34 \\
\hline 7 & 35 & 20 & 0.57 & 16.10 \\
\hline 8 & 35 & 25 & 0.71 & 17.08 \\
\hline
\end{tabular}

\subsubsection{Discussions}

Since the leakage through the interface of plug surface and tunnel wall depends on the orientation of the plug, the leakage rate varied considerably for tests conducted on different days. Hence an attempt was made to conduct each trials of the above test on the same day. Note that each test level has three trials as indicated in Table 5.2. The average leakage values of the three trials were taken up for further study. Each leakage reading increases with the increase in the pressure ratio for a corresponding value of plug and tunnel pressure. A plot on the dependency of leakage rate on pressure ratios is provided in Figure 5.1.

In Figure 5.1, the two linear trend lines for plug pressure of 30 psi and 35 psi shows two equations of line with similar slopes and intercepts. This can be used as a support for the explanation that the leakage depends more on the pressure ratio than the individual pressure values of the plug and the tunnel. 


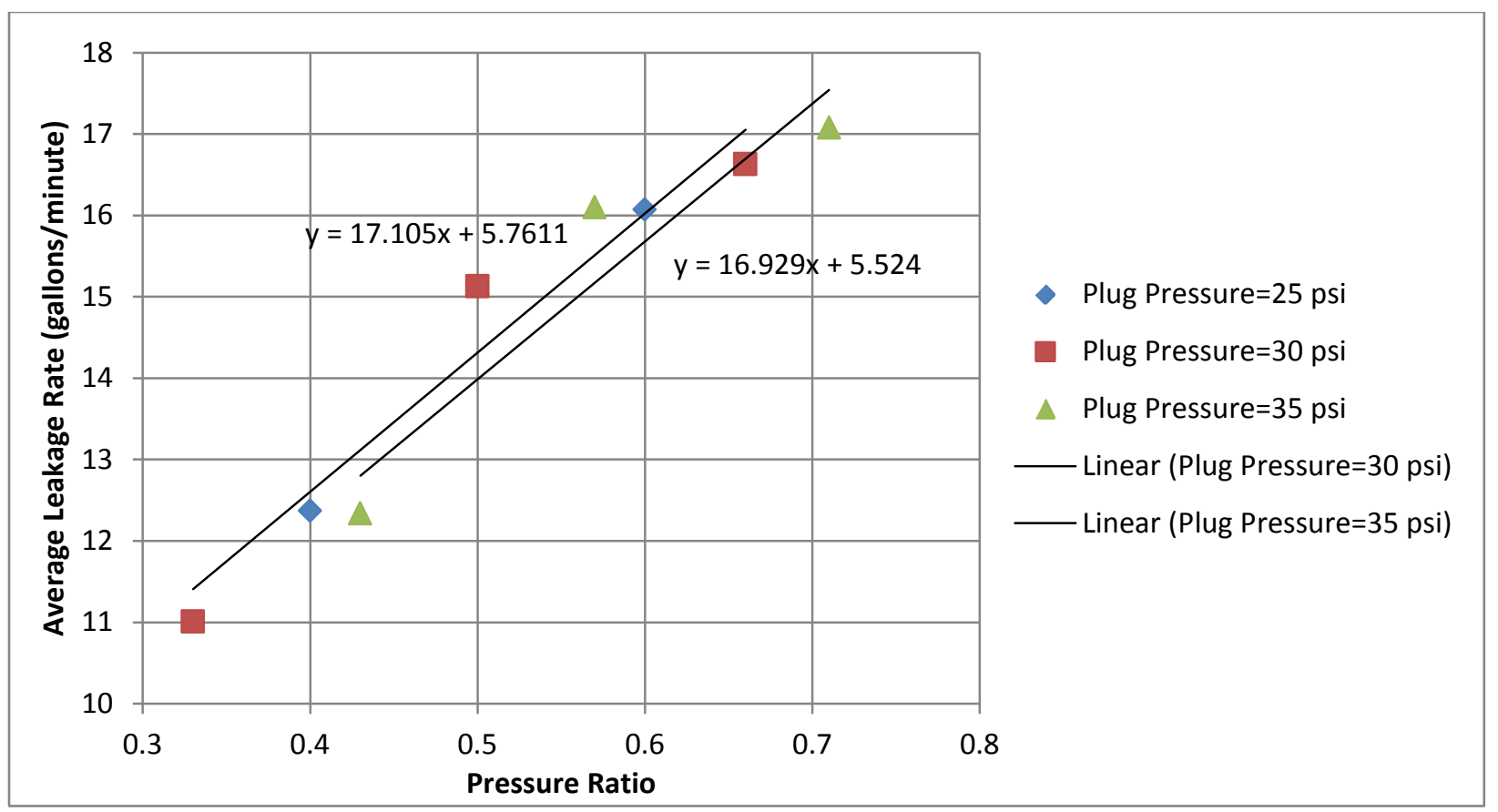

Figure 5.1: Average leakage rate relation to pressure ratios

The leakage data from the above set of testing was further compared with the data available in [17] previously for tunnel wall as smooth concrete. Table 5.3 summarizes the results obtained in [17].

Table 5.3: Leakage data for single layered Vectran plug [17] for plug pressure of $25,30 \& 35$ psi

\begin{tabular}{|c|c|c|c|}
\hline $\begin{array}{c}\text { Plug Pressure } \\
\text { (psi) }\end{array}$ & $\begin{array}{c}\text { Tunnel Pressure } \\
\text { (psi) }\end{array}$ & Pressure Ratio & $\begin{array}{c}\text { Leakage Rate } \\
\text { (Gallons/min) }\end{array}$ \\
\hline 25 & 10 & 0.40 & 0.58 \\
\hline 25 & 15 & 0.60 & 0.79 \\
\hline 30 & 6 & 0.20 & 0.37 \\
\hline 30 & 12 & 0.40 & 0.61 \\
\hline 30 & 18 & 0.60 & 0.84 \\
\hline 30 & 24 & 0.80 & 1.1 \\
\hline 35 & 7 & 0.20 & 0.39 \\
\hline 35 & 14 & 0.40 & 0.63 \\
\hline 35 & 21 & 0.60 & 0.87 \\
\hline 35 & 28 & 0.80 & 1.16 \\
\hline
\end{tabular}




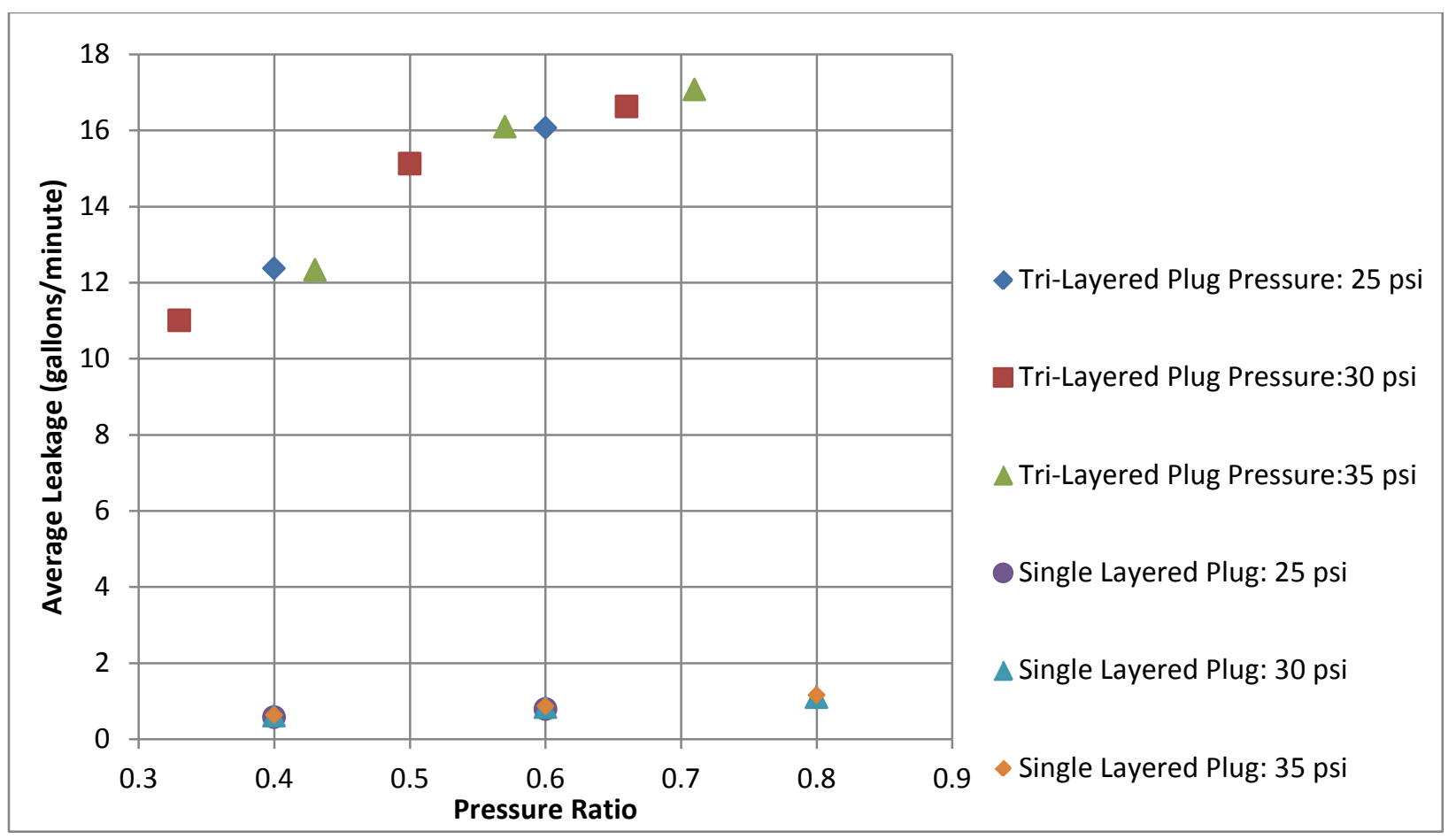

Figure 5.2: Single layered plug \& tri-layered plug leakage comparison

As can be seen from Figure 5.2 there has been an approximate increase by 10 times in the leakage rate of the tri-layered plug as compared to the single layered Vectran plug. This was a considerable jump and the possible reasons for this jump are discussed below.

The probable factors governing the leakage rate are 1 ) ratio of tunnel to plug pressure $\left.\left(p_{e} / p_{i}\right), 2\right)$ the over sizing of the plug, 3) the plug surface characteristics and 4 ) plug deployment/orientation. Considering each of the above points a discussion has been made below:

\subsubsection{Ratio of Tunnel to Plug Pressure $\left(p_{e} / p_{i}\right)$}

The ratio of the tunnel to the plug pressure has been considered one of the main factors for the leakage rate. As seen in the above plots in Figure 5.1 and Figure 5.2, the pressure ratio, rather than the individual plug and tunnel pressure, guides the amount of leakage. But again, if the tests were carried on a different day with the plug re-oriented in the tunnel, the leakage data would turn out to be different for the same pressure ratios. Therefore several measurements were needed to establish a tendency for different pressure ratios. The tables are provided in the Appendix E.

\subsubsection{The Over-Sizing of the Plug}

The over-sizing of the plug as discussed in Table 3.1 could have increased leakage for the tri-layered plug. The single layered Vectran plug used had a cylindrical unconfined diameter of 50" against a tunnel internal diameter of 48" which when compared to the new tri-layered plug had a maximum cylindrical diameter of 49" with a slightly tapering cylindrical surface. Under confined conditions, the amount of over-sizing could have not 
been enough to create an effective contact. Therefore, the sealing capacity of the plug was reduced when compared to the single layered Vectran plug.

\subsubsection{The Plug Surface Characteristics}

This matrix of webbings facilitates the formation of interstitial pore spaces on the surface of the plug between and under the webbings. Also, it can be noted from the Figure 5.3, the webbings are not woven perfectly with axial/hoop webbings missing single/couple of webbings in the direction perpendicular to it. The slight distortion in the matrix will facilitate the formation of water seepage pressure irrespective of however low the plug pressure is. The presence of inter-webbing spaces allows water to seep through between the plug surface and the tunnel wall. This seeping water can have a major impact on the leakage rate.

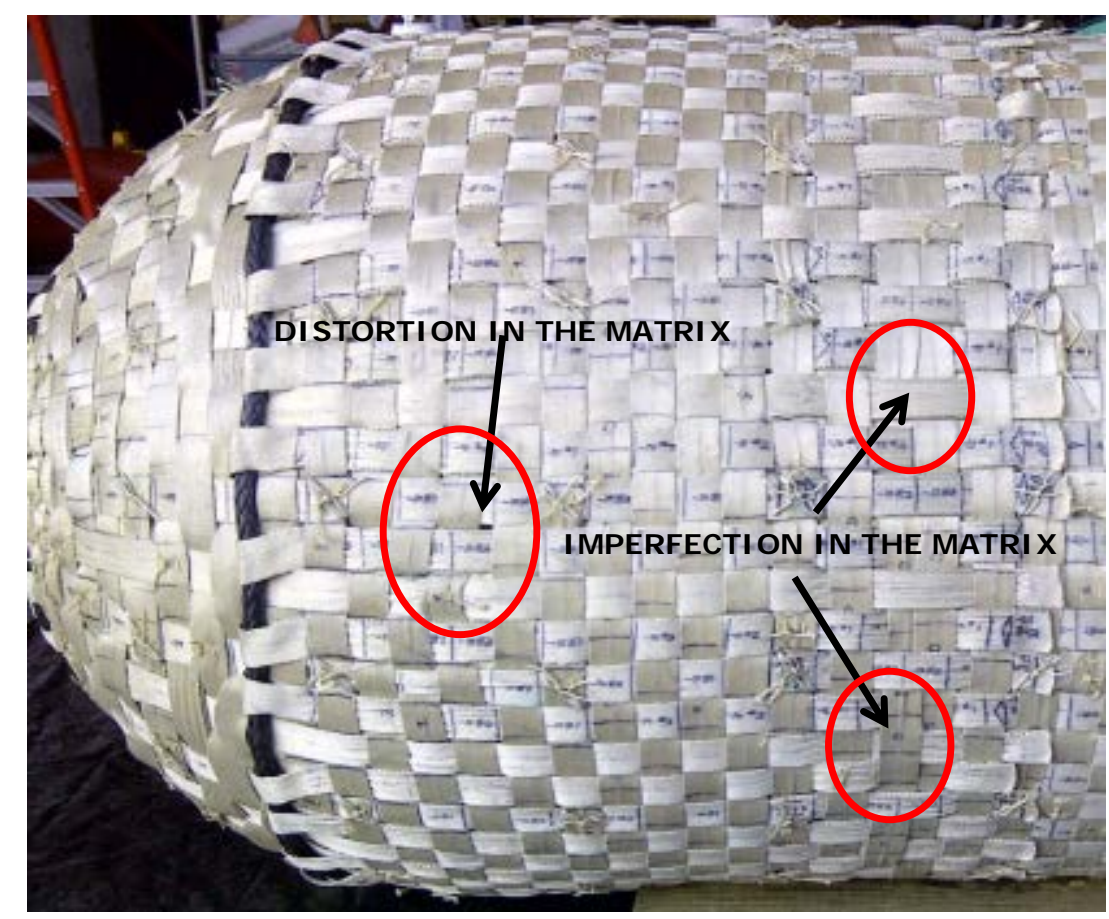

Figure 5.3: Representative plug surface

For leakage, with an increased cylindrical surface with similar texture (as for the full scale plug), the leakage rate can magnify considerably as the product of the increased factor of cylindrical surface area and the leakage rate.

For slippage, this seeping water between the surfaces of the plug and the tunnel can develop a situation of boundary lubrication. The pressure of pore water with certain amount of kinetic energy (due to the applied tunnel pressure) can force between the asperities of the surfaces and forming a thin monolayer. This could reduce friction considerably.

Hence, the above effect of the plug surface characteristics makes it imperative to conduct a seepage water pressure study. The study should deal with reading the pressure of water at various points along the length of the cylindrical section to ascertain the kinetic energy of the seeping water and hence its impact on slippage and leakage. 


\subsubsection{Plug Deployment/ Orientation}

The plug deployment for the full scale or the plug orientation for the quarter scale during the onset of testing can have a major impact on the leakage rate. Hence, for the same pressure ratio the leakage rate may be higher or lower depending on the plug orientation for testing on different days. Figure 5.4 shows different orientation of the plug for different instances. The laser pointing at the center of the end cap represents perfect straight alignment but the laser pointer to the left or right of the tip indicates a skewed alignment. The skewed alignment was due to non-uniform slip of the plug during the slippage tests.

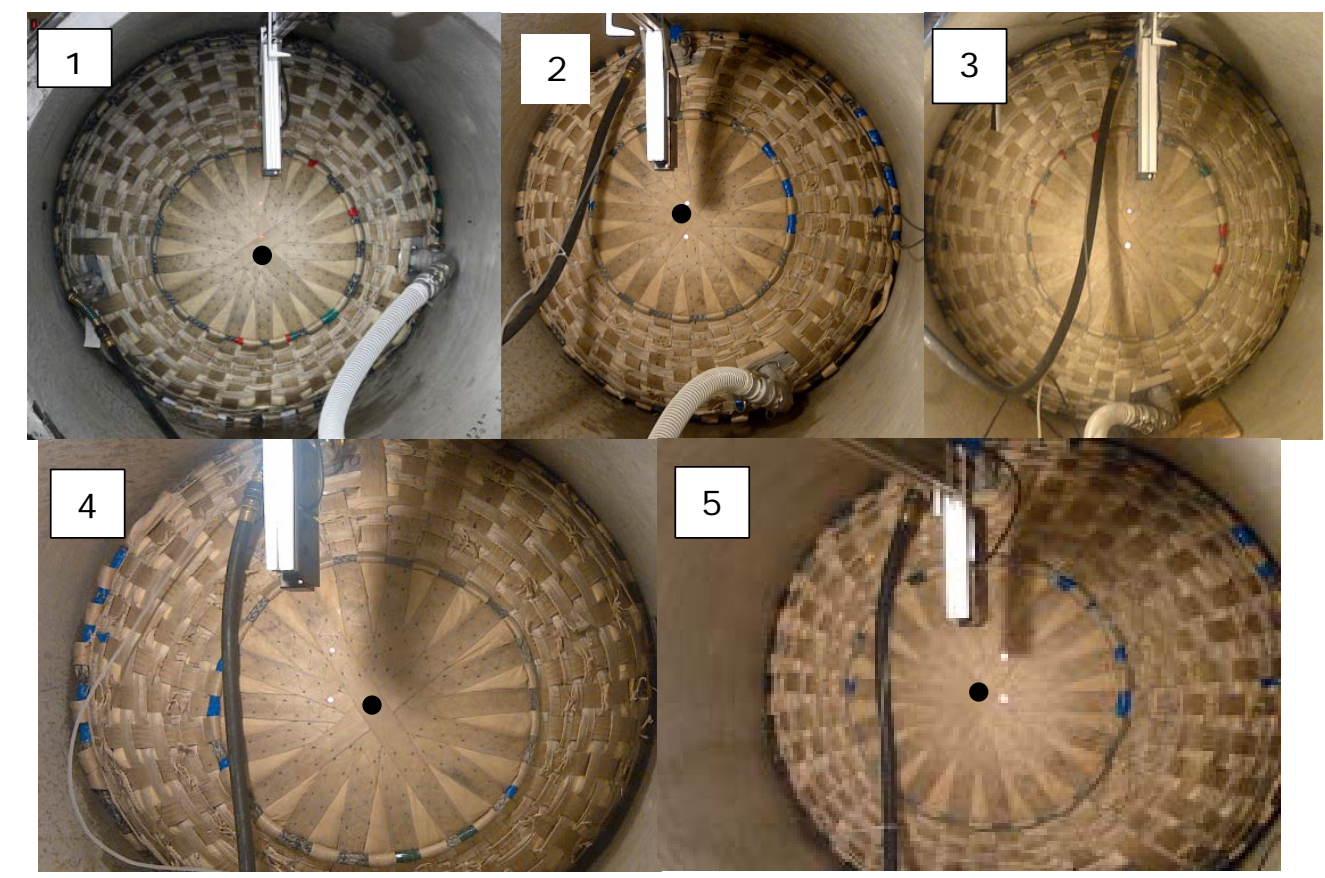

Figure 5.4: Different orientations of the plug: 1) end cap facing downward; 2) end face upward; 3) laser b pointing at the center; 4) end cap face left (laser b pointer on right); 5) end cap face right (laser $b$ pointer on the left)

\subsection{Prediction of Full Scale Prototype Leakage}

The leakage rate of the plug has a major influence due to the occurrence of seepage water pressure effect which was not observed in the single layered Vectran plug [17]. This was validated by considerable increase in leakage as seen in the quarter scale tests. This leads to an assumption that the surface area available for developing seepage water flow on the cylindrical surface of the plug is directly proportional to leakage of the system. Hence, by comparing the cylindrical surface area of the full scale and the quarter scale plug, a factor can be obtained which, if multiplied by the current leakage of the quarter scale, will predict the leakage of the full scale plug. It should also be noted that this value of leakage for the full scale plug is considering the plug being used in a tunnel (of 16' diameter) of the 
same interior contour as the quarter scale one. This is rough estimation, considering the complexity of full scale tunnel cross section. However, this estimation provides an order of magnitude of what can be expected on tests of full scale.

For Full Scale Plug Assuming:

$$
\begin{gathered}
\text { Cylindrical Length }=30^{\prime} \\
\text { Cylindrical Diameter }=16^{\prime} \\
\text { Cylindrical Surface Area }\left[\text { in }^{2}\right]\left(\text { CSA }_{F}\right)=217146.9
\end{gathered}
$$

For the Quarter Scale plug:

$$
\begin{gathered}
\text { Cylindrical Effective Contact Length }=50 " \\
\text { Cylindrical diameter }=48^{\prime \prime} \\
\text { Cylindrical Surface Area }\left[\text { in }^{2}\right]\left(C S A_{Q}\right)=7539.8
\end{gathered}
$$

Leakage Prediction Factor (L.P.F) of the Full Scale Tunnel:

$$
\text { L.P.F }=\frac{C S A_{F}}{C S A_{Q}}=28.8
$$

The average value of leakage for the quarter scale plug for an internal design pressure of $68 \mathrm{psi}$ and maximum attainable external pressure of 48 psi was 11.7 gallons/minute (Appendix E). Hence, leakage prediction for the above condition of the full scale system considering at the highest value of attainable external and internal pressure:

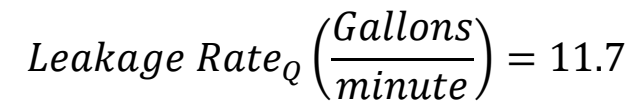

$$
\begin{aligned}
& \text { Leakage Rate }_{F}\left(\frac{\text { Gallons }}{\text { minute }}\right)=\text { L.P.F } * \text { Leakage Rate }_{Q} \\
& \text { Leakage Rate }{ }_{F}\left(\frac{\text { Gallons }}{\text { minute }}\right)=28.8 * 11.7=337
\end{aligned}
$$

Hence, it can be deduced that for the full scale plug with same surface characteristics as the quarter scale, under conditions similar to the testing of the quarter scale, at its maximum design pressure limit of tunnel and plug, the leakage rate is predicted to be at least 337 gallons/minute. Now with the change in all the constant parameters mentioned above in the full scale, other than the pressures, the leakage rate will possibly be more than what it is predicted. 


\subsection{Leakage Mitigation}

An attempt was made to reduce the amount of leakage by positioning a 1 " thick and 6" wide Neoprene pad just behind the rear cylindrical surface rope on the plug surface. The original aim was to review its impact and if successful go ahead with dry slippage testing. But the nature of the results for leakage with Neoprene pads was inconsistent bringing into question, the odds of a perfect plug orientation. The plug pressure was maintained at 30 psi and leakage data was obtained for tunnel pressure varying from 5-20 psi. The data was then compared to similar data collected during the one set of testing (Test 1) and another data collected after the removal of the neoprene pads (Test 2 ). These data are summarized in Table 5.4. Figure 5.5 shows the positioning of the Neoprene pad inside the tunnel.

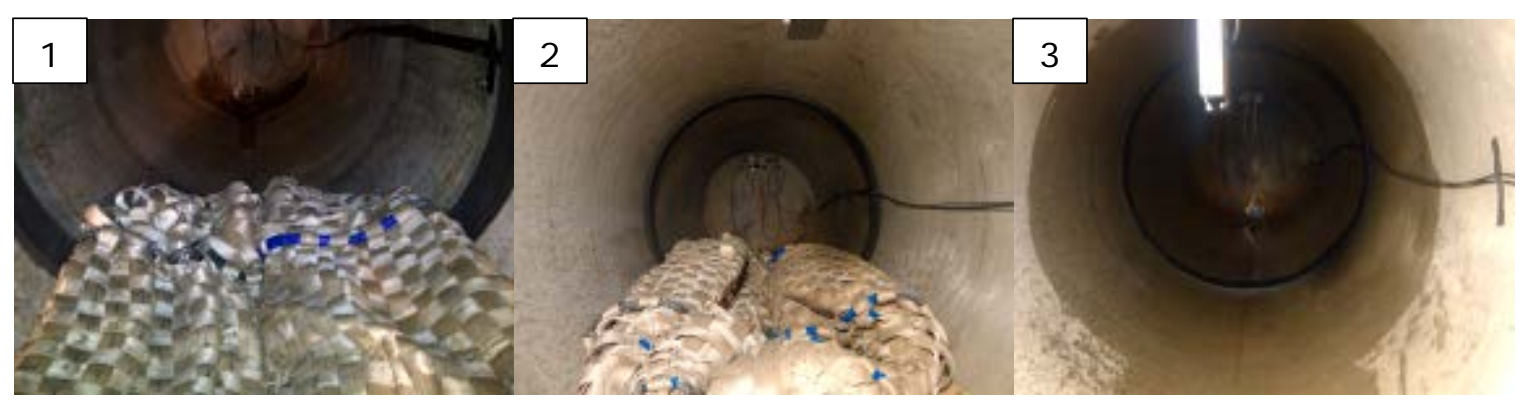

Figure 5.5: Leakage mitigation setup: 1) neoprene pad positioning with respect to the plug; 2 ) the test set up; 3 ) wet tunnel wall after the test showing leak

\subsubsection{Results}

The leakage mitigation results are shown in Table 5.4.

Table 5.4: Leakage mitigation comparison with neoprene pads

\begin{tabular}{|c|c|c|c|c|c|c|}
\hline $\begin{array}{c}\text { Plug } \\
\text { Pressure } \\
\text { (psi) }\end{array}$ & $\begin{array}{c}\text { Tunnel } \\
\text { Pressure } \\
\text { (psi) }\end{array}$ & $\begin{array}{c}\text { Leakage } \\
\text { without } \\
\text { Neoprene } \\
\text { (Test 1) } \\
\text { (gpm) }\end{array}$ & $\begin{array}{c}\text { Leakage } \\
\text { without } \\
\text { Neoprene } \\
\text { (Test 2) } \\
\text { (gpm) }\end{array}$ & $\begin{array}{c}\text { Leakage } \\
\text { with } \\
\text { Neoprene } \\
\text { (gpm) }\end{array}$ & $\begin{array}{c}\% \\
\text { Decrease } \\
\text { (Test 1) }\end{array}$ & $\begin{array}{c}\% \\
\text { Decrease } \\
\text { (Test 2) }\end{array}$ \\
\hline 30 & 5 & 6.1 & 5.0 & 4.4 & $-37.7 \%$ & $-13.5 \%$ \\
\hline 30 & 10 & 11.0 & 7.8 & 6.8 & $-61.0 \%$ & $-14.0 \%$ \\
\hline 30 & 15 & 15.1 & 10.4 & 10.2 & $-48.6 \%$ & $-2.4 \%$ \\
\hline 30 & 20 & 16.6 & 12.6 & 11.7 & $-42.3 \%$ & $-7.6 \%$ \\
\hline \multicolumn{7}{r|r}{} \\
\hline
\end{tabular}

\subsubsection{Discussion}

As discussed earlier in Section 5.3.2.4, the plug orientation was different on different instances of testing and the difference in plug orientation may have affected the phenomenon of leakage considerably.

The results from leakage data of Neoprene pads when compared to Test 1, show an average percentage decrease of $47 \%$ in the leakage rate over a range of tunnel pressure 
from 5-20 psi. But, on the other hand, when the data was compared with Test 2, the average reduction of leakage was around only $9.4 \%$. Hence, it can be concluded that the reduction in leakage surely happened with Neoprene pads but it was not a dependable option in terms of conclusive numbers.

Appendix $\mathrm{E}$ provides the data for all the iterations of the leakage tests. Each of the above leakage tests had at least three to five iterations for each level of testing. It was noted that the leakage values for the first iteration were always higher than the next subsequent iterations. This prompts the theory of small enough inter-webbing spaces allowing greater amount of water to pass through until it gets saturated, after which the these passages get blocked for the same level of pressure. An increase in pressure pushes the water out of these zones showing higher level of leakage for the next level of pressure.

\subsection{Summary}

Leakage tests were conducted predominantly at lower ranges of plug pressure yielding leakage rates in the range from $4.43 \mathrm{gpm}$ to $17.08 \mathrm{gpm}$. It was also conducted at design pressure of the plug with the maximum attainable tunnel pressure. The results obtained for leakage at the design pressure (or close to the design pressure) of the plug with maximum attainable tunnel pressure was a comparable value (ranged $9.1 \mathrm{gpm}$ to 11.7 gpm) to the ones conducted at lower plug pressures. This showed the importance of pressure ratios. All the tests conducted at the lower pressure combination reflected the assumption of the pressure ratios being the guiding factor for leakage rate than the individual values of tunnel and plug pressure. The factors predominantly affecting the occurrence of leakage was found to be 1 ) ratio of tunnel to plug pressure $\left.\left(p_{e} / p_{i}\right), 2\right)$ the amount over-sizing of the plug with respect to tunnel diameter, 3) the plug surface characteristics and 4) plug orientation/deployment.

A comparison was made with leakage data of the single layered Vectran plug from [17], which showed a 10 times increase of leakage rate for the new tri-layered plug. Hence, it seems that leakage is a phenomenon that is affected by the new design of the plug due to a combination of factors mentioned in the above paragraph. An effort was made to project the leakage rate for the 16' full scale plug assuming the full scale having the same cross section profile as the quarter scale tunnel.

An attempt was made to reduce the amount of leakage by using 1" thick and 6" wide Neoprene pads, which turned out to be an inconclusive success due to a percentage reduction of $47 \%$ in one test to a percentage reduction of only $9.4 \%$ in another. This spells the importance of the plug deployment as for the full scale or plug orientation as for the quarter scale testing. Since, this consistent deployment/orientation is hard to achieve, leakage in all the case scenarios should best be expressed in terms of a range, rather than in terms of a single defined value for a particular pressure ratio. 


\section{Chapter 6 Seepage Water Pressure Study}

\subsection{Introduction}

The webbed structure of the plug has necessitated the study of the pressure of the seeping water along the length of the plug at different locations and at different depths. This is in order to judge the profile of seepage water flow along the length and around the circumference of the plug. Pressure values were recorded for different combinations of plug and tunnel pressure at rear transverse rope, three quarter, half and one-quarter of the cylindrical length from the front. These measurements were initially carried out at an orientation of $0^{\circ}, 90^{\circ}, 180^{\circ}$ and $270^{\circ}$ followed by another set at $45^{\circ}, 180^{\circ}, 225^{\circ}$ and $315^{\circ}$ with respect to the circumference of the tunnel. Each location has a recording of three trials for each combination of tunnel and plug pressures.

Table 6.1 shows the various pressure levels of the plug and the corresponding tunnel at which the seepage pressure readings were taken.

Table 6.1: Pressure levels for seepage water pressure test

\begin{tabular}{|c|c|c|c|}
\hline Level & Sub-level & $P_{i}(p s i)$ & $P_{e}(p s i)$ \\
\hline \multirow{2}{*}{1} & a & \multirow{2}{*}{25} & 10 \\
\hline & $b$ & & 15 \\
\hline \multirow{3}{*}{2} & $a$ & \multirow{3}{*}{30} & 10 \\
\hline & $b$ & & 15 \\
\hline & C & & 20 \\
\hline \multirow{3}{*}{3} & a & \multirow{3}{*}{35} & 15 \\
\hline & $b$ & & 20 \\
\hline & C & & 25 \\
\hline
\end{tabular}

\subsection{Test Procedure}

Figure 6.1 shows the schematic test set up and the test procedure can be found in Appendix A. 


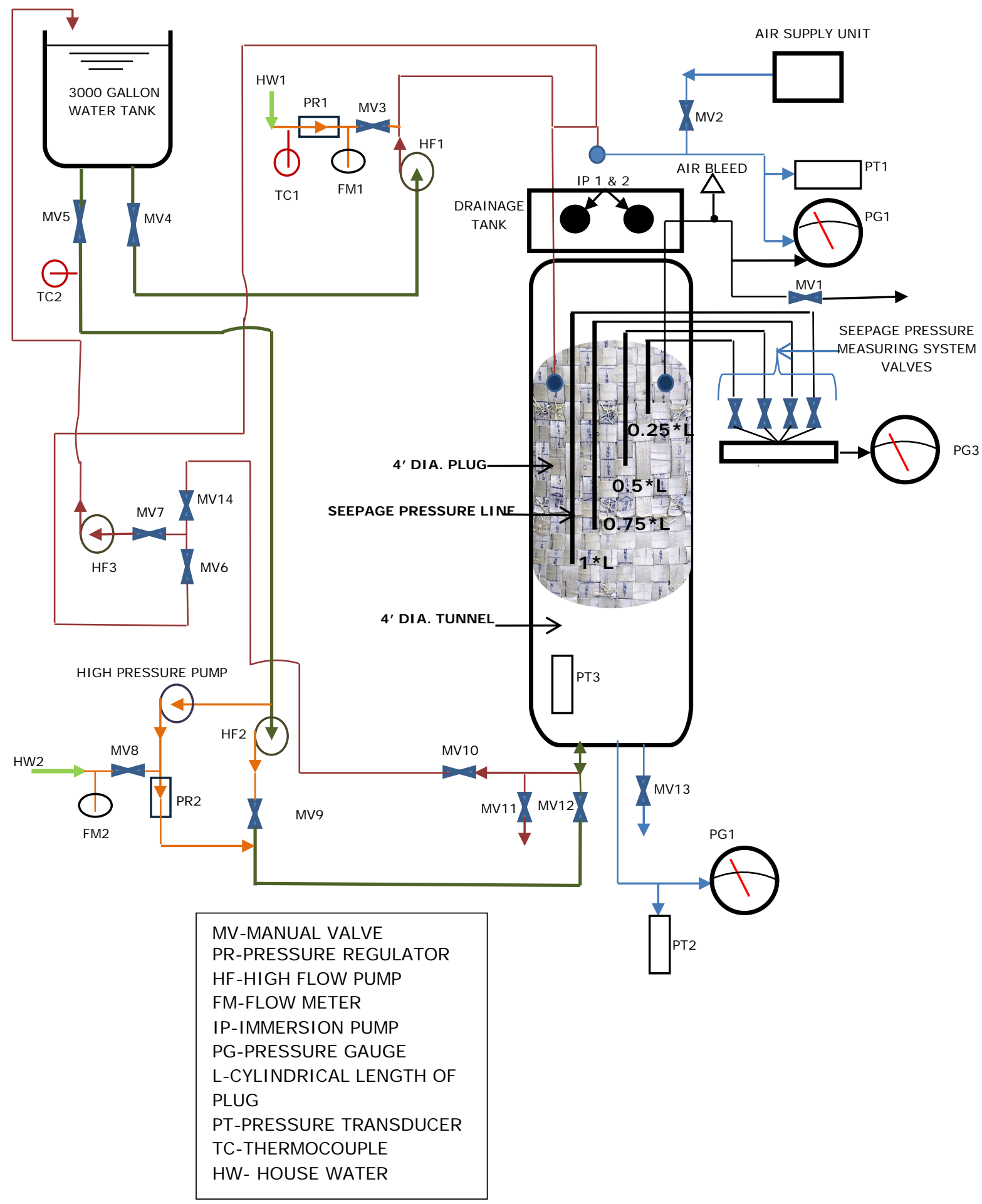

Figure 6.1: Schematic for setting up for seepage pressure measuring system 


\subsection{Results}

The pressure readings were taken at every quarter of the rope-to-rope cylindrical contact length from the front where ' $L$ ' (referred in Table 6.2 to Table 6.9) being the cylindrical rope-to-rope length of the plug. The value $1 * L$ corresponds to the wet side of the plug whereas $0.25 * \mathrm{~L}$ located close to the open end of the tunnel.

Table 6.2: Seepage water pressure results level 1a

\begin{tabular}{|c|c|c|c|c|c|c|c|c|}
\hline \multirow{4}{*}{$\mathrm{p}_{\mathrm{i}}=25 \mathrm{psi}$} & Location & $0^{\circ}$ & $45^{\circ}$ & $90^{\circ}$ & $180^{\circ}$ & $225^{\circ}$ & $270^{\circ}$ & $315^{\circ}$ \\
\cline { 2 - 9 } $\mathrm{p}_{\mathrm{e}}=10 \mathrm{psi}$ & $1 * \mathrm{~L}$ & 9.3 & 9.8 & 9.2 & 9.3 & 9.8 & 9.3 & 9.8 \\
\cline { 2 - 9 } & $0.75^{*} \mathrm{~L}$ & 4.7 & 6.8 & 6.0 & 8.3 & 7.7 & 5.4 & 4.9 \\
\cline { 2 - 9 } & $0.5^{*} \mathrm{~L}$ & 3.9 & 4.1 & 3.6 & 5.3 & 3.4 & 3.2 & 3.9 \\
\cline { 2 - 9 } & $0.25 * \mathrm{~L}$ & 1.3 & 1.6 & 1.3 & 3.4 & 1.3 & 1.4 & 0.9 \\
\hline
\end{tabular}

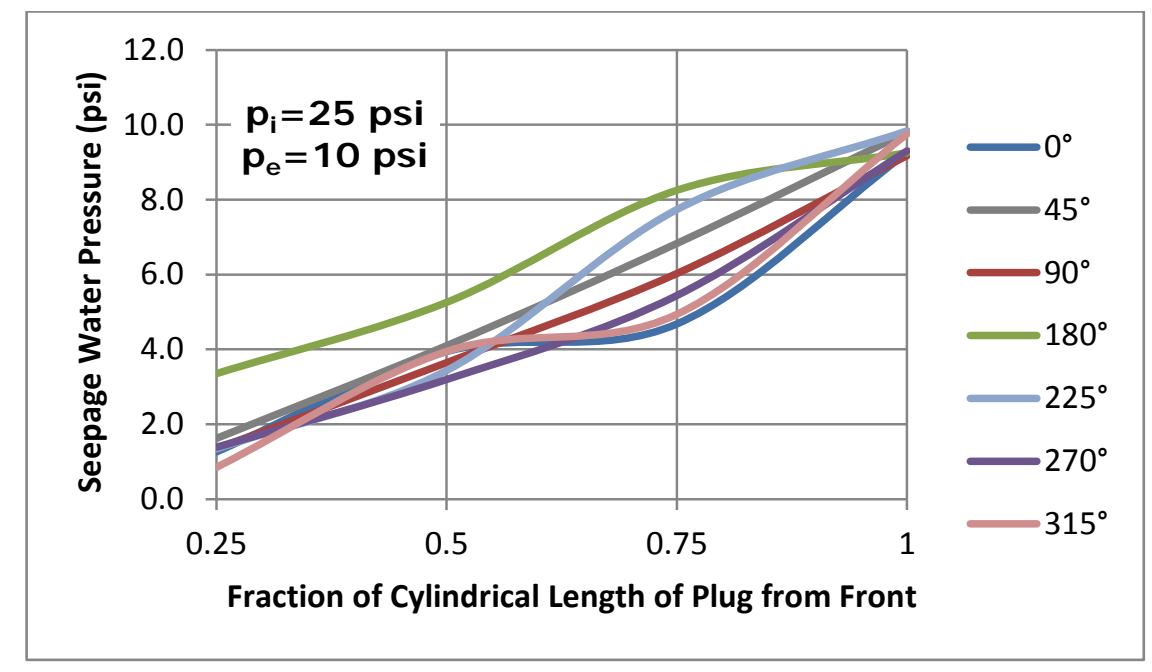

Figure 6.2: Seepage water pressure plot level 1a

Table 6.3: Seepage water pressure result level 1b

\begin{tabular}{|c|c|c|c|c|c|c|c|c|}
\hline & Location & $0^{\circ}$ & $45^{\circ}$ & $90^{\circ}$ & $180^{\circ}$ & $225^{\circ}$ & $270^{\circ}$ & $315^{\circ}$ \\
\cline { 2 - 8 } & $1^{*} \mathrm{~L}$ & 14.2 & 14.9 & 14.3 & 14.2 & 14.9 & 14.3 & 14.9 \\
\cline { 2 - 9 } $\mathrm{p}_{\mathrm{i}}=25 \mathrm{psi}$ & $0.75^{\star} \mathrm{L}$ & 7.1 & 10.5 & 9.4 & 12.8 & 12.0 & 8.6 & 7.5 \\
\cline { 2 - 9 } $\mathrm{p}_{\mathrm{e}}=15 \mathrm{psi}$ & $0.5^{*} \mathrm{~L}$ & 6.0 & 6.2 & 5.7 & 8.6 & 5.2 & 5.0 & 6.1 \\
\cline { 2 - 9 } & $0.25^{\star} \mathrm{L}$ & 1.8 & 2.3 & 2.3 & 5.5 & 2.3 & 2.4 & 1.2 \\
\hline
\end{tabular}




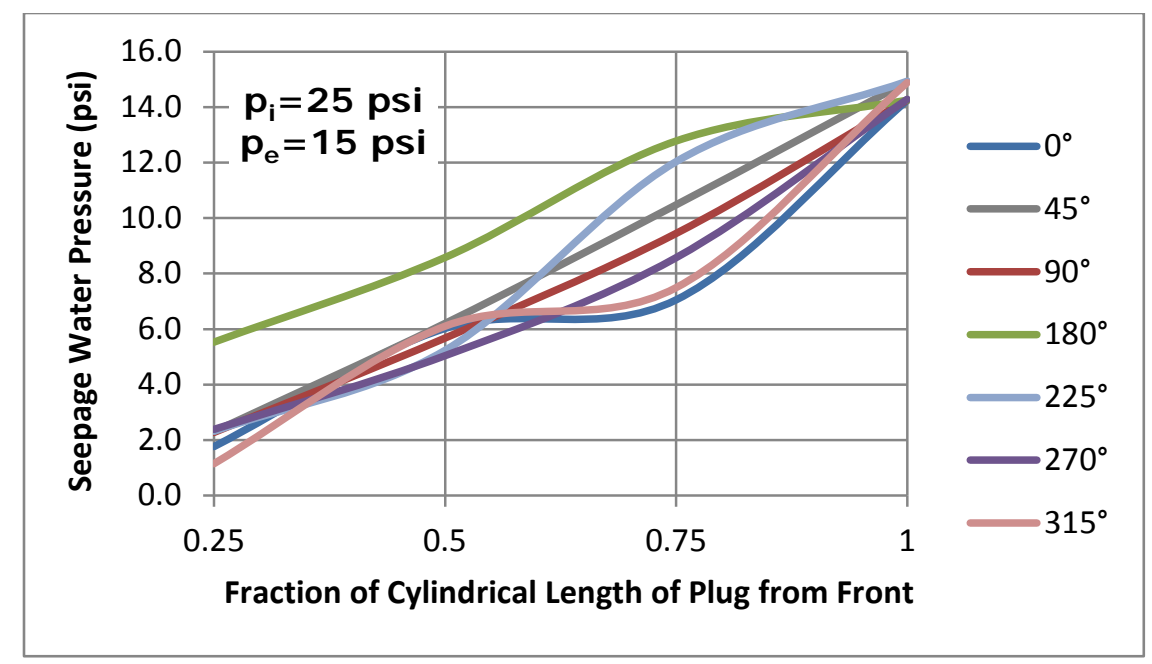

Figure 6.3: Seepage water pressure plot level 1b

Table 6.4: Seepage water pressure result level 2a

\begin{tabular}{|c|c|c|c|c|c|c|c|c|}
\hline & Location & $0^{\circ}$ & $45^{\circ}$ & $90^{\circ}$ & $180^{\circ}$ & $225^{\circ}$ & $270^{\circ}$ & $315^{\circ}$ \\
\cline { 2 - 9 } $\mathrm{p}_{\mathrm{i}}=30 \mathrm{psi}$ & $1^{*} \mathrm{~L}$ & 9.4 & 9.7 & 9.4 & 9.4 & 9.7 & 9.5 & 9.7 \\
\cline { 2 - 9 } $\mathrm{p}_{\mathrm{e}}=10 \mathrm{psi}$ & $0.75^{\star} \mathrm{L}$ & 4.5 & 6.3 & 6.1 & 8.4 & 7.6 & 5.8 & 4.8 \\
\cline { 2 - 9 } & $0.5^{\star} \mathrm{L}$ & 3.2 & 3.7 & 3.4 & 5.5 & 3.1 & 3.1 & 3.9 \\
\cline { 2 - 9 } & $0.25^{\star} \mathrm{L}$ & 1.4 & 1.5 & 1.5 & 3.4 & 1.0 & 1.4 & 1.0 \\
\hline
\end{tabular}

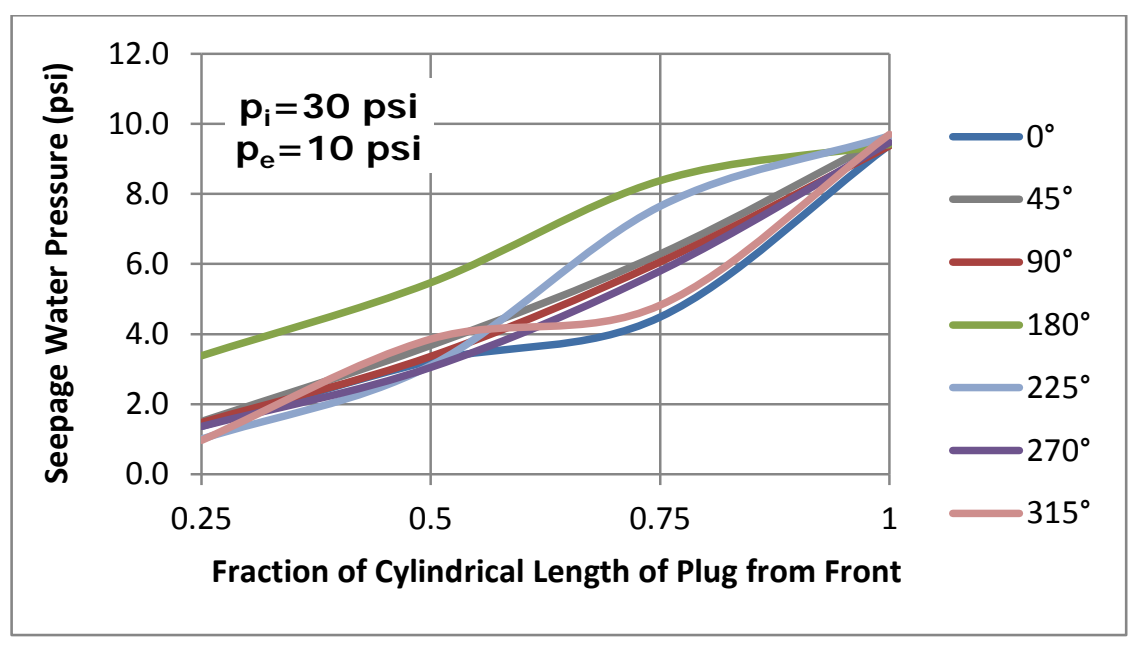

Figure 6.4: Seepage water pressure plot level 2a 
Table 6.5: Seepage water pressure result level 2b

\begin{tabular}{|c|c|c|c|c|c|c|c|c|}
\hline & Location & $0^{\circ}$ & $45^{\circ}$ & $90^{\circ}$ & $180^{\circ}$ & $225^{\circ}$ & $270^{\circ}$ & $315^{\circ}$ \\
\cline { 2 - 9 } & $1^{\star} \mathrm{L}$ & 14.7 & 13.8 & 14.7 & 14.7 & 13.8 & 14.8 & 13.8 \\
\cline { 2 - 9 } $\mathrm{p}_{\mathrm{i}}=30 \mathrm{psi}$ & $0.75^{\star} \mathrm{L}$ & 7.5 & 8.7 & 9.5 & 13.1 & 11.1 & 9.1 & 6.8 \\
\cline { 2 - 9 } $\mathrm{p}_{\mathrm{e}}=15 \mathrm{psi}$ & $0.5^{\star} \mathrm{L}$ & 6.2 & 5.8 & 5.4 & 8.8 & 4.6 & 4.8 & 5.3 \\
\cline { 2 - 9 } & $0.25^{\star} \mathrm{L}$ & 1.6 & 2.0 & 2.2 & 5.5 & 1.8 & 2.3 & 1.1 \\
\hline
\end{tabular}

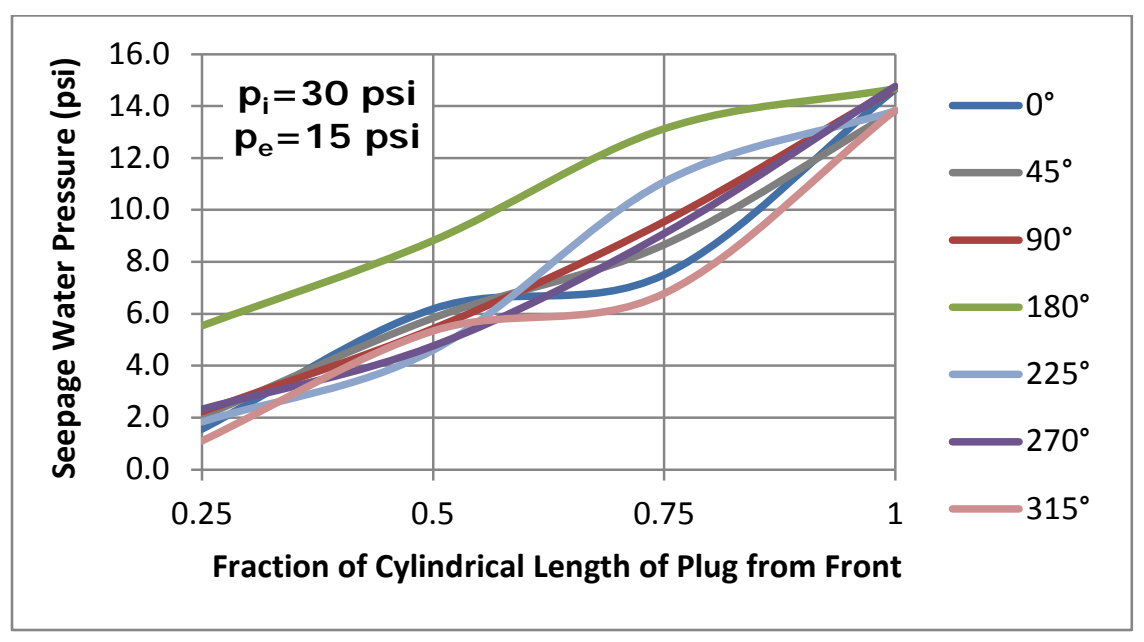

Figure 6.5: Seepage water pressure plot level $\mathbf{2 b}$

Table 6.6: Seepage water pressure result level 2c

\begin{tabular}{|c|c|c|c|c|c|c|c|c|}
\hline & Location & $0^{\circ}$ & $45^{\circ}$ & $90^{\circ}$ & $180^{\circ}$ & $225^{\circ}$ & $270^{\circ}$ & $315^{\circ}$ \\
\cline { 2 - 8 } & $1^{*} \mathrm{~L}$ & 19.4 & 18.9 & 19.4 & 19.4 & 19.0 & 19.4 & 19.0 \\
\cline { 2 - 9 } $\mathrm{p}_{\mathrm{i}}=30 \mathrm{psi}$ & $0.75^{*} \mathrm{~L}$ & 10.0 & 12.7 & 12.7 & 17.5 & 15.6 & 12.1 & 9.4 \\
\cline { 2 - 9 } $\mathrm{p}_{\mathrm{e}}=20 \mathrm{psi}$ & $0.5^{*} \mathrm{~L}$ & 8.2 & 7.6 & 7.2 & 11.9 & 6.5 & 6.5 & 7.4 \\
\cline { 2 - 9 } & $0.25^{\star} \mathrm{L}$ & 1.8 & 2.8 & 2.8 & 7.6 & 3.0 & 3.3 & 1.4 \\
\hline
\end{tabular}




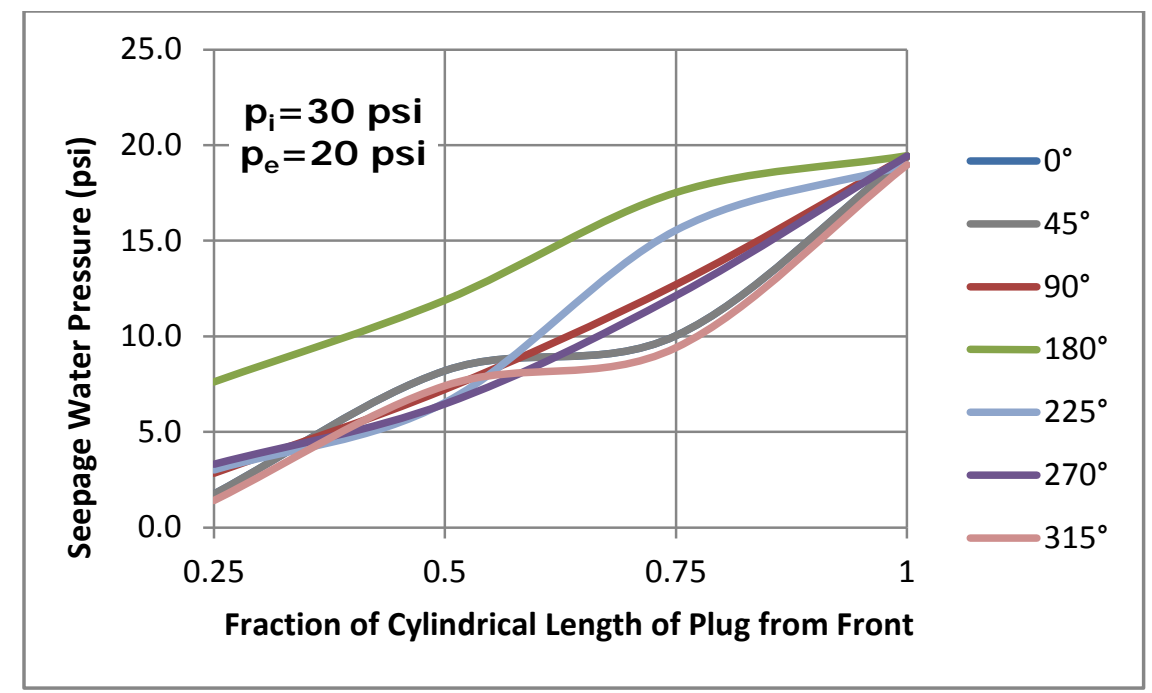

Figure 6.6: Seepage water pressure plot level 2c

Table 6.7: Seepage water pressure result level 3a

\begin{tabular}{|c|c|c|c|c|c|c|c|c|}
\hline \multirow{4}{*}{$\mathrm{p}_{\mathrm{i}}=35 \mathrm{psi}$} & Location & $0^{\circ}$ & $45^{\circ}$ & $90^{\circ}$ & $180^{\circ}$ & $225^{\circ}$ & $270^{\circ}$ & $315^{\circ}$ \\
\cline { 2 - 9 } $\mathrm{p}_{\mathrm{e}}=15 \mathrm{psi}$ & $1^{\star} \mathrm{L}$ & 14.3 & 13.8 & 14.3 & 14.4 & 13.8 & 14.3 & 13.8 \\
\cline { 2 - 9 } & $0.75^{\star} \mathrm{L}$ & 6.8 & 8.9 & 9.3 & 12.9 & 11.3 & 9.2 & 6.9 \\
\cline { 2 - 9 } & $0.5^{\star} \mathrm{L}$ & 6.2 & 5.2 & 4.3 & 8.7 & 4.6 & 4.6 & 5.4 \\
\cline { 2 - 9 } & $0.25^{\star} \mathrm{L}$ & 1.5 & 2.1 & 2.2 & 5.4 & 2.0 & 2.1 & 1.1 \\
\hline
\end{tabular}

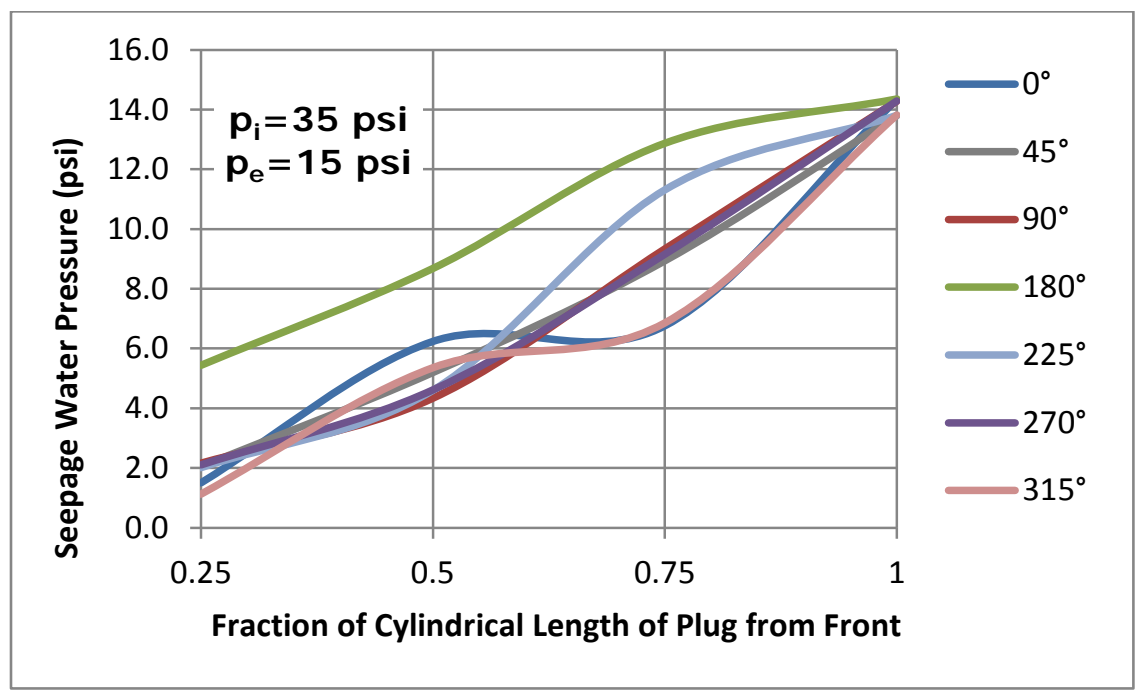

Figure 6.7: Seepage water pressure plot level 3a 
Table 6.8: Seepage water pressure result level 3b

\begin{tabular}{|c|c|c|c|c|c|c|c|c|}
\hline & Location & $0^{\circ}$ & $45^{\circ}$ & $90^{\circ}$ & $180^{\circ}$ & $225^{\circ}$ & $270^{\circ}$ & $315^{\circ}$ \\
\cline { 2 - 8 } & $1^{\star} \mathrm{L}$ & 19.1 & 19.0 & 19.1 & 19.1 & 19.0 & 19.1 & 19.1 \\
\cline { 2 - 9 } $\mathrm{p}_{\mathrm{i}}=35 \mathrm{psi}$ & $0.75^{\star} \mathrm{L}$ & 9.2 & 12.5 & 12.5 & 17.2 & 16.0 & 12.5 & 9.5 \\
\cline { 2 - 9 } $\mathrm{p}_{\mathrm{e}}=20 \mathrm{psi}$ & $0.5^{\star} \mathrm{L}$ & 8.2 & 7.3 & 6.7 & 11.8 & 6.6 & 6.2 & 7.5 \\
\cline { 2 - 9 } & $0.25^{\star} \mathrm{L}$ & 1.7 & 2.8 & 3.0 & 7.5 & 3.1 & 3.3 & 1.4 \\
\hline
\end{tabular}

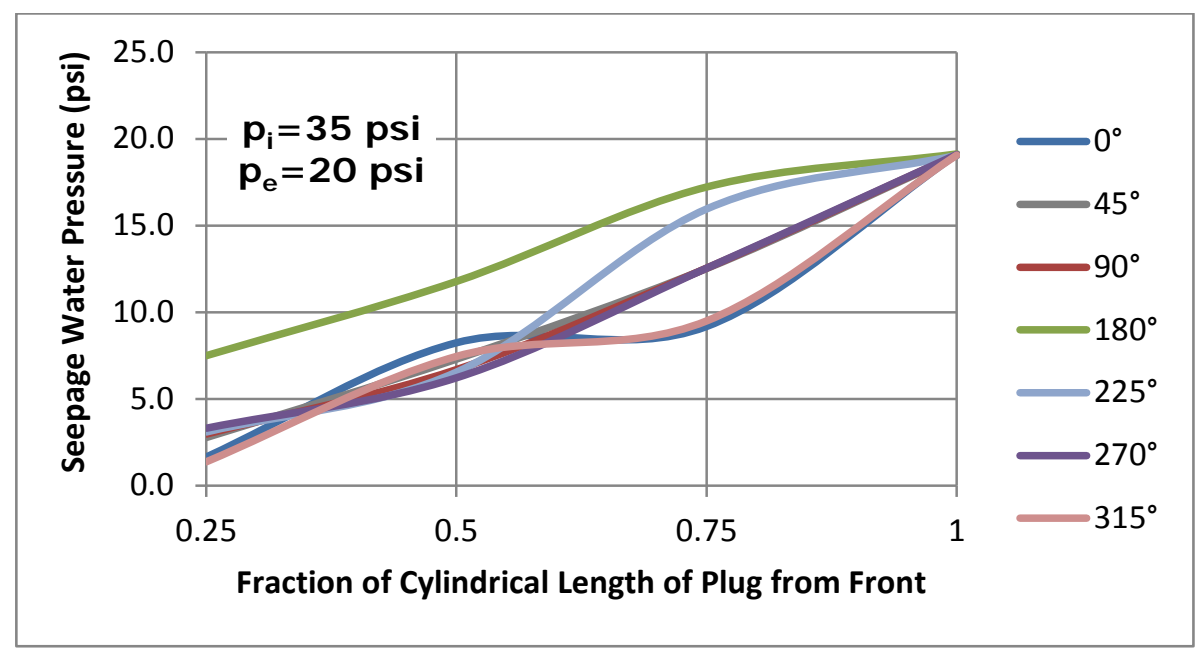

Figure 6.8: Seepage water pressure plot level 3b

Table 6.9: Seepage water pressure result level 3c

\begin{tabular}{|c|c|c|c|c|c|c|c|c|}
\hline & Location & $0^{\circ}$ & $45^{\circ}$ & $90^{\circ}$ & $180^{\circ}$ & $225^{\circ}$ & $270^{\circ}$ & $315^{\circ}$ \\
\cline { 2 - 9 } & $1^{*} \mathrm{~L}$ & 24.1 & 24.3 & 24.1 & 24.1 & 24.3 & 24.2 & 24.3 \\
\cline { 2 - 9 } $\mathrm{p}_{\mathrm{i}}=35 \mathrm{psi}$ & $0.75^{*} \mathrm{~L}$ & 12.2 & 16.4 & 16.1 & 21.8 & 20.3 & 16.0 & 12.4 \\
\cline { 2 - 9 } $\mathrm{p}_{\mathrm{e}}=25 \mathrm{psi}$ & $0.5^{\star} \mathrm{L}$ & 10.5 & 9.6 & 9.5 & 15.1 & 8.6 & 8.3 & 9.6 \\
\cline { 2 - 9 } & $0.25^{*} \mathrm{~L}$ & 1.9 & 3.5 & 4.0 & 9.7 & 4.2 & 4.6 & 1.6 \\
\hline
\end{tabular}




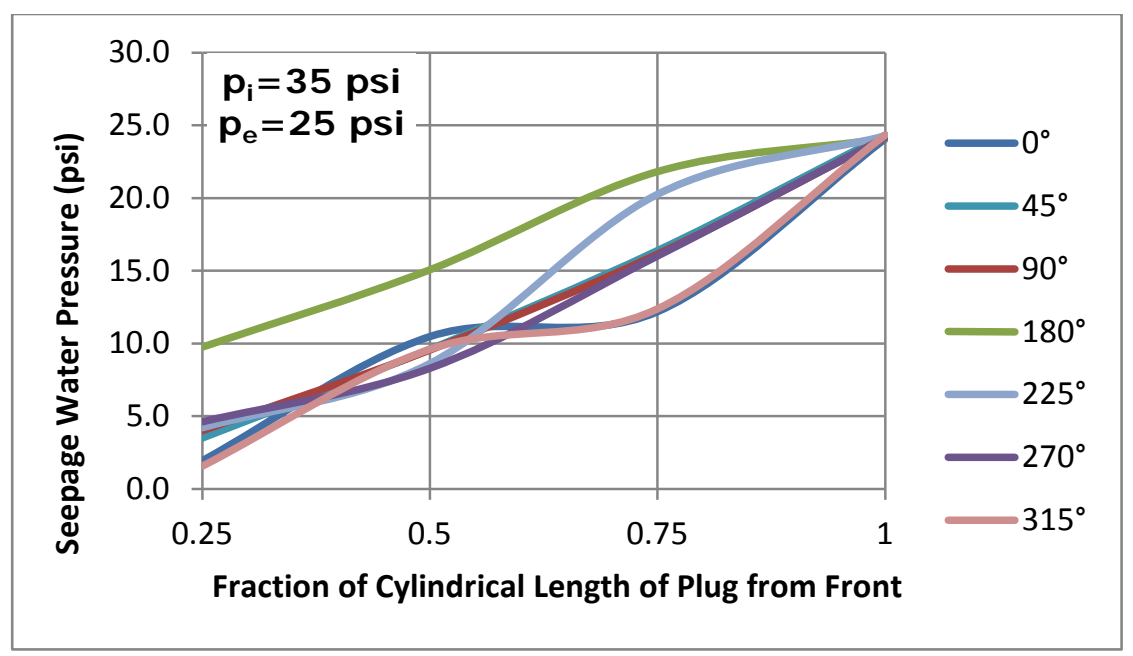

Figure 6.9: Seepage water pressure plot level 3c

\subsection{Discussions}

As seen from the plots above in Figure 6.2 to Figure 6.9 the seepage water pressure at the bottom (i.e. $180^{\circ}$ ) were significantly higher than the other pressure values except at the farthest rear point (i.e. $1^{*} \mathrm{~L}$ ). The pressure read at the bottom most point varied from the average of the pressures read at other locations around the circumference from about $0 \%$ at $1 * L$ to $200 \% 0.25^{*} \mathrm{~L}$ for different pressure levels (Table 6.1 ). Hence the coefficients of variation (COV) for the pressures at particular fraction of cylindrical length at different orientation of the circumference of the tunnel were noted. Figure 6.10 shows the variation of COV of seepage pressure from $1 * \mathrm{~L}$ to $0.25 * \mathrm{~L}$.

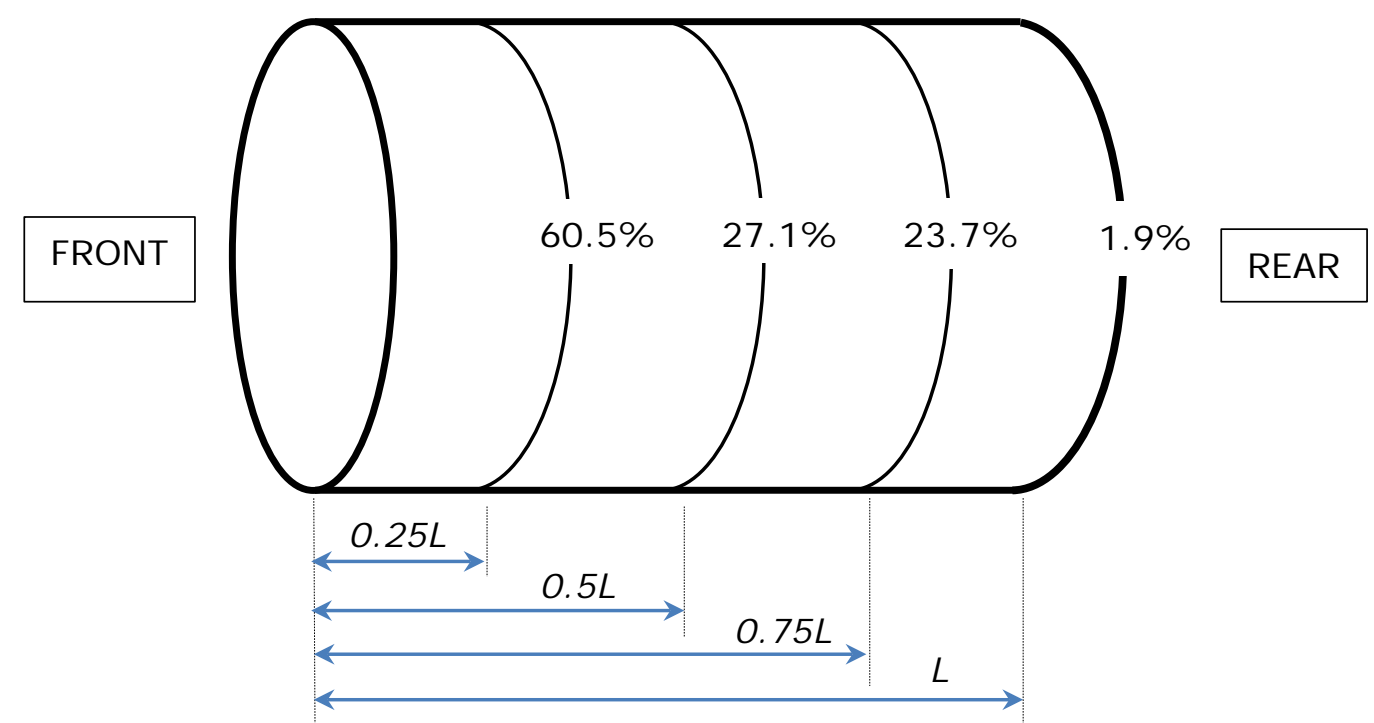

Figure 6.10: Variation of COV for seepage pressure study at various locations of circumference. 
This study illustrated in Figure 6.10 reflects the movement of seepage water in two representative directions namely horizontal and vertical. The COV at $1 * \mathrm{~L}$ of only $1.9 \%$ shows the effect of pressurized tunnel water in the immediate vicinity with reduction from the effective applied pressure due to the presence of plug webbings and the tunnel wall. The water flow is predominantly considered horizontal at this location.

At three quarter of the plug cylindrical length $\left(0.75^{*} \mathrm{~L}\right)$ from the front, the COV rises to about $23.7 \%$ (a 10 times rise). The plots from Figure 6.2 to Figure 6.9 shows a distinct variation of seepage pressure with depth, with sensors at $90^{\circ}$ and $270^{\circ}$ orientation exhibiting the same pressure. Also the sensors at $0^{\circ}$ and $315^{\circ}$ orientations represent close values of pressure as does the pair sensors at $180^{\circ}$ and $225^{\circ}$ orientations. The above plots showed that higher the depth of the sensors on circumference of the tunnel, higher were the pressures readings from them. This was an anomaly when compared with sensors at $1 * \mathrm{~L}$. This was because we do not have any effect of hydrostatic pressure with increasing depth since there was no standing water in between the webbings or between the plug surface and tunnel wall. Hence, the major reason for the variation of pressure with depth can be attributed to seepage flow in two different directions, one along the axial webbings of the plug due to its own pressure and the other along the circumferential webbings of the plug due to gravity. Lower pressure at $0^{\circ}$ and $315^{\circ}$ at $0.75^{*} \mathrm{~L}$ reflected the water exhibiting only kinetic energy due to horizontal pressurized flow. But the sensors at a radial depth of $180^{\circ}$ and $225^{\circ}$ were getting influenced by 1 ) kinetic energy of flow along axial webbings, 2) kinetic energy of flow along hoop webbings. Hence, the sensors at a greater depth reflected greater pressure.

The sensors at $0.5 * \mathrm{~L}$ and $0.25 * \mathrm{~L}$ reflected a COV of $27.1 \%$ and $60.5 \%$, respectively (see Figure 6.10). This difference in COV was primarily due to the presence of $180^{\circ}$ sensor in the study. As stated above, the variation of $180^{\circ}$ sensor from the average of other pressure for corresponding location of plug varied from about $0 \%$ at $1 * L$ to $200 \%$ at $0.25^{*} \mathrm{~L}$. The rest of the sensors showed closer readings along with the difference of the pair $0^{\circ}$ and $315^{\circ}$ showing higher pressure readings than $90^{\circ}$ and $270^{\circ}$ pair at $0.5^{*} \mathrm{~L}$ (see Figure 6.2 to Figure 6.9). This difference can be explained theoretically by stating that the loss in kinetic energy (due to loss of head from webbing friction) due to horizontal seepage flow exceeds the gain in kinetic energy (loss of hydraulic head of seepage water being converted into kinetic energy) from the circumferential flow towards gravity. The bottom $180^{\circ}$ sensor showing higher reading at the above locations can be theoretically justified by stating that the gain in kinetic energy of the circumferential seepage flow from the top to the bottom exceeds the loss in kinetic energy to the horizontal seepage flow showing higher pressure readings.

From Bernoulli principle, under incompressible flow, the mass density of the fluid is considered to be constant with the variation of fluid pressure. This prompts the following equations to be valid. 
At the rear of the plug in the tunnel as per Bernoulli's equation [32]:

$$
\frac{v^{2}}{2}+g z+\frac{P_{a}}{\rho}=K(\text { Constant })
$$

Where $\frac{v^{2}}{2}=0 ; g z=0 ; P_{a}=$ applied tunnel pressure; $g=$ acceleration due to gravity; $\rho=$ density of water.

At the location $1^{*} \mathrm{~L}$ of the sensors we have:

$$
\frac{v^{2}}{2}+g z+\frac{P_{1}}{\rho}+h_{f}=K
$$

Where $v=$ velocity of seepage water; $z=0$ (since the flow is considered horizontal/axial and there is no loss of hydraulic head); $P_{1}=$ seepage pressure at $1 * \mathrm{~L}$; $\mathrm{g}=$ acceleration due to gravity; $\rho=$ density of water; $h_{f}=$ head loss due to friction effect from the plug webbings and the tunnel wall in axial seepage flow

At location $0.75^{*} \mathrm{~L}, 0.5^{*} \mathrm{~L}$ and $0.25^{*} \mathrm{~L}$ we have

$$
\begin{gathered}
\frac{v_{h}^{2}}{2}+g z_{h}+\frac{P_{h}}{\rho}+h_{f h}=K \\
\frac{v_{v}^{2}}{2}+g z_{v}+\frac{P_{v}}{\rho}+h_{f v}=K \\
P_{(\text {measured })}=P_{h}+P_{v}
\end{gathered}
$$

Where for equation (6.3) $v_{h}=$ velocity of seepage water in the axial direction; $z_{h}=0$ (since the flow is considered horizontal/axial and there is no loss of hydraulic head); $P_{h}=$ seepage pressure due to axial flow; $h_{f h}=$ head loss due to friction effect from the plug webbings and the tunnel wall in axial seepage flow.

For equation (6.4): $v_{v}=$ velocity of seepage water in the circumferential direction; $z_{v} \neq 0=$ loss of hydraulic head due to water seepage in circumferential direction; $P_{v}=$ seepage pressure due to circumferential flow; $h_{f v}=$ head loss due to friction effect from the plug webbings and the tunnel wall in circumferential seepage flow.

For equation (6.5); $P_{(\text {measured })}=$ pressure measured from the seepage pressure sensors at $0.75 * \mathrm{~L}, 0.5^{*} \mathrm{~L}$ and $0.25 * \mathrm{~L}$ all around the circumference.

There are more number of unknowns in the above equation than the number of available equations and hence the above equations are not solvable. Values of parameters like loss of head due to webbing friction and velocity of seepage water are unknown for the above equations. The only known parameter was the pressure measured. Equation (6.1) to 
(6.5) shows only the mathematical representation of the occurrence of seepage water effect without any actual predictive results.

Figure 6.11 displays the shade of the tunnel wall after the seepage pressure test.

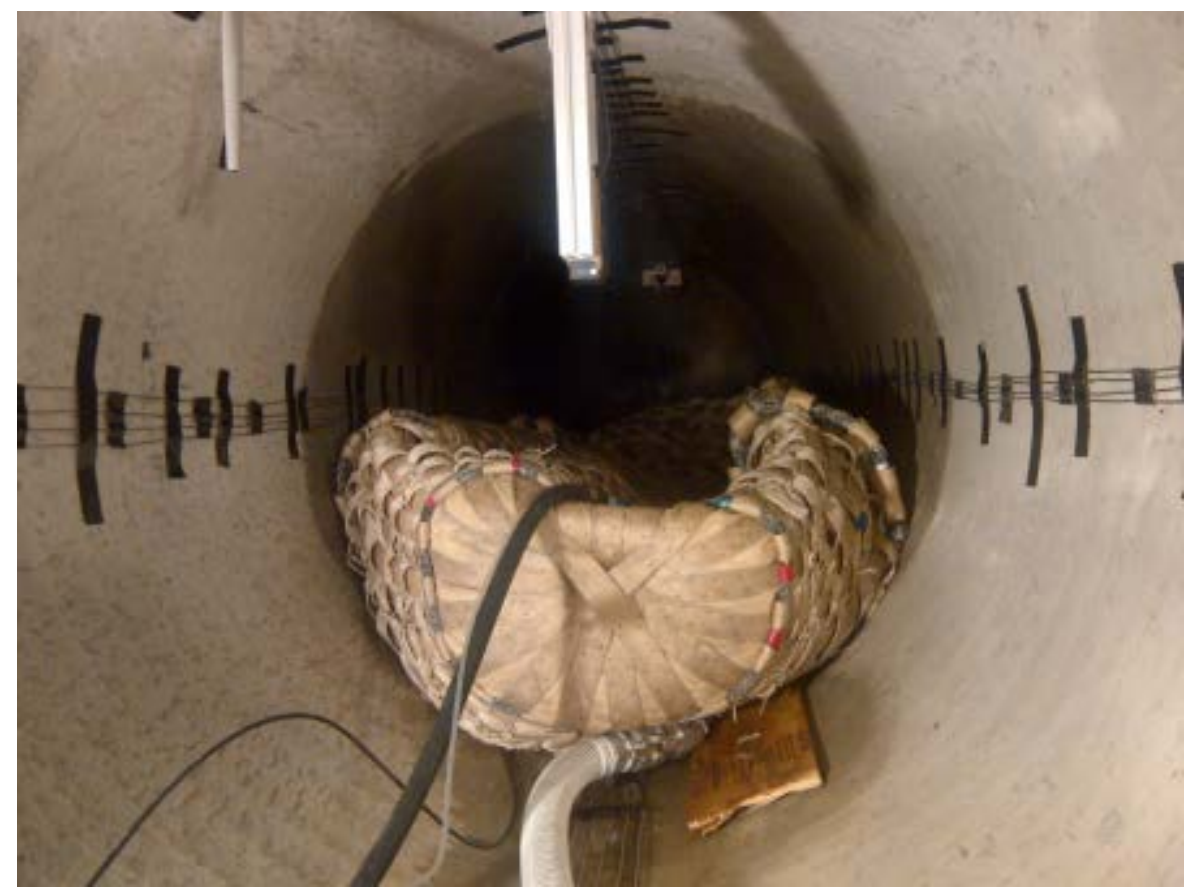

Figure 6.11: Seepage water-mark post testing on the tunnel wall

\subsection{Summary}

The seepage water pressures were recorded at circumferential depths of $0^{\circ}, 45^{\circ}, 90^{\circ}$, $180^{\circ}, 225^{\circ}, 270^{\circ}$ and $315^{\circ}$ of the tunnel wall (see Figure 3.8). Tests were conducted to record the seepage pressure behavior over a range of plug and tunnel pressures (see Table 6.1). The seepage water pressure were recorded along the rope-to-rope length (' $L$ ') of the plug at locations of $1 * \mathrm{~L}, 0.75^{*} \mathrm{~L}, 0.5^{*} \mathrm{~L}$ or $0.25^{*} \mathrm{~L}$. Three trials were conducted for each pressure combination and for each particular sensor location.

The subsequent results and plots (see Table 6.2 - Table 6.9; Figure 6.2 - Figure 6.9) were analyzed on the basis of coefficient of variation of the pressure values recorded along one circumferential length i.e. $1^{*} \mathrm{~L}, 0.75^{*} \mathrm{~L}, 0.5^{*} \mathrm{~L}$ or $0.25^{*} \mathrm{~L}$. It was observed that the $180^{\circ}$ (bottom of the tunnel) sensor pressure values for the four locations increased from around $0 \%$ at $1 * L$ to about $200 \%$ at $0.25 * L$ when compared to the average pressures of the other sensors at their corresponding locations. It was also observed that the coefficient of variation between the pressure values along certain circumferential location increased steadily from $0.25^{*} \mathrm{~L}$ to $1^{*} \mathrm{~L}$ (see Figure 6.10 ). It was also observed that the seepage water pressure increased with depth except for $1 * \mathrm{~L}$.

The deductions were made from the above observations stating that the seepage water flows in axial direction only at $1 * \mathrm{~L}$ sensor location showing a COV of $1.9 \%$. Thereafter 
the seepage water has a tendency of flowing both along circumferential direction and axial direction along the surface of the plug and the tunnel wall. The seepage water flow was abetted by the gap in circumferential and axial webbing matrix. This resulted in considerable loss of hydraulic head of flow in both the directions due to webbing friction. The texture of the woven webbings which allows water to travel from $1 * L$ (wet side) to $0 * \mathrm{~L}$ (dry side) through the interstices left between the webbings that are not fully in contact with the tunnel wall.

Seepage water flow for this plugging configuration has a considerable impact on leakage resulting in it being around 10 times higher than what was reported in [17] for the same combination of pressures.

There is no clear cut evidence that the slippage is impacted by the presence of seeping water pressure in the above study. As with the pressure values the seepage pressure at the rear at $1 * \mathrm{~L}$ and $0.75 * \mathrm{~L}$ locations are quite high and can influence the contact between the plug wall and the tunnel surface, but taking the concept of equilibrium into consideration on either side of plug wall, the concept of hydrodynamic layer in macro scale is unlikely. Additional studies including a combination of contact sensors/films and seepage pressure sensors would throw some light on the effect of seepage pressures on the system friction coefficient. This is considering the actual effective contact area captured by the contact films. 


\section{Chapter 7 Conclusions and Recommendations}

\subsection{Conclusions}

The free elongation of the plug at low pressure under unconstrained condition showed a relative shrinkage of the front end cap and normal expansion of the rear end with the increase in applied pressure. The total elongation of the end caps of the plug was found to be linear. The above tendency points at a possibility of unequal material distribution between the front and the rear. A measurement of the unconfined inflated dimensions also indicated smaller oversizing ( $2 \%$ vs. $4.2 \%$ ) with respect to single layer Vectran plug [17]. The constrained inflation was conducted at the high pressure going up till the design pressure (68 psi) and surface and corresponding contour plots were obtained for the expanding front end cap. The end cap expansion was compared for 15, 30, 45 and 60 psi. The 3-D best-fit contour and surface plot revealed expansion of the front end cap along with irregular shrinkage at certain pressures. The constrained end cap elongation showed a marked difference between the front and the rear end cap with much lower values for front end cap. This was possibly because of the presence of the inflation port on the front end cap pushing against the front end cap.

Slippage tests were conducted under various circumstances of loading, tunnel surface conditions, plug surface conditions and plug mass variation. The initial tests showed a holding resistance of $0.75-0.83$ which went down to 0.72 with change in plug effective contact length with tunnel concrete. After the extended testing, the holding resistance went up with abraded tunnel concrete and plug surface to a range of $0.97-1.14$ and with only abraded plug surface and smooth concrete it was of the range of 0.92-1.09. The friction coefficient of the system remained same for slippage tests of [17] and initial set around 0.19 but increased with tunnel concrete abrasion and plug surface abrasion to a range of $0.23-0.25$. There was also a higher level of abrasion noted on the cylindrical plug surface up front than at the rear. There was no appreciable effect noted with the change in plug mass from $100 \%$ to $75 \%$ but higher holding resistances were noted at $50 \%$ of plug mass.

Leakage tests showed a dependency on the value of pressure ratio instead of the individual values of internal or external pressures. The occurrence was guided predominantly by the following factors: 1 ) ratio of tunnel to plug pressure $\left.\left(p_{e} / p_{i}\right), 2\right)$ the amount of over-sizing of the plug with respect to tunnel diameter, 3) the plug surface characteristics and 4) plug orientation/deployment. A comparison with single layered Vectran plug [17] reflected a remarkable jump in the value of leakage by about 10 times [17] primarily change in plug surface design. Leakage mitigation with neoprene pad reflected an inconclusive result with one set of average reduction of $47 \%$ and another set of average reduction of only $9.4 \%$. This reflected the importance of the variability of plug orientation. A projection of leakage for the full scale 16' diameter plug under deployment was also estimated based on projected increase of cylindrical surface area.

Seepage water pressure tests revealed the nature of water flow between the tunnel wall and the plug surface at various points along the cylindrical length and various circumferential depths. The water flow was found to be axial at $1^{*} L$ and combination of axial and circumferential thereafter at $0.75 * \mathrm{~L}, 0.5 * \mathrm{~L}$ and $0.25 * \mathrm{~L}$. An explanation was also 
provided for the variation of pressure with increasing depth beyond $1 * L$ prompting a higher coefficient of variation as the seepage water approached the front. This occurrence has impact on leakage due to the pressure flow at the interface. But the effect of seepage water flow on the phenomenon of slippage is still inconclusive.

From the slippage tests it was found that the friction coefficient from [17] and trilayered Vectran initial tests were both around 0.19 prompting an explanation that all the other external factors like external lubrication by pressurized water seepage appears not to be affecting the system during slippage based on the coefficient of friction. It was also discovered that the rear of the plug has lesser abrasion on the cylindrical surface than on the front. The seepage pressure also has much higher value at the rear, closer to the tunnel pressure than at the front, possibly abetting the formation of separated interface between tunnel wall and plug surface. These two points makes it an inconclusive agenda based on visual effects and physical occurrence.

\subsection{Recommendations}

The constrained elongation of the plug end cap was effectively captured by the Leica lasers mounted on the aluminium laser stand. The tunnel has an internal radius of 24" whereas the farthest distance from the center of the tunnel face that was read by the laser was only 7.7". More points can be read by the lasers of the front end cap at different pressure levels for better representation of the spherical end cap between the ranges of 7.7 " to 24 " radius.

For slippage, leakage and seepage water pressure effect, an over-sizing effect on the plug can be ascertained by reducing the internal diameter of the tunnel circumference by installing concrete tiles or FRP strips on the concrete tunnel lining. The oversizing can be a total of 1 " thickness with a total reduction in diameter of 2 ".

Contact sensors can be installed at various locations of the tunnel surface to read the actual pressure exerted on the concrete wall by the plug and examine whether the plug exerts the same pressure at all locations and under all scenarios. This can throw some light on the predominant occurrence of abrasion on the front part of the cylindrical surface. The positioning of contact sensors can also be used to detect any change in contact pressure of the plug with the tunnel wall with the introduction of water and subsequent pressurization behind the plug in the tunnel space. This can throw some light on whether the effect of seepage water pressure influences the occurrence of slippage in any way. It can also provide some conclusive evidence on the theory of seepage water providing a hydrodynamic lubricating layer, abetting slip. This can provide a better estimation of the actual friction coefficient of the system.

A material of higher modulus of elasticity than neoprene can be used for leakage mitigation control provided a detailed data for allowable stresses in the plug are available for the location where the block will be placed with respect to the plug on the tunnel wall. This was to ensure that the stress concentration developed in the zone of block deployment stay within the allowable stress limit for the plug wall. 


\section{References}

1. Cadogan, D., William, G. and Smith, T. Inflatable and Rigidizable Wings for unmanned aerial vehicles, ILC Dover, 2003.

2. Cadogan, D., Scheir, C., Dixit, A., Ware, J. and Ferl, J. Intelligent Flexible Materials for Deployable Space Structures (InFlex). ILC Dover LP. 2006.

3. Beukers, A., Mölder, O. and Vermeeran, C. Inflatable Structure in Space Engineering, Journal of the International Association for Shell and Spatial Structures: IASS, vol. 41, pp. 177-190, 2000, n. 134.

4. Hanlon, Mike. Inflatable Composite Structures Enable Lightweight Transportable Buildings, 2005, http://www.gizmag.com/go/4017/

5. Nemo. Air Supported Technology. Cited Online: May 6, 2012. http://www.nemoequipment.com/airsupported_technology

6. Lindstrand Technologies. Inflatable Tunnel Plug. Cited Online: May 5, 2012. http://www.lindstrandtech.com/innovation_centre.html

7. Petersen. Case Study on Large Mine Flooding Remediation. Cited Online: May 5, 2012. http://www.petersenproducts.com/case_study/Large_Mine_Flooding_Remediation.aspx

8. Petersen. Inflatable Pipe Plugs. Cited Online: May 5, 2012. http://www.petersenproducts.com/Product_Selection_Guide/Select_Guide_Inflatable_PI ugs.aspx

9. Journal of Commerce. Inflatable Shelters Offer Protection from Elements and Explosions. Cited Online: May 5, 2012. http://www.joconl.com/article/id43330

10. Firetactics. Kings Cross Fire - London 2007, London Fire J ournal. Cited Online: March 5 , 2012. http://www. firetactics.com/KINGSCROSS.htm.

11. Randall R. and Jacobazzi, D. The Great Chicago Flood of 1992. Civil Engineering-ASCE, Vol. 62, No. 11, November 1992, pp. 52-55

12. Wikipedia. Chicago Flood. Cited Online: May 5, 2012. http://en.wikipedia.org/wiki/Chicago_Flood

13. Vectran. Tensile Properties of Vectran. Cited Online: May 5, 2012. http://www. vectranfiber.com/BrochureProductI nformation/TensileProperties. aspx

14. Department of Homeland Security. Science \& Technology. "Put a Plug In It! The SuperDuper Plugger-Upper J ust Got Better". Cited Online: J une 22, 2012. http://www.dhs.gov/files/programs/gc_1255112849504.shtm

15. "Researchers successfully test New Tunnel Safety System"; EngineeringWV Magazine, WVU College of Engineering and Mineral Resources, Fall 2009, Volume 5, Issue 2, pp. 2. Available at: http://www.statler.wvu.edu/news/magazine/EngineeringWV-Fall09.pdf 
16. Popular Mechanics. The Inflatable, 35,000-Gallon Subway Plug. Cited Online: May 5, 2012. http://www. popularmechanics.com/technology/engineering/infrastructure/theinflatable-35000-gallon-subway-plug-7795767

17. Sill, Joshua. Master's Thesis. Friction and Leakage Characteristics of Inflatable Structures in Tunnels. West Virginia University. 2011.

18. SwicoFil. About Vectran. Cited Online: May 5, 2012. http://www.swicofil.com/vectran.html

19. Department of Homeland Security. Science \& Technology. 5000 Gallons of Prevention: Containing a Tunnel Flood with an Inflatable Stopper. Cited Online: May 5, 2012. http://www.dhs.gov/files/programs/st-snapshots-35000-gallons-of-prevention. shtm

20. "Resilient Tunnel Plug Continues to Impress Research Partners"; EngineeringWV Magazine, WVU College of Engineering and Mineral Resources, Spring 2012, Volume 8, Issue 1, pp. 7. Available at: http://www.statler.wvu.edu/news/magazine/EngineeringWV_Spring12.pdf

21. wvutoday. WVU researchers successfully test tunnel plug. Cited Online: J une 22, 2012. http://wvutoday.wvu.edu/n/2011/12/21/wvu-researchers-successfully-test-tunnel-plug

22. Federal Emergency Management Agency. In Development Technology Details: Resilient Tunnel Project. Cited Online: J une 22, 2012. https://www.rkb.us/technologydetail.cfm?technologies_id=3

23. Gizmag. Giant plug for sealing off subway tunnels in a hurry. Cited Online: J une 22, 2012. http://www.gizmag.com/subway-tunnel-plug/21970/

24. ILC Dover. History of Webbed Inflatable. Cited Online: May 5, 2012. http://spirit.as. utexas. edu/ fiso/telecon/Cadogan_4-2507/ILC\%20Dover\%20Habitation\% 200verview\%20Short\%202-07.pdf

25. ICRI (International Concrete Repair Institute). Guideline for Selecting and Specifying Concrete Surface Preparation for Sealers, Coatings, and Polymer Overlays. 1997.

26. ILC Dover. Resilient Tunnel Plug. Cited Online: May 5, 2012. http://www.ilcdover.com/Resilient-Tunnel-Plug/

27. McMaster-Carr. Suction and Discharge Water Hose with Wear Strips. Cited Online: May 6, 2012. http://www. mcmaster.com/\#catalog/118/249/=hf5x6j

28. Dowdy, S., Wearden, S., and Chilko, D. Statistics for Research ( $3^{\text {rd }}$ Edition), Wiley Series in Probability and Statistics, p 240.

29. Hoyt, E., Bareuther, C. and Chamberlain, N., A Concise Physics for Engineering Students, P. Blakiston's \& Co. 
30. Ajayi, J., Fabric Smoothness, Friction and Handling, Textile Research Journal, Volume 62, Issue 1, 1992, Pages: 52 -59

31. International, ASTM. Standard Test Method for Static and Kinetic Coefficients of Friction of Plastic Film and Sheeting. ASTM D1894.

32. Young, D., Munson, B., Okishi, T. and Huebsch, W. A Brief Introduction to Fluid Mechanics. [ed.] Lea Radick. 4th. s.I.: John Wiley \& Sons, Inc., 2007. 


\section{Appendix A: Test Procedures}

\section{Procedure for Free Elongation Test:}

The following procedure was followed to conduct the free inflation test:

1. Set-up the inflation system per Figure 3.1.

2. Attach air supply hose from the supply unit to the inflation port by bypassing through an air control valve to control the rate of air flow.

3. Attach the manual pressure gauge to the air release port.

4. Verify that the test area is clean and clear of any debris or obstacles.

5. Position the Leica laser on either side of the plug (see Figure 3.1) and set them up. Laser should be pointing along the longitudinal length of the plug as shown in Figure 3.2.

6. Begin the data acquisition system and video recording.

7. Open the air control valve slowly and begin air inflation.

8. Once the test inflatable reaches shape, place the wooden brakes under the plug. Care should be taken in preventing any external deforming or loading of webbings. Ensure that the laser pointers are at the center of the plug and recording data.

9. Let the air flow in until it pressurizes to 14 inches of water i.e. 0.5 psi.

10. Visually check the shape and overall construction and take pictures.

11. Verify presence of leakages through tear in the fabric or at the junctions of the metal air-release/inflation ports.

12. Make sure that the lasers are at the center of the plug.

13. Record and save the data in independent files for each pressure level.

14. Subsequently, raise the pressure to $28,42,50,56,60,70,80$ and 90 inches of water (i.e. $1,1.5,1.7,2.0,2.1,2.5,2.8$ and 3.2 psi) and repeat steps $10,11,12$ and 13.

15. Open both the ports and drain the air out, let the plug deflate.

\section{Procedure for Constrained Elongation Test:}

The following were the test procedures for conducting the constrained elongation test:

1. Set-up the inflation system per Figure 2.2.

2. Verify that the test area is clean and clear of any debris or obstacles.

3. If the plug is already positioned from the last test proceed to step 11 else proceed to step 4.

4. Place deflated article at the center of the tunnel.

5. Attach air inflation hose to the inflation port open MV2 from Figure 2.2.

6. Attach the manual pressure gauge of range $0-100$ inches of water, to the air release port.

7. Inflate the plug with air to 28 inches of water.

8. Once the test article reaches shape, check alignment and correct any kinking of hoses.

9. Check the position of the inflation and air release port so that it does not interfere with the laser reading and we have free inflation.

10. Shut MV2, Open Valve MV1 and deflate the plug and reposition the plug if required. 
11. Fix both lasers $A$ and $B$ to the front of the plug with the bottom laser coinciding with the center of the tunnel. Ensure that the laser does not hit the hoses.

12. Activate laser 1 and 2 inside the tunnel and check whether they are reading and are well within the reading range. See Figure 3.5 and Figure 3.6 for laser positioning.

13. Begin the data acquisition system and video recording.

14. Open Valve MV4, run the pump HF1 and inflate the plug with water; keep MV1 open to release air and let the pump run unless there is a steady jet coming out of air release pipe. Then shut MV4 and open MV3 and use PR1 to pressurize the plug to about 5 psi.

15. Check the plug for any leakages.

16. Check whether there is any visual structural defect on the surface like twisted and loose webbings.

17. Increase plug pressure $\left(p_{i}\right)$ using the PR1 to 15 psi (see Table 3.3) and let it stabilize for a couple of minutes.

18. Record circular laser displacement data at the initial position. Lift the front lasers by 10 $\mathrm{cm}$ and record circular laser displacement data. Record the laser position each time on the scale attached to the laser stand. See Figure 3.5 and Figure 3.6 for laser positioning.

19. Increase to the next pressure level (Table 3.3) and repeat step 11, 15, $18 \& 19$.

20. After draining the tunnel open MV4 to release the plug pressure, close MV4, close MV14 and open MV6 and run the pump HF3 to drain the plug.

21. Stop the data acquisition and video recording

\section{Procedure for Slippage Test:}

The following were the test procedures for conducting the slippage test:

1. Set-up the inflation and pressurization system as per Figure 4.1.

2. Verify that the test area is clean and clear of any debris or obstacles. Check if there is any live wire lying on the ground where there is a possibility of having water.

3. If the plug is already positioned from the last test proceed to step 11 else proceed to step 4.

4. Place deflated article at the center of the tunnel.

5. Attach air inflation hose to the inflation port open MV2 from Figure 4.1.

6. Attach the pressure sense line to the air release port.

7. Inflate the plug with air to 28 inches of water ( 1 psi).

8. Once the test article reaches shape, check alignment and correct any kinking of hoses.

9. Check the position of the inflation and air release port so that it does not interfere with the laser reading.

10. Shut MV2, Open Valve MV1 and deflate the plug and reposition the plug if required.

11. Fix both lasers $A$ and $B$ to the front of the plug with the bottom laser coinciding with the center of the tunnel. Ensure that the laser does not hit the hoses.

12. Fix a drainage tank at the mouth of the quarter scale tunnel (as in Figure 4.1) to measure volume of water leaked and record the time of leak and the pressure of both tunnel and plug.

13. Activate laser 1 and 2 inside the tunnel and check whether they are reading and are well within the reading range. 
14. Begin the data acquisition system and video recording.

15. Open Valve MV4, run the pump HF1 and inflate the plug with water; keep MV1 open to release air and let the pump run unless there is a steady jet coming out of air release pipe. Then shut MV4 and open MV3 and use PR1 to pressurize the plug to about 5 psi. Check the plug for any leakages.

16. Increase plug pressure $\left(p_{i}\right)$ using the PR 1 and maintain certain pressure as Sequence A1, Level 1 Table 4.1

17. Open valve MV5 and MV9 and run HF2 to fill the tunnel (back of the plug) with the tunnel air release port open (Open MV13) to release all the air until and a steady jet of water comes out of the air release port. Close MV13 and MV9; Shut HF2 and activate HW2 and the High Pressure Pump to attain the pressure as in $p_{e}$ in Table 4.1 for Level 1 . Release water from the pressurized plug through manual control of MV1 such that the plug pressure remains constant at the desired pressure for forced slippage. For uncontrolled slippage (Sequence A-2) DO NOT control MV1; keep MV1 shut.

18. Check at what tunnel pressure the plug slips.

19. Do not allow displacement of more than 0.5", which if occurs, initiate depressurization of the tunnel by releasing PR2.

20. After each slippage, release the tunnel pressure. Remember to activate the immersion pump occasionally such that the drainage tank does not overflow.

21. Make sure the lasers $A$ and $B$ has not run out of battery before going to the next level.

22. Continue to Level 2 and 3 (Table 4.1) and repeat steps 11, 12, 16, 17, 18, 19, 20, 21 and 22.

23. Take pictures of the system.

24. After the completion of Sequence A-1 and A-2 continue to Sequence B as in Table 4.3.

25. Adjust plug pressure $\left(p_{i}\right)$ by PR1 and maintain certain pressure as Sequence $B$, Level 1 Table 4.3.

26. Attain the tunnel pressure as in $p_{e}$ in Table 4.3 for Level 1.

27. Reduce the pressure of the plug $\left(p_{i}\right)$ by releasing the MV1 and PR1 as in Table 4.3, Level 1.

28. Continue to Level 2 and 3 (Table 4.3) and repeat steps 11, 12, 26, 27, 28, 18, 19, 20 , 21 and 22.

29. Take pictures of the system.

30. Open MV5 to depressurize completely and begin emptying of the tunnel by closing MV5; opening MV10, MV14 and MV7 and running the pump HF3 to drain the water back into the tank.

31. After draining the tunnel open MV4 to release the plug pressure, close MV4, close MV14 and open MV6 and run the pump HF3 to drain the plug.

32. Stop the data acquisition and video recording.

\section{Procedure for Leakage Test:}

The following were the test procedures for conducting the leakage test:

1. Set-up the inflation system per Figure 4.1.

2. Verify that the test area is clean and clear of any debris or obstacles. Check if there is any live wire lying on the ground where there is a possibility of having water. 
3. If the plug is already positioned from the last test proceed to step 11 else proceed to step 4.

4. Place deflated plug at the center of the tunnel.

5. Attach air inflation hose to the inflation port open MV2 from Figure 4.1.

6. Attach the pressure sense line to the air release port.

7. Inflate the plug with air to 28 inches of water (1 psi).

8. Once the test plug reaches shape, check alignment and correct any kinking of hoses.

9. Check the position of the inflation and air release port so that it does not interfere with the laser reading and we have free inflation.

10. Shut MV2, Open Valve MV1 and deflate the plug and reposition the plug if required.

11. Fix both lasers $A$ and $B$ to the front of the plug with the bottom laser coinciding with the center of the tunnel. Ensure that the laser does not hit the hoses.

12. Fix a drainage tank on a weighing scale at the mouth of the quarter scale tunnel (as in Figure 4.1) to measure mass of water leaked. Fix the drainage tank with two immersion pumps to recycle the water back in to the water tank.

13. Activate laser 1 and 2 inside the tunnel and check whether they are reading and are well within the reading range.

14. Begin the data acquisition system and video recording.

15. Open Valve MV4, run the pump HF1 and inflate the plug with water; keep MV1 open to release air and let the pump run unless there is a steady jet coming out of air release pipe. Then shut MV4 and open MV3 and use PR1 to pressurize the plug to about 5 psi. Check the plug for any leakages.

16. Increase plug pressure $\left(p_{i}\right)$ using the PR1 and maintain certain pressure as in Level 1 Table 5.1.

17. Open valve MV5 and MV9 and run HF2 to fill the tunnel (back of the plug) with the tunnel air release port open (Open MV13) to release all the air until and a steady jet of water comes out of the air release port. Close MV13 and MV9; Shut HF2 and activate HW2 and the High Pressure Pump to attain the pressure as in $p_{e}$, Table 5.1 for Level 1.

18. Control valve MV1 to keep a steady plug pressure.

19. Let the tunnel pressure stabilize for a minute.

20. Check the leakage for Level 1 by allowing the leaked water to flow in the drainage tank, let the tank fill up, drain the tank with the submersible pump and let it fill again. Continue this to get 4-5 set of drainage tank filling data.

21 . Do not allow the plug and the tunnel pressure to vary beyond \pm 0.5 psi from the designated value.

22. Continue to Level 2-8 (Table 5.1) and repeat steps 18, 19, 20, 21 and 22.

23. Take pictures of the system.

24. Open MV5 to depressurize completely and begin emptying of the tunnel by closing MV5; opening MV10, MV14 and MV7 and running the pump HF3 to drain the water back into the tank.

25. After draining the tunnel open MV4 to release the plug pressure, close MV4, close MV14 and open MV6 and run the pump HF3 to drain the plug.

26. Stop the data acquisition and video recording. 


\section{Procedure for Seepage Pressure Study:}

1. Set-up the inflation system per Figure 6.1. Set up the pore pressure lines at the rear transverse tie i.e. $1^{*} \mathrm{~L}, 0.75^{*} \mathrm{~L}, 0.5^{*} \mathrm{~L} \& 0.25^{*} \mathrm{~L}(\mathrm{~L}=$ Cylindrical Length of the plug $)$ at $0^{\circ}, 90^{\circ}, 180^{\circ} \& 270^{\circ}$, followed by set up at $45^{\circ}, 180^{\circ}, 225^{\circ}$ and $315^{\circ}$.

2. Verify that the test area is clean and clear of any debris or obstacles. Check if there is any live wire lying on the ground where there is a possibility of having water.

3. If the plug is already positioned from the last test proceed to step 11 else proceed to step 4.

4. Place deflated article at the center of the tunnel.

5. Attach air inflation hose to the inflation port open MV2 from Figure 6.1.

6. Attach the pressure sense line to the air release port.

7. Inflate the plug with air to 28 inches of water (1 psi).

8. Once the test article reaches shape, check alignment and correct any kinking of hoses.

9. Check the position of the inflation and air release port so that it does not interfere with the laser reading and we have free inflation.

10. Shut MV2, Open Valve MV1 and deflate the plug and reposition the plug if required

11. Fix both lasers $A$ and $B$ to the front of the plug with the bottom laser coinciding with the center of the tunnel. Ensure that the laser does not hit the hoses.

12. Fix a drainage tank at the mouth of the quarter scale tunnel to measure volume of water leaked and record the time of leak and the pressure of both tunnel and plug. Fix the drainage tank with two immersion pumps as shown in Figure 6.1.

13. Activate laser 1 and 2 inside the tunnel and check whether they are reading and are well within the reading range.

14. Begin the data acquisition system and video recording.

15. Open Valve MV4, run the pump HF1 and inflate the plug with water; keep MV1 open to release air and let the pump run unless there is a steady jet coming out of air release pipe. Then shut MV4 and open MV3 \& activate HW1 and use PR1 to pressurize the plug to about 5 psi. Check the plug for any leakages.

16. Increase plug pressure $\left(p_{i}\right)$ using the PR1 to 25 psi.

17. Open valve MV5 and MV9 and run HF2 to fill the tunnel (back of the plug) with the tunnel air release port open (Open MV13) to release all the air until and a steady jet of water comes out of the air release port. Close MV13 and MV9; Shut HF2 and activate HW2 and the high pressure pump to attain the pressure as in $p_{e}$ of 10 psi. Release water from the pressurized plug through manual control of MV1 such that the plug pressure remains constant at the desired pressure.

18. Record the pore pressure data for all the location as mentioned in Step 1 by opening any one of the pore pressure measuring system valves (depending on the location under study). Read the pressure as long as it stabilizes. Repeat this step for three iterations.

19. Follow Figure 3.3 and adjust the plug pressure as per the next level and repeat step 18.

20. Take pictures of the system. 
21. Open MV5 to depressurize completely and begin emptying of the tunnel by closing MV5; opening MV10, MV14 and MV7 and running the pump HF3 to drain the water back into the tank.

22. After draining the tunnel open MV4 to release the plug pressure, close MV4, close MV14 and open MV6 and run the pump HF3 to drain the plug. 


\section{Appendix B: Front End Cap Surface Plot Data}

Table B-1: Laser A, 3.8" radius of rotation by $360^{\circ}$

\begin{tabular}{|c|c|c|}
\hline Plug Pressure(psi) & $\begin{array}{l}\text { Position of Stand mounted } \\
\text { Lasers (degrees) }\end{array}$ & Elongation ( Laser A) (in) \\
\hline 15 & 0 & 0.00 \\
\hline 30 & 0 & 0.16 \\
\hline 45 & 0 & 0.30 \\
\hline 60 & 0 & 0.34 \\
\hline 68 & 0 & 0.41 \\
\hline 15 & 45 & 0.00 \\
\hline 30 & 45 & 0.12 \\
\hline 45 & 45 & 0.25 \\
\hline 60 & 45 & 0.27 \\
\hline 68 & 45 & 0.39 \\
\hline 15 & 90 & 0.00 \\
\hline 30 & 90 & 0.05 \\
\hline 45 & 90 & 0.17 \\
\hline 60 & 90 & 0.17 \\
\hline 68 & 90 & 0.26 \\
\hline 15 & 135 & 0.00 \\
\hline 30 & 135 & 0.06 \\
\hline 45 & 135 & 0.08 \\
\hline 60 & 135 & 0.12 \\
\hline 68 & 135 & 0.11 \\
\hline 15 & 180 & 0.00 \\
\hline 30 & 180 & 0.04 \\
\hline 45 & 180 & 0.07 \\
\hline 60 & 180 & 0.06 \\
\hline 68 & 180 & 0.10 \\
\hline 15 & 225 & 0.00 \\
\hline 30 & 225 & 0.02 \\
\hline 45 & 225 & 0.06 \\
\hline 60 & 225 & 0.06 \\
\hline 68 & 225 & 0.10 \\
\hline 15 & 270 & 0.00 \\
\hline 30 & 270 & 0.32 \\
\hline 45 & 270 & 0.19 \\
\hline 60 & 270 & 0.35 \\
\hline 68 & 270 & 0.41 \\
\hline 15 & 315 & 0.00 \\
\hline 30 & 315 & 0.21 \\
\hline 45 & 315 & 0.24 \\
\hline 60 & 315 & 0.30 \\
\hline 68 & 315 & 0.35 \\
\hline
\end{tabular}


Table B-2: Laser A (7.7") and Laser B (3.9") radius of rotation by $360^{\circ}$

\begin{tabular}{|c|c|c|c|}
\hline Plug Pressure(psi) & \begin{tabular}{c|}
$\begin{array}{c}\text { Degree of } \\
\text { Rotation }\end{array}$ \\
\end{tabular} & \begin{tabular}{|c|}
$\begin{array}{c}\text { Elongation ( Laser A) } \\
\text { (in) }\end{array}$ \\
\end{tabular} & $\begin{array}{c}\begin{array}{c}\text { Elongation ( Laser B) } \\
\text { (in) }\end{array} \\
\end{array}$ \\
\hline 15 & 0 & NA & 0.00 \\
\hline 30 & 0 & NA & 0.20 \\
\hline 45 & 0 & NA & 0.22 \\
\hline 60 & 0 & NA & 0.33 \\
\hline 68 & 0 & NA & 0.37 \\
\hline 15 & 45 & 0.00 & 0.00 \\
\hline 30 & 45 & 0.39 & 0.12 \\
\hline 45 & 45 & 0.33 & 0.15 \\
\hline 60 & 45 & 0.44 & 0.27 \\
\hline 68 & 45 & 0.53 & 0.28 \\
\hline 15 & 90 & 0.00 & 0.00 \\
\hline 30 & 90 & 0.20 & 0.12 \\
\hline 45 & 90 & 0.14 & 0.18 \\
\hline 60 & 90 & 0.21 & 0.21 \\
\hline 68 & 90 & 0.28 & 0.24 \\
\hline 15 & 135 & 0.00 & 0.00 \\
\hline 30 & 135 & 0.00 & 0.03 \\
\hline 45 & 135 & -0.07 & 0.03 \\
\hline 60 & 135 & -0.11 & 0.04 \\
\hline 68 & 135 & -0.11 & 0.01 \\
\hline 15 & 180 & 0.00 & 0.00 \\
\hline 30 & 180 & -0.04 & 0.00 \\
\hline 45 & 180 & -0.12 & 0.03 \\
\hline 60 & 180 & -0.18 & 0.05 \\
\hline 68 & 180 & -0.09 & 0.09 \\
\hline 15 & 225 & 0.00 & 0.00 \\
\hline 30 & 225 & -0.06 & -0.07 \\
\hline 45 & 225 & -0.08 & -0.02 \\
\hline 60 & 225 & 0.04 & -0.05 \\
\hline 68 & 225 & -0.05 & 0.00 \\
\hline 15 & 270 & 0.00 & 0.00 \\
\hline 30 & 270 & 0.33 & 0.07 \\
\hline 45 & 270 & 0.25 & 0.14 \\
\hline 60 & 270 & 0.22 & 0.20 \\
\hline 68 & 270 & 0.42 & 0.20 \\
\hline 15 & 315 & 0.00 & 0.00 \\
\hline 30 & 315 & 0.18 & 0.18 \\
\hline 45 & 315 & 0.21 & 0.21 \\
\hline 60 & 315 & 0.31 & 0.31 \\
\hline 68 & 315 & 0.31 & 0.31 \\
\hline
\end{tabular}




\section{Appendix C: Extended Test Slippage Plots}
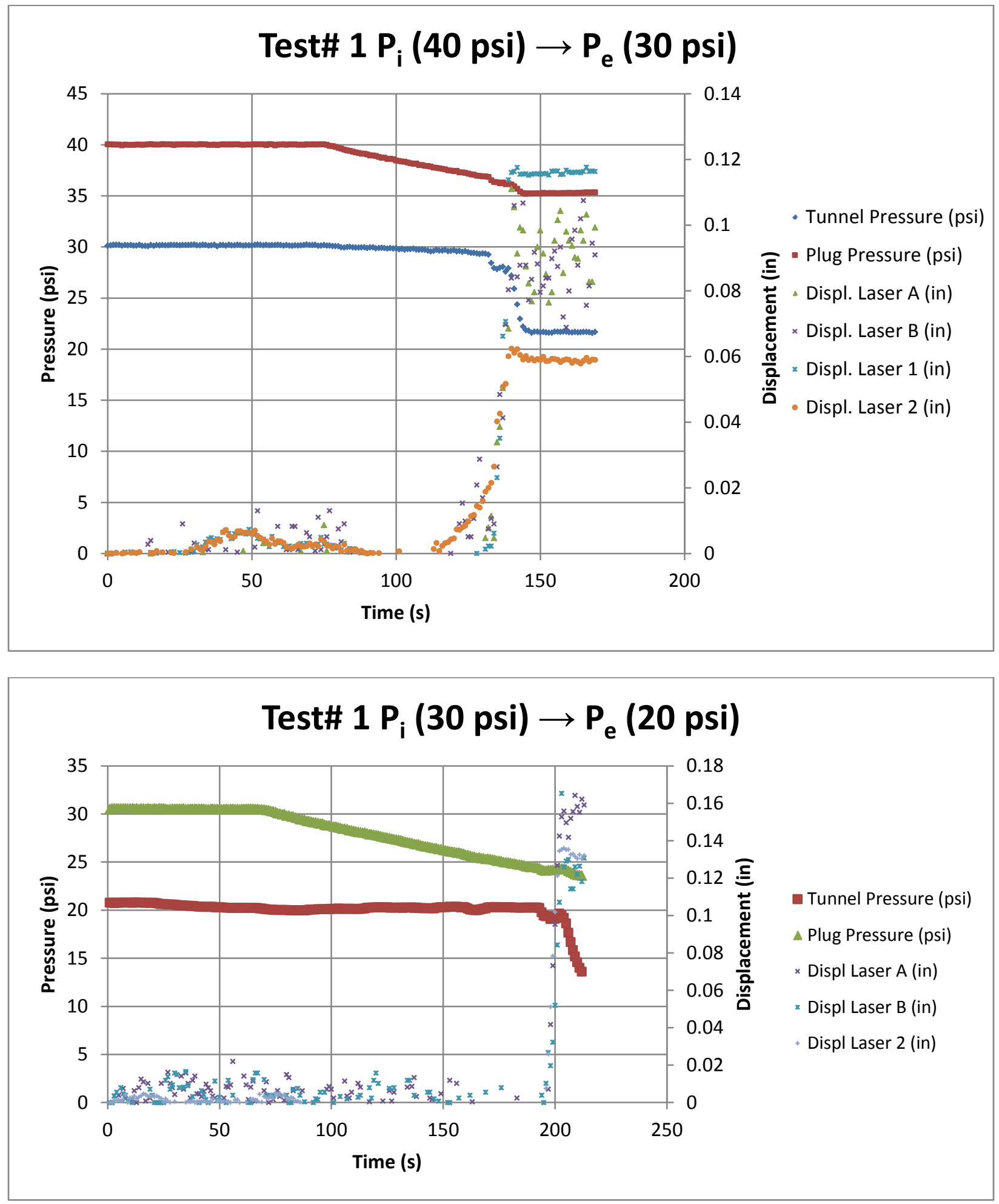

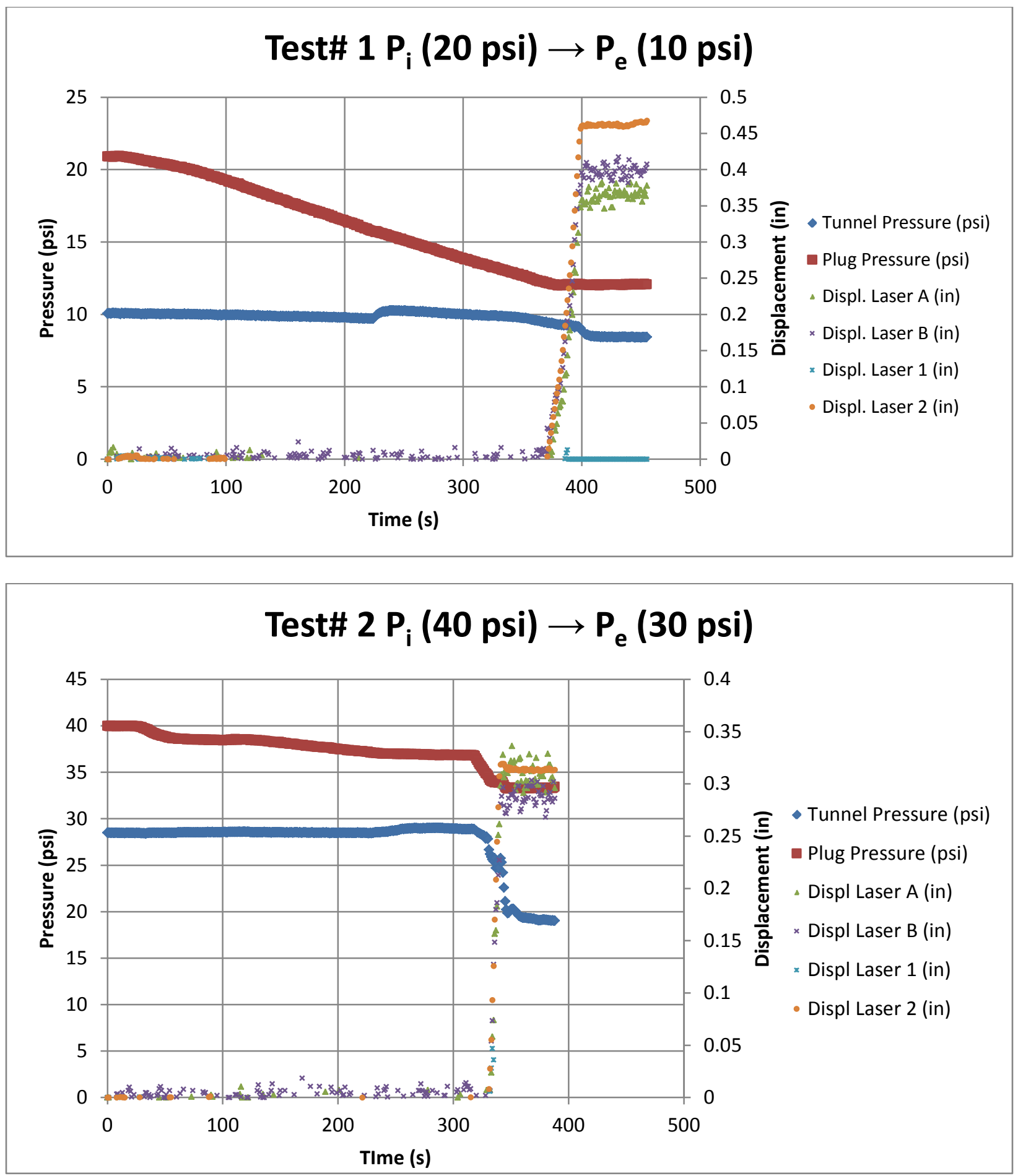

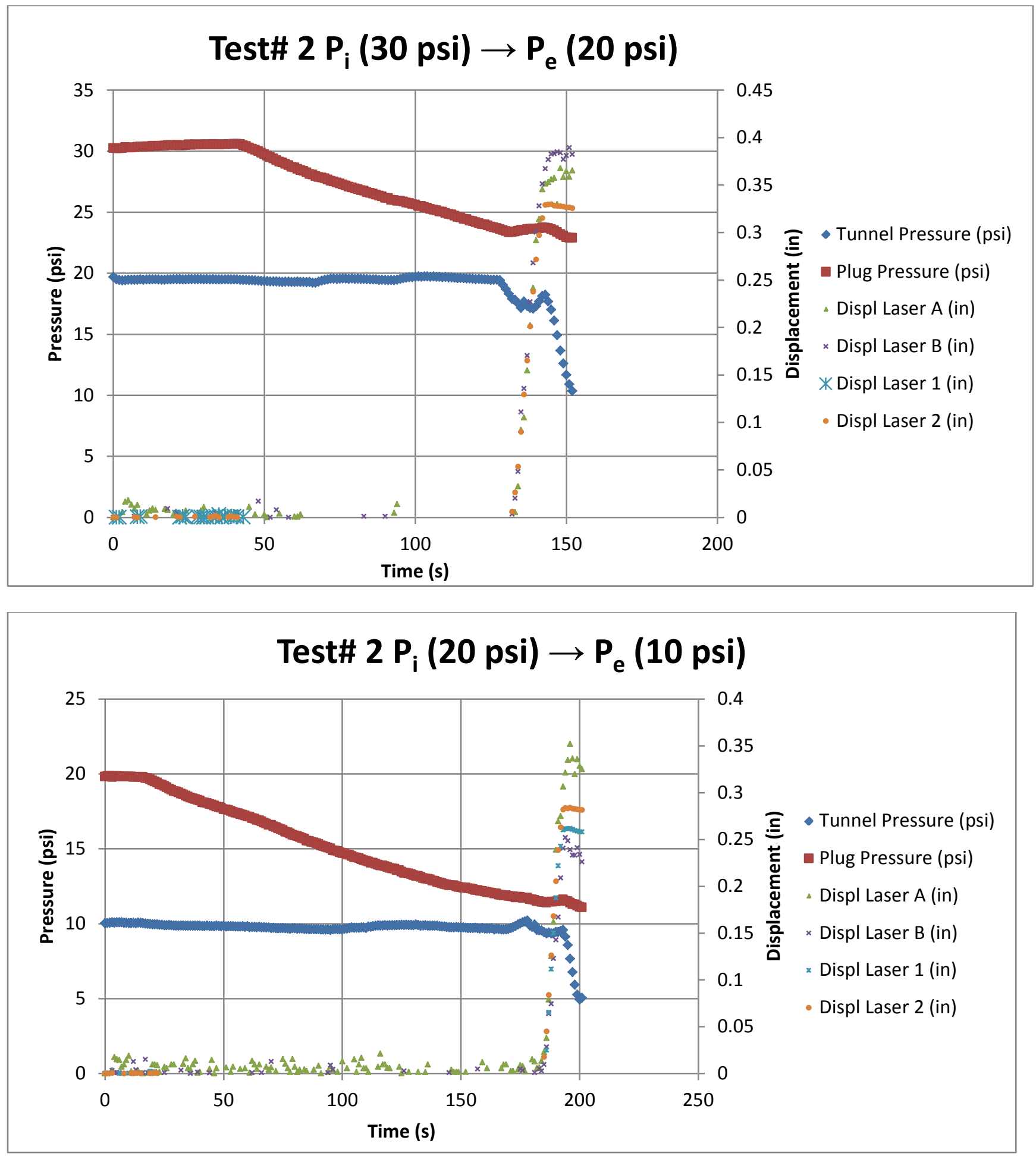

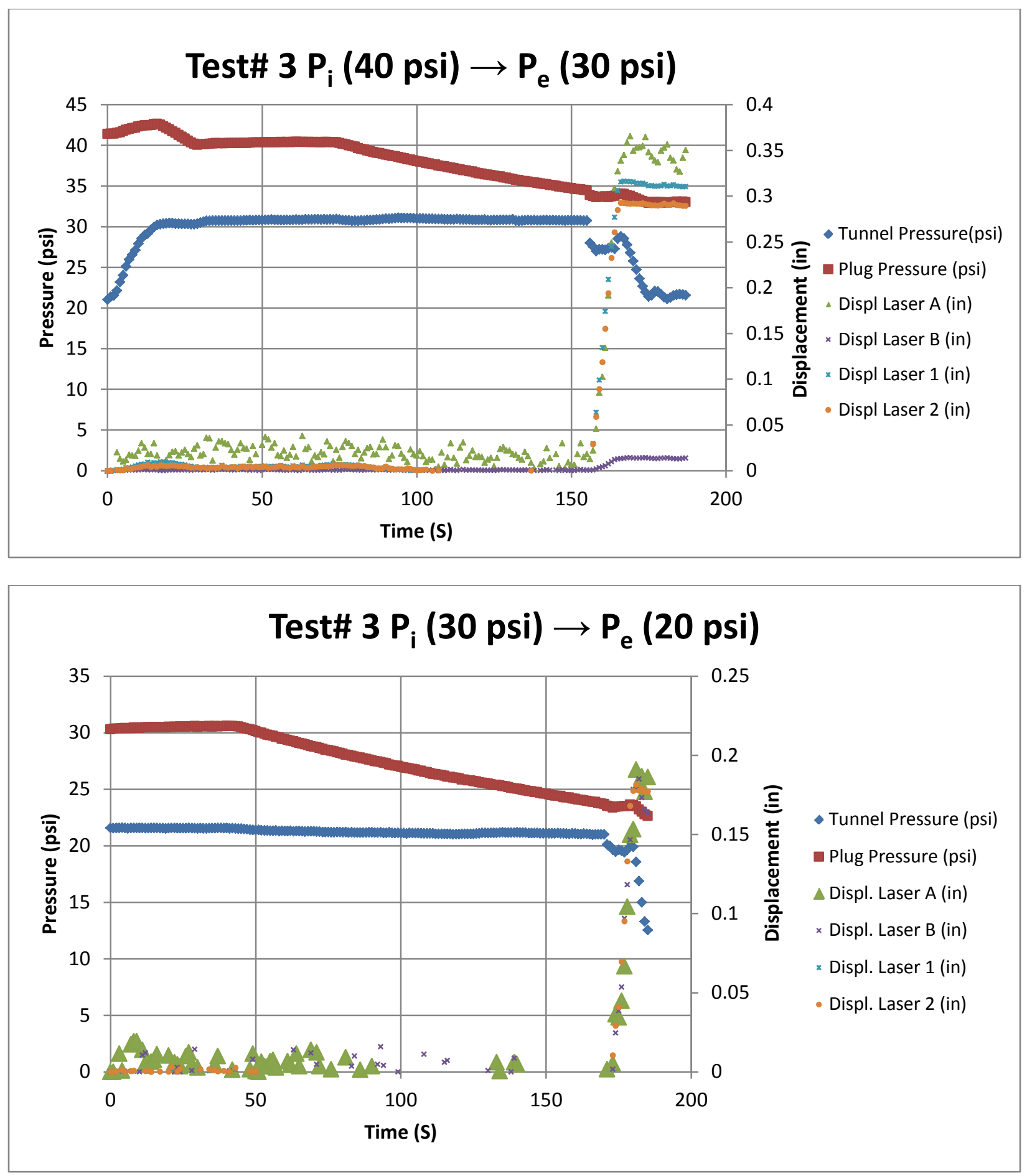

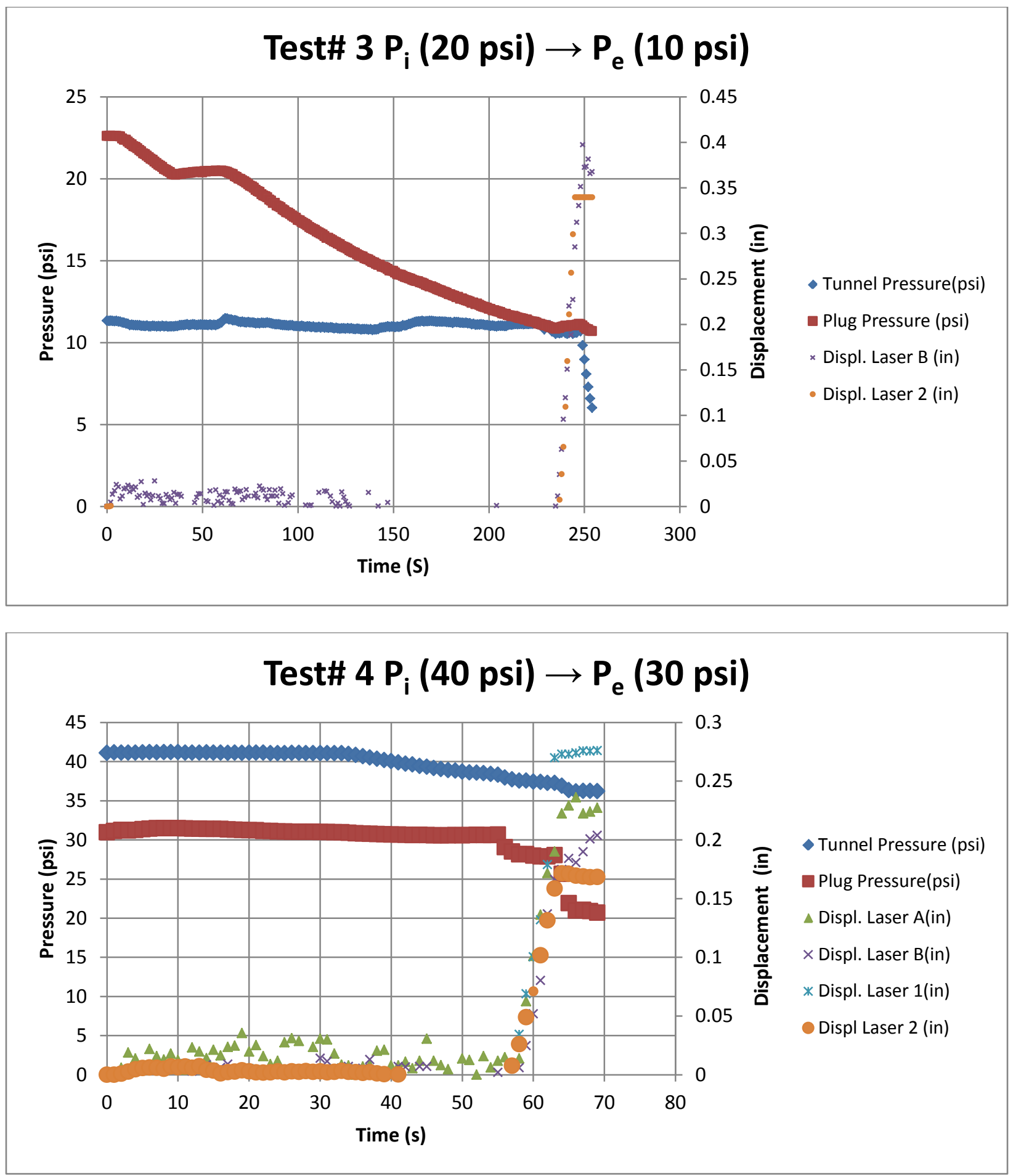

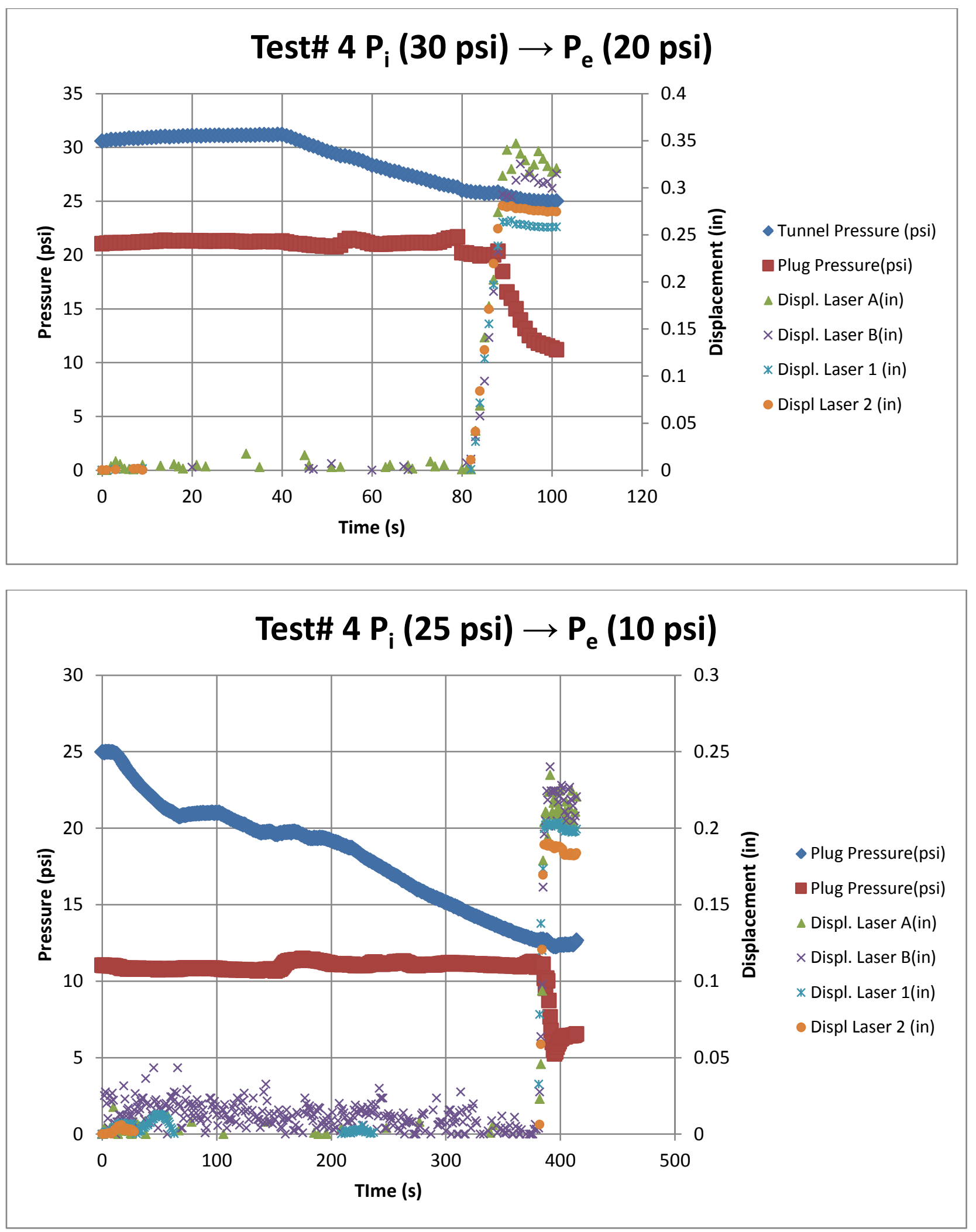

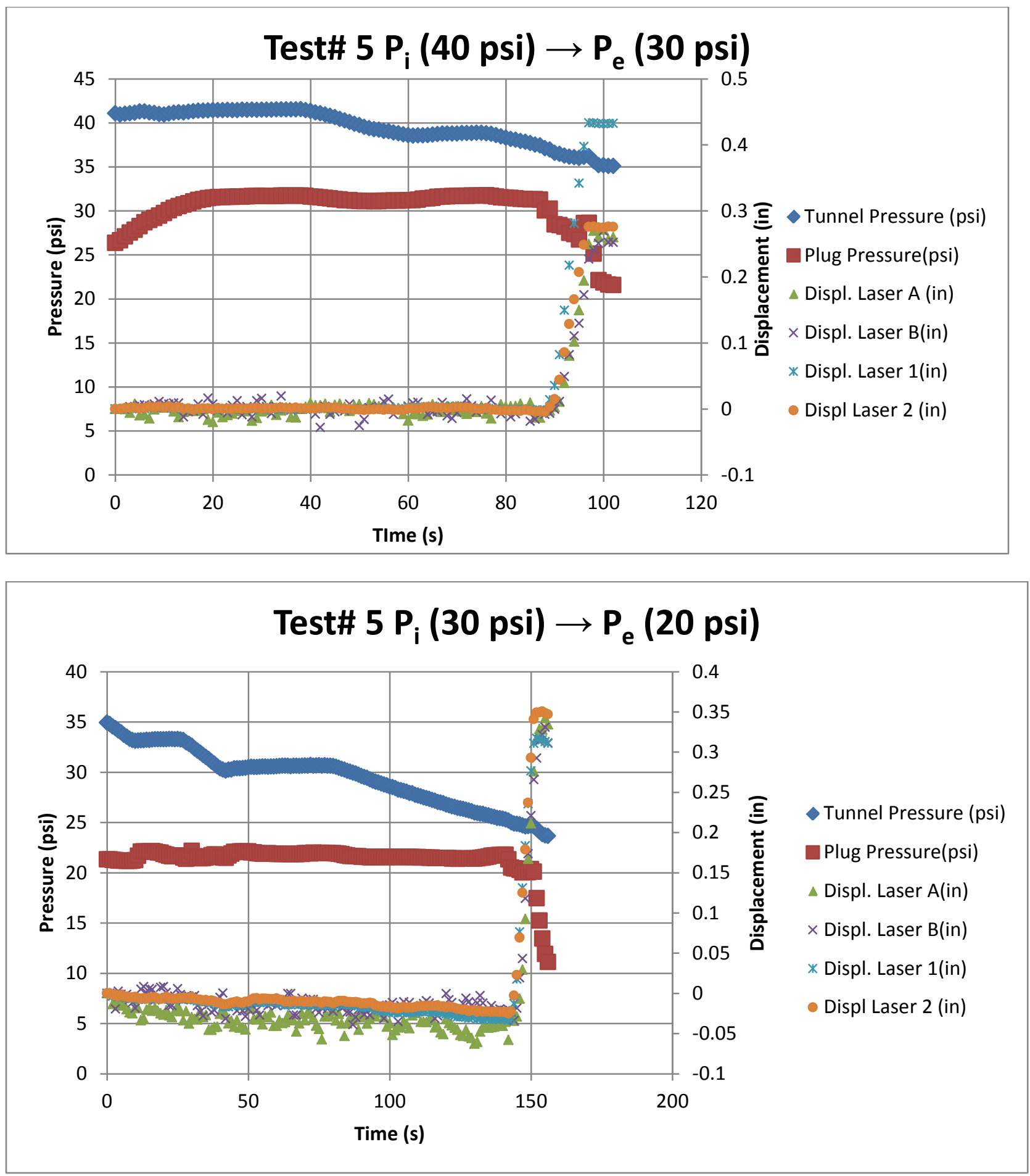

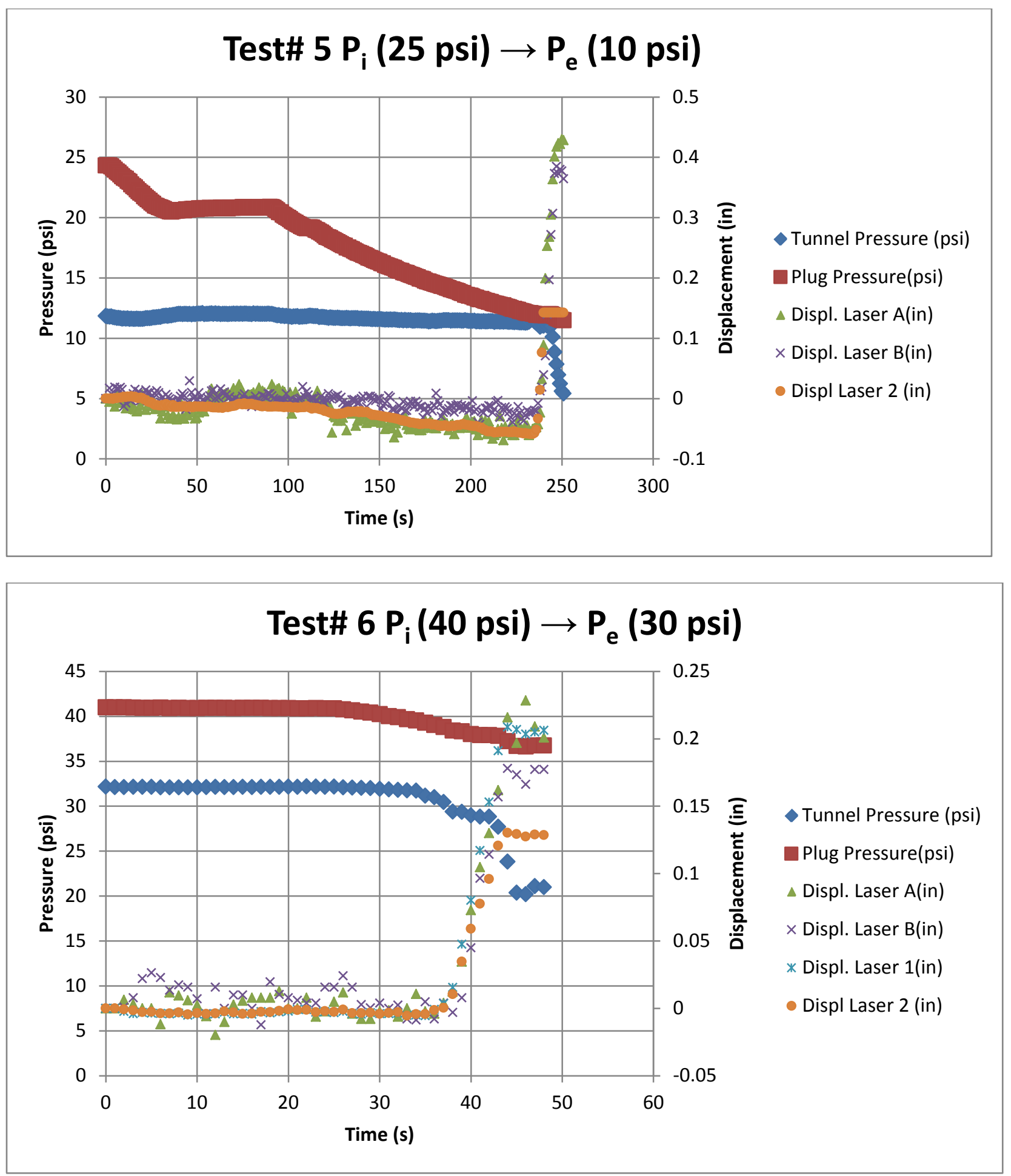

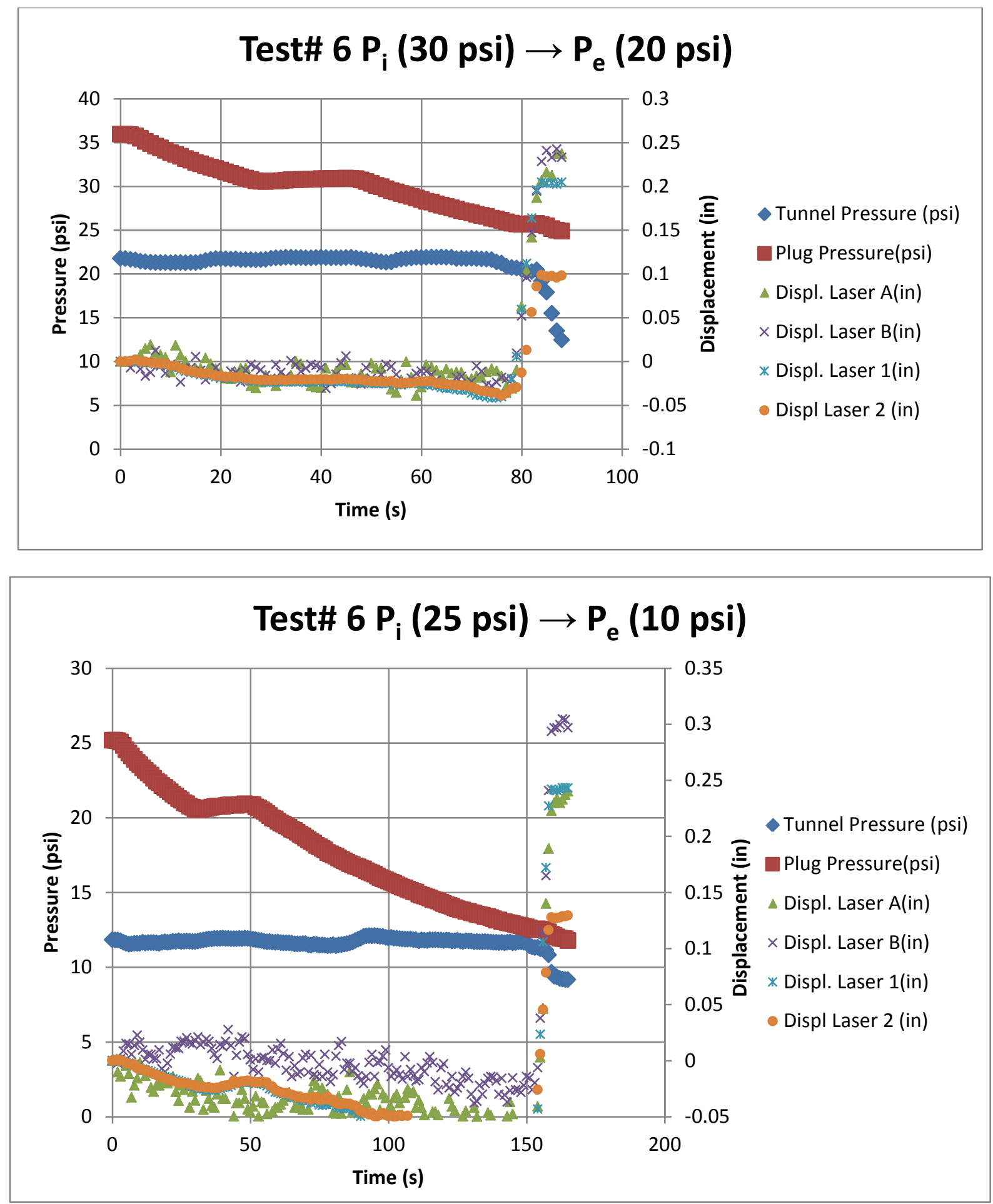

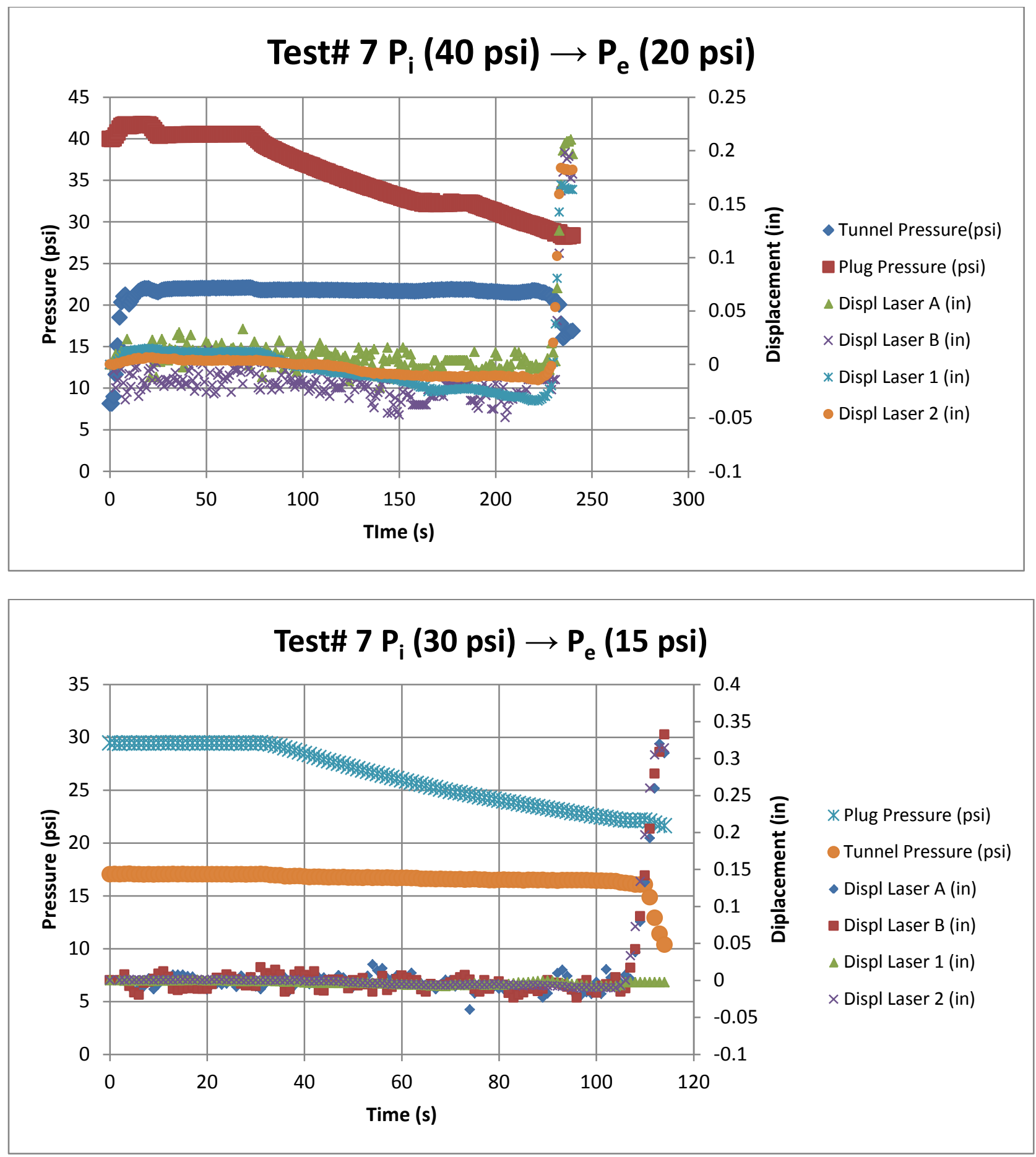

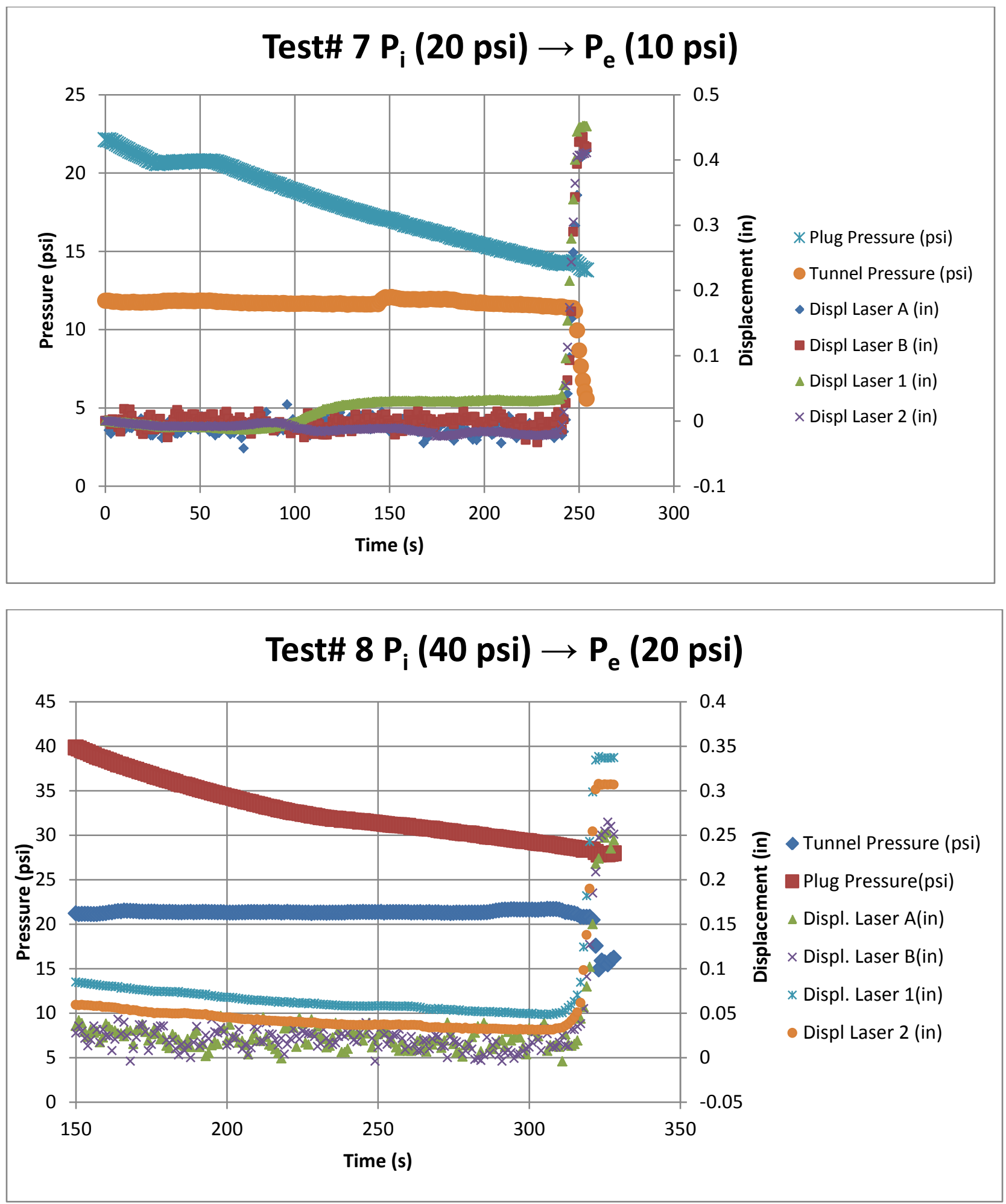

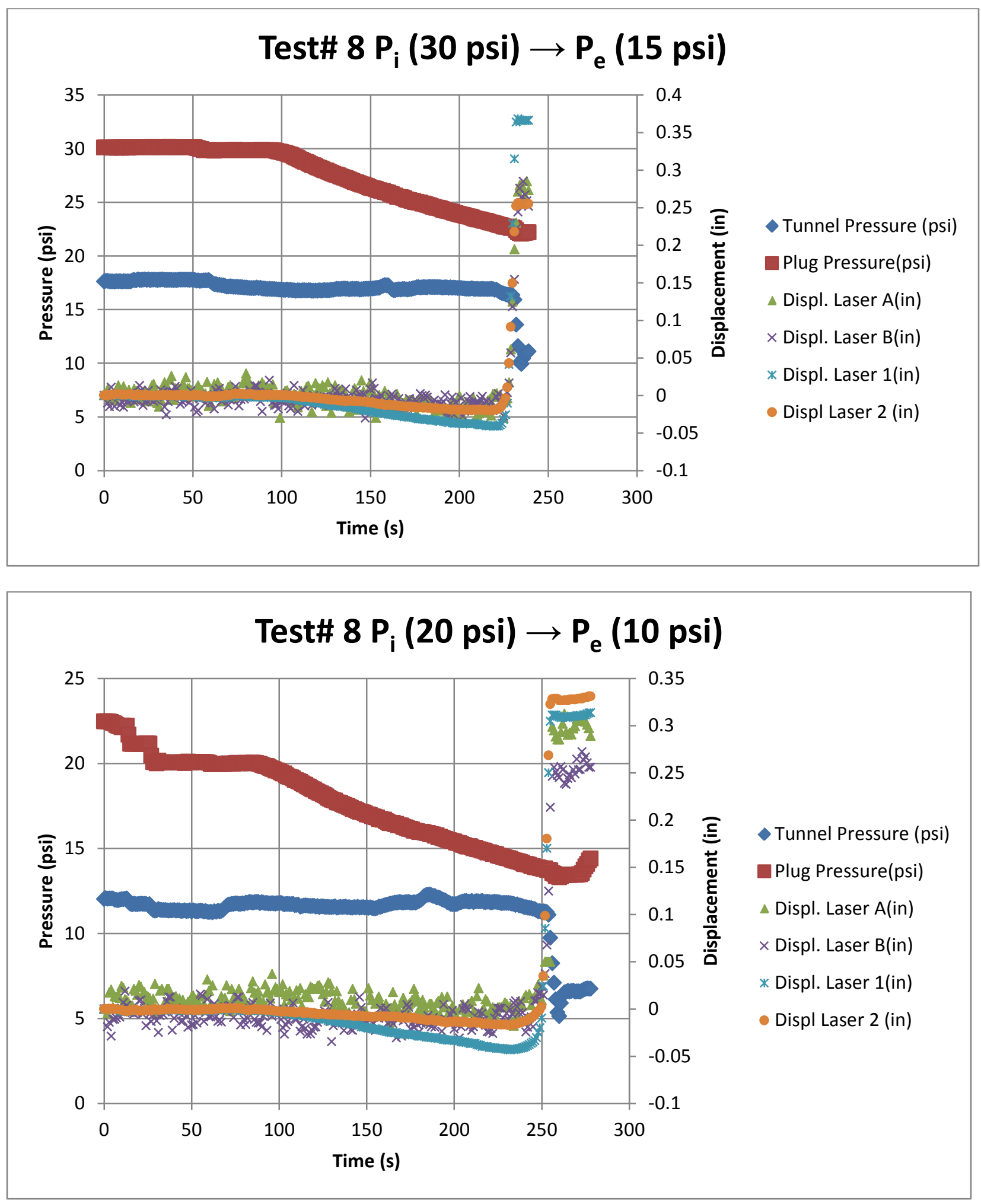

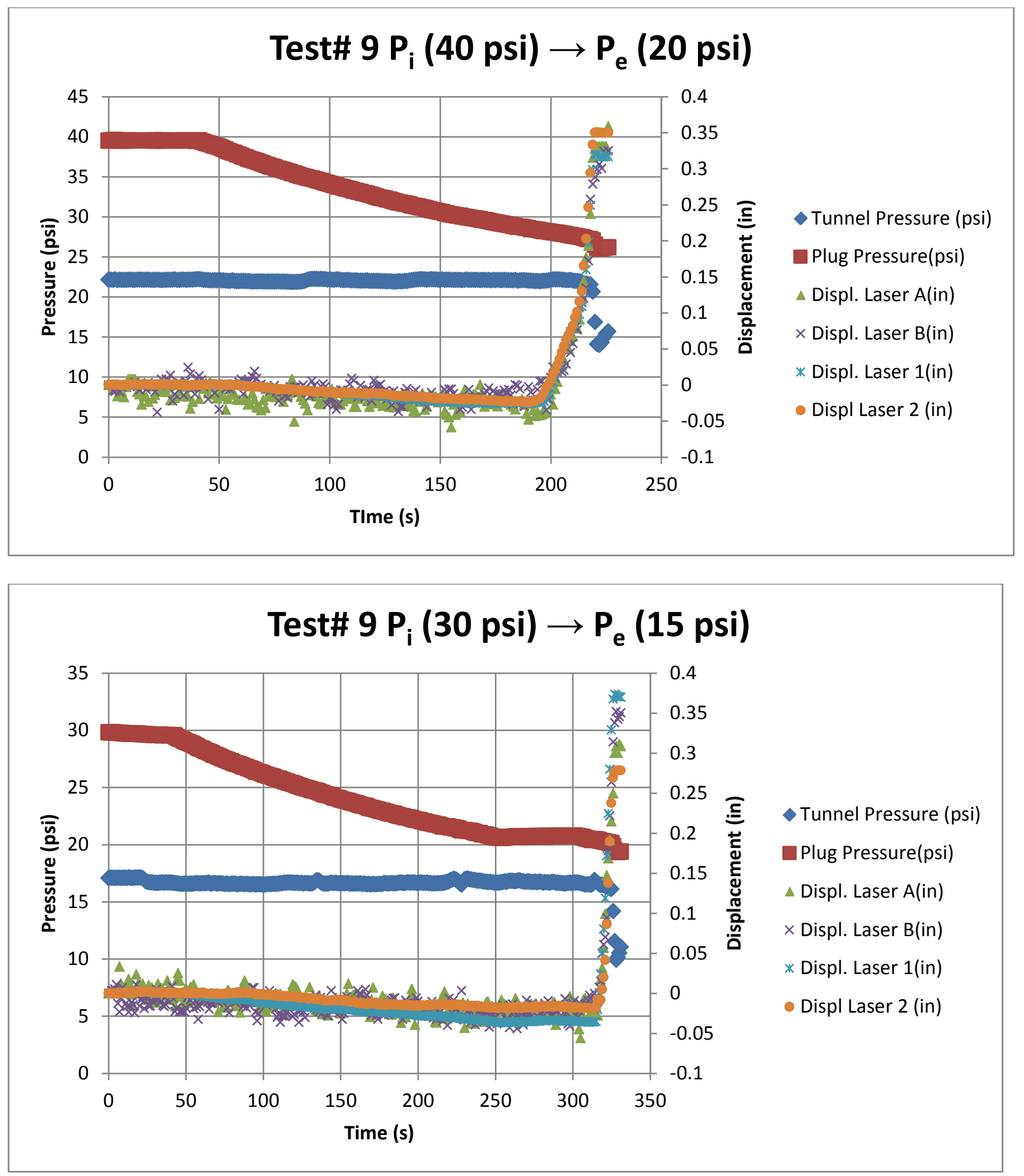

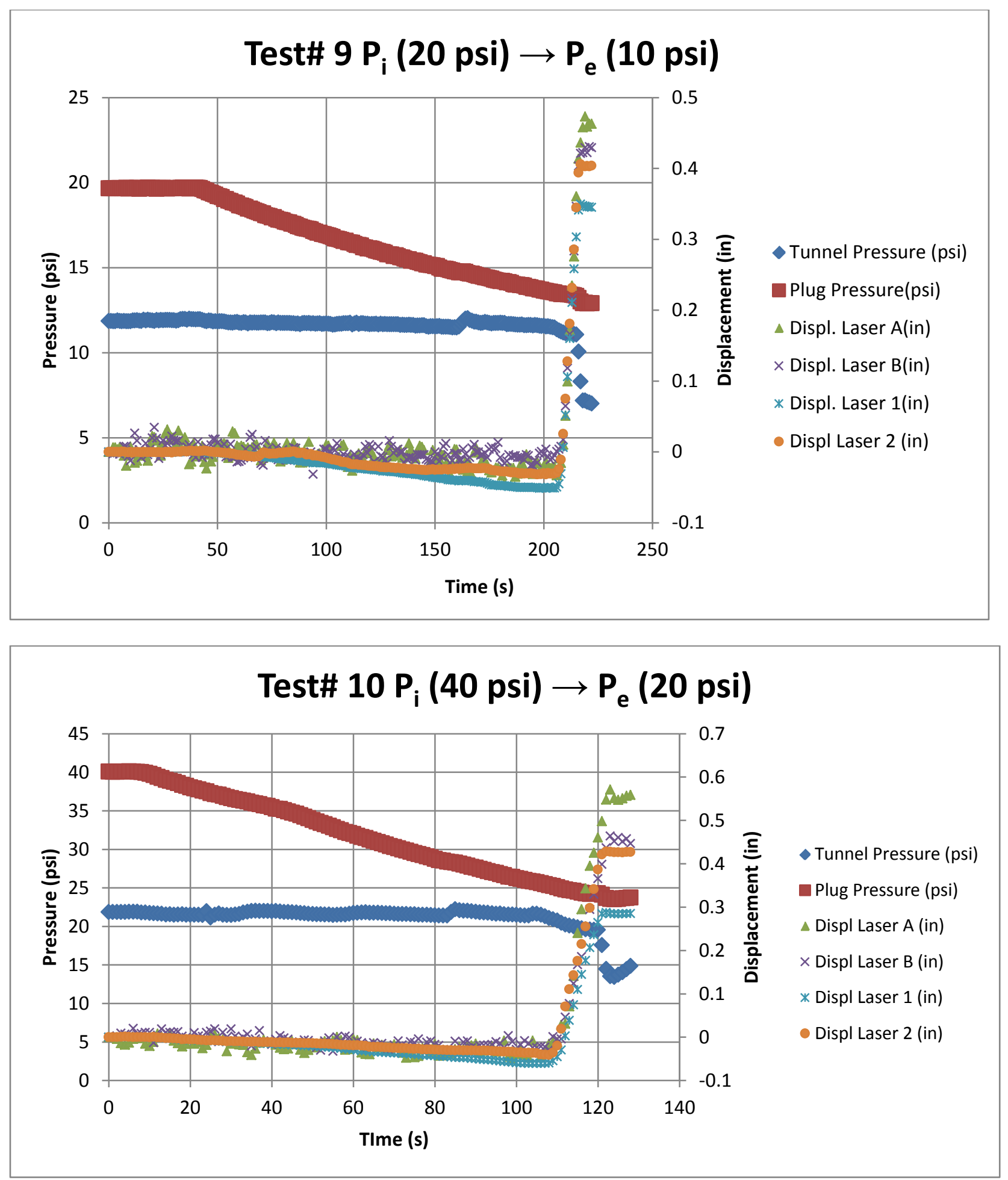

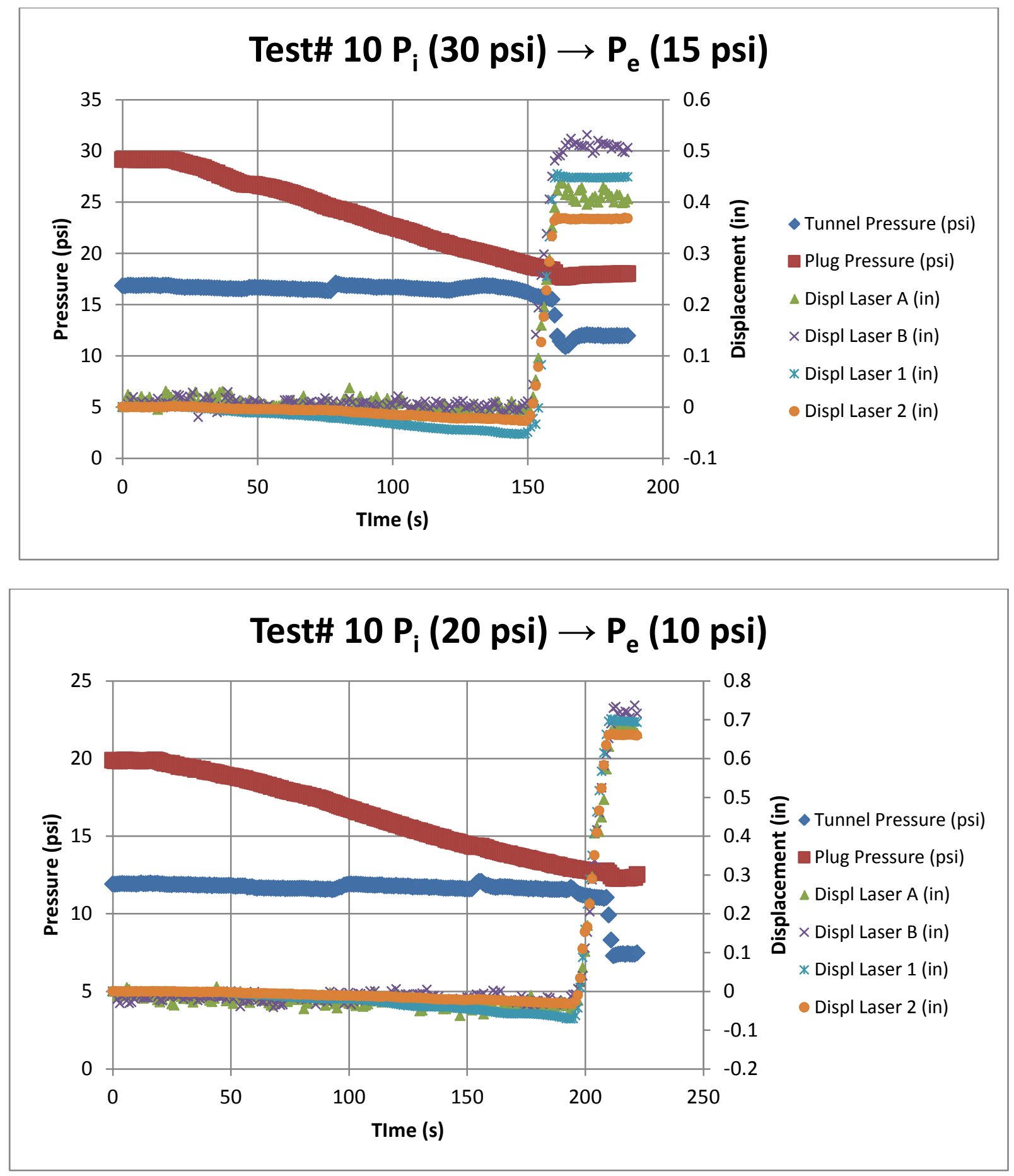

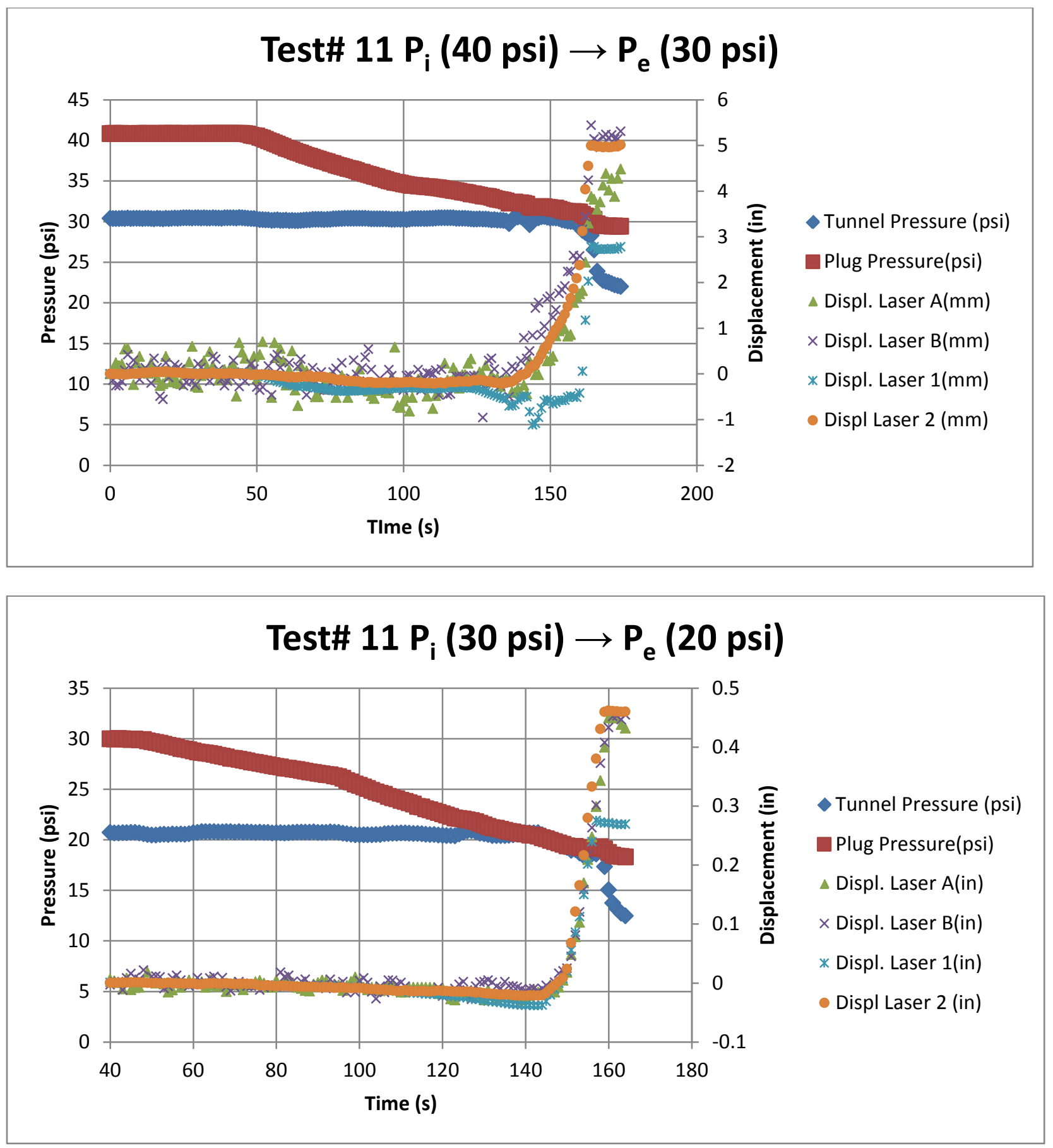

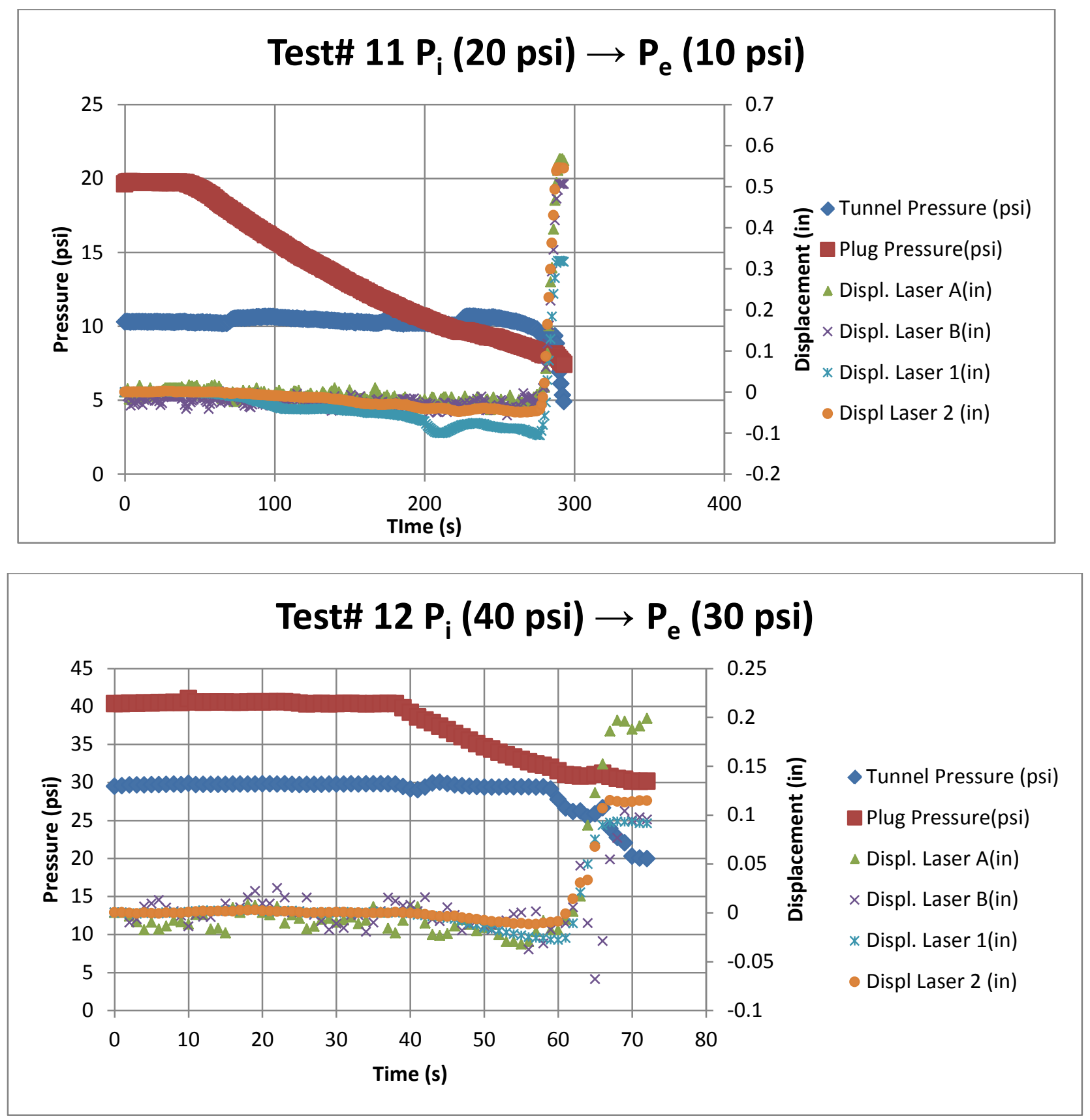

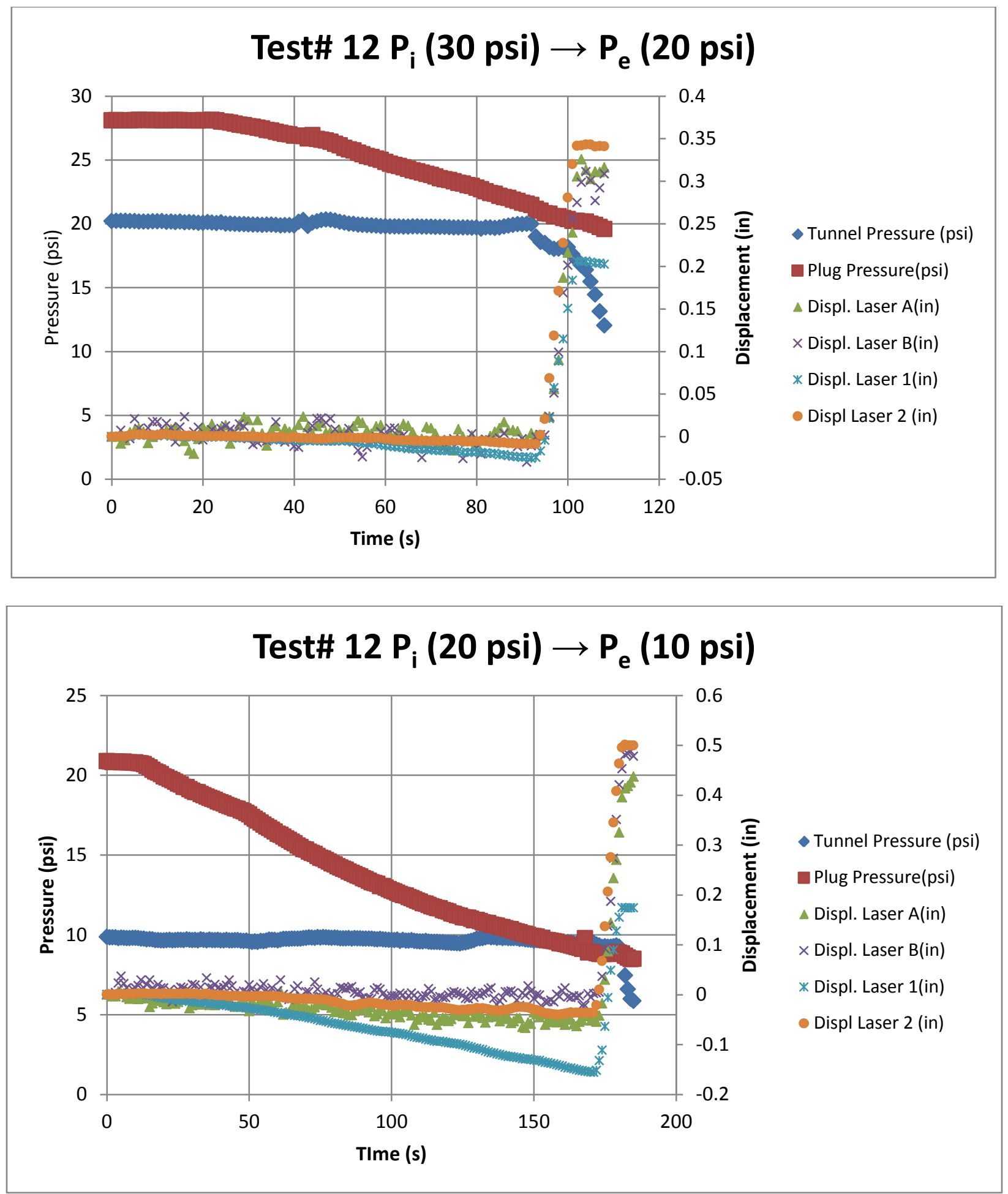

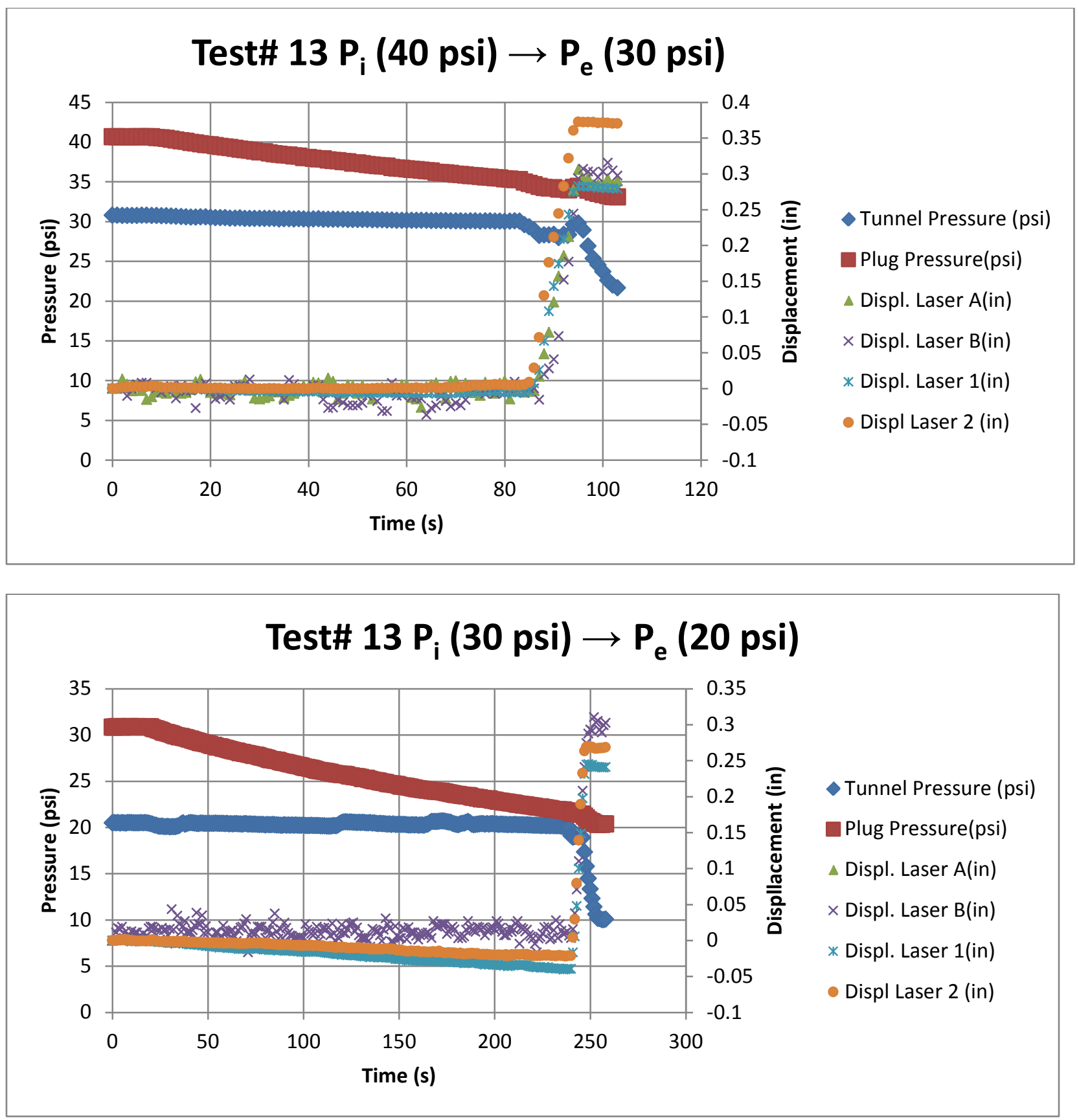

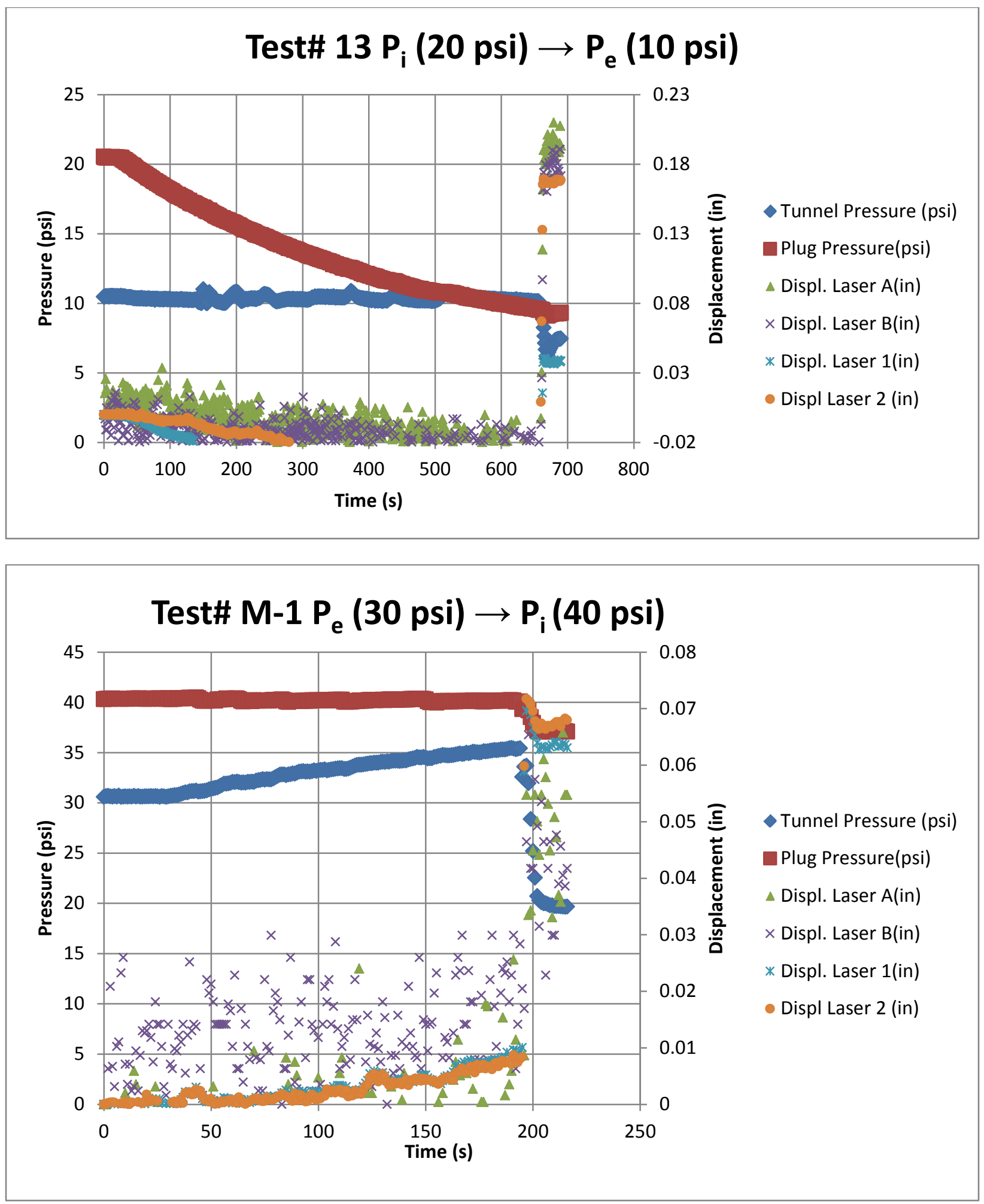

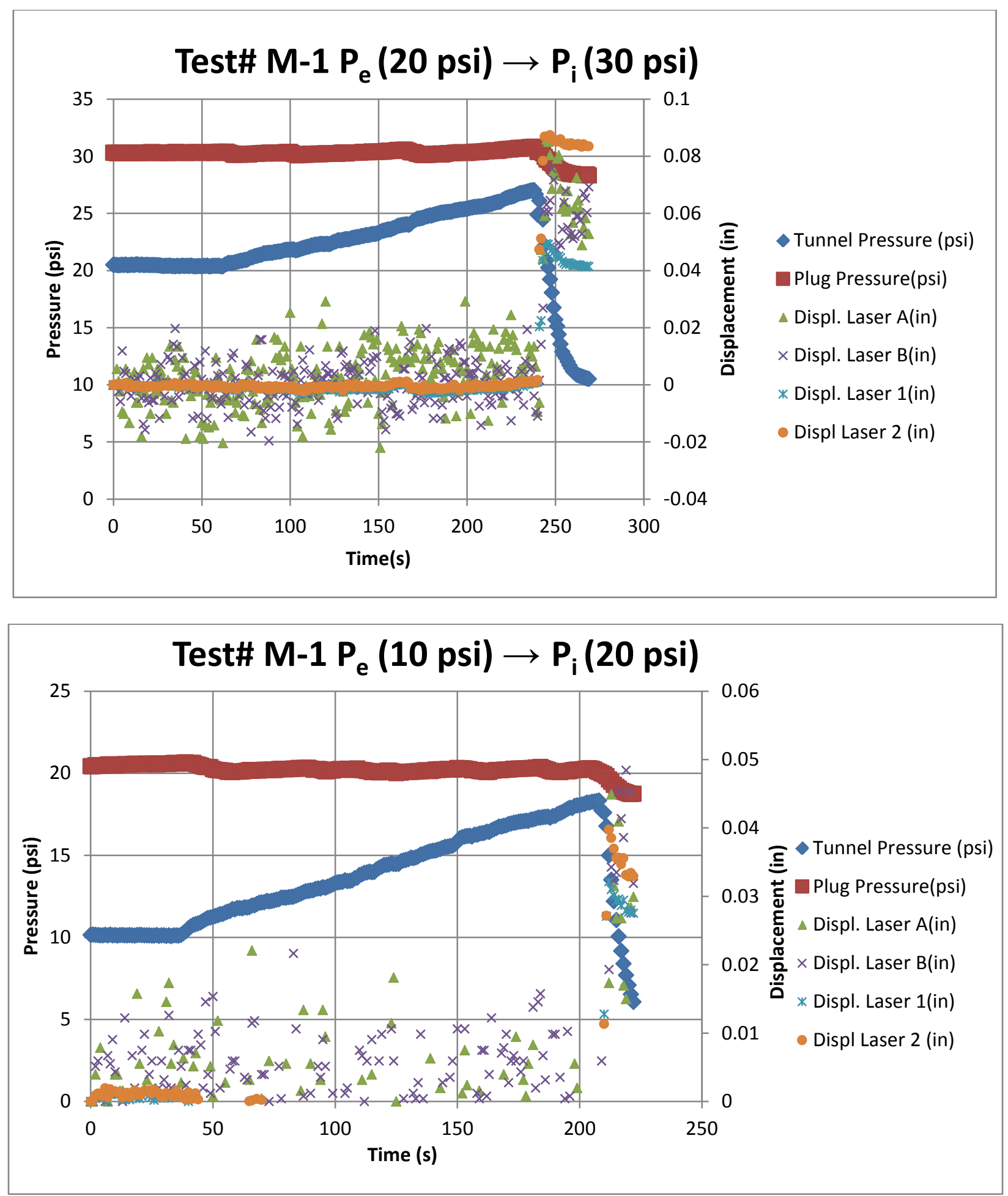

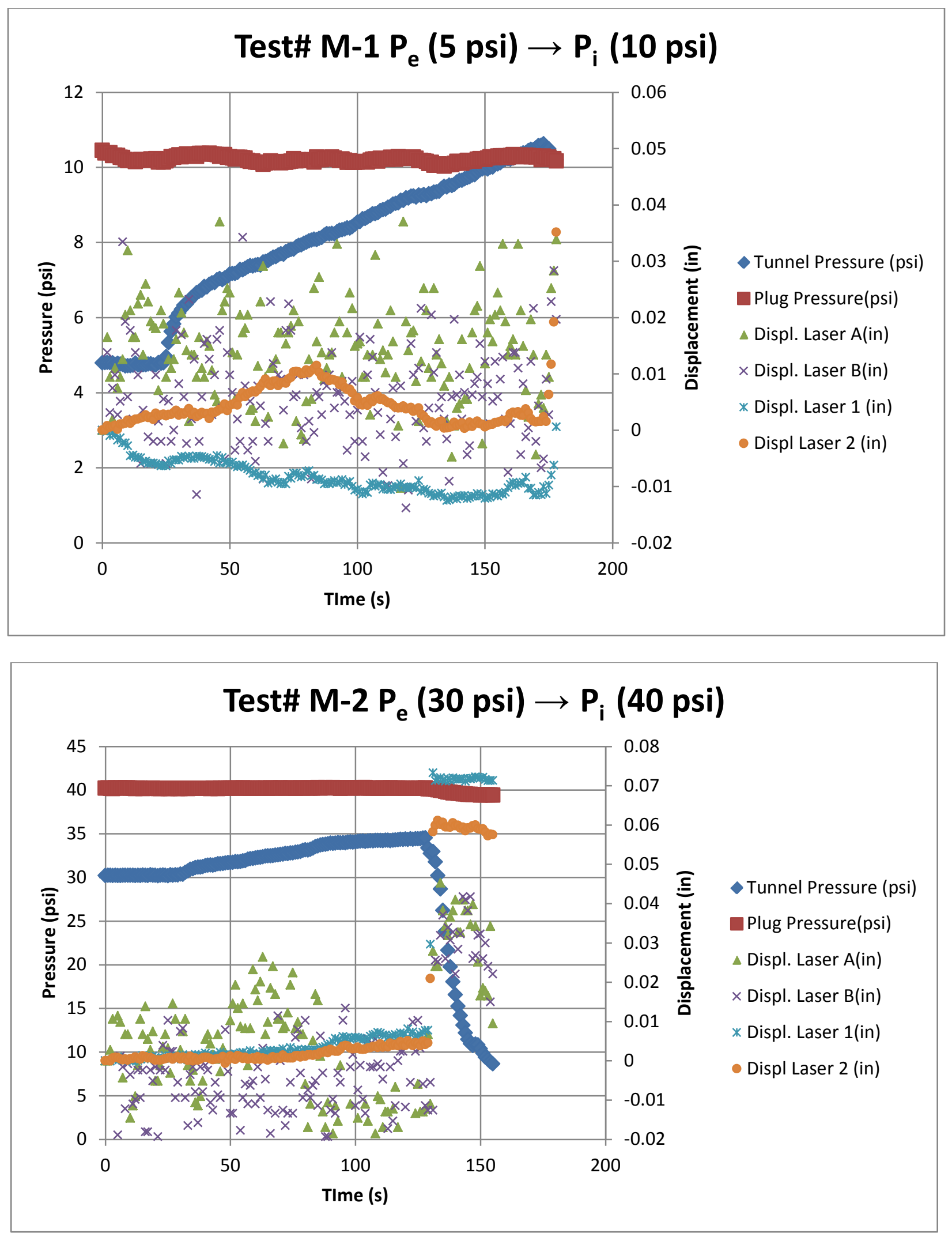

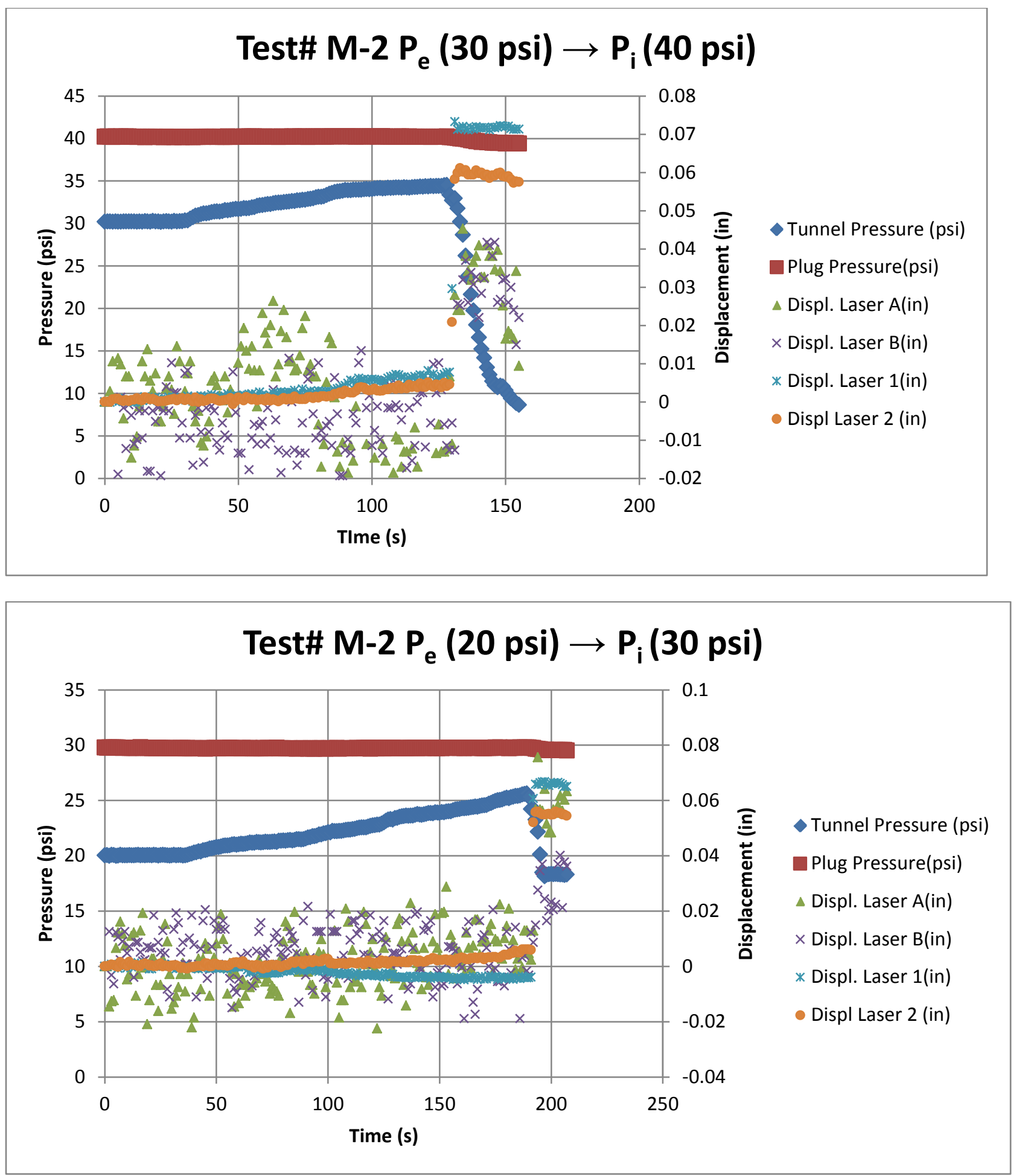

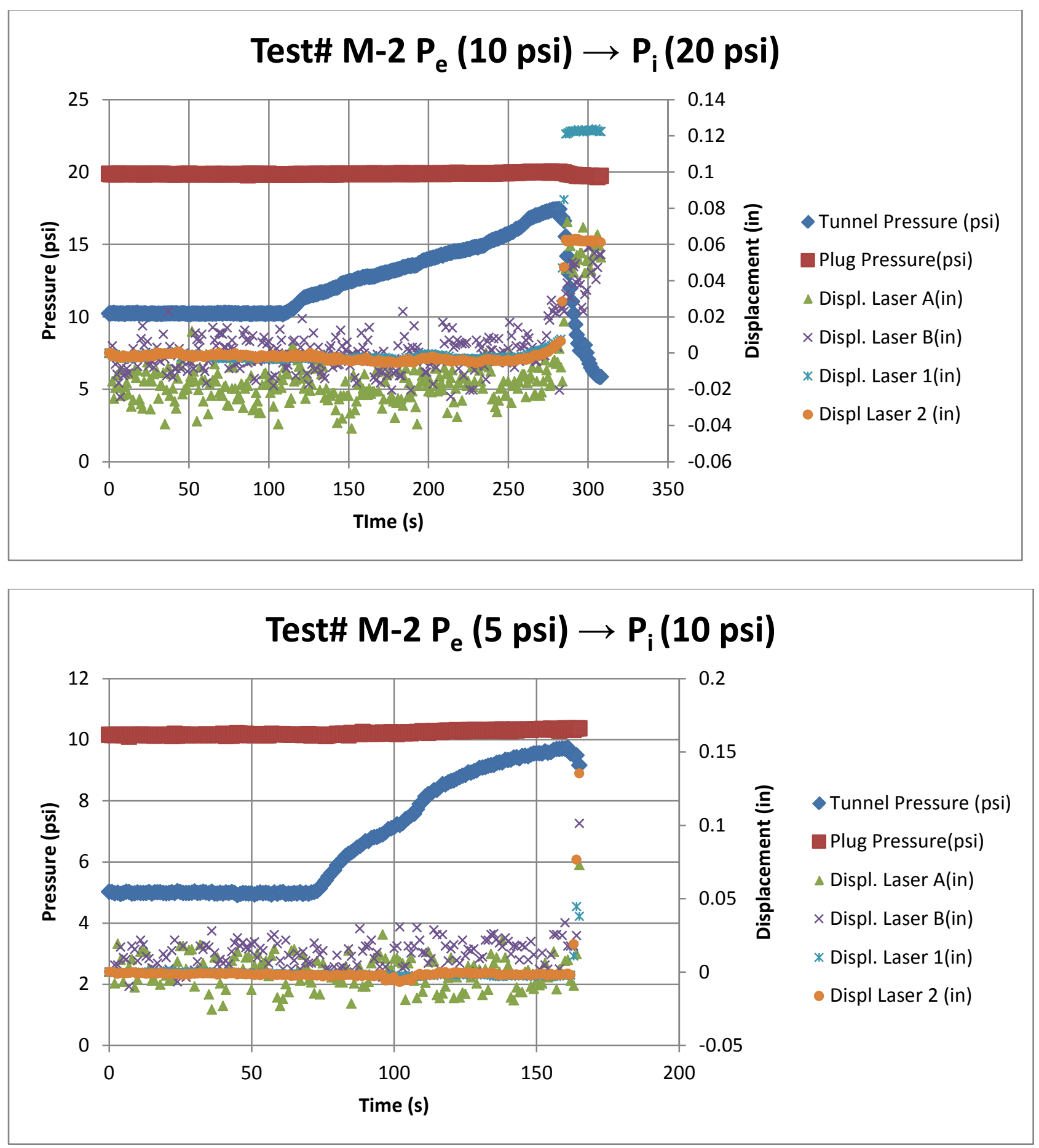


\section{Test\# M-3 $\mathrm{P}_{\mathrm{e}}\left(30\right.$ psi) $\rightarrow \mathrm{P}_{\mathrm{i}}(40$ psi)}
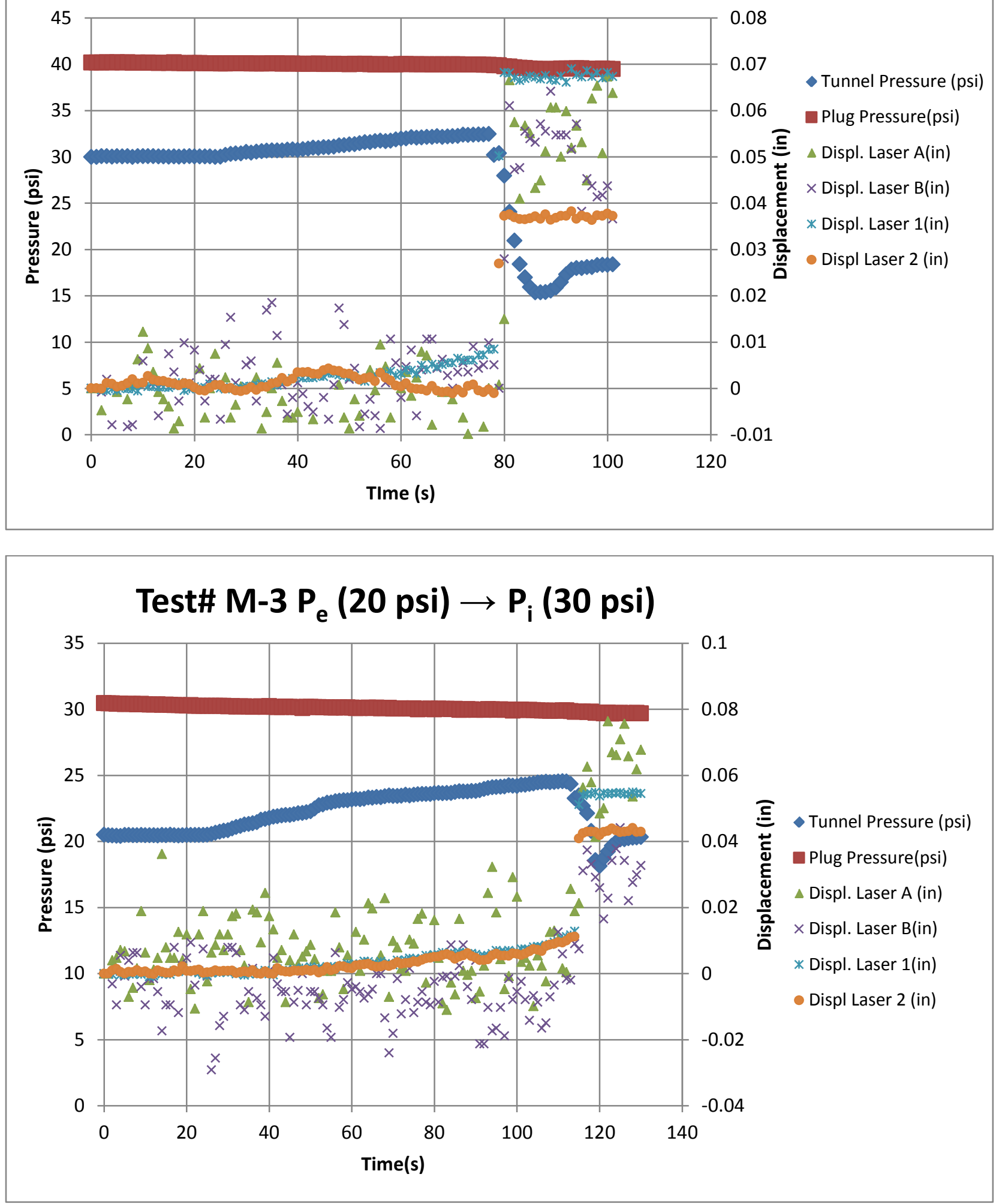

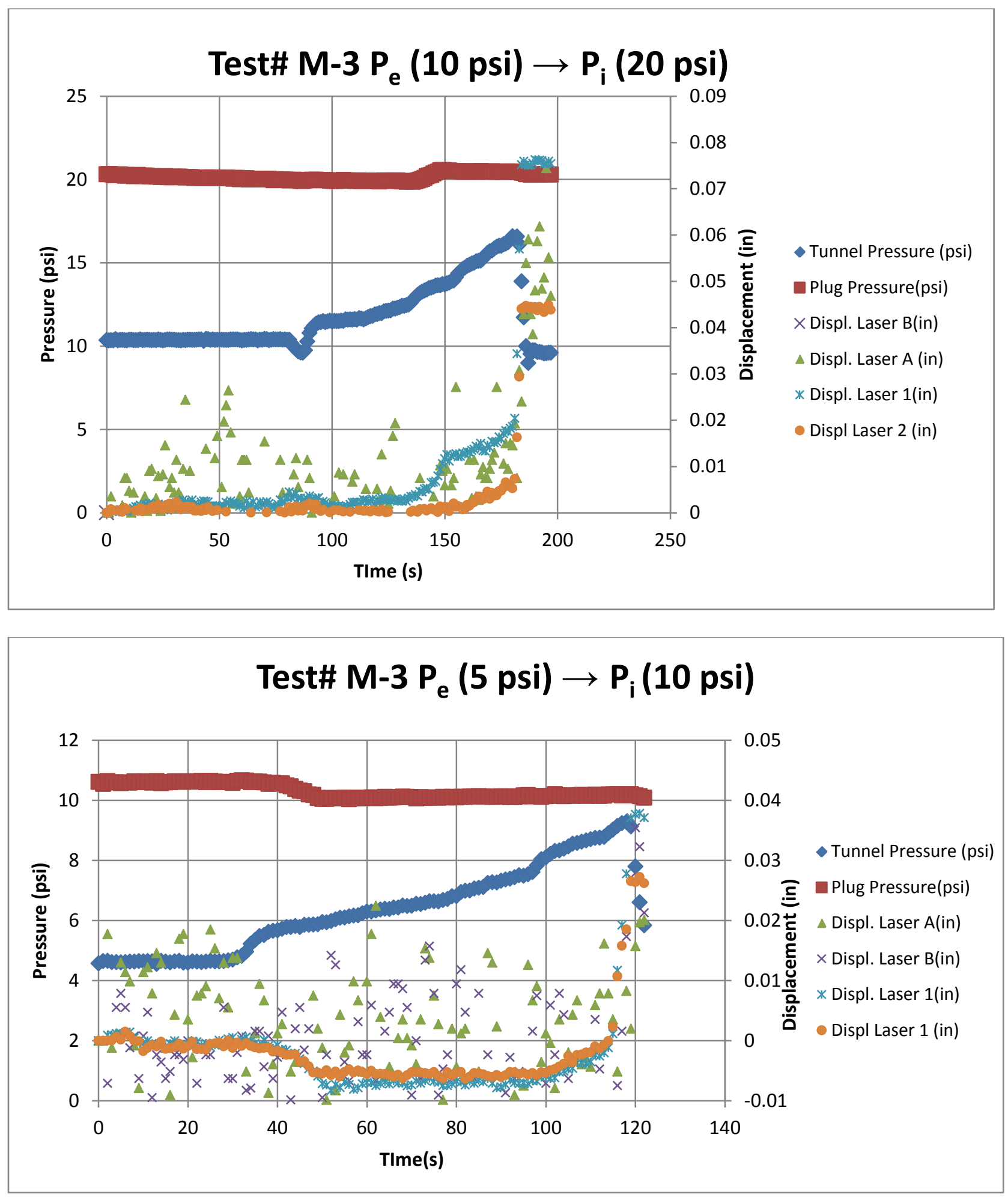

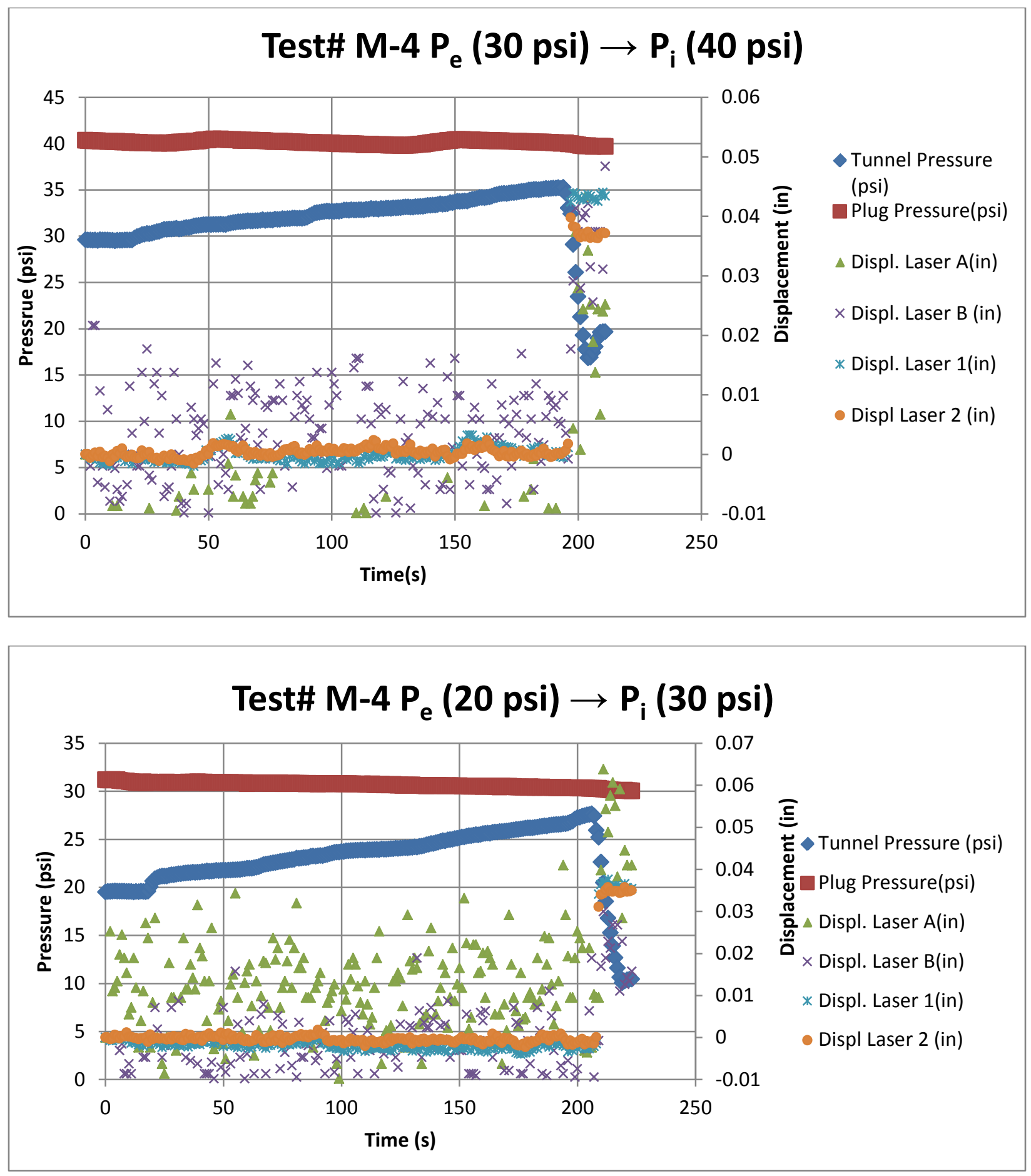

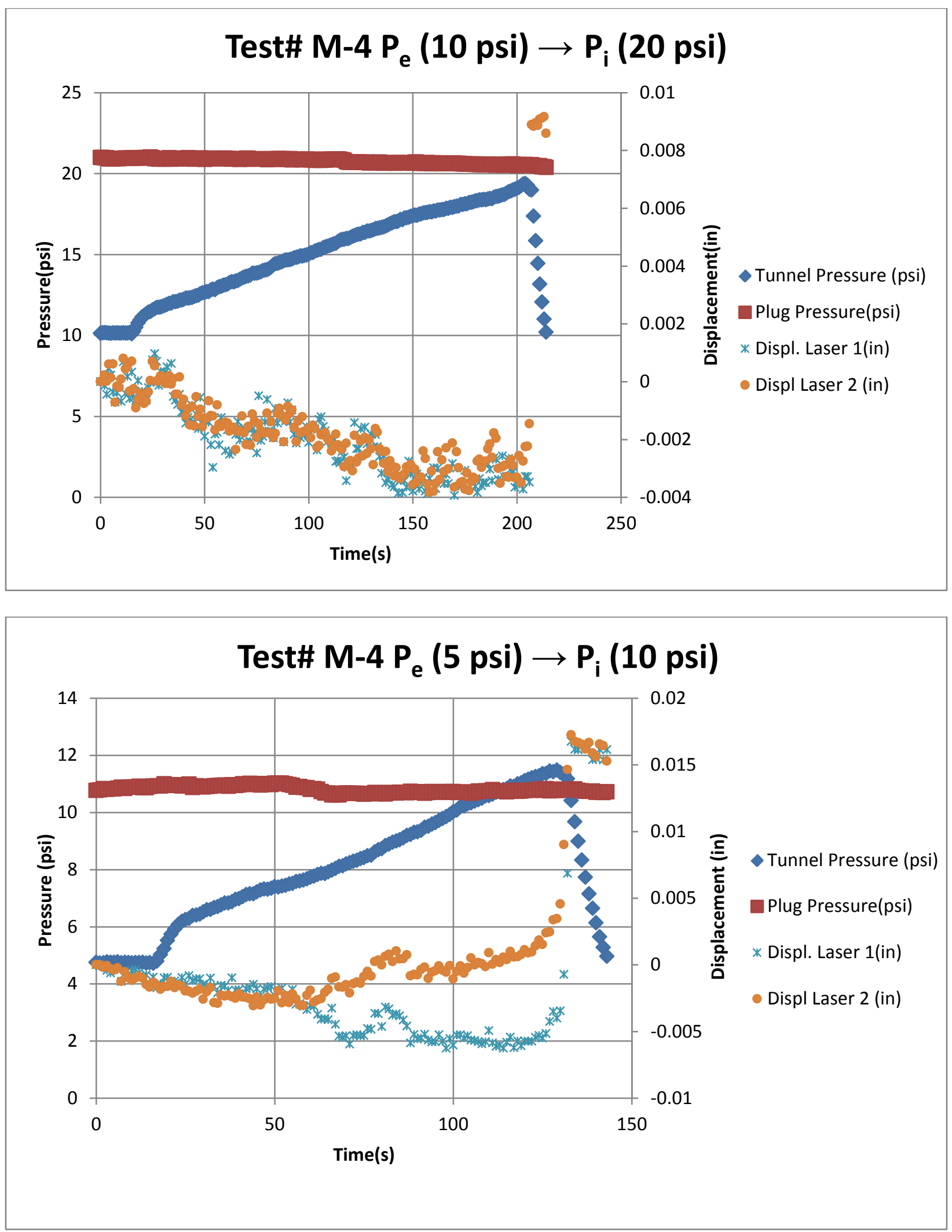


\section{Appendix D: Friction Coefficient Evaluation}

Friction coefficient of Teflon and plastic (polyethylene) material used in extended set of slippage testing was evaluated according to [31].

Figure D-1 shows the test set-up for the friction coefficient testing. The Vectran fabric was normally loaded with normal pressures 5, 10, 1520,25 psi having an effective area of application of $4 \mathrm{in}^{2}$. The webbing was pre-tensioned to $30 \mathrm{ft}$-lbs to simulate the axial stress on the plug wall due to internal pressure. The surface of the Teflon and plastic was kept wet and the webbing was saturated with water to simulate the wet condition of the tunnel. The wet surface was pushed by an actuator controlled by a computer program.

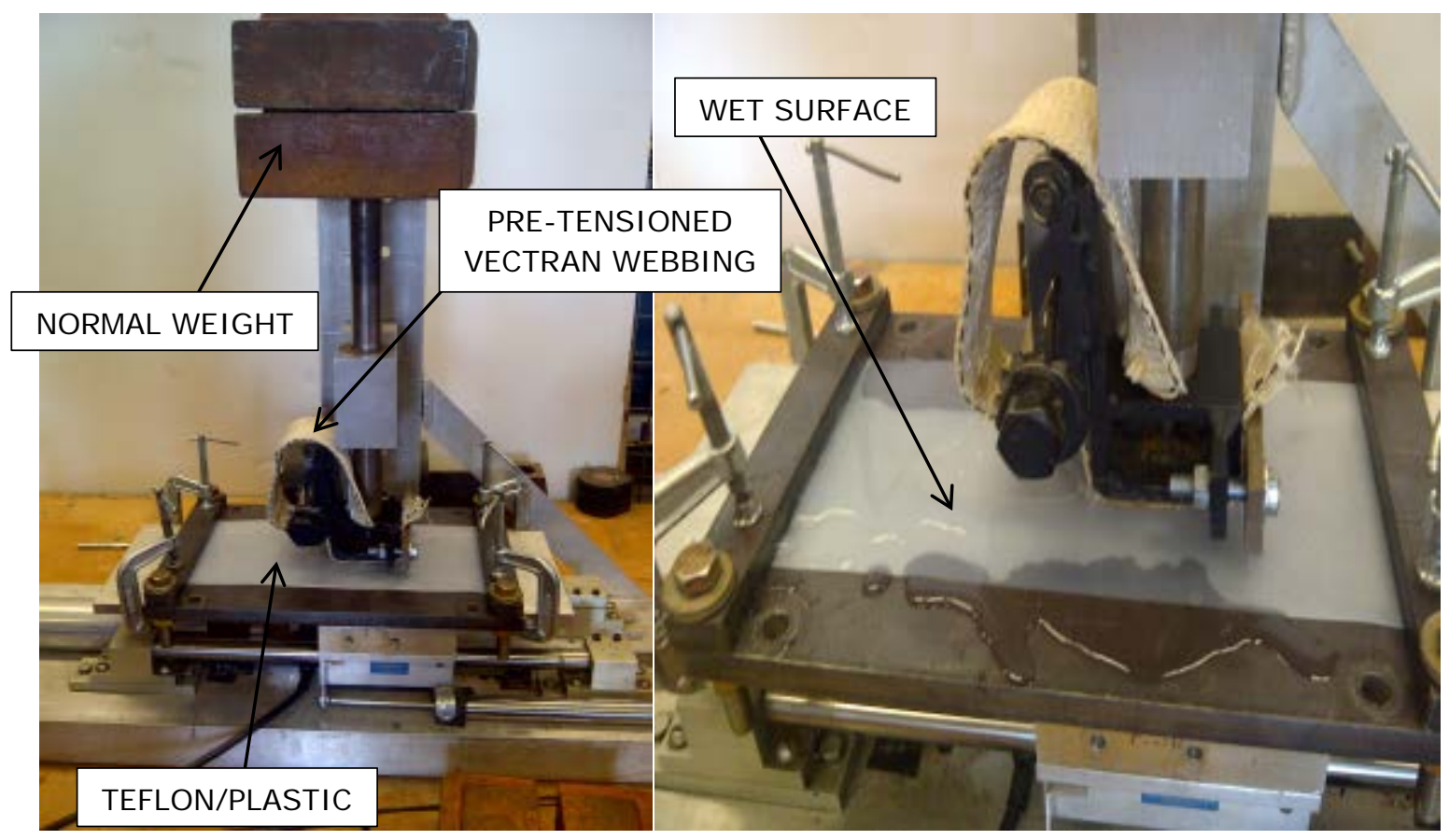

Figure D-1: Test set-up for evaluating friction coefficient

The results of the wet tests for the above mentioned pressure levels are shown in Table D-1.

Table D-1: Friction coefficient of Teflon and plastic under wet condition

\begin{tabular}{|c|c|c|}
\hline $\begin{array}{c}\text { Normal Pressure } \\
\text { on } \\
\text { Webbing (psi) }\end{array}$ & Wet Teflon & Wet Plastic \\
\cline { 2 - 3 } & $\mu$ & $\mu$ \\
\hline 5 & 0.237 & 0.258 \\
\hline 10 & 0.179 & 0.192 \\
\hline 15 & 0.169 & 0.181 \\
\hline 20 & 0.151 & 0.167 \\
\hline 25 & 0.143 & 0.182 \\
\hline
\end{tabular}




\section{Appendix E: Leakage Data}

Table E-1: Leakage data for plug pressures close to design pressure

\begin{tabular}{|c|c|c|c|}
\hline Pressure combination & Trials & $\begin{array}{l}\text { Leakage } \\
\text { Rate } \\
\text { (gpm) }\end{array}$ & $\begin{array}{l}\text { Average } \\
\text { Leakage } \\
\text { Rate } \\
\text { (gpm) }\end{array}$ \\
\hline \multirow{3}{*}{$\begin{array}{l}\text { Tunnel Pressure }=30 \\
\text { psi } \\
\text { Plug Pressure }=50 \mathrm{psi}\end{array}$} & 1 & 7.28 & \multirow{3}{*}{10.40} \\
\hline & 2 & 11.13 & \\
\hline & 3 & 11.17 & \\
\hline \multirow{3}{*}{$\begin{array}{l}\text { Tunnel Pressure }=30 \\
\text { psi } \\
\text { Plug Pressure }=60 \mathrm{psi}\end{array}$} & 1 & 6.51 & \multirow{3}{*}{9.70} \\
\hline & 2 & 10.46 & \\
\hline & 3 & 10.47 & \\
\hline \multirow{3}{*}{$\begin{array}{l}\text { Tunnel Pressure=30 } \\
\text { psi } \\
\text { Plug Pressure }=68 \mathrm{psi}\end{array}$} & 1 & 7.19 & \multirow{3}{*}{9.1} \\
\hline & 2 & 9.57 & \\
\hline & 3 & 9.62 & \\
\hline \multirow{3}{*}{$\begin{array}{l}\text { Tunnel Pressure=48 } \\
\text { psi } \\
\text { Plug Pressure }=68 \mathrm{psi}\end{array}$} & 1 & 11.09 & \multirow{3}{*}{11.70} \\
\hline & 2 & 10.99 & \\
\hline & 3 & 12.77 & \\
\hline
\end{tabular}

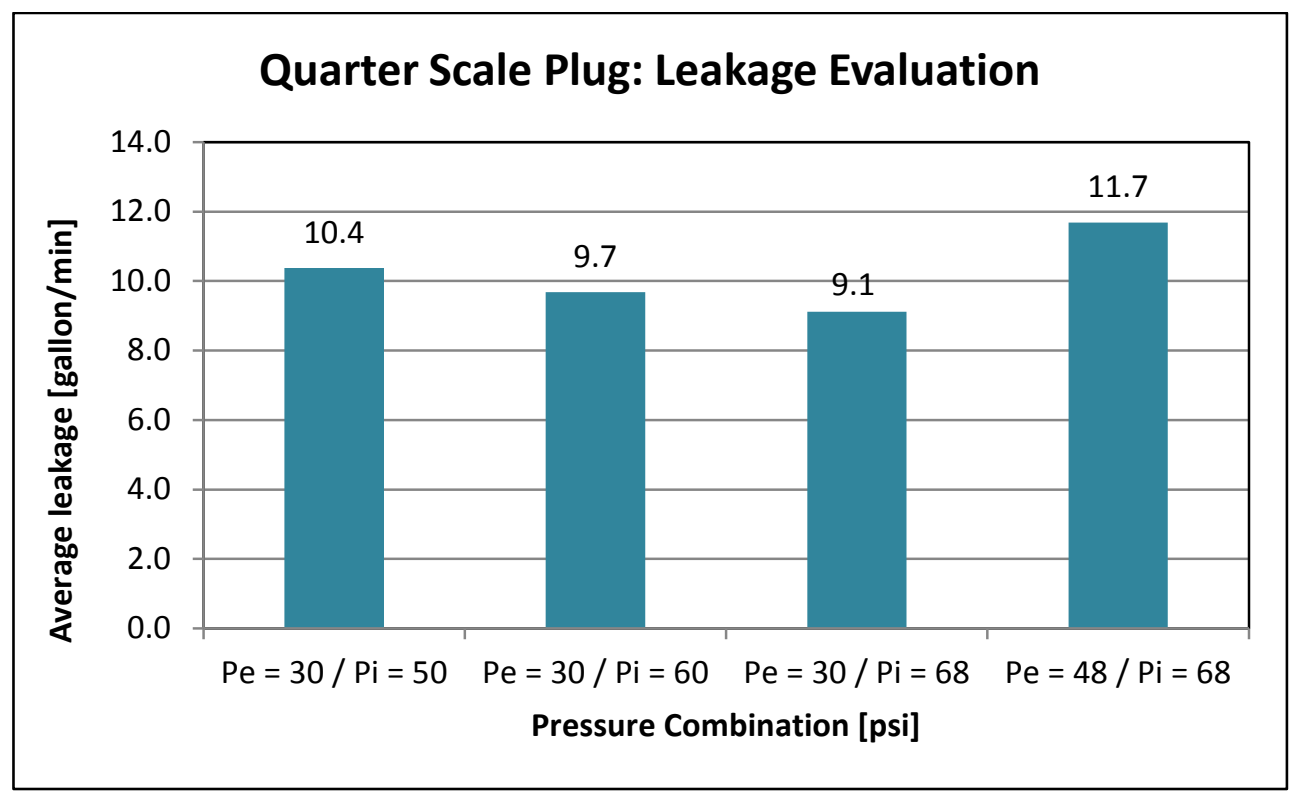

Figure E-1: Leakage data plots for pressure combinations 
Table E-2: Leakage data for various tunnel pressure and plug pressure 30 psi

\begin{tabular}{|c|c|c|c|}
\hline Pressure combination & Trials & $\begin{array}{c}\text { Leakage } \\
\text { Rate } \\
\text { (gpm) }\end{array}$ & $\begin{array}{c}\text { Average } \\
\text { Leakage } \\
\text { (gpm) }\end{array}$ \\
\hline \multirow{4}{*}{$\begin{array}{l}\text { Tunnel Pressure }=5 \text { psi } \\
\text { Plug Pressure }=30 \text { psi }\end{array}$} & 1 & 5.45 & \multirow{4}{*}{5.03} \\
\hline & 2 & 4.84 & \\
\hline & 3 & 4.81 & \\
\hline & 4 & 5.03 & \\
\hline \multirow{4}{*}{$\begin{array}{l}\text { Tunnel Pressure }=10 \mathrm{psi} \\
\text { Plug Pressure }=30 \mathrm{psi}\end{array}$} & 1 & 8.82 & \multirow{4}{*}{7.80} \\
\hline & 2 & 7.47 & \\
\hline & 3 & 7.42 & \\
\hline & 4 & 7.47 & \\
\hline \multirow{4}{*}{$\begin{array}{l}\text { Tunnel Pressure }=15 \mathrm{psi} \\
\text { Plug Pressure }=30 \mathrm{psi}\end{array}$} & 1 & 11.82 & \multirow{4}{*}{10.42} \\
\hline & 2 & 10.11 & \\
\hline & 3 & 9.50 & \\
\hline & 4 & 10.24 & \\
\hline \multirow{4}{*}{$\begin{array}{l}\text { Tunnel Pressure }=20 \mathrm{psi} \\
\text { Plug Pressure }=30 \mathrm{psi}\end{array}$} & 1 & 14.25 & \multirow{4}{*}{12.58} \\
\hline & 2 & 13.25 & \\
\hline & 3 & 10.93 & \\
\hline & 4 & 11.89 & \\
\hline
\end{tabular}


Table E-3: Leakage data for various combination of tunnel pressure and plug pressure

\begin{tabular}{|c|c|c|c|}
\hline Pressure combination & Trials & $\begin{array}{c}\text { Leakage } \\
\text { Rate } \\
\text { (gpm) }\end{array}$ & $\begin{array}{c}\text { Average } \\
\text { Leakage } \\
\text { (gpm) }\end{array}$ \\
\hline \multirow{3}{*}{$\begin{array}{l}\text { Tunnel Pressure }=10 \mathrm{psi} \\
\text { Plug Pressure }=25 \mathrm{psi}\end{array}$} & 1 & 12.08 & \multirow{3}{*}{12.37} \\
\hline & 2 & 13.23 & \\
\hline & 3 & 11.81 & \\
\hline \multirow{3}{*}{$\begin{array}{l}\text { Tunnel Pressure }=15 \mathrm{psi} \\
\text { Plug Pressure }=25 \mathrm{psi}\end{array}$} & 1 & 16.06 & \multirow{3}{*}{16.07} \\
\hline & 2 & 16.08 & \\
\hline & 3 & 16.06 & \\
\hline \multirow{3}{*}{$\begin{array}{l}\text { Tunnel Pressure }=10 \mathrm{psi} \\
\text { Plug Pressure }=30 \mathrm{psi}\end{array}$} & 1 & 11.87 & \multirow{3}{*}{11.01} \\
\hline & 2 & 10.15 & \\
\hline & 3 & 11.00 & \\
\hline \multirow{3}{*}{$\begin{array}{l}\text { Tunnel Pressure }=15 \text { psi } \\
\text { Plug Pressure }=30 \text { psi }\end{array}$} & 1 & 15.14 & \multirow{3}{*}{15.13} \\
\hline & 2 & 15.13 & \\
\hline & 3 & 15.14 & \\
\hline \multirow{3}{*}{$\begin{array}{l}\text { Tunnel Pressure }=20 \mathrm{psi} \\
\text { Plug Pressure }=30 \mathrm{psi}\end{array}$} & 1 & 16.60 & \multirow{3}{*}{16.64} \\
\hline & 2 & 16.64 & \\
\hline & 3 & 16.68 & \\
\hline \multirow{3}{*}{$\begin{array}{l}\text { Tunnel Pressure }=15 \mathrm{psi} \\
\text { Plug Pressure }=35 \mathrm{psi}\end{array}$} & 1 & 12.93 & \multirow{3}{*}{12.34} \\
\hline & 2 & 12.80 & \\
\hline & 3 & 11.30 & \\
\hline \multirow{3}{*}{$\begin{array}{l}\text { Tunnel Pressure }=20 \mathrm{psi} \\
\text { Plug Pressure }=35 \mathrm{psi}\end{array}$} & 1 & 16.77 & \multirow{3}{*}{16.1} \\
\hline & 2 & 15.45 & \\
\hline & 3 & 11.30 & \\
\hline \multirow{3}{*}{$\begin{array}{l}\text { Tunnel Pressure }=25 \mathrm{psi} \\
\text { Plug Pressure }=35 \mathrm{psi}\end{array}$} & 1 & 16.96 & \multirow{3}{*}{17.08} \\
\hline & 2 & 17.20 & \\
\hline & 3 & 11.30 & \\
\hline
\end{tabular}


Table E-3: Leakage data for various combination of tunnel pressure and plug pressure for leakage mitigation

\begin{tabular}{|c|c|c|c|}
\hline Pressure combination & Trials & $\begin{array}{c}\text { Leakage Rate } \\
\text { (gpm) }\end{array}$ & $\begin{array}{c}\text { Average Leakage } \\
\text { (gpm) }\end{array}$ \\
\hline \multirow{5}{*}{$\begin{array}{l}\text { Tunnel Pressure }=5 \text { psi } \\
\text { Plug Pressure }=30 \mathrm{psi}\end{array}$} & 1 & 5.23 & \multirow{5}{*}{4.43} \\
\hline & 2 & 4.21 & \\
\hline & 3 & 4.38 & \\
\hline & 4 & 4.15 & \\
\hline & 5 & 4.17 & \\
\hline \multirow{5}{*}{$\begin{array}{l}\text { Tunnel Pressure }=10 \mathrm{psi} \\
\text { Plug Pressure }=30 \mathrm{psi}\end{array}$} & 1 & 7.94 & \multirow{5}{*}{6.84} \\
\hline & 2 & 6.45 & \\
\hline & 3 & 6.69 & \\
\hline & 4 & 6.45 & \\
\hline & 5 & 6.67 & \\
\hline \multirow{5}{*}{$\begin{array}{l}\text { Tunnel Pressure }=15 \mathrm{psi} \\
\text { Plug Pressure }=30 \mathrm{psi}\end{array}$} & 1 & 11.33 & \multirow{5}{*}{10.18} \\
\hline & 2 & 10.29 & \\
\hline & 3 & 9.95 & \\
\hline & 4 & 9.54 & \\
\hline & 5 & 9.77 & \\
\hline \multirow{5}{*}{$\begin{array}{l}\text { Tunnel Pressure }=20 \mathrm{psi} \\
\text { Plug Pressure }=30 \mathrm{psi}\end{array}$} & 1 & 13.66 & \multirow{5}{*}{11.69} \\
\hline & 2 & 10.79 & \\
\hline & 3 & 11.91 & \\
\hline & 4 & 10.13 & \\
\hline & 5 & 11.95 & \\
\hline
\end{tabular}




\section{Appendix F: Pressure Sensor Documentation}

Table F-1: Pressure transducer details

\begin{tabular}{|c|c|c|}
\hline \multicolumn{2}{|c|}{ Pressure Transducer Details } \\
\hline Model Number & $\begin{array}{c}\text { Range } \\
\text { ( psi) }\end{array}$ & Online Documentation \\
\hline PX305-100GI & $0-100$ & $\underline{\text { http://www.omega.com/pptst/Px305.html }}$ \\
\hline PX209-030G5V & $0-30$ & $\underline{\text { http://datasheets.globalspec.com/ds/2/Omegadyne/E182 }}$ \\
\hline $\begin{array}{c}\text { PX309-050G5V } \\
\text { AST4500L00030P4X } \\
\text { 1065 }\end{array}$ & $0-50$ & $\frac{\text { http://datasheets.globalspec.com/ds/2/Omegadyne/791B }}{\underline{\text { ADF4-6C78-454D-B5A3-672F2F5CB2A6 }}}$ \\
\hline PX603-015G5V & $0-15$ & $\underline{\text { http://www.instrumart.com/search?query=AST4500L000 }}$ \\
\hline
\end{tabular}

